
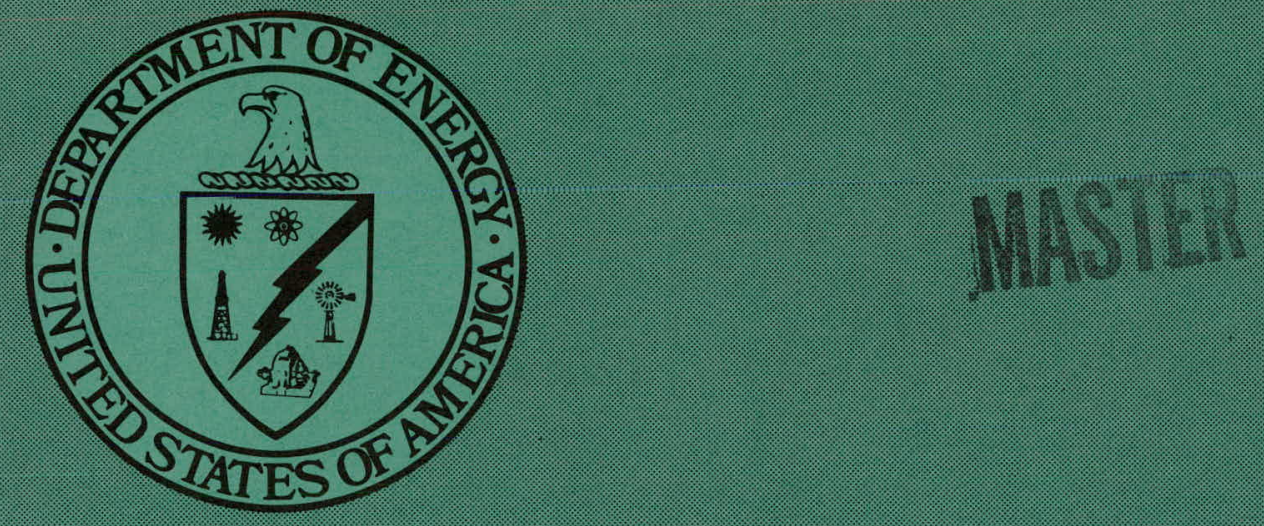

BERC/RI-77/10

A STUDY TO DETERMINE THE FEASIBILITY OF

OBTAINING TRUE SAMPLES OF OIL AND GAS RESERVOIRS

FINAL REPORT

By

Maurer Engineering, Incorporated

Prepared for ERDA Under Contract No. EY-76-C-02-0035

Date Published-October 1977

Bartlesville Energy Research Center

Uniter States Department of Eneryy

Bartlesville, Oklahoma

TECHNICAL INFORMATION CENTER UNITED STATES DEPARTMENT OF ENERGY 


\section{DISCLAIMER}

This report was prepared as an account of work sponsored by an agency of the United States Government. Neither the United States Government nor any agency Thereof, nor any of their employees, makes any warranty, express or implied, or assumes any legal liability or responsibility for the accuracy, completeness, or usefulness of any information, apparatus, product, or process disclosed, or represents that its use would not infringe privately owned rights. Reference herein to any specific commercial product, process, or service by trade name, trademark, manufacturer, or otherwise does not necessarily constitute or imply its endorsement, recommendation, or favoring by the United States Government or any agency thereof. The views and opinions of authors expressed herein do not necessarily state or reflect those of the United States Government or any agency thereof. 


\section{DISCLAIMER}

Portions of this document may be illegible in electronic image products. Images are produced from the best available original document. 


\section{NOTICE}

This report was prepared as an account of work sponsored by the United States Government. Neither the United States nor the United States Department of Energy, nor any of their employees, nor any of their contractors, subcontractors, or their employees, makes any warranty, express or implied, or assumes any legal liability or responsibility for the accuracy, completeness or usefulness of any information, apparatus, product or process disclosed, or represents that its use would not infringe privately owned rights.

This report has been reproduced directly from the best available copy.

Available from the National Technical Information Service, U. S. Department of Commerce, Springfield, Virginia 22161.

Price: Paper Copy $\$ 12.50$

Microfiche $\$ 3.00$ 


\section{A STUDY TO DETERMINE THE FEASIBILITY OF-OBTAINING TRUE SAMPLES OF OIL AND GAS RESERVOIRS}

\section{FINAL REPORT}

By

Charles E. Ward

A. Richard Sinclair

Maurer Engineering, Incorporated

10301 NW Freeway, Suite 202

Houston, Texas 77092

Prepared for the Energy Research and Development Administration Under Contract No. EY-76-C-02-0035 as Report BERC-0035-11

C. Ray Williams, Technical Project Officer Bartlesville Energy Research Center United States Department of Energy P.O. Box 1398

Bartlesville, Oklahoma 74003 This report was prepared as an account of work sponsored by the United States Govemment. Neither the United States not the United States Department of
Energy, nor any of their employees, nor any of their contractors, subeontractors, of their employees, makes any warranty, express or implied, or assumes any legal iability or responsibility for the accuracy, completeness or usefulness of any information, apparatus, product or process diselosed, or represents that its use would not infringe privately owned rights.

Date Submitted-December 1976

Date Published-October 1977

UNITED STATES DEPARTMENT OF ENERGY TECHNICAL INFORMATION CENTER 


\section{Foreword}

The work described in the following pages was performed by Maurer Engineering, Inc. under a contract with the Energy Research and Development Administration (ERDA) and was sanctioned by personnel at the Bartlesville Energy Research Center (BERC) in Bartlesville, Oklahoma. The contract resulted from an unsolicited proposal submitted by Maurer on Aug. 4, 1975, which proposed to determine if it is feasible to recover, retrieve, and test an unaltered core sample while maintaining reservoir conditions on the sample. The contract was 1 year in duration with work beginning on Dec. 1, 1975.

Many personnel at BERC are proficient in tertiary oil recovery and massive hydraulic fracturing for stimulating low-permeability gas wells. They realized that the ability to obtain an unaltered reservoir sample would be a significant contribution. Enormous investments are usually necessary to perform tertiary or stimulation operations, and accurate information on important reservoir parameters would assist in making decisions for such investments. As a result, BERC personnel were hopeful that a tool could be built that would evaluate the actual reservoir contents before, and after, a flood front and could provide accurate watersaturation values in low-permeability gas reservoirs.

The results of the study indicate that it is not economically feasible to obtain an unaltered true fluid core under reservoir conditions but that improvements can be made in existing pressure core barrels that should make them operate more reliably. The results also indicate that mud invasion and flushing of the core might be reduced, or eliminated, if a coring device such as the Phase I system could be successfully built and tested. It is likely that ERDA will build and test the Phase I system as described in the final report.

\section{Ray Williams}

Technical Project Officer

Bartlesville Energy Research Center 
Current formation evaluation techniques do not provide information of the accuracy desirable for making sound, economic decisions. The ERDA Fossil Energy Division funded this study to analyze the problem and identify feasible alternatives for solutions.

The study concludes that a feasible solution is possible which would provide up to about $90 \%$ information accuracy under many operating conditions. This accuracy would be well within the economic range for most oil and gas operations.

The study also concludes that there is potential. feasibility for the development of systems to approach $100 \%$ information accuracy under many operating situations. However, the cost of such a system is far beyond those considered practical within the economics of the competitive oil and gas industry. The Justification of such a system has been likened to that, of a "moon shot" approach and would take several years of development before true feasibility and probability of success could be assessed. 


\section{Conclusions}

After completion of the assigned tasks and assessment of the technology accumulated, the following conclusions have been reached:

1) A practical and improved system capable of approaching $90 \%$ accuracy in the determination of true fluid saturations appears to be feasible.

2) The best first-stage approach is a fairly uncomplicated pressure core barrel.

3) It appears to be feasible to build an ultra sophisticated system to achieve information accuracies approaching $100 \%$ if given "unlimited" resources.

4) One concept considered feasible under the "moon shot" approach is based on a highly complicated pressure core barrel system.

5) Another highly sophisticated system which appears to be feasible involves examination of the core at the bottom of the hole using various logging techniques.

6) The major problem which must be overcome regardless of the techniques involved is that of cutting the core without disturbing the true fluid content.

7) Additional studies are required in order to increase the probability of success of any true fluid coring approach. 
Areas requiring additional study include:

a) Evaluation of the influence of proposed and other bit designs on fluid invasion,

b) Évaluate drilling fluid additives to improve non-invading properties.

Recommendations

If true fluid coring is to be pursued, the following short-term programs should be initiated:

1) The design and manufacture of a prototype pressure coring system similar to the Phase 1 concept outlined in this report.

2) An evaluation of bit design influences on fluid invasion with the objective of developing the most ideal bit design.

3) A study to identify drilling fluid additives improving non-invading characteristics. This study should probably be done in conjunction with the bit design evaluation.

4) A study to identify the most suitable composition for lhe non-invading, non-freezing gel proposed in Phase 1 of this study.

A long-range program aimed at the more sophisticated solution to the true fluid coring problem would be the development of a downhole "core logging" procedure to determine if this approach can in fact achieve the desired data accuracy.

Other advanced systems technologies are basically extensions of Phase 1 concepts and definition of future programs will be more appropriate following development and testing of the Phase l system. 
We wish to express our thanks to the fossil Fuels Division of ERDA for the financial support of this project. Our special appreciation goes to Mr. Ray Williams (ERDA, Bartlesville) for his interest and contributions to the project.

The following industry personnel also made valuable contributions:

$\begin{array}{ll}\text { Skip Bilhartz } & \text { Atlantic Richfield Co. } \\ \text { Harold Bridwell } & \text { Rucker Hycalog } \\ \text { Bob Griffin } & \text { Terra Tek, Inc. } \\ \text { Ralph Jenkins } & \text { Core Laboratories } \\ \text { Dare Keelan } & \text { Core Laboratories } \\ \text { Steve Pontious } & \text { Shell Oil } \\ \text { David Rowley } & \text { Christensen, Inc. } \\ \text { Dick Walker } & \text { Lamar University } \\ \text { Lindsay Yell } & \text { Loomis Hydraulic Testing Co. }\end{array}$




\section{A STUDY TO DETERMINE THE FEASIBILITY. \\ OF OBTAINING TRUE SAMPLES OF OIL OR GAS RESERVOIRS}

Chapter

Title

Page

Summary. . . . . . . . . . . . . . . . i

Conclusions and Recommendations. . . . . . . . i i

Acknowledgment . . . . . . . . . . . . . iv

Table of Contents. . . . . . . . . . . . v

1. Introduction of Coring . . . . . . . . . . . . 1

Review of Present Problems. . . . . . . 3

Objectives of the Study........... . 5

11. History of Coring. . . . . . . . . . . . 6

11I. Applications and Uses of Core Data . . . . . . . . 17

IV. Core Handling and Preservation . . . . . . . . 37

Conventional Cores. . . . . . . . . 38

Pressure Cores. . . . . . . . . . . . 4 43

V. Present Coring Technology. . . . . . . . . . 62

VI. Limitations of Present Coring Methods. . . . . . . 86

VII. Specifications for a True Fluid Coring System. . . 105

VIII. Concepts for Improvement of Present Technology . . . 110

Core Cutting. . . . . . . . . . . . . 112

Core Transportation . . . . . . . . . 133

Core Analysis .. . . . . . . . . . . . 140

IX. Feasibility of a True Fluid Coring System. . . . . 144

X. Phase 1 System ................ 146

XI. Phase 2 System ................ 150

Appendix A--Conventional and Special Core Analysis . 155

Appendix B--Patents. ..... . . . . . . . . 317

Appendix C--Literature Search on Coring Equipment. . 319 


\section{INTRODUCTION}

Review of Present Problems

objectives of the Study 


\section{INTRODUCTION}

In early drilling, the people involved in the business of exploration wondered what types of rock or lithology would be the best for producing oil. From this innatedesire to know what was downhole, the drillers studied, smelled and tasted drill cuttings and chips in an attempt to characterize the rocks or formations. In order to logically extend their knowledge, it became very important to examine the rocks which actually contained oil.

The search for oil was then, as it is now, a very risky business and there was a definite need for better information so that each drilling attempt might have a better chance of success. As much information as possible on each drilling site was required and someone, perhaps inadvertantly, hit upon the idea of using a type of coring device to recover part of the downhole formation. When early oilwell drilling operations began in Pennsylvania during the $1870^{\prime} s$, several patents had already been filed on coredrills. The science of coredrilling was just beginning.

Early drillers and geologists cut cores primarily to provide geologic correlations. Coring overcame some of the objections to unreliable techniques of cuttings examination. Although early analysis techniques were crude, they did provide much useful information to geologists, engineers. drillers and the designers of drilling equipment.

As additional information was obtained from cores, more and more questions arose. As analysis techniques improved, more exact information about the reservoirs was discovered and today, a wide range of tests give factual. : interpretive and evaluative information about strata being: drilled. 
Review of Present Problems

The continued growth in demand for petroleum resources coupled with declining reserves has resulted in increased pressure on reservoir engineers to improve the reliability of their reserve estimates and to evaluate efficiency. of recovery techniques. Tertiary recovery systems are extremely expensive and, therefore, accuracy of residual oil saturation estimates is important to risk analysis. Although various logging techniques have been improved significantly in the past few years, the results are still only an indirect measurement of formation properties and the accuracy of interpretation is 1 imited by assumed formation factors. A true fluid coring system would have appreciable application in development of both new and old reservoirs as shown in Table 1 .

\section{TABLE I}

APPLICATIONS OF TRUE FLUID CORE ANALYSIS DATA

\begin{tabular}{|c|c|}
\hline Parameter Measured & Application \\
\hline \multirow{2}{*}{$\begin{array}{l}\text { NEW RESERVOIRS } \\
\text { Initial fluid saturations } \\
\text { Porosity } \\
\text { Formation resistivity factors } \\
\text { Acoustic velocity }\end{array}$} & \multirow[b]{2}{*}{$\begin{array}{l}\text { Improved reserve estimates } \\
\text { and better evaluation of } \\
\text { logs on later wells }\end{array}$} \\
\hline & \\
\hline $\begin{array}{l}\text { Relative permeability } \\
\text { Relative wettability } \\
\text { Flow tests }\end{array}$ & $\begin{array}{l}\text { Planning for future } \\
\text { secondary and tertiary } \\
\text { recovery }\end{array}$ \\
\hline OLD RESERVOIRS & \multirow[b]{2}{*}{$\begin{array}{l}\text { Evaluation of secondary } \\
\text { and tertiary recovery } \\
\text { economics }\end{array}$} \\
\hline $\begin{array}{l}\text { Present fluid saturations } \\
\text { Porosity }\end{array}$ & \\
\hline $\begin{array}{l}\text { Relative permeability } \\
\text { Relative wettability } \\
\text { Flow tests }\end{array}$ & $\begin{array}{l}\text { Selection and planning } \\
\text { of recovery programs }\end{array}$ \\
\hline
\end{tabular}


Several major oil companies have sponsored RED projects aimed at the accurate determination of fluid saturations in oil and gas reservoirs. All of the major efforts have included taking a core sample of the formation and techniques have centered on controlling the properties of the drilling fluid while coring as a means of reducing or totally eliminating alterations of true fluid saturation. These approaches are extremely costly and in general have not been successful. In addition, they do not prevent changes in the fluid content resulting from reduction in the confining pressure..as the core is brought to the earth's surface.

0 ther techniques have attempted to recover the core while maintaining a constant pressure environment. This method has eliminated one source for error; pressure reduction, but does not adequately prevent flushing during the coring operation.

A simple combination of special drilling fluids and a pressure core barrel does not provide the total solution, but may suggest a concept for more sophisticated systems capable of capturing "true fluid" cores. 
Objectives of the Study

This program was undertaken to assess the requirements, to define the problems, and to evaluate the feasibility of various alternative solutions.

The work was divided into five main tasks.

Task 1 Review and evaluate existing pressure coring capabilities.

Task 2 Examine and evaluate alternative concepts for obtaining uncontaminated cores.

Task 3 Examine and evaluate alternative concepts for transporting uncontaminated cores to the surface test facilities while maintaining reservoir temperature and pressure.

Task 4 Examine alternative concepts for evaluating reservoir properties by conducting core analysis at reservoir temperatures and pressures.

Task 5 Assuming a positive response to the question of feasibility, make recommendations regarding the development of an improved coring system.

The following report summarizes the findings and evaluations resulting from the work on this program. 


\section{HISTORY OF CORING}

3,000 B.C.

Double Core Barrels

Pressure Core Barrels

Special Coring Fluids

References 
3000 B.C.

Stone quarries used by the Egyptians as early as 3000 B.C. as a source of building materials for the great pyramids provide the first known record of the practical use of holes bored in rock. Solid rods were rotated in the rock, probably with quartz sand or other hard minerals added as cutting abrasives. At some point in time, hollow tubes were used in order to reduce the total amount of rock to be removed (Figure 1)! Rock cores resulted from the use of the hollow tubes. Holes drilled as deep as 20 feet using this technique have been found!

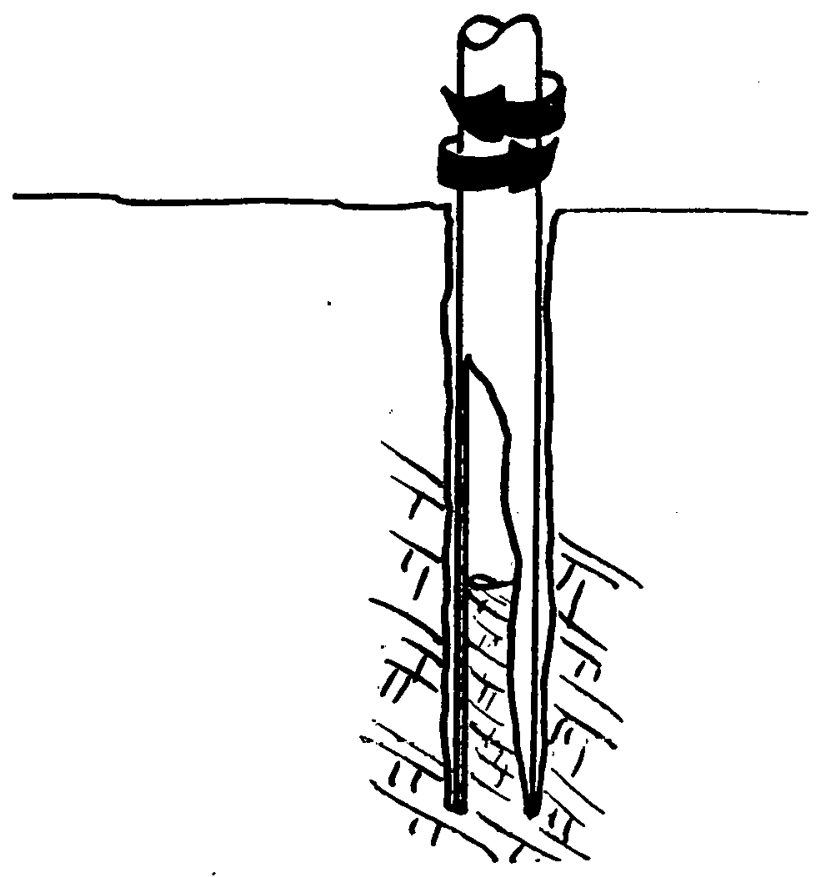

Figure 1

Hollow Rod and Abrasive "Corer" 
This relatively simple and inexpensive technique has been used throughout history. A very similar approach to cutting rock is still used in stone quarries today where large blocks of stone are sawn by the use of long steel cables drawn through a slot in the rock with sand added as an abrasive.

Coring techniques apparently changed very little until rotary drilling machines were developed and came into common usage. About this time coring bits were manufactured by cutting a saw tooth pattern on the bottom end of the drilling tube (Figure 2). 2

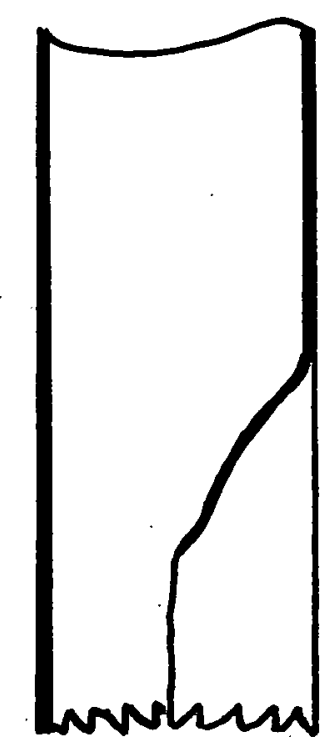

Figure 2

\section{Single Tube Sawtooth Corer}

The core was captured inside the tube by one of several methods. One technique was to bounce the tube against the bottom of the hole bending the saw tooth fingers in, thus retaining the core. Another technique was to pour sand and gravel down the tube where it would wedge between the core and the inside the core tube. 
In 1863, a French engineer, R. Leschot, received a patent on a rotary drilling mâchine and a hollow coring bit set with diamonds (Figure 3$)^{3}$.

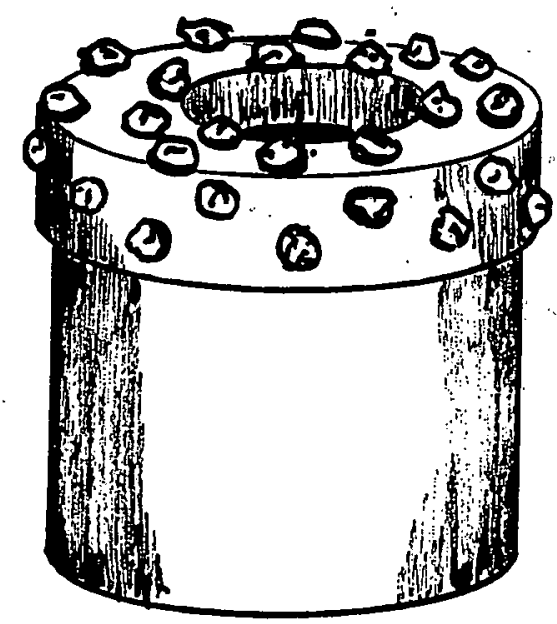

\section{Figure 3}

Handset Diamond Core Bit

Leschot's diamond set core bit constituted a major improvement in coring capabilities. The bit was manufactured by peening or brazing large industrial quality diamonds in holes drilled into a soft metal bit crown.

Double Tube Core-Barrels.

The Leschot patent was later purchased by a group of investors and in $1892 \mathrm{M}$. C. Bullock, an important member: of the group, received a patent for the first double tube core barrel (Figure 4$)$. $^{4}$ 


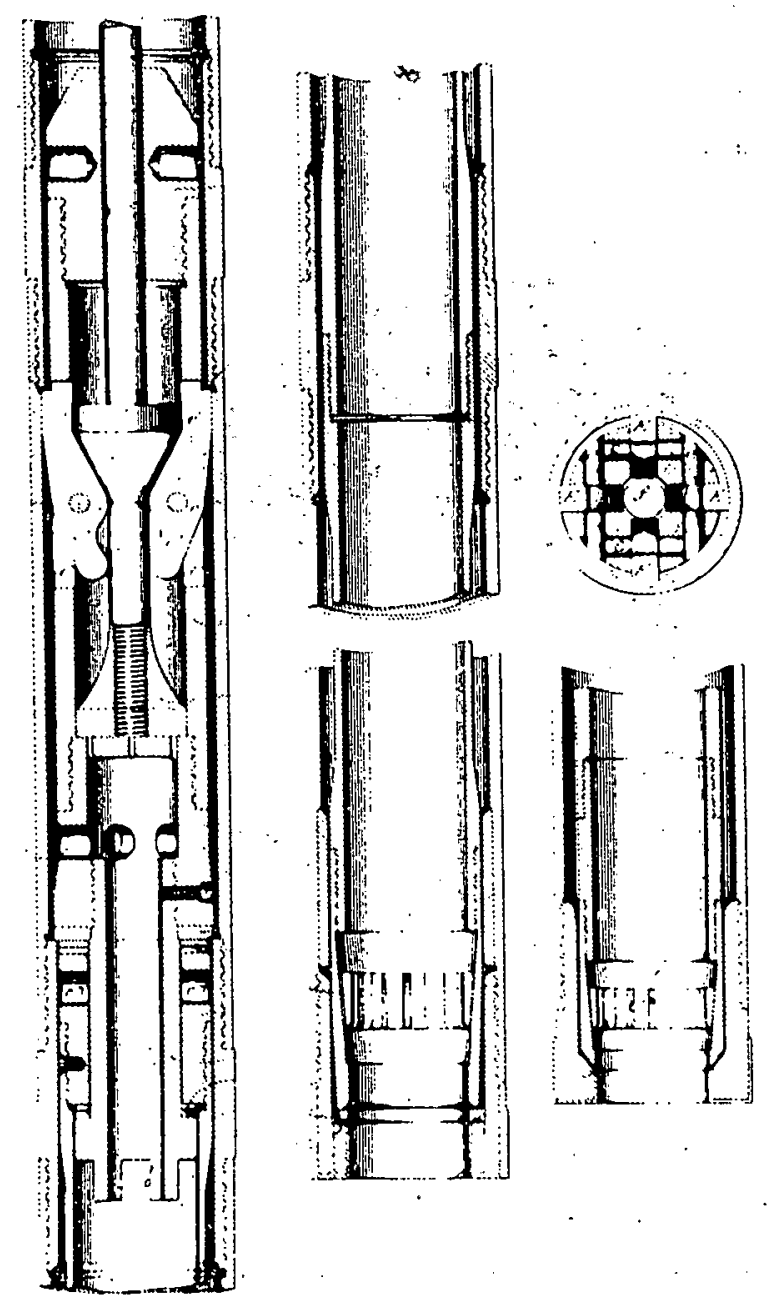

Figure 4

Bullock Double Tube Core Barrel

Thé Iriver tubc permitted longer cores to be cut and recovered; "since the core was protected from the drilling fluid flow through the barrel and was confined inside a tube much closer to the corediameter itself.. A tapered spring-type "core-catcher" was located inside the lower end of the inner tube. This spring gripped the core and held it inside the barrel for removal from the hole. Corecatchers of a similar type are still used in core barrels today. 
In 1908, following the earlier introduction of roller cutter bits, McLoughlin and Wynn applied for a patent on a roller-type coring bit. Rights to this patent was later purchased by Howard Hughes (Figure 5). 5
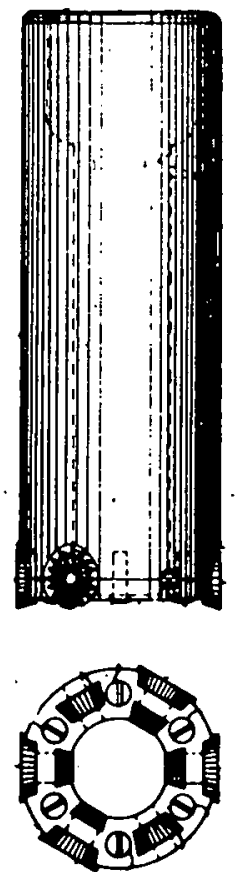

Figure 5

McLoughlin and Wynn Roller Core Bit

By the early $1920^{\prime} \mathrm{s}$, the double-tube barrel had been improved to permit the inner barrel to rotate on a bearing. Thus, during the coring operation, the inner barrel could remain stationary, while the outer barrel was rotated. This feature reduced damage and bieakage of core and as a result, longer, better cores were then possible.

Today, almost all petroleum related coring is done using diamond core bits (Figure 6) and similar double-tube coring systems (Figure 7). These barrels are readily available in sizes suitable for use in all common hole sizes and are available with a number of special purpose attachments or auxiliary systems to improve the type and amount of 
information determined from cores as shown in Table 1 below:

TABLE 1

SPECIAL PURPOSE CORING SERVICES

\begin{tabular}{ll}
\hline \multicolumn{1}{c}{ SERVICE } & \multicolumn{1}{c}{ APPLICATION } \\
\hline Oriented Coring & $\begin{array}{l}\text { Permits studies of directional } \\
\text { properties of the formation } \\
\text { cored. }\end{array}$ \\
\hline Wireline Core Barrel & $\begin{array}{l}\text { Primary application in mining } \\
\text { and offshore sediments studies } \\
\text { requiring continuous coring } \\
\text { where tripping the pipe to re- } \\
\text { move cores is inconvenient. }\end{array}$ \\
\hline Plastic Inner Tube Liner & $\begin{array}{l}\text { Simplified handling of medium } \\
\text { to soft cores. }\end{array}$ \\
\hline Rubber Sleeve Core Barrel & $\begin{array}{l}\text { Permits recovery of soft un- } \\
\text { consolidated cores not recover- } \\
\text { able with conventional core } \\
\text { barrels. }\end{array}$ \\
\hline Pressure Core Barrel & $\begin{array}{l}\text { Recovers core at bottomhole } \\
\text { pressure for study of forma- } \\
\text { tion in undisturbed state. }\end{array}$ \\
\hline Sidewall Coring $*$ & $\begin{array}{l}\text { Permits taking samples after } \\
\text { a formation has been drilled } \\
\text { by running equipment on a } \\
\text { wireline. }\end{array}$ \\
\hline
\end{tabular}

* Not a rotary coring technique. 


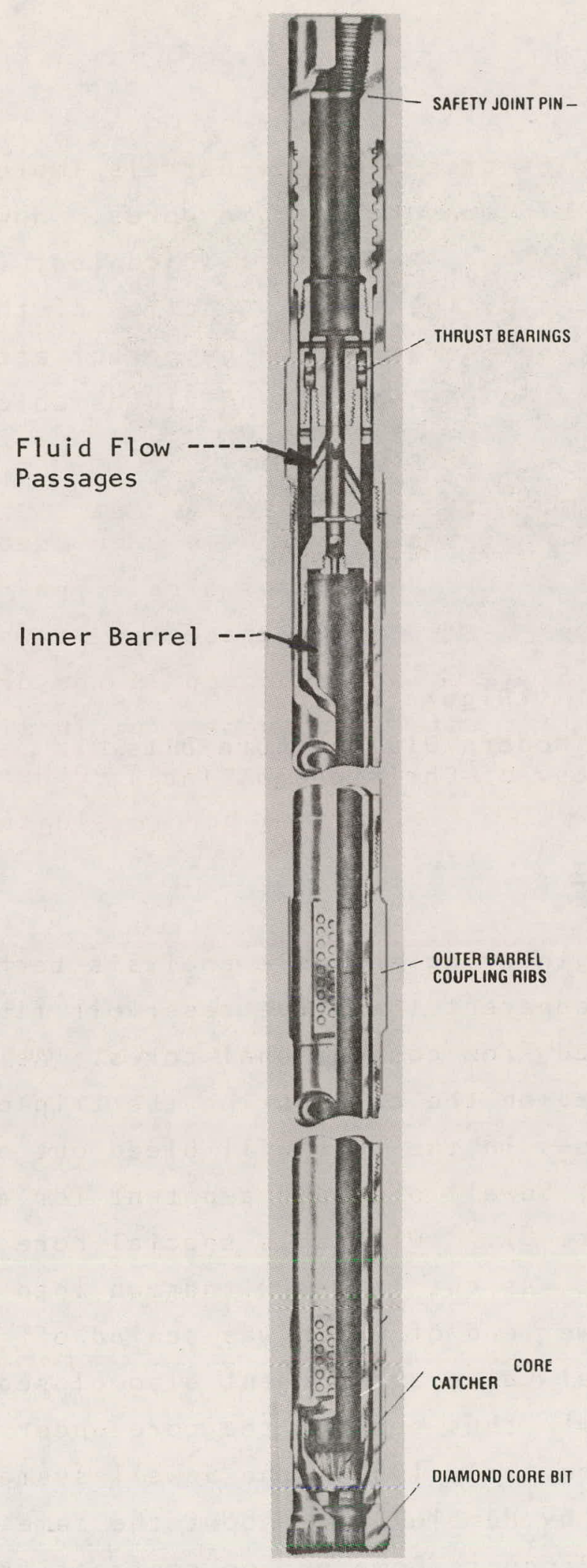

Figure 7

Modern Double Tube Core Barrel (Courtesy American Coldset Corp.) 


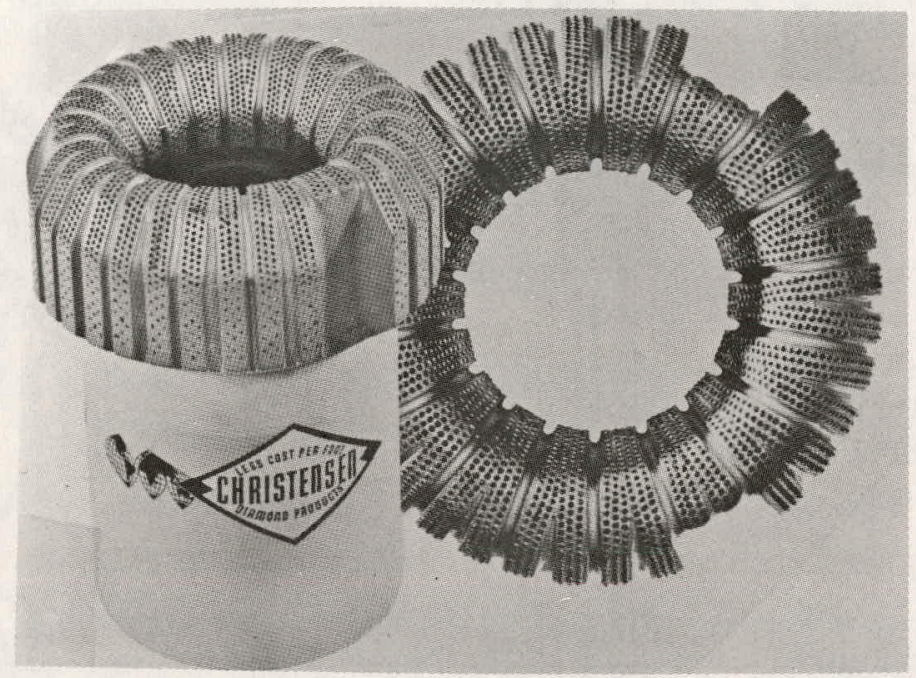

Figure 6

Typical Modern Diamond Core Bits

(Courtesy of Christensen, Inc.)

\section{Pressure Core Barrels}

As reservoir engineering and core analysis technologies improved, it became apparent that true reservoir fluid information is not obtained from conventional cores. As the hydrostatic head is reduced on the coie during the trip out of the hole, oil and gases in the core will bleed out of the rock pores. In 1940, Sewell obtained a patent for a "Pressure Coring Device" (Figure 8). 6 With this special core barrel device, once ihe core was cut it was withdrawn into an intermediate tube, the lower end of which was sealed off by a ball valve. A special valve arrangement also closed off the top of the inner barrel, thus sealing the core under bottom hole pressure. In the early 1960's the Sewell system was revived and modified by Humble $0 i 1$. About the same time Christensen Diamond Products Company, on contract from Shell 0il, designed and built a barrel similar in principle. The Humble barrel was later licensed to Loomis Hydraulic Testing Co., who still markets the system today. 
The introduction of pressure core-barrels improved. the reliability of fluid measurements. in cores. However, it has been discovered that the true fluid content in cores is drastically modified by the flushing action of the coring fluid during the cutting operation. A number of attempts have been made to develop special coring fluids which would. not invade or alter formation fluid volumes in the core.

\footnotetext{
Special oil base drilling fluids have been used with some success in cejtain limestone reservoirs. One research program attempted to seal the core surfaces as it was cut by using a latex rubber material suspended in the drilling fluid. This approach was totally unsuccessful in limestones and only marginally successful in sandstones. Other nonwetting, non-contaminating fluids have been evaluated with similar success.
}

In some cases, much improved information has been obtained by using a special fluid in combination with a pressure core barrel. In general, however, the technique is much too unwieldy and too expensive for practical application. 
REFERENCES

1. Brantley, J.E., History of Oil Well Drilling, Gulf Publishing Co., Houston, Texas, 1971 , p. 1.00.

2. Ibid, pp. 1110-1111.

3. Leschot, USP 39,235 .

4. Brant ley, J.E., Op. Cit.

5. Brantley, J.E., Op Cit., pp. 1072-1073.

6. Sewe11, USP $2,216,962$

$-16-$ 
111. APPLICATIONS AND USES OF CORE DATA

Specific Information Provided by Coring

Interpretive Data

Evaluation of Reservoir Parameters

General Tests

Special Tests

References 
Specific Information Provided By Coring

The main reason for cutting cores (preserving and examining them in a virgin state, if possible) is to know exactly what amount and type of fluid is present in the formation of interest. Also, cores provide cross correlation and calibration of logging techniques in certain areas and reservoirs. Other reasons for coring formations are that a much better estimate of reservoir quantity and potential can be made and a prediction of the field or well's performance can be stated.

The data that can be measured precisely on a core is the depth, permeability, and porosity. These measurements are considered to be an approximation of the reservoir at the depth where the sample was obtained. This depth is, of course, measured by the length of drill pipe in the hole (Figure l). 

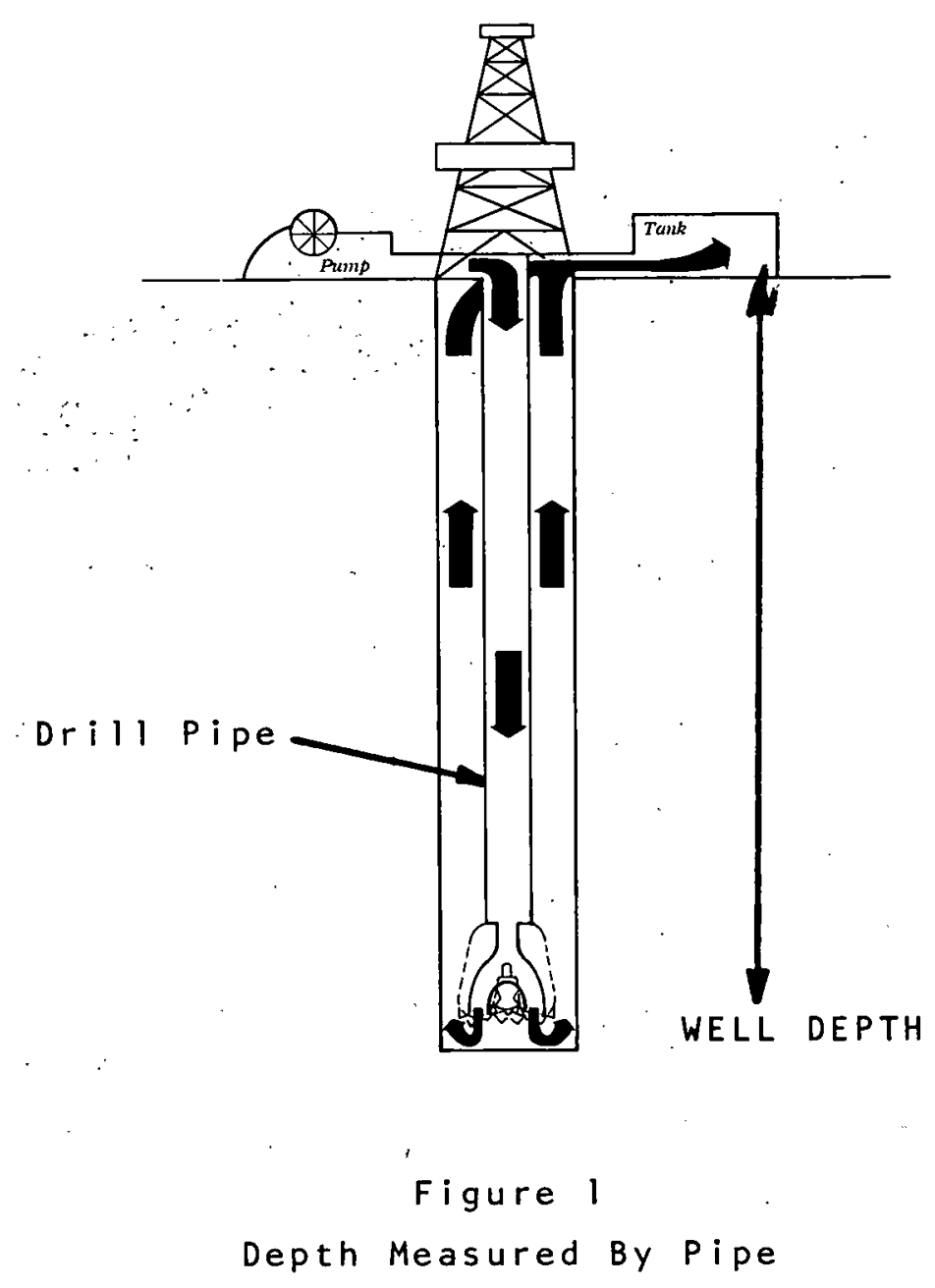

Each conventional core brought back to the surface is probably contaminated by drilling fluids and filtrate; but after cleaning, air or nitrogen can be flowed through the core or a plug of the core to measure core permeability (Figure 2). 
FLUID

FLOW

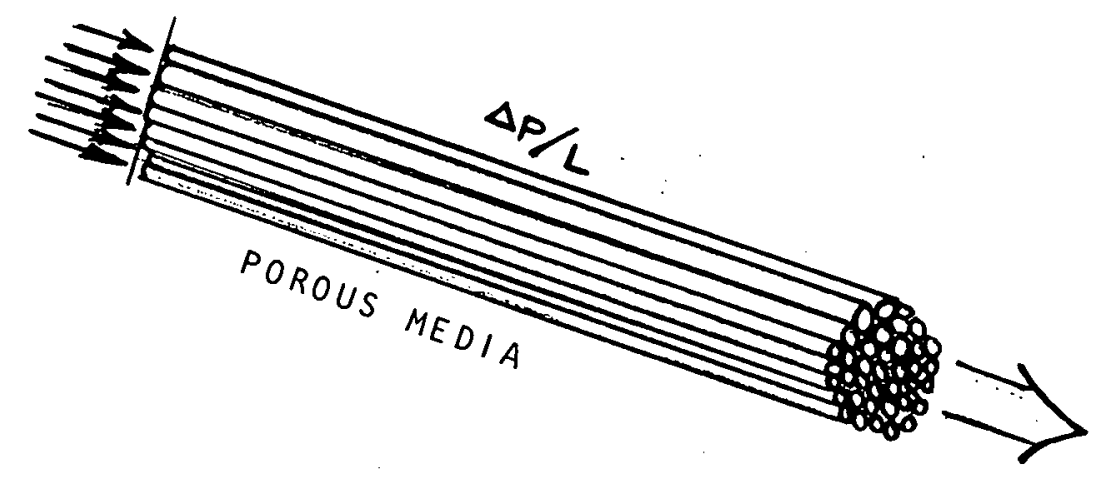

PERMEAB ILITY $(K)=\frac{Q \mu L}{A \Delta p}$ (darcies)

Figure 2.

Permeability

Permeability is the measure of the resistance of a fluid to flow through a porous media and is measured in darcies or millidarcies. A higher permeability has a lower resistance to flow and often allows a higher recovery rate.

A porous media is made up of many small sand grains, compacted media, or other sedimentary rock. Porosity is defined.as the percentage of the total volume of the rock that is pore volume (Figure 3 ). Each of the different types of rock, such as sandstone, limestone, dolomites, etc. have different porosities. For example, sandstone can be thought of as having many small sand grains cemented together leaving pore spaces between the grains. Generally, sand and sandstones have a porosity of between 10 and 40 percent. Limestone and dolomite have a lower average porosity of 5 to 25 percent, but may have large vugs (cavities) or fractures that potentially can accomodate and store large quantities of oil and gas. 


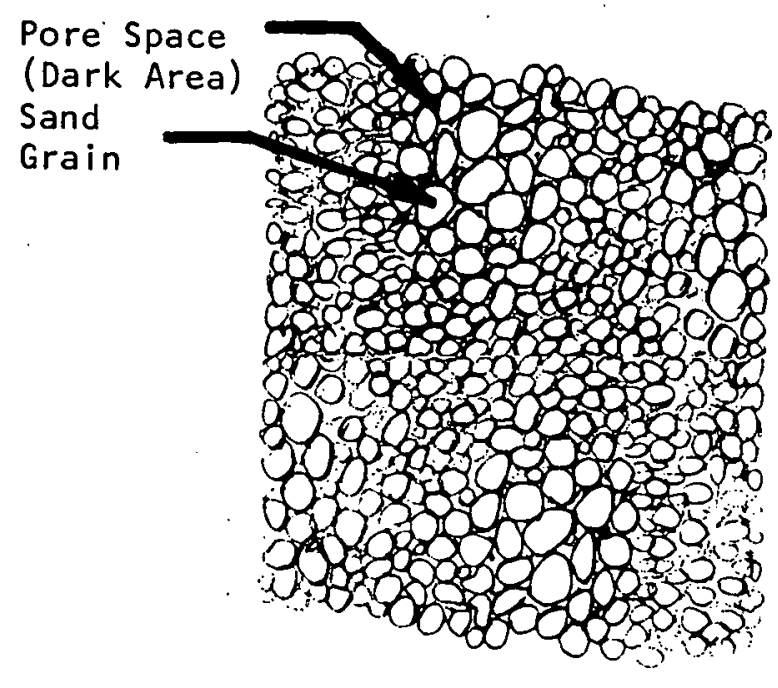

Porosity $=\frac{\text { Pore Volume }}{\text { Total Volume }} \times 100$

Figure 3

Porosity

The size of the pores largely determines what proportion of the space can be filled with oil or gas, while the nature of their interconnection determines the percent of oil that is recoverable. Pore size variation ranges from molecular size to cavern size.

With both permeability and porosity, large variations will be found even in the same reservolr or formation due to the natural deposition processes which produce heterogeneous rocks.

By collecting cores over a known interval and measuring permeability and pososity versus depth, the information shown in Table 1 can be calculated: 
Position of Permeable Zone

Position of barriers to vertical flow

Magnitude of permeability (average permeability over an interval)

Magnitude of porosity (average porosity over an interval)

Variation of permeability with depth

Permeability distribution

Pore structure interconnection

Presence or absence of oil if uncontaminated and preserved

Core analysis data interpretation permits predictions of the distribution of fluids and the type of production to be expected from a particular reservoir. Fluid contacts, whether they be gas-oil or oil-water, have important inferences during completion and production operations. Proper location of the perforated interval is often decided from cores. The type of production expected determines perforated interval, tubing size and surface equipment requirements. Some of interpretive data obtained from core analysis are shown in Table 2: 
TABLE 2

\begin{tabular}{|l|} 
Production Information Provided By Cores \\
Type of fluid production \\
Transition zone definftlons \\
Fluid contact position. \\
Zones of potential water or gas \\
coning \\
Depleted zone production \\
Gas production. possibilities \\
Condensate production possibilities.
\end{tabular}

When discussing the above parameters, the first three can be lumped together. The exact position of an oil-water contact can sometimes be found by an abrupt change in the saturations of the fluids, although filtrate invasion usually obscures interpretation of the available information. Also, alternating stringers of high and low permeability sands near the contact make the finding of fluid-to-fluid contacts difficult.

Dirty sands are likely to have non-uniform pore size. distributions and will have a large transition zone from oil to water. If a low gravity oil is found, then the problem of water production can. be aggravated by the oil's high viscosity; hence, lower mohility.

Certain other information ${ }^{\prime}$ from cores allow some general rules of thumb to be established.for certain types of reservoirs. These rules permit interpretation of core properties based on: changes in water and oil. saturations; magnitude of water and oil saturations; 
FLUID CONTACT

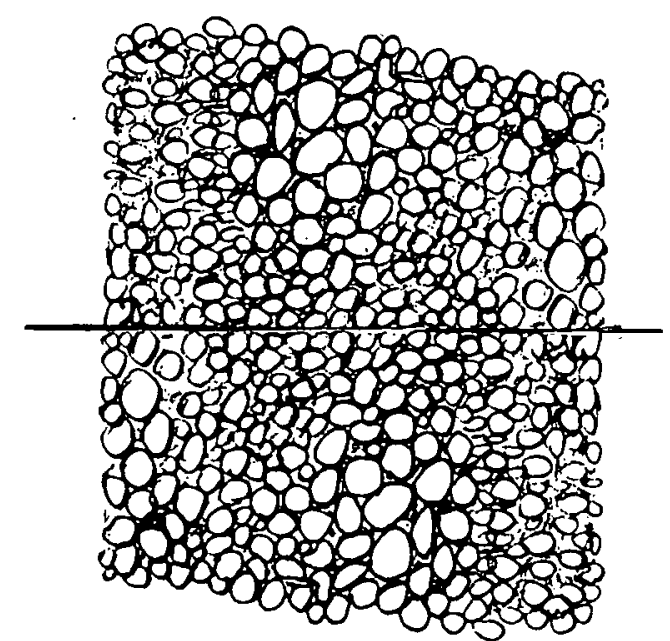

Figure 4
-0 il saturation $=70 \%$

- Water Saturation $=30 \%$

- 0 il Saturation $=20 \%$

- Water Saturation $=80 \%$

\section{Change In Saturation Fluid Indicates Fluid Contact}

The magnitude of the total water saturation helps to interpret the ability of a formation to produce: Prior history of the particular reservoir is sometimes essential to make a correct assessment of the situation. A ratio of oil and water saturation indicates the type of fluid production to be expected. In California, for example, the residual oil-water ratios are found to be 0.05 to 0.35 to 1.0. The critical limit for this ratio varies with the particular area in question.

A gas-water ratio is another criterion that is useful in either gas or oil zones since it tells something about gas cap expansion or oil shrinkage.

Water or gas coning can be estimated by measurement of vertical core permeability and proximity of the producing formation to a water contact (Figure 4). The thickness of the productive interval is important to minimize coning problems. Also, withdrawal rate or drawdown influences the magnitude of coning. Shale breaks or barriers help 
to prevent coning from having a significant effect. "The absolute magnitude of permeability is not as important as the ratio of the horizontal to vertical permeability which is usually estimated quite closely from analysis of the recovered cores (Figure 5).

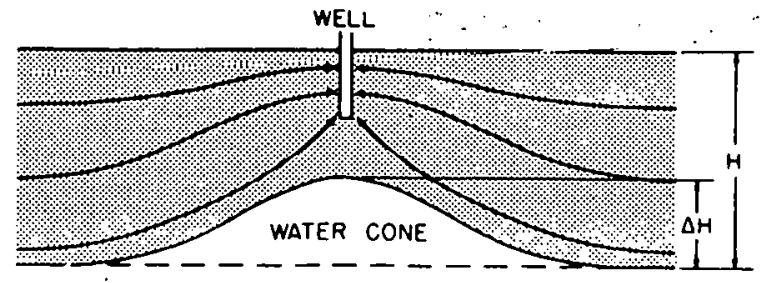

Figure 5

Water cone beneath a partially penetrating well in a bottom water drive reservoir

Gas producing formations are easier to find from cores because of the more abrupt transition of gas to oil or gas to water. Fluid-to-fluid transitions are more subtle and spread out. When a contact is not intersected by the core, the interpretation as to gas. or water production can be made on the basis of total relative water saturation. Generally, gas saturations increase.with depth while water saturations tend to. decrease. In some cases, shallow high-porosity, dirty sands may show total water saturations of over $80 \%$ and still produce gas while deep, low-porosity limestone. may show water saturations below $50 \%$ and be water producers.

A gas condensate formation presents an interpretive problem similar to a gas reservoir, hut i ight-culored liquid hydrocarbones may be present in amounts ranging from a trace to about $5 \%$ of the pore space. At intermediate depths, oil saturations above $2 \%$ may indicate an oil rim around a condensate reservoir. One complications is the 
retrograde condensation which presents unusual interpretive complications if. cores were not taken in pressure core barrels. Below 10,000 ft, with. oil. saturations of about 3 to $8 \%$, the reservoir is near the critical region where the distinction between gas and liquid phase diminishes.

Evaluation of Reservoir Parameters

Cores and core data are used to make overall

evaluations which are estimates of a semiquantitative nature. These are mainly estimated production rates, reserves in place and recoverable reserves. The rate of production is estimated from permeability data of the cores. The controlling factor is the total millidarcy-foot capacity of the section exposed to production. Usually it is communicated as the productivity index or barrels of oil per day per psi pressure drop.

The water intake rate is needed when planning a water injection or water flood program. Other information cores will provide are: zones of highest intake, number of injection well s required and well head pressure required. The estimates are based on the injectivity index or barrels of water injected per day/per psi pressure differential. There are two cases to consider: one, injection into a depleted zone and the other injection into a reservoir at equilibrium pressure.

Core samples of an oil-bearing formation provide the only means for direct measurement of many important properties of the formation. Knowledge of the core properties is important in developing well completion techniques and methods. Subsequent workover operations, fièld development and operating. practices are also guided by crucial core information. 
Specific applications of interpreted core analysis may require composite informations from many cores in a reservoir or related area. Also, the core analysis may not be used solely as a basis for complex decisions, but in conjunction with all available information from other formation evaluation methods. A summary of the principal applications and uses of core analysis is given in Table 3 .

For exploration wells, the zones that are productive in related reservoirs are cored to test for permeability, porosity and oil saturation. If oil is found, an estimate of commerciality is made to decide on whether the well can be completed.

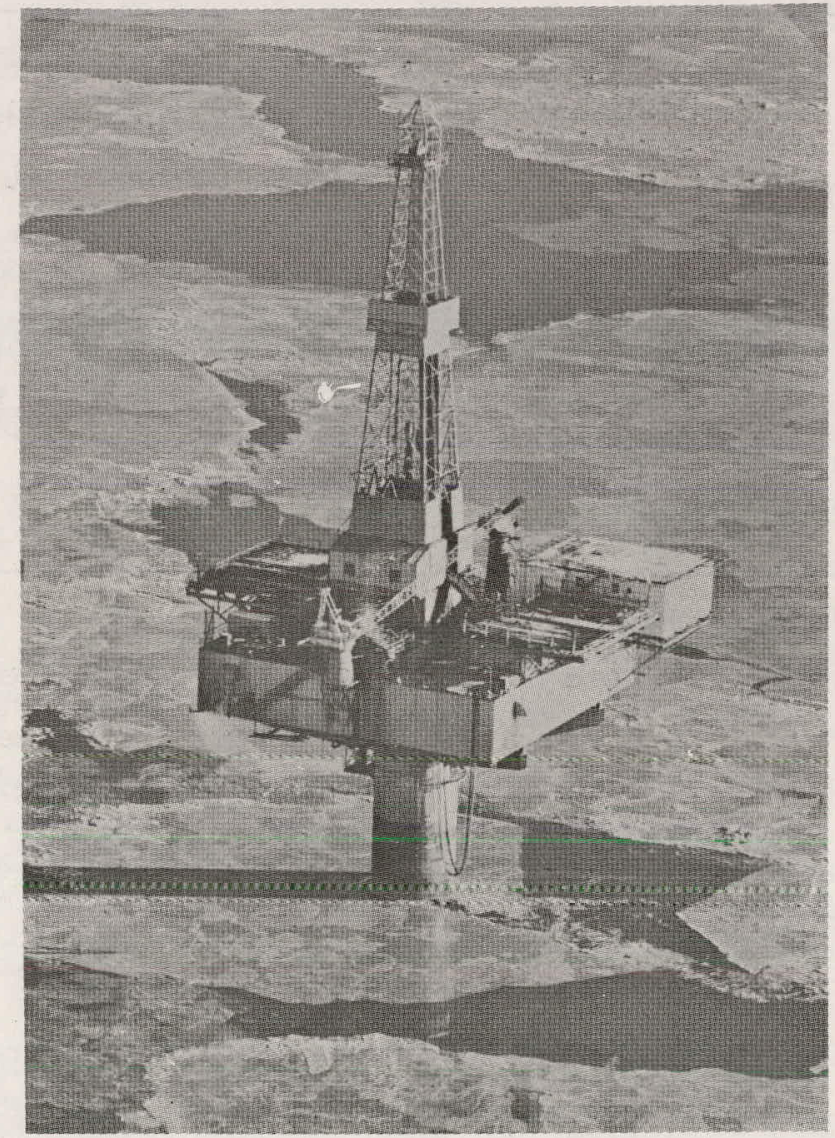

Figure 6

Exploration Operation 
Area of Interest

Specific Applications

\begin{tabular}{|c|c|}
\hline Exploration Wells & $\begin{array}{l}\text { Evaluate productive possibilities of edge wells, } \\
\text { field extension and wildcats } \\
\text { Determine subsurface structural and stratigraphic } \\
\text { conditions }\end{array}$ \\
\hline Field Development & $\begin{array}{l}\text { Determine optimum spacing } \\
\text { Determine new locations } \\
\text { Define field limits } \\
\text { Find capacity of field tankage and pumpage } \\
\text { Define fluid contacts in field } \\
\text { Determine structural and stratigraphic } \\
\text { correlations } \\
\text { Establish a cross check on well-logging methods } \\
\text { Select water intake wells } \\
\text { Select optimum completion intervals }\end{array}$ \\
\hline $\begin{array}{l}\text { Well Completion and } \\
\text { Workover Operations }\end{array}$ & $\begin{array}{l}\text { Select drill stem test intervals } \\
\text { Interpret drill stem test information } \\
\text { Select sequence of completion of multiple zones } \\
\text { Determine packer and plug seats } \\
\text { Determine perforation depths } \\
\text { Determine hydraulic fracturing and acidizing } \\
\text { requirements. } \\
\text { Evaluate completion } \\
\text { Determine recompletion intervals }\end{array}$ \\
\hline $\begin{array}{l}\text { Well and Reservoir } \\
\text { Evaluation }\end{array}$ & $\begin{array}{l}\text { Find the net pay } \\
\text { Estimate initial production and pressure drawdown } \\
\text { Estimate water intake rate and injection pressure } \\
\text { Estimate zone depletion schedule } \\
\text { Estimate probable recovery } \\
\text { Find oil or gas in place } \\
\text { Help in unitization operations } \\
\text { Help in rescrvoir studies } \\
\text { Help plan pressure maintenance } \\
\text { Help plan secondary recovery operations } \\
\text { Provide information on future uses of the } \\
\text { reservoir }\end{array}$ \\
\hline
\end{tabular}


Correlation of core data from the various:wellswin: a field is important for developing a thorough understanding of the size and characteristics of that specific reservoir.

The analysis of cores provides specific information. necessary for properly completing every zone of interest: in a well.

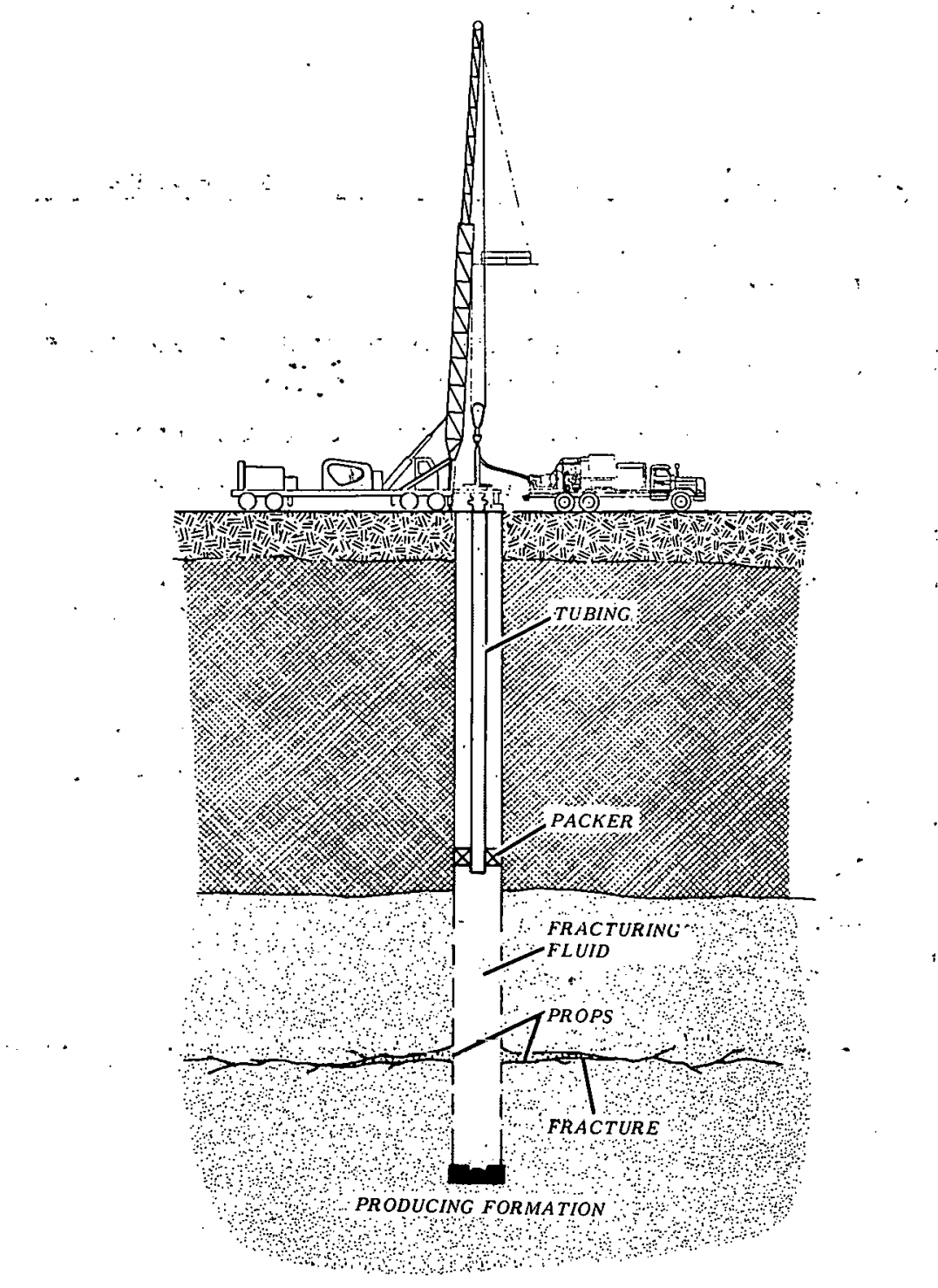

Figure 7

Formation Fracture Treatment 
- In modern day core analysis tests, each series of cores will be analyzed and the interpretations made in a formal report. The depth over which the cores are taken will be plotted on a depth chart (coregraph). Any corresponding well logs at this depth will be. compared to the coregraph. The important data included in the report are shown in Table 4:

\section{TABLE 4}

Data Included On Core Analys is Report

The cored or analyzed interval

The number of permeable and productive feet in the interval

The capacity of the productive interval

The averages of the core analysis data meașurements

The calculated, approximate and preliminary values of original stock tank oil in place in an oil productive interval

Estimate of recoverable oil by both solution gas drive and water drive in unit.s per acre/foot

Net pay thickness

Connate water content

Reserves in place 
Under certain conditions special tests will be run on cores to provide even more detailed information on rock properties. Specifically méasured data on fluid distribution and multiphase flow cháracteristics of the reservoir rock are essential to detailed reservoi the tests are performed on preserved cores; but they also can be used on fresh cores if available. A brief listing and description of these tests are as follows:

1. Capillary Pressure Curve.

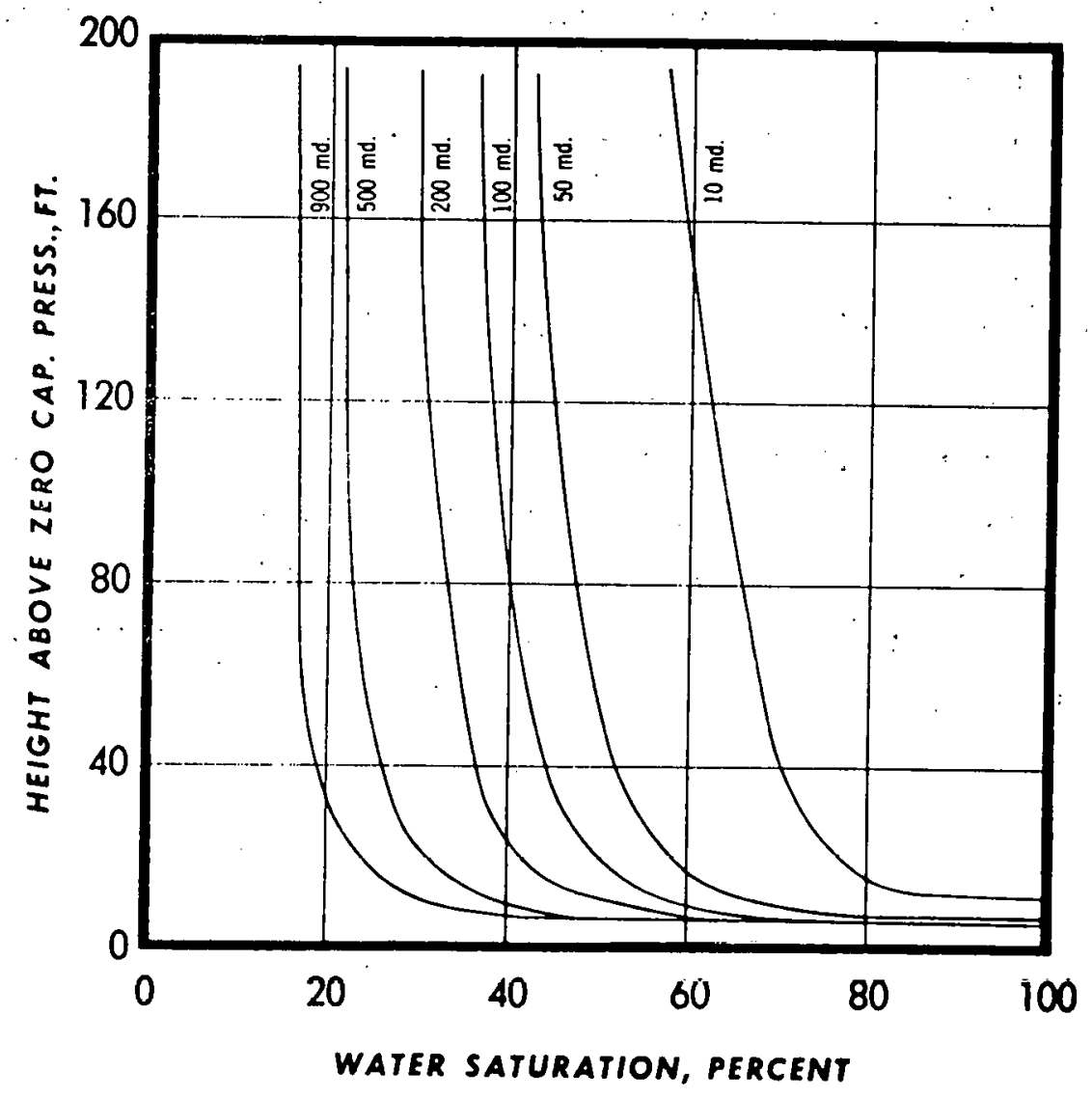

Figure 8

Capillary Pressure Curve

Air is used as a non-wetting phase to enter large pores at low pressure head and smaller ones at higher pressure. Figure 8 shows the typical curves for six different permeability cores. Results of this test show the irreducible minimum water saturation. 
2. 0 il-Waterflow Data

These tests measure relative permeability effects (or interference) of the flow of oil and water. Now, fresh cores give best results but old cores can be given a restored saturation of oil and water and. flow data measured.

3. Residual oil Data

A sample is saturated with brine, then restored to reservoir oil and water saturations. Permeability to oil is measured and the sample is then flooded with brine until only water is produced. Permeability to brine is then measured and the residual oil content calculated.

4. Waterflood Susceptiblity Tests

These tests are water/oil relative permeability measurements that predict the effectiveness of an artificially introduced water drive on natural water drive. The results of the test are shown in Fig. 9 where the water cut and water input is related to the amount of oil recovered. 


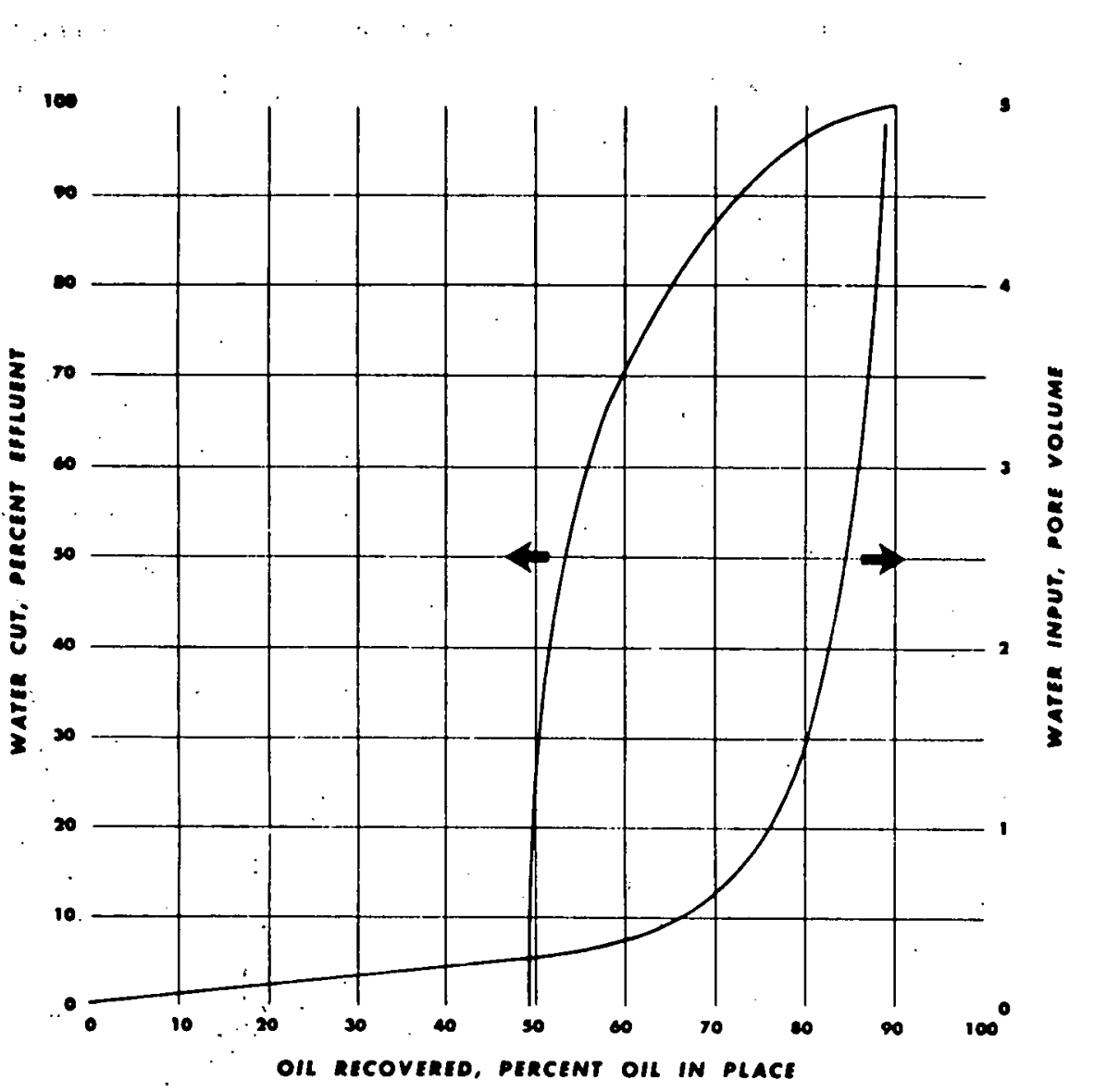

Figure 9

Waterflood Evaluation Curves 
5. Gas-0il Relative Permeability Data

These tests are needed for gas drive, gas injection, expanding gas cap or gravity drainage production. One method of calculation for gas-oil permeability was developed by Welge ${ }^{2}$. Although not a simple calculation, computers can easily solve and plot the gas-oil permeability curves when given all required input information: A typical gas-oil relative permeability curve is shown in Fig. 10.

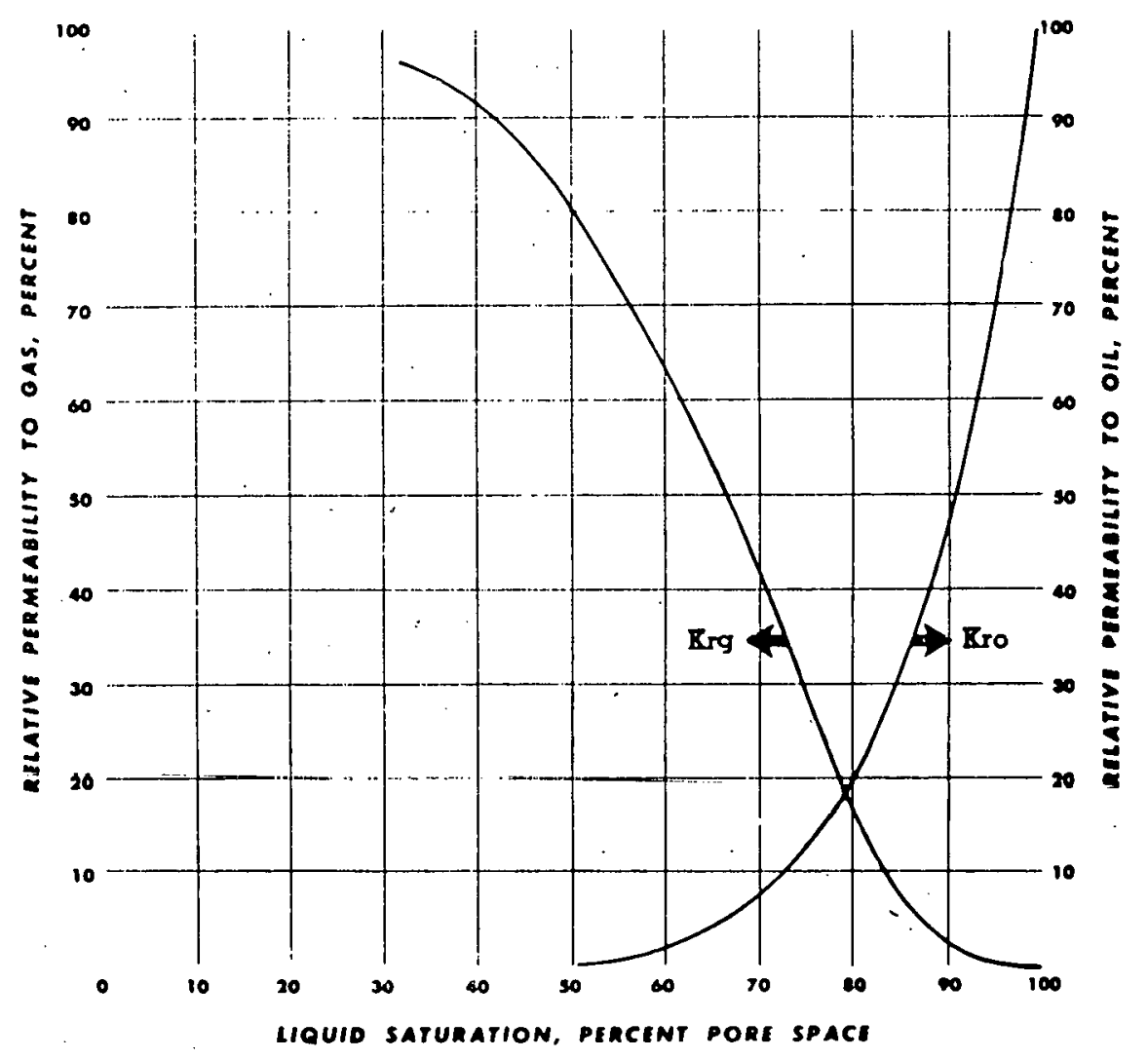

Figure 10

Relative Permeability Curves 
6. Water Permeability Data

Fresh water damage or blockage can be measured when swelling clays are present in, the core.

7. Electric Resistivity Measurement

A formation resistivity factor and ratio are measured from the cores. This information is used to refine electrical log calculations. After core and logs are calibrated, other wells that were not cored can be correlated very accurately with the wells and formations that were cored. 


\section{References}

1. Elmdahl, B. A., "Core Analysis" of Wilcox Sands," World 0il, 134 (June, 1952), ppg. 181-190.

2. Welge,H. J., "A, Simplified Method for..Computing 0 il Recovery. by Gas or Water Drive," AIME Trans. 195 $(19.52)$, . $9.1 \ldots$ 


\section{CORE HANDL ING AND PRESERVATION}

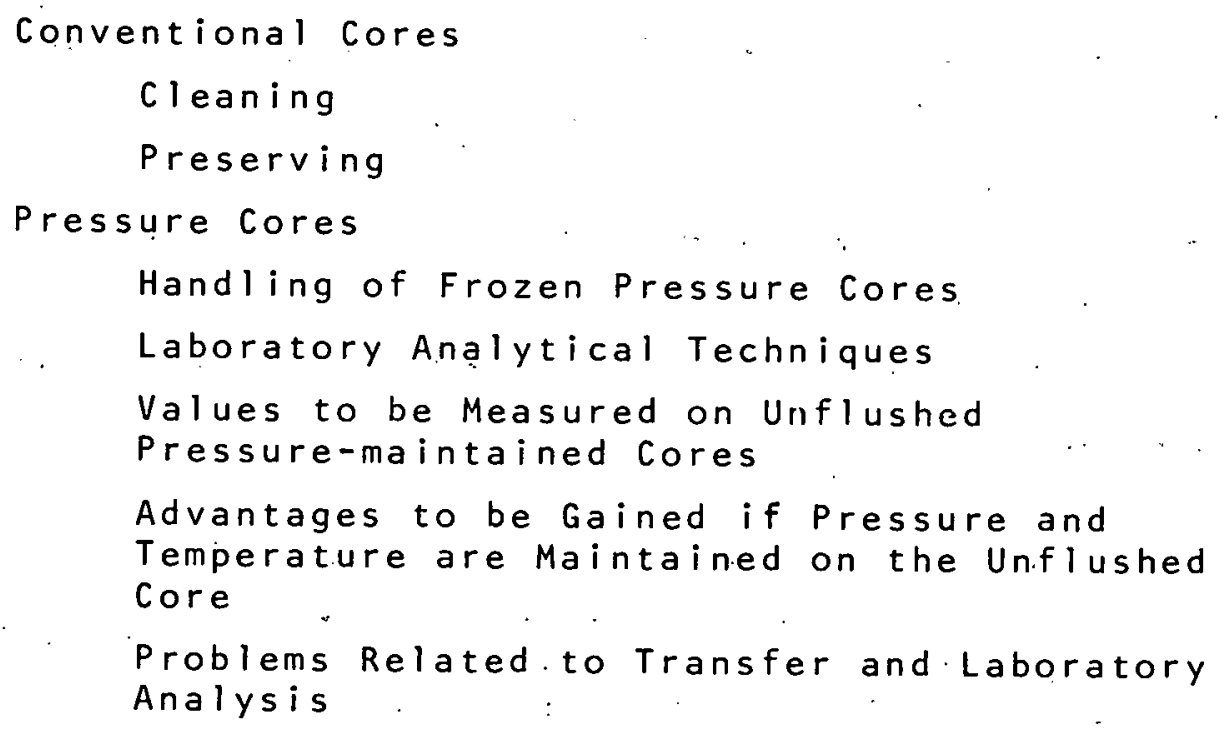




\section{Conventional Cores}

Practices for handling and preserving conventional cores vary considerably, and are depended upon oil company policies, type of core being analyzed, type of analysis planned and the length of time from removal until the analysis will be performed. However, most practices are based on variations" of American Petroleum Institute procedures: I

\section{"2.113 Cleaning the Core}

It is recommended that the core be wiped to remove soft mud cake and excess mud as soon as possible following its removal from the core barrel. The excess mud should be wiped off with a damp - not wet nor dry - rag. Preferably, the rag should be dampened in drilling fluid and wrung out as often as necessary to prevent its becoming too wet. core samples to be sent to the laboratory should never be washed with water or any other liquid after removal from the barrel. Depending upon the firmness of the core, there may be a question whether the mud cake should be removed either by wiping with a rag or scraping with a knife. If field examination is required, it may be necessary to scrape part of the core in order to make the examination. Emphasis must be placed on never washing the mud from the core. In any event, the wiping, examination, and sampling procedure following removal from the core barrel should take a minimum of time. The time a core is exposed to the drilling fluid and the atmosphere will affect the subsequent core analysis.

Even a few minutes exposure of cores, depending upon atmospheric conditions, can cause the loss of both water and 1 ight hydrocarbon fractions. Tests have shown that as little as $1 / 2$ hour exposure to the atmosphere can result in 10 to 25 percent loss in water content. If the core is accidentally washed with water, allowed to remain in the core barrel, or let stand before sealing in a container, then a notation of the washing, the number of hours in the core barrel, or the length of exposure time before sealing in the container should be made." 
The preservation of the core is an attempt to maintain it as nearly as possible in the same condition as existed upon its removal from the core barrel until it is ready for analysis. An additional objective of preservation is to prevent breakage of the core during shipment and storage. Hard and consolidated cores may be durable enough not to require special precautions and support. However, special care should be taken to give adequate support to cores which are soft or poorly consolidated. The use of glass jars, easily deformable plastics, paper cartons, and other non-rigid containers should be avoided if core samples are to be shipped or will be subjected to other rough handling. As previously stated, there are a number of acceptable practices for preserving cores during transportation and storage. These methods are clearly described in API RP $40: 2$

\subsection{Sealing in Air-tight Cans}

Core samples selected for analysis, particularly when saturation determinations are critical, may be sealed in metal cans. This is an efficient, rapid method. Cores may be canned directly or sealed in cans after a preliminary wrapping using aluminum foil, or polyethylene or other suitable plastic. There should be a minimum of space between the core sample and the can, particularly if no preliminary wrap is used. If the core is friable, some provision to prevent its movement in the can during shipping should be made. The use of paper, wax paper, cardboard, or materials which may absorb moisture or oil from the core should be avoided. If the entire core is shipped to the laboratory following the selection and canning of samples for fluid-saturation tests, the canned samples - each properly labeled for depth - may be replaced in the position from which they were removed from the core. The core should be properly logged on its arrival at the laboratory. Normally, it is recommended that cores not be canned with any fluid surrounding the core. The sealed container should not be subjected to large temperature fluctuations, if possible, in order to minimize evaporation and condensation of core fluids in the container. 
2.132 Sealing in Air-tight Steel, Aluminum, or Plastic Tubes

Using suitable couplings, caps, or 0 -ring seals the entire core may be preserved for analysis by placing it in steel, aluminum, or plastic tubes. close-fitting tube is desirable. Normaliy, no fiuids should be used in packaging the cores although the cores may be pre-wrapped in plastic or metal foil.. Large variations in temperature during storage and shipment should be avoided.

\subsection{Sealing in Plastic Bags}

Core samples which are sealed in plastic bags should have a minimum of air space between the core and the bag wall. Any excess bag can be folded against the core wall and taped in place to assure a tight fit. Excess air may be withdrawn by suction. Care must. be taken in adjusting the bag so that sharp. points on the core do not puncture the bag. In some cases, more than one layer of plastic bag or sheeting may be used for wrapping cores. Cores sealed in plastic bags may be packed in boxes with suitable packing to prevent their being broken in shipment, or they may be canned or placed in metal or plastic tubes. The same precautions must be observed for cores sealed in plastic bags as for those sealed in cans, so far as exposure to extremes of temperature is concerned.

\subsection{Freezing in Dry lce}

$$
\text { (U.S. Patent No. 2,617,296) }
$$

Cores which are preserved by freezing should be frozen very rapidly by application of dry ice. slow freezing may result in the migration of fluids within the core structure or breakage of the core. Cores are commonly frozen when the core-analysis laboratories are local. Preservation by freezing of cores for extended storage requires refrigeration or continuous repacking with dry ice. If it is necessary to allow the core to warm to room temperature before testing, the condensation of moisture from the atmosphere onto the core surface must be: prevented. Slow thawing of the core will cause some redistribution of the fluids within the core matrix.

Freezing will affect properties of cores flushed with fresh water more than those flushed with saline mud filtrate. These effects will decrease with liquid saturation. 


\subsection{Wrapping in Metal Foil and Plastic Tape}

Cores should be wrapped with metal foil and plastic tape only if they are consolidated enough to withstand shipment and will be analyzed in a few hours. Care must be taken that the foil is not punctured by" sharp points of "the core. To preclude this, cores are often double or triplewrapped. Effective wrapping with metal foil is best accomplished by lapping the edges along the length of the core as well as on the ends and folding once or twice, finally pressing the folded edges down against the core. The use of a self-sealing vinyl tape has been substituted for plastic, after foil wrapping. Foil wrapping prevents the adhensive on the tape from absorbing oil from the corre.

\subsection{Plastic Coatings}

Plastic coatings have been used wherecores are not to be tested within a few hours and need to be transported over distances which may involve rough handiing. The cores should be scraped rea. sonably free of mud.cake, dipped in the molten plastic, tagged, and. shipped in this condition. One procedure used.for dipping cores in molten plastic requires a thermostatically controlled melting pot to hold the plastic in a barely melted condition. The core to be coated is grasped by tongs or by the thumb and forefinger at one end submerged about two-third of its length in the molten plastic, immediately removed, and allowed to cool and set for a few seconds. It is then grasped by the coated end and dipped, allowing the second plastic layer to overlap the initial one.

A dip such as that just described should leave a. plastic layer about $1 / 16$ in. thick, completely surrounding and sealing the core with no air space between, yet not penetrating the core beyond one sand grain depth. If transportation over long distances is anticipated or if cementation of the core is not good, it may be advisable to repeat the dipping process, thereby building up the thickness of the coating. This can be continued to achieve any reasonable thickness desired. However, for normal physical protection, the inlicial dip coat is satisfactory. Very poorly consolidated cores may be wrapped in foil before dipping. 
Plastic used for coating cores must have certain properties, as follows:

a. It must be dimensionaliy stable over long period of time.

b. It must not react with oil or water.

c. It must not contain oleic acid, oil, solvent, or any other liquid which may be exuded when set.

d. It must be impermeable to gases, oils, and water when set.

e. It must have a low melting point, preferably below $200 \mathrm{~F}$. maximum.

f. It must have a fairly low viscosity when melted. The viscosity should be similar to that of an average oil paint such that it will pour readily or drip slowly from a small opening, yet will not quickly. penetrate capillary openings.

g. When removed from heat and exposed to normal air temperatures, it should dry and set tack-free within 5 to $15 \mathrm{sec}$.

h. When set, it should be tough but pliable, slightly elastic, but with good tensile strength; and not melt at temperatures below $180 \mathrm{~F}^{2}$ 


\section{Pressure Cores}

The most commonly used procedure for preserving pressure cores is by freezing with dry ice. 3,4 on cores taken with the Loomis pressure barrel, it is first necessary to remove the drilling fluid entrapped between the inner barrel and the outer barrel prior to freezing. If this is not done, the drilling fluid will become frozen, locking the inner barrel inside so that it cannot be properly removed.

To accomplish proper flushing, a back-pressure regulator is attached to a port in the ball valve housing and a highpressure positive displacement pump is attached to the flushing head at the top of the inner barrel. A material such as gelled varsol is then carefully pumped into the annular space between the inner and outer barrels maintaining the desired bottomhole pressure during the process. The gelled material is slowly forced through the barrel until all of the drilling fluids have been displaced. The core barrel is then placed into an insulated container and carefully frozen with dry ice.

The freezing procedure requires approximately one hour. Once this has been accomplished, the pressure maintenance is disconnected and the outer tube removed from around the inner barrel. Standard pipe cutters are then used to section the $10 \mathrm{ft}$. inner barrel into easily handled lengths and the core is broken at each cut. Since prolonged exposure of the core to materials such as nitrogen, hydrogen and oxygen can significantly alter formation wettabilities, the cores should be quickly capped and wrapped with aluminum foil or plastic as quickly as possible, replaced in insulated containers and covered with dry ice. Cores preserved in this manner can be transported and stored for several months before thawing and analysis without apparent damage. 
In 1947, Wisenbaker proposed the process of preserving cores by freezing with dry ice. ${ }^{5}$ His studies of over 80 samples from 4 different wells showed that no appreciable porosity change was caused by quick freezing samples fully or partially saturated with water. No appreciable change in permeability was noticed for samples with $10 \%$ or more gas saturation. Samples fully saturated with water but with a permeability of more than $10 \mathrm{millidarcys}$ also showed no substantial change. Samples fully saturated with water and with permeability of less than $10 \mathrm{millidarcys}$ showed some change in permeability. Fresh core samples adjacent to those analyzed at the well were frozen and analyzed at times ranging from 20 hours to 30 days after freezing with no appreciable change in permeability, porosity, oil or water saturation attributable to quick freezing.

\section{In 1953, Kelton 6 , reported on a study conducted to} verify Wisenbaker's findings. Eighty-six pairs of samples from the Gulf Coast, West Texas and the Mid-Continent area were analyzed. The data was then grouped with that obtained by Wisenbaker with the resulting total of 177 sample pairs from 10 different wells. The results of this study are shown in Table. 1:

- TABLE 1

- A Comparison of Permeability and Porosity Averages of Samples Frozen at Well-Site vs Corresponding Averages for Adjacent Samples Not Frozen

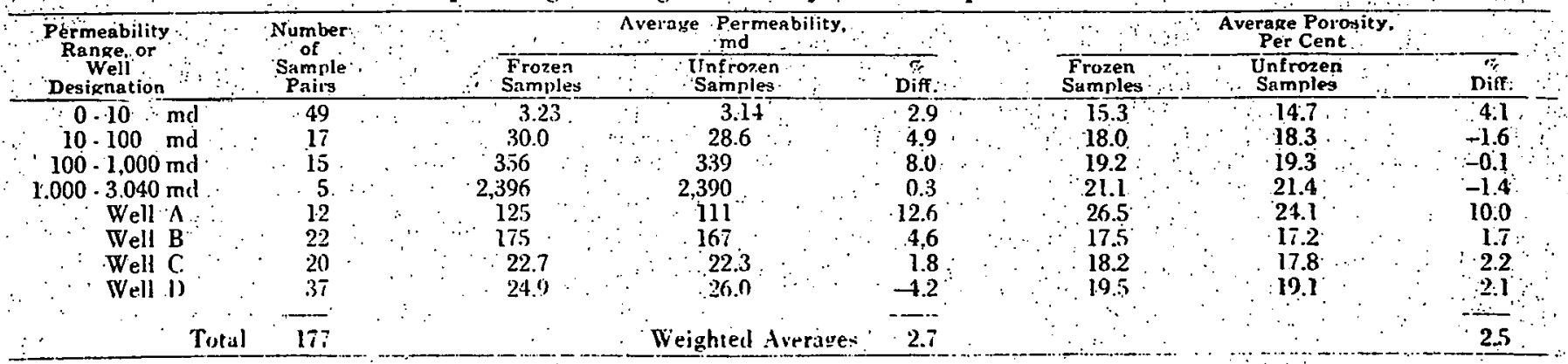


The final conclusions of Kelton's study was the same as previously found: that for all practical purposes, any changes in permeability, porosity and fluid saturation of oil well cores brought about by quick freezing are negligible.

\section{Handling of Frozen Pressure Cores}

The following steps are required to prepare frozen cores for analysis: 7

(1) Core removal from metal pressure barrel

(a) The sleeve containing the frozen core is cut into 3-4 ft. lengths in the field.

(b) After arrival at the laboratory, two grooves are milled down the axial length of the sleeve and on opposite sides of the core while maintaining the core in a frozen state. See Figures $1,2,3 \varepsilon$ 4. The groove is deepened until only paper thin metal remains. The barrel is cooled with liquid nitrogen during the milling operation. Problems are encountered here with freezing damage to the milling equipment.

(c) The final sleeve removal occurs in the laboratory by wedging a tool in the milled groove of the sleeve and twisting or tapping. See Figure 5 .

(2) Mud removal from sample circumference after core is out of the metal pressure barrel but still frozen. 


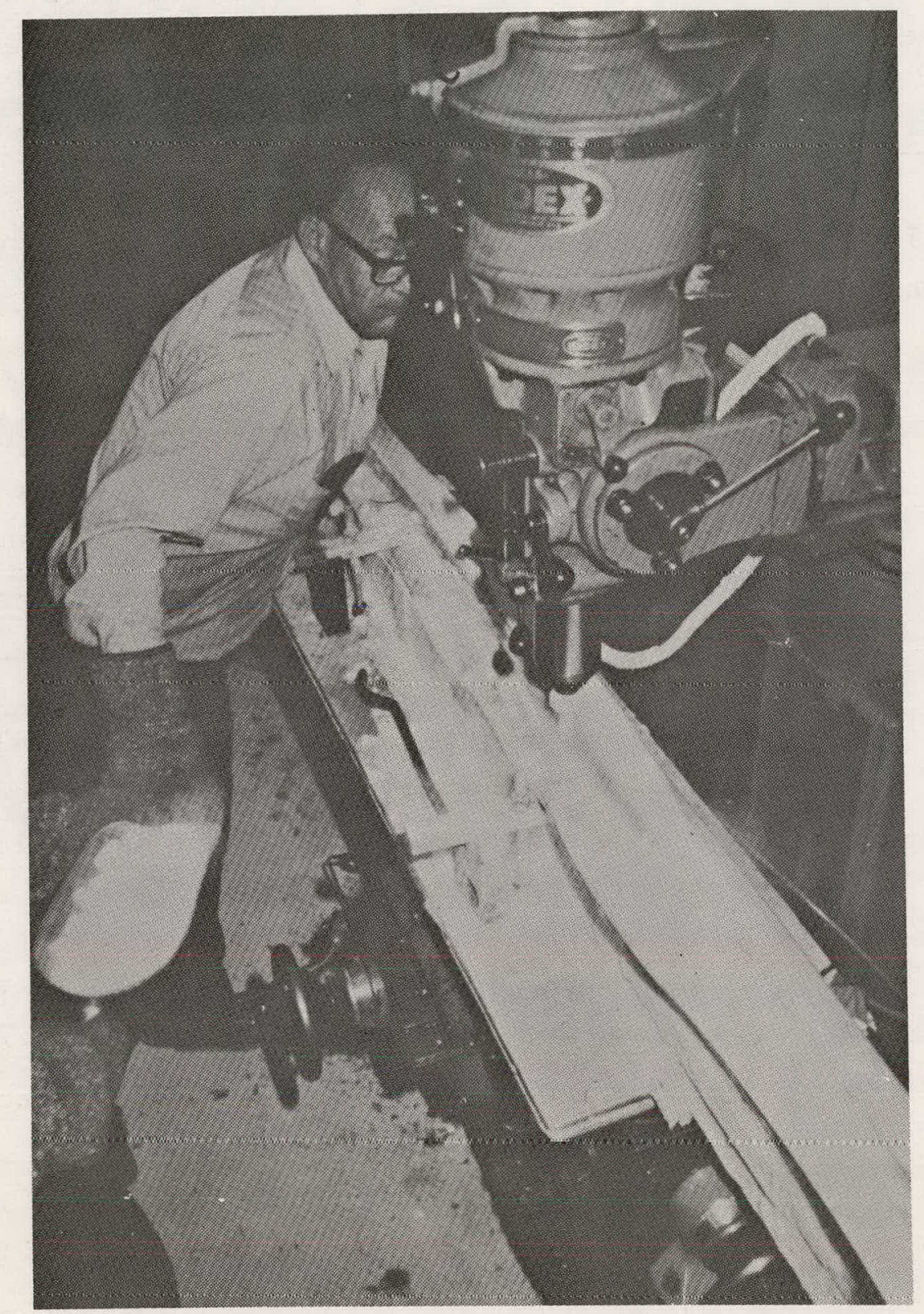

Figure 1 - Milling Frozen Core. 


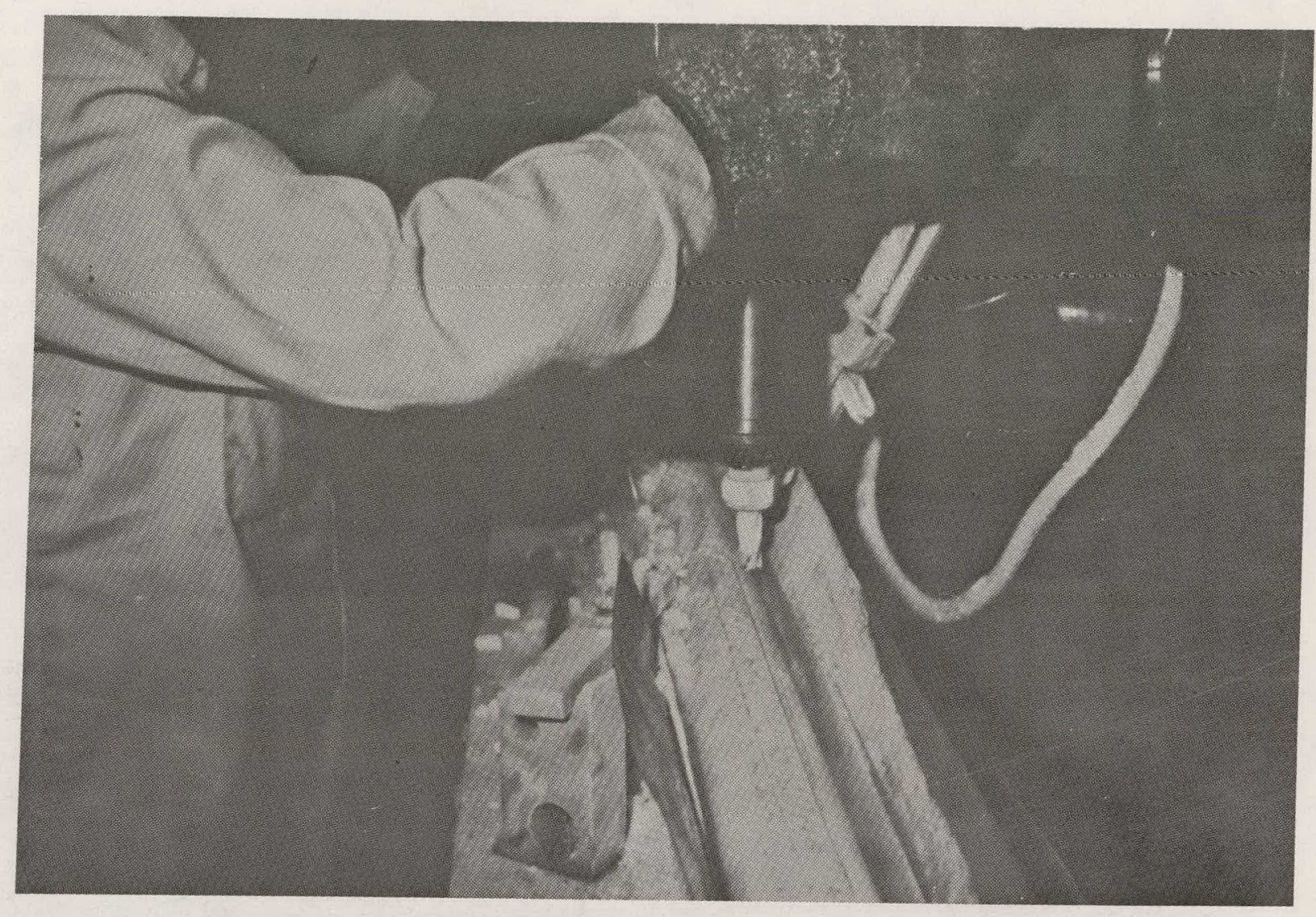

Figure 2

Milling Off Metal Sheath Around Frozen Core 


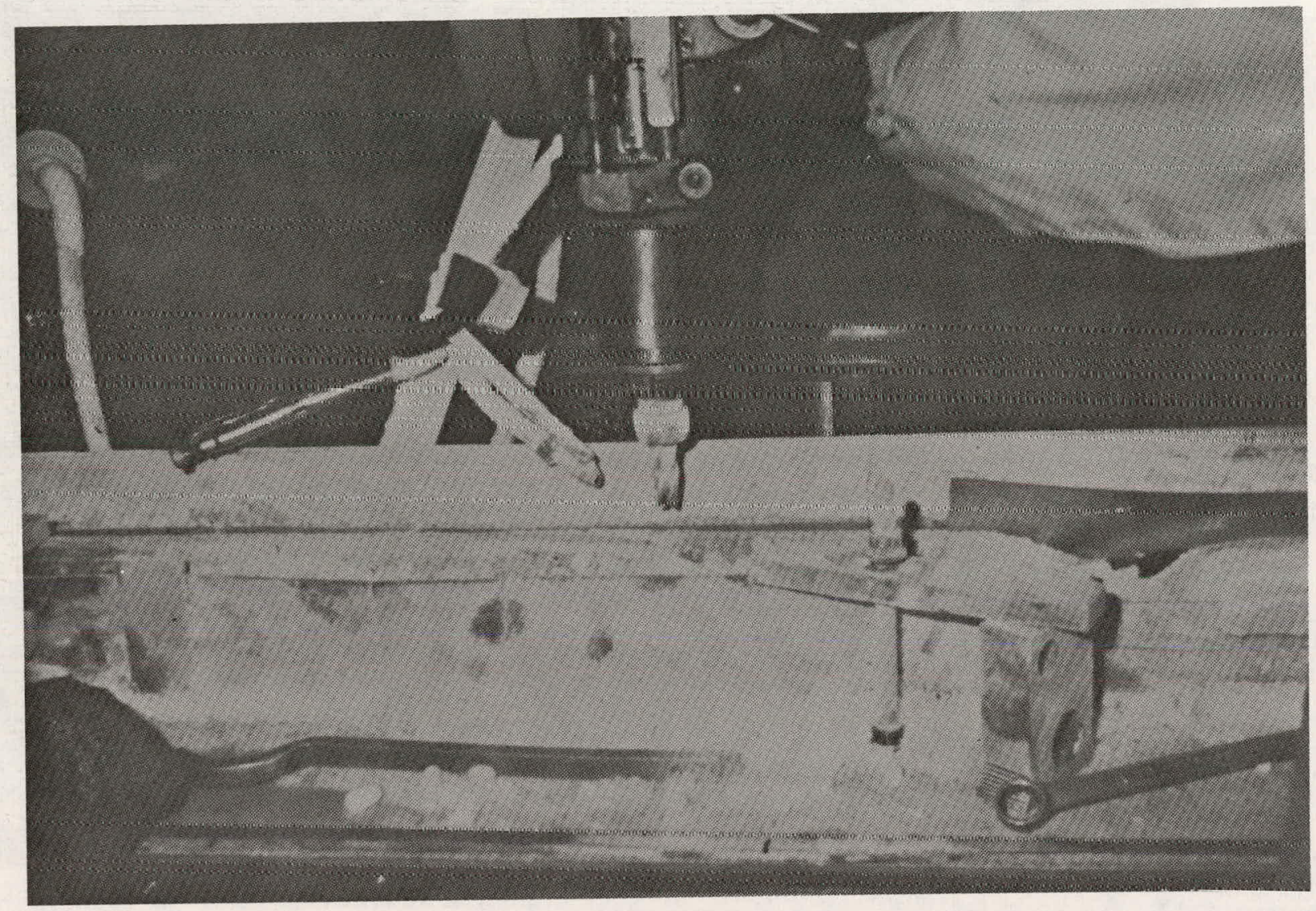

Figure 3

Side View of Milling off Sheath of Frozen Core 


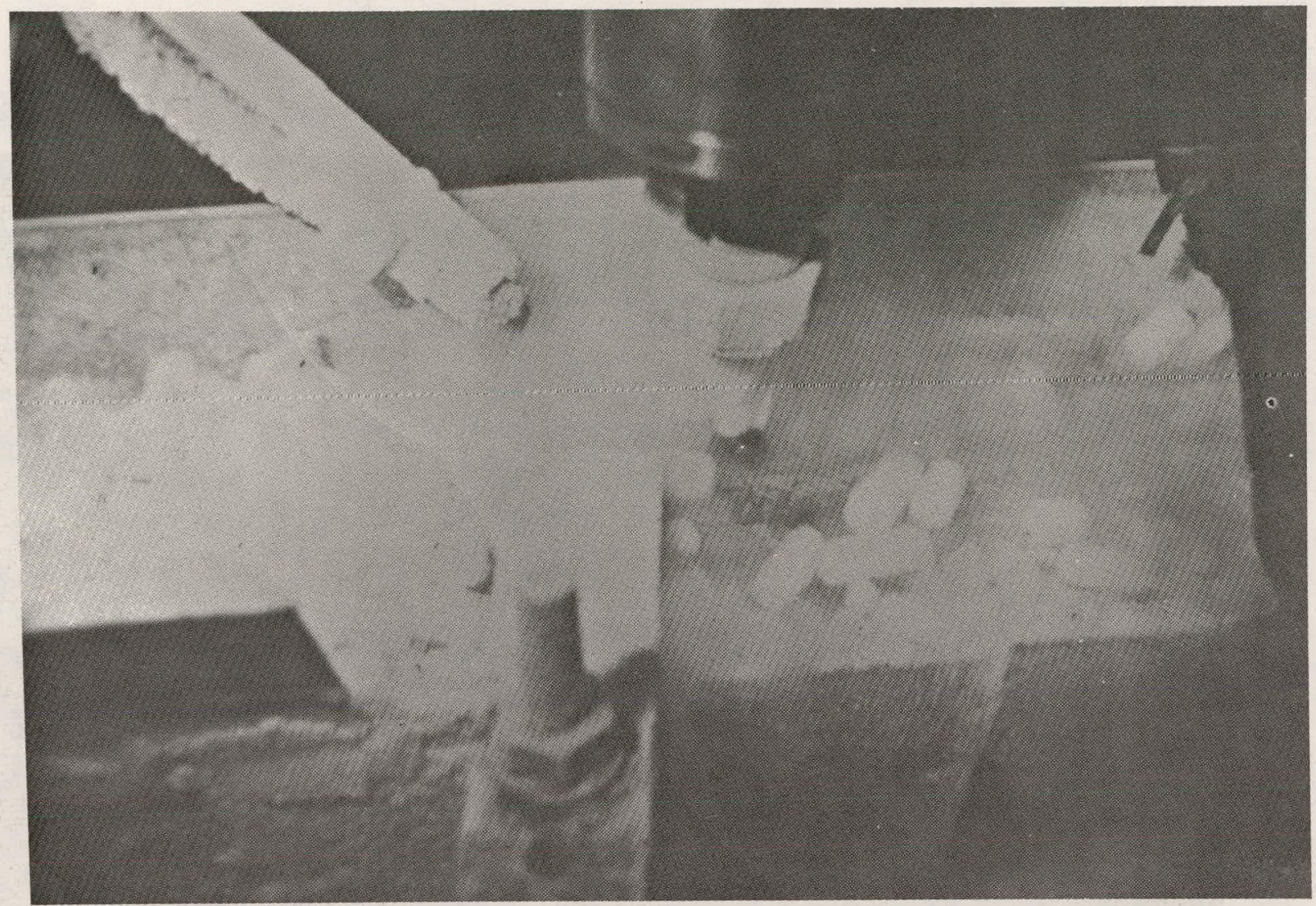

Figure 4

Close Up of Milling Operation

(a) Frozen mud adheres to the core surface and is difficult to remove. A similar difficulty exists with both water base and polymer muds.

(b) The mud must be rasped off or a chipping process must be used. The core must be isolated from the atmosphere to prevent moisture condensation on the surface. This can be accomplished if the core is worked on in a deep chest surrounded by $\mathrm{CO}_{2}$ vapor. See Figures 6,7 and 8 . 


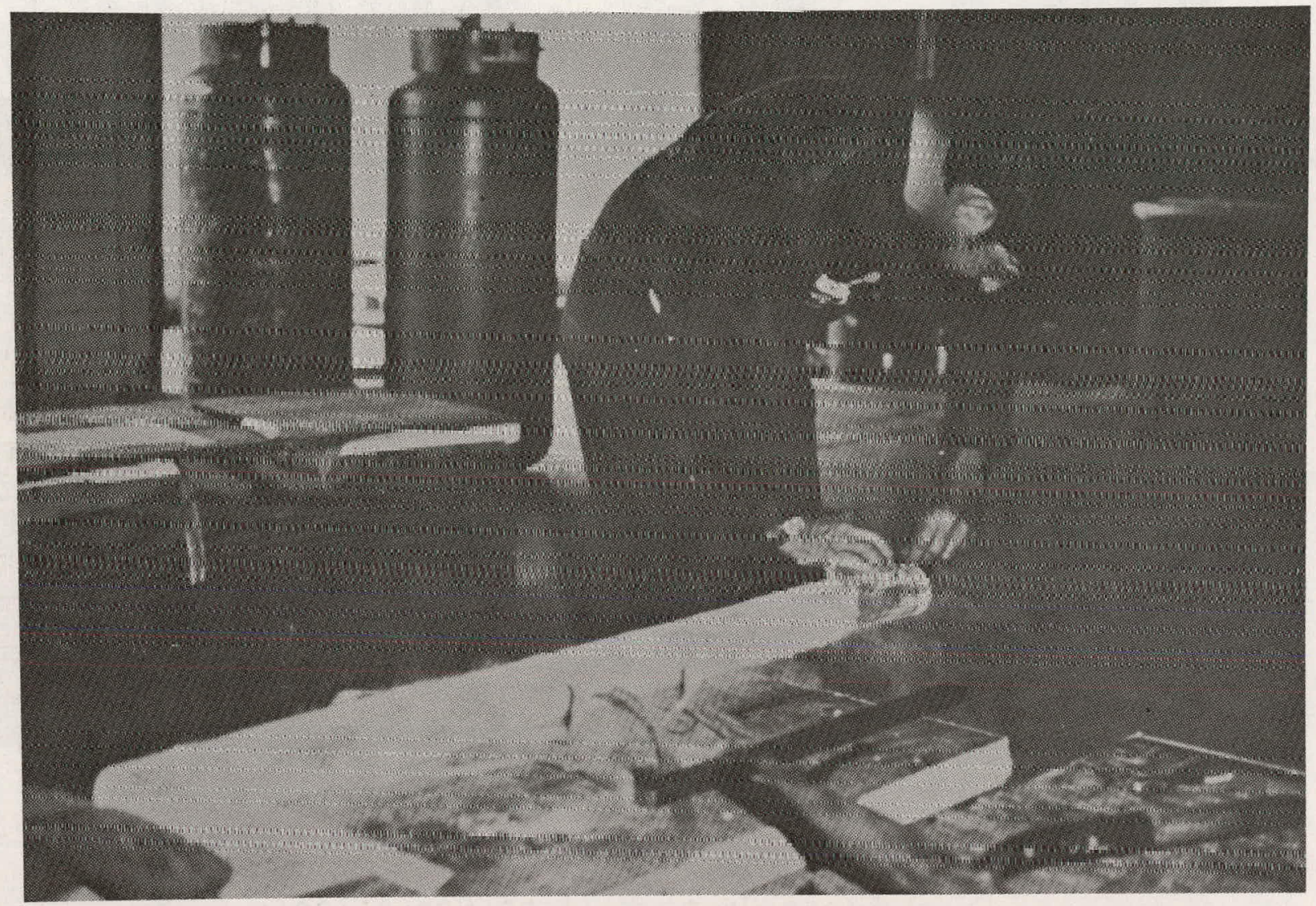

Figure 5

Wedging off Sheath from Frozen Core. 


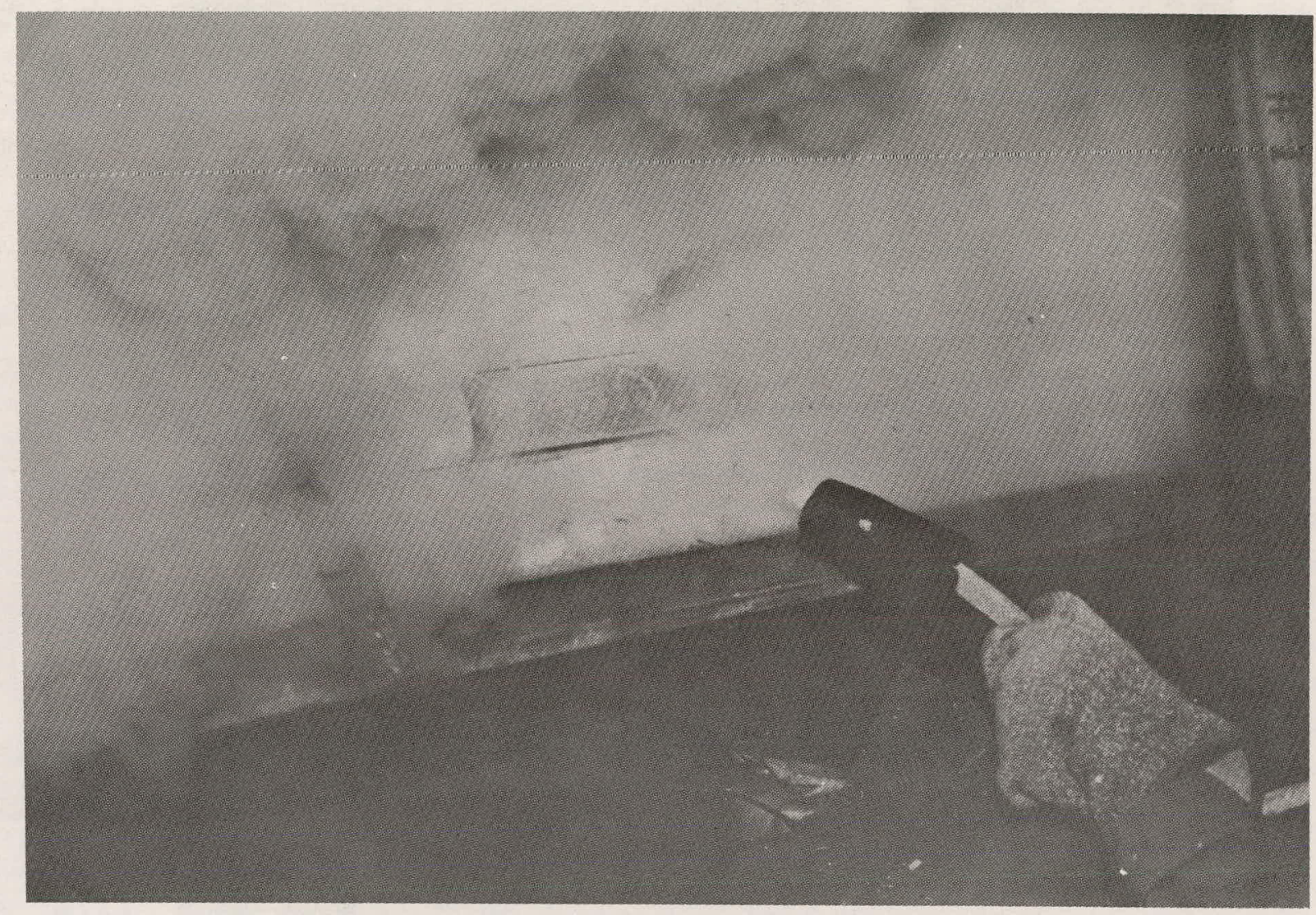

Figure 6

Cooling Core for Final Cleaning.

$-51-$ 


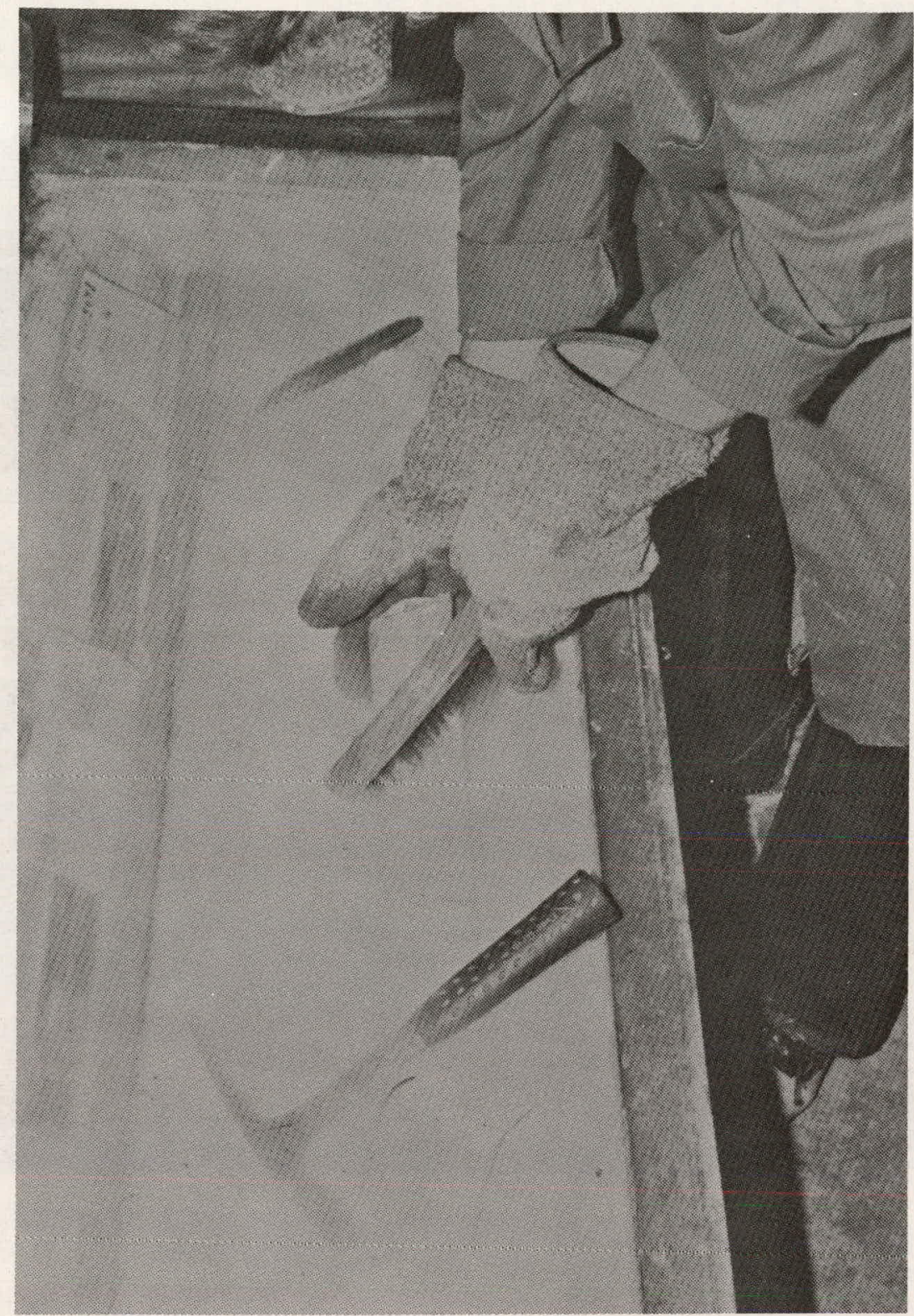

Figure 7

Rasping off Frozen Mud From Core 


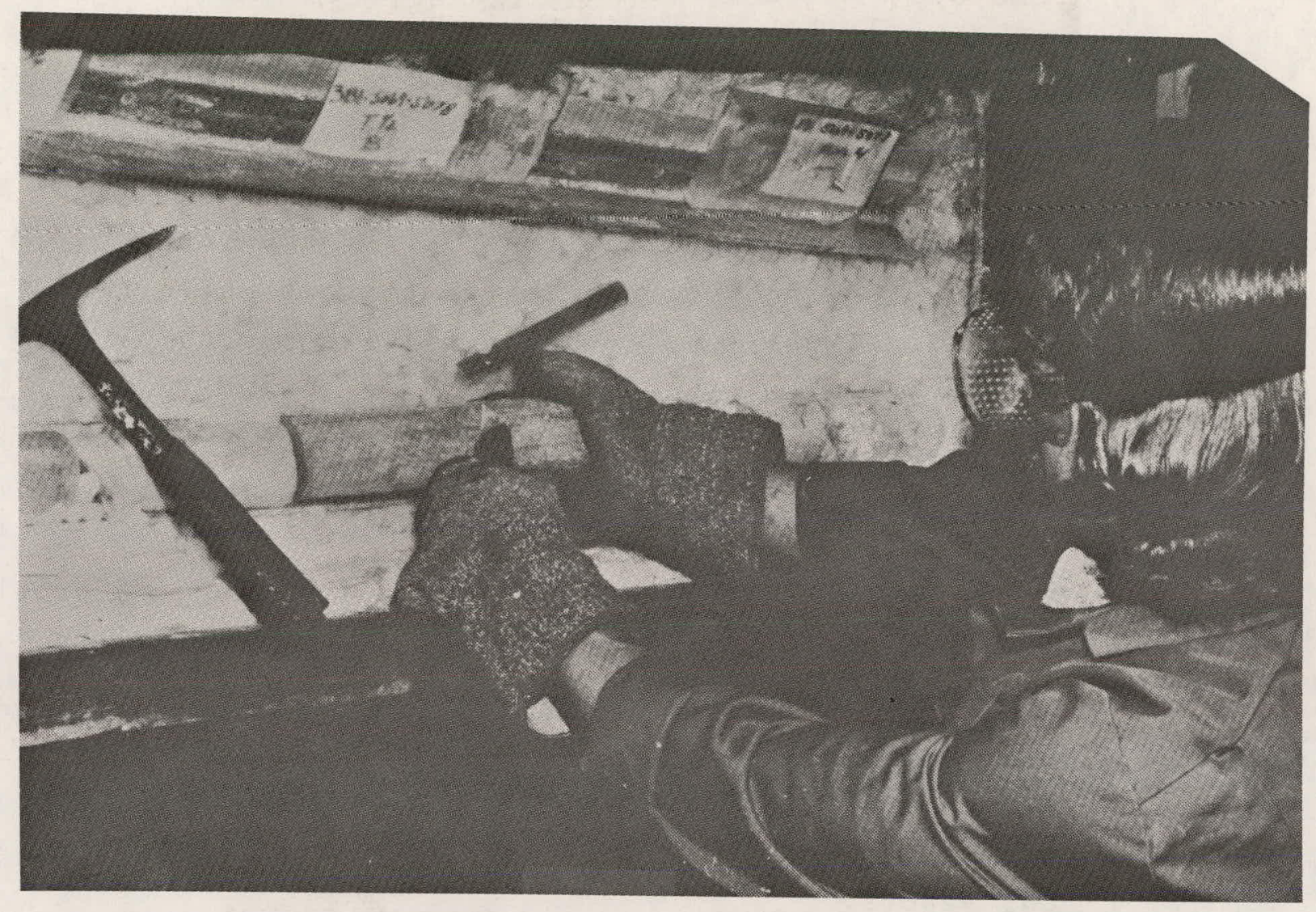

Figure 8

Scraping Frozen Core 
(3) Trimming and drilling of core samples after mud removal.

(a) Samples are cut into 4" to 8" right cylinders while frozen. This yields full diameter samples normally used in subsequent tests. Samples must be sawed while frozen. If necessary, the trimming process can be stopped while the core is refrozen, or liquid nitrogen can be directed to the cutting surface. See Figure 9 .

(b) Plugs ( 1 "' or $\left.1 \frac{1}{2}^{\prime \prime}\right)$ can be drilled from the frozen core using liquid nitrogen as the bit lubricant.

(4) Exclusion of core from oxygen and nitrogen is a problem only if core wettability changes are to be avoided. The shipment of the core in the metal barrel, and subsequent storage in dry ice, minimizes this problem. It is also minimized during surface mud removal in the deep chest with the core in the $\mathrm{CO}_{2}$ vapors.

(5) The expansion of fluids within pore space that is one hundred percent liqdid saturated can be a problem in certain formations. This saturation condition occurs when cores are from virgin formations at initial pressure conditions, or when taken from within a water flooded zone maintained at initial pressure. Fluid expansion in these cases may increase the measurable pore (storage) volume of the rock, and volume of the rock, and in unconsolidated formations result in changes in bulk volume as well. Where gas saturation is present to furnish volume into which the fluids can expand, no alteration in measured properties is likely to occur. 


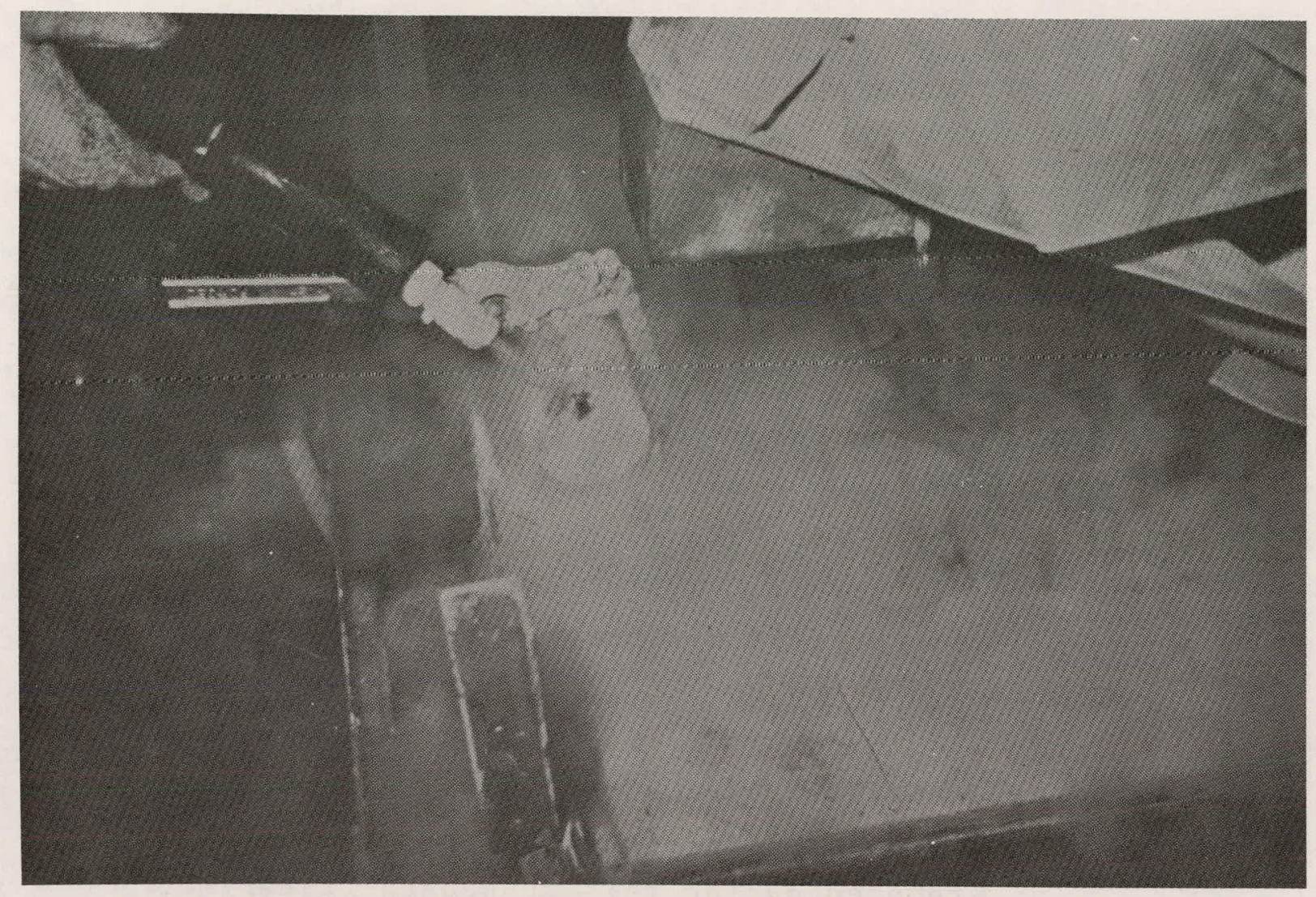

Figure 9

Liquid Nitrogen Being Used to Cool Cores During Trimming Process.

Laboratory Analytical Techniques (Dependent on Data Required)

(1) The frozen full diameter sample is measured for length, diameter and weight and is placed in an air tight container. A quick ( 15 second) vacuum is applied to remove air surrounding the sample within the container.

(2) The sample is then allowed to thaw overnight. Gas evolves during the thawing process and expands. The gas is trapped, and its volume is measured. 
(3) Composition of the evolved gas can be determined by chromatograph.

(4) Heat is applied to the core container to vaporize the oil and water - which are recovered in a calibrated receiving tube attached to the underside of the container. The receiving tube is submerged in liquid nitrogen, or a suitable coolant, to condense the vaporized fluids. See Figure 10 .

(a) $450^{\circ} \mathrm{F}$ and vacuum application is used in some processes. This effectively cleans and dries the core if oil gravity is $35^{\circ}$ API or above.

(b) $250^{\circ} \mathrm{F}$ and no vacuum will remove all water and some oil. The core must be weighted, oil extracted by an independent process, and the core re-weighed to find the additional oil removed during this subsequent cleaning.

(5) After the core is cleaned and dried, the pore volume is determined using one of several suitable techniques. Porosity (pore volume divided by bulk volume) is then computed.

(6) Permeability is determined on the clean, dry core.

Values To Be Measured On Unflushed, Pressure-maintained Cores

Porosity, permeability, and oil, gas and water saturations are the principal measurements that would be made on unflushed, pressure-maintained cores. Of these measurements, the oil, gas and water saturation measurements would be the most important 


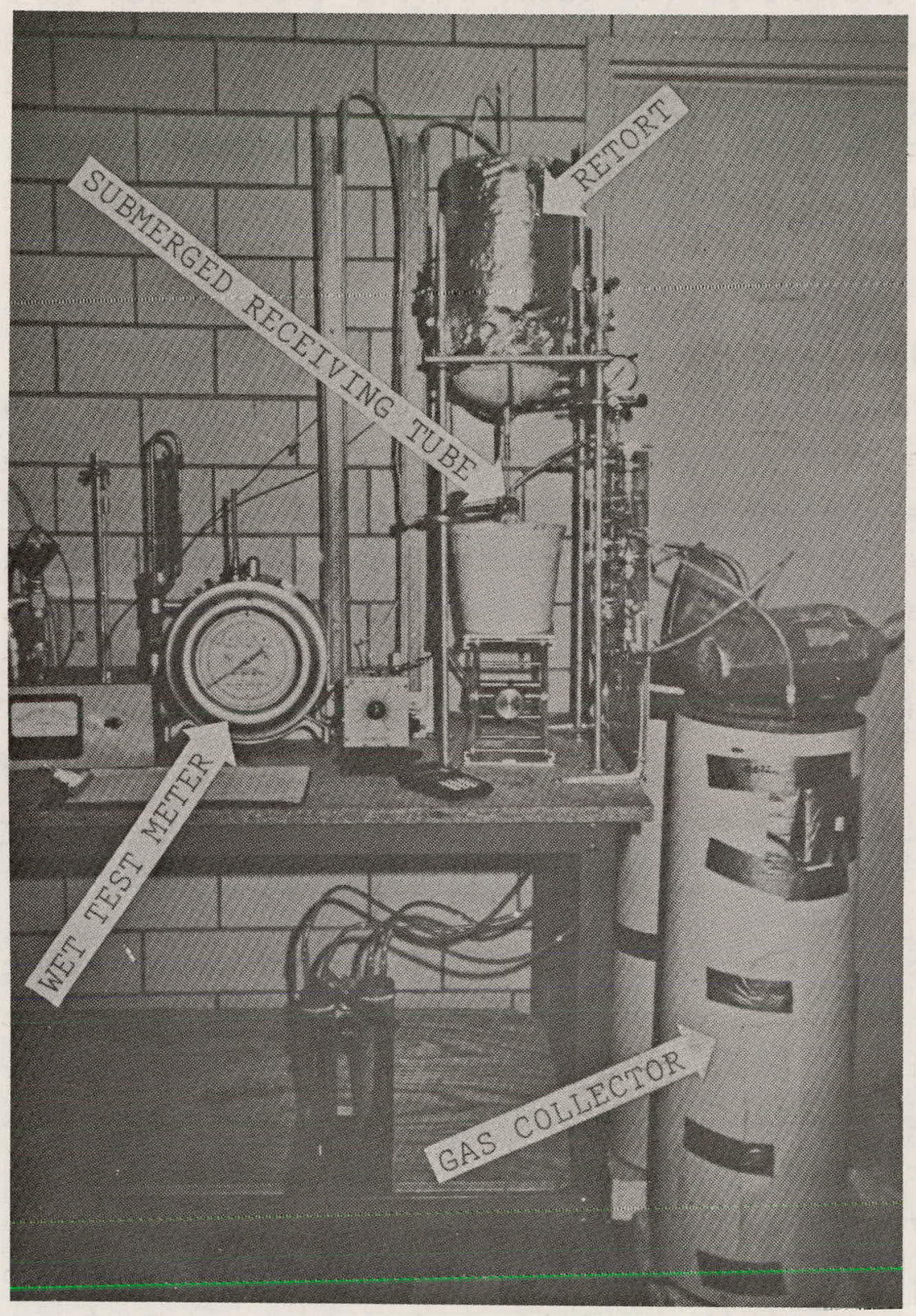

Figure 10

Collecting and Analyzing Apparatus For Core Examination 
since they would represent values that cannot be determined otherwise. Adequately accurate permeability and porosity values can be obtained from conventionally cut cores in most cases. Where a formation is unconsolidated, such as many in California, the analysis of pressure-maintained cores may yield more accurate porosity values.

It must be emphasized that the volume of oil determined to be present in unflushed, pressure-maintained cores would be the best possible evaluation of oil reserves, both for new reservoirs and for reservoirs at flood-out. The volume of gas produced from such cores and a compositional analysis of the gas would also be important and would be an early indicator of the quality of the oil, the gas-oil ratio, and the bubble point, or perhaps the dew-point if one exists.

\section{Advantages To Be Gained If Pressure And Temperature} Are Maintained On The Unflushed Core

It has been observed that certain laboratory tests sensitive to the surface kinetics or "wettability" of the rock-fluid systems are sensitive to temperature. $8,9,10,11,12,13,14$. Rel ative permeability and sometime capillary pressure tests are examples of such tests. There are no known studies of the effects of temperature reduction on the wettability of pressure maintained cores. This would perhaps be futile because of the probability of altering the wettability of the system during coring which al ready has been recognized. It cannot be accepted a priori that an unflushed, pressure maintained core, if kept isolated from air, would undergo a permanent wettability change upon temperature reduction. It may be possible that certain salts or waxes would precipitate which would not go back into solution upon returning the core to reservoir temperature. This could 
have an effect on the surface kinetics and thus the relative positions of the oil and water phases.

Problems Related To Transfer And Laboratory Analys is of Pressure And Temperature Maintained Cores

The transfer and analysis of cores while maintaining reservoir pressure and temperature will constitute a large subclass of problems. it will be assumed here that since no flushing has taken place, that there will be no contamination of the core and no need for core cleaning. The cores will have to be shaped into right cylinders for mounting in appropriate laboratory instruments. Both horizontally and vertically oriented samples would be necessary because of the vector nature of some properties, Exclusion of air or any other material from the core samples while transferring, shaping, or mounting samples for tests would be required. No loss of pore fluid should be allowed during these processes. The procedure of freezing the samples during transferring and preparation in the case of pressure only maintenance, of course, cannot be employed in the temperature and-pressure maintenance case.

Since such ideal formation samples have never been within reach of the core analyst and reservoir engineer, little thought has previously gone into solution of the above mentioned problems. It is believed, however, that presented with high probability of eminent availabilily of the cores, suitable solutions to the problems of analysis would be forthcoming. 


\section{REFERENCES}

1. API RP 40, "API Recommended Practice For Core Analysis Procedure," American Petroleum Institute, Dallas; Texas, First Ed., August, 1960, p. 6.

2. Ibid, pp. $7 \& 9$.

3. Yell, Lindsay, Loomis Hydraulic Testing Co., Interview, February 3,1976

4. Walker, Dick, Lamar University, Interview, january 26 , 1976 .

5. Wisenbaker, j. D. "Quick Freezing of Cores," 0 il \& Gas Journal, Jan. 25,1947 , pp. 275-281.

6. Kelton, F. C., "Effect of Quick-Freezing vs Saturation of oil Weil Cores," Journal of Petroleum Technology, January, 1953, pp. 21-22.

7. Jenkins, Ralph, "Handling Frozen Pressure Cores," A special report prepared for ERDA Project E(34-1)-0035, Core Laboratories, Dallas, Texas.

8. Bobek, J.E., Mattax, C.C., and Denekas, M.0., "Reservoir Rock Wettability-lts Signirlicance and Evaluation." Journal of Petroleum Technology, (1958), No. 213,213.

9. McCaffery, F.G., "The Measurement of Interfacial Tensions and Contact Angles at High Temperature and Pressure," Journal of Canadian Petroleum Technology (1972) 11 , No. 3,26 .

10. Colpitts, G.P, and Hunter, D.E., "Laboratory Displacement of 0 il by Water Under Simulated Reservoir Conditions," Journal of Canadian Petroleum Techiology, 1964, 3, No. 2,66. 
11. Odeh, A.S. and Cook: E :L., " "Discussion - Effect of Temperature on Waterflooding," Journal Canadian Petroleum Technology, 1965 , 4, No. 4, 242 .

12. Edmondson, T.A., "Effect of Temperature on Haterflooding," Journal of Canadian Petroleum Technology, 1965, 4, No. 4,236.

13. Davidson, L.B., "The Effect of Temperature on the Relative Permeability Ratio of Different Fluid'Pairs in Two Phase Systems," Journal of Petroleum Technology, 1969, No. 8,1037 .

14. Poston, S.W., Ysrael, S., Hossain, A.K.M.S., Montgomery, E.F., and Ramey, H.J., Jr., "The Effect of Temperature on Relative Permeability of Unconsolidated Sands," Society of Petroleum Engineers Journal, 1970, 10, No. 2,171 . 
V. PRESENT CORING TECHNOLOGY

Introduction

Double Tube Core Barrels

Oriented Coring

Wireline Core Barrels

Rubber Sleeve Core Barrels

Pressure Core Barrels

Loomis Pressure Barrels

Shell/Christensen System

References 


\section{PRESENT CORING TECHNOLOGY}

\section{Introduction}

The analysis of cores'taken in hydrocarbon and minerals source rocks has become a standard source of data for evaluation of production, potentials. To meet the specific needs of the drilling industry; a number of companies have become expert at coring and have developed variety equipment and services for industry.

In addition to providing coring equipment for a wide range of hole sizes and depth of operation, these service companies have developed a number of specialized coring systems. The most commonly used systems are shown in Table 1:

\begin{tabular}{|c|}
\hline $\begin{array}{c}\text { TABLE } 1 \\
\text { MOST COMMONLY USED CORING SYSTEMS }\end{array}$ \\
\hline $\begin{array}{l}\text { Conventional Double-tube Barrel } \\
\text { Wireline Barrel } \\
\text { Rubber Sleeve Barrel } \\
\text { Pressure Barrel }\end{array}$ \\
\hline
\end{tabular}

While each of these coring systems liave been designed to meet specific requirements, they all have similar components necessary to the task (Figure 1). The bit is located at the lower end of the system and is connected to the bottom of the drill string through an nilter tube which dcts as the torque and load-bearing member. Most coring systems have an inner core receiving tube which is attached at the top to the outer tube through a swivel assembly so that the inner tube remains stationary. while the outer tube rotates. 


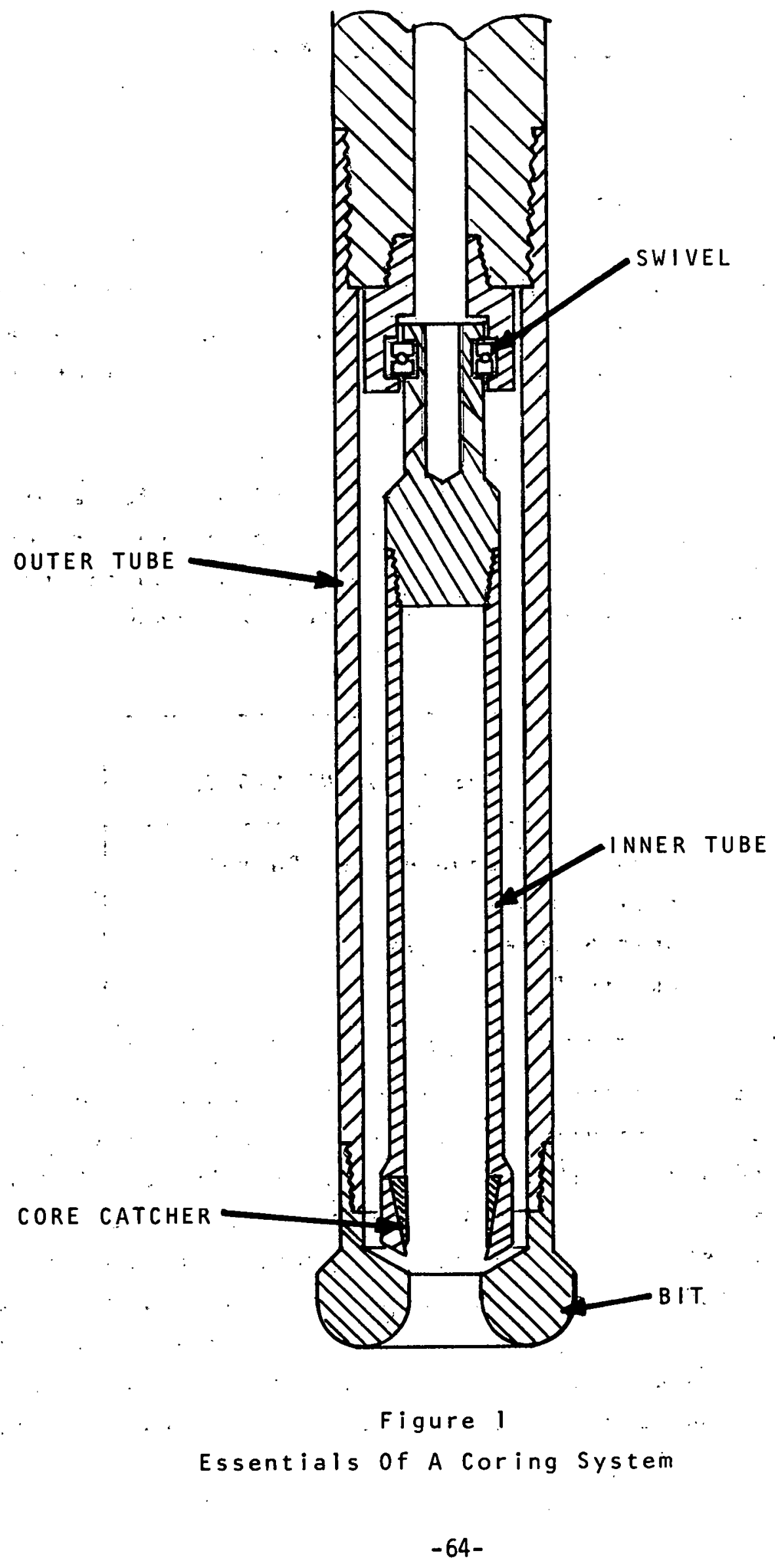


The lower end of the inner; tube is normally located in the throat of the core bit and contains a core grasping device to hold the coreduring the trip out of the hole:(Figure 2).

\section{One of the most sophisticated coring systems available} in the petroleum industry is the rubber sleeve core barrel (RSCB) which was developed to permit recovery of "very" soft unconsolidated formations which could not be captured using the conventional double-tube coring, system.'.

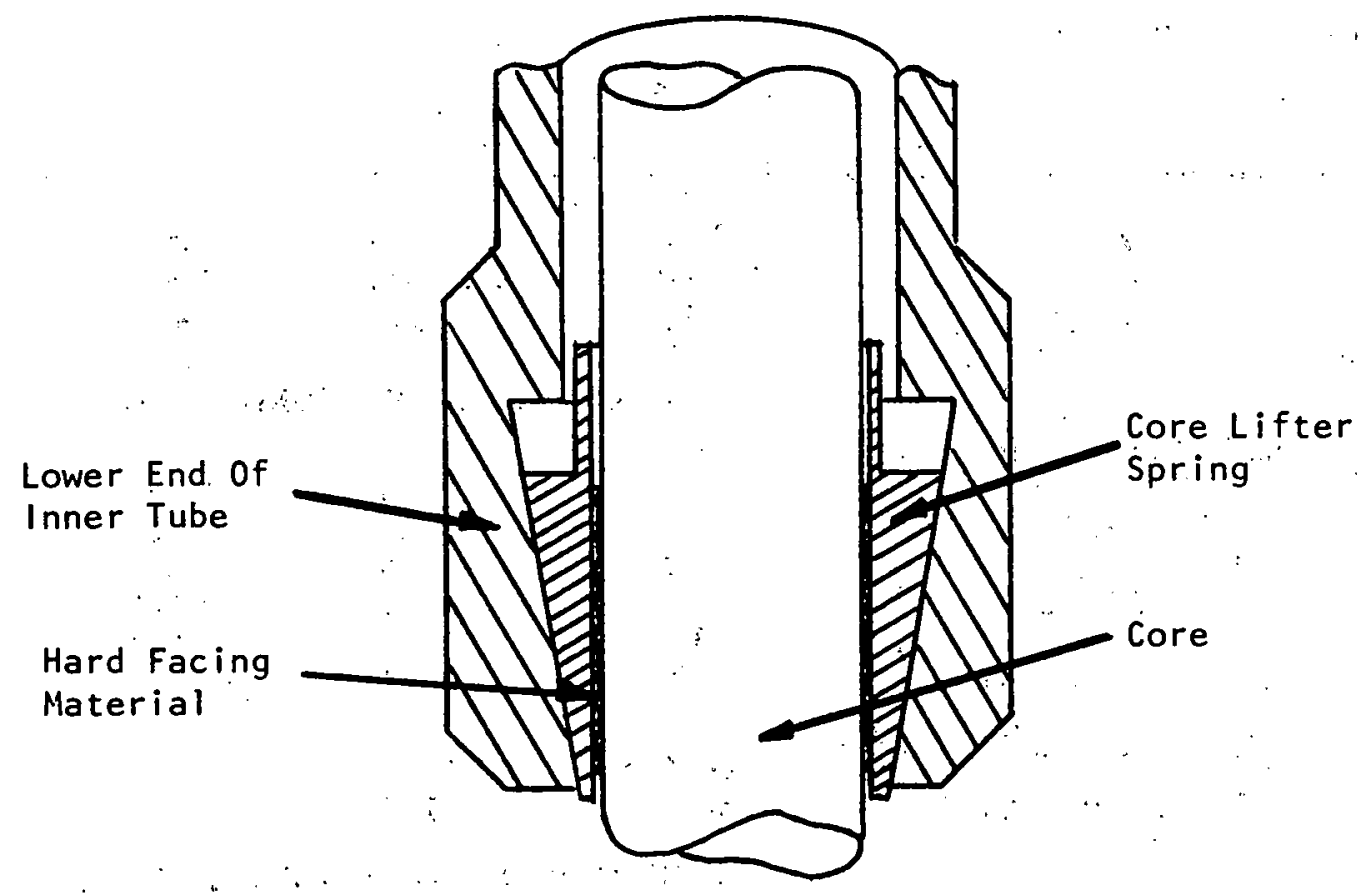

Figure 2

Core Catcher 
The pressure core barrel is of greatest significance to this study because these barrels are designed to deliver the core to the surface under bottomhole pressure. This and the other coring systems are discussed in greater detail below.

Double Tube Core Barrels

The conventional double tube corebarrel is used for most oilfield coring requirements. (Figure 3 ). The wide variety of available barrels and sizes of barrels are shown in Table 2:

TABLE 2

T.YPES OF CORE BARRELS

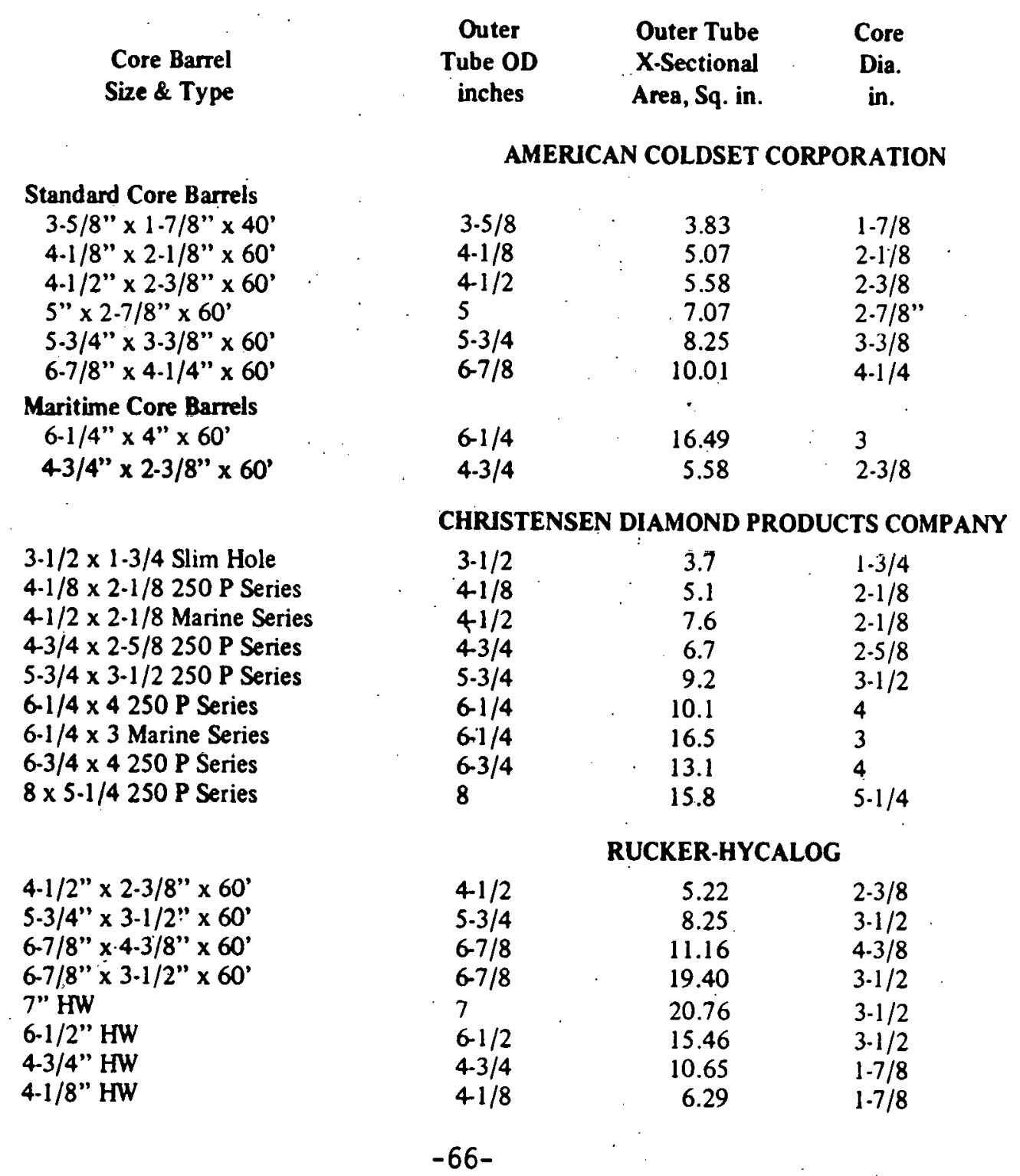




\section{PART NAME}

COMPLETE BARREL (less tools \& core head) 1. SAFETY JOINT ASSEMBLY
A. Safety Joint Pin
B. Spring (3 required)
C. Plunger (3 required)
D. Friction Ring
E. "O" Ring
F. Safety Joint Box
G. "O" Ring

2. SWIVEL ASSEMBLY

A. Cartridge Cap

B. Shims

C. Bearing Retaine

D. Thrust Bearing

E. Cartridge Plug

F. Inner Tube Plug

G. 1" Steel Ball

H. Pressure Relief Plug

3. OUTER TUBE SUB $\cdots$

4. OUTER TUBE ( $30 \mathrm{ft}$, with sub. -2 required)

5. THREAD PROTECTOR (upper)

6. THREAD PROTECTOR (lower)

7. INNER TUBE (30 ft. -2 required)

8. THREAD PROTECTOR (upper)

9. THREAD PROTECTOR (lower)

10. INNER TUBE SHOE (complete)

A. Inner Tube Shoe (upper half)

B. Inner Tube Shoe (lower half)

11. CORE CATCHER (standard)
Figure 3 - Double Tube Core Barrel

(Courtesy Christensen

Diamond Products Company).

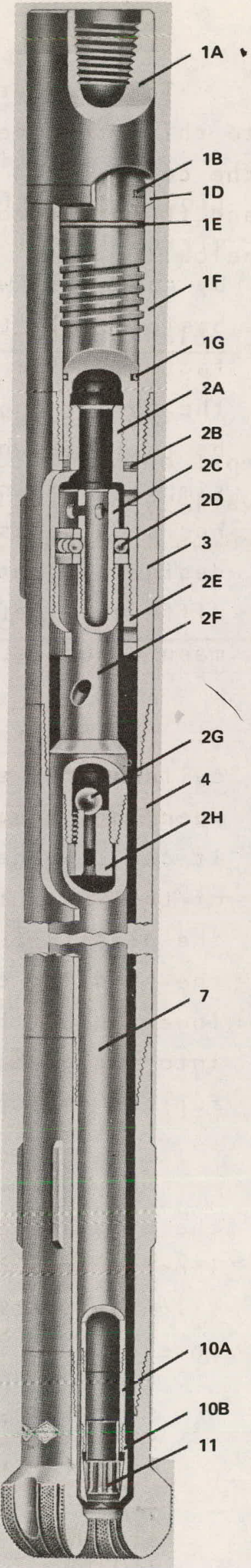


It should be noted that most oilfield coring applications are performed using diamond core bits. Therefore, virtually all coring systems are manufactured and marketed by companies who also market diamond bits. The design of basic double tube coring systems is predicated by several factors. The equipment must be strong enough to withstand the forces applied during coring operations. It should also be reliable, have long, low cost operating life and be simple to maintain. In order to achieve these goals, it has been necessary to utilize very simple, uncomplicated design parameters with the result that there is very little difference between core barrels available from the various manufacturers.

A number of more sophisticated modifications are avilable for special coring requirements. For example, when coring very soft formations, such as offshore sediments, it can be beneficial to use a plastic liner (Figure 4) inside of the inner tube. Once the core is brought to the surface, the plastic tube is removed in one section, thus facilitating the handling of the very soft core. Once removed from the inner tube, the core containing plastic sleeve can be cut into manageable lengths and capped for transportation without further disruption of the core.

Any standard core barrel can be adapted for use with the plastic liner by providing a liner retaining lip in the inner tube shoe and providing core catching means for the slightly reduced core diameter necessitated by the small internal diameter of the plastic liner. 


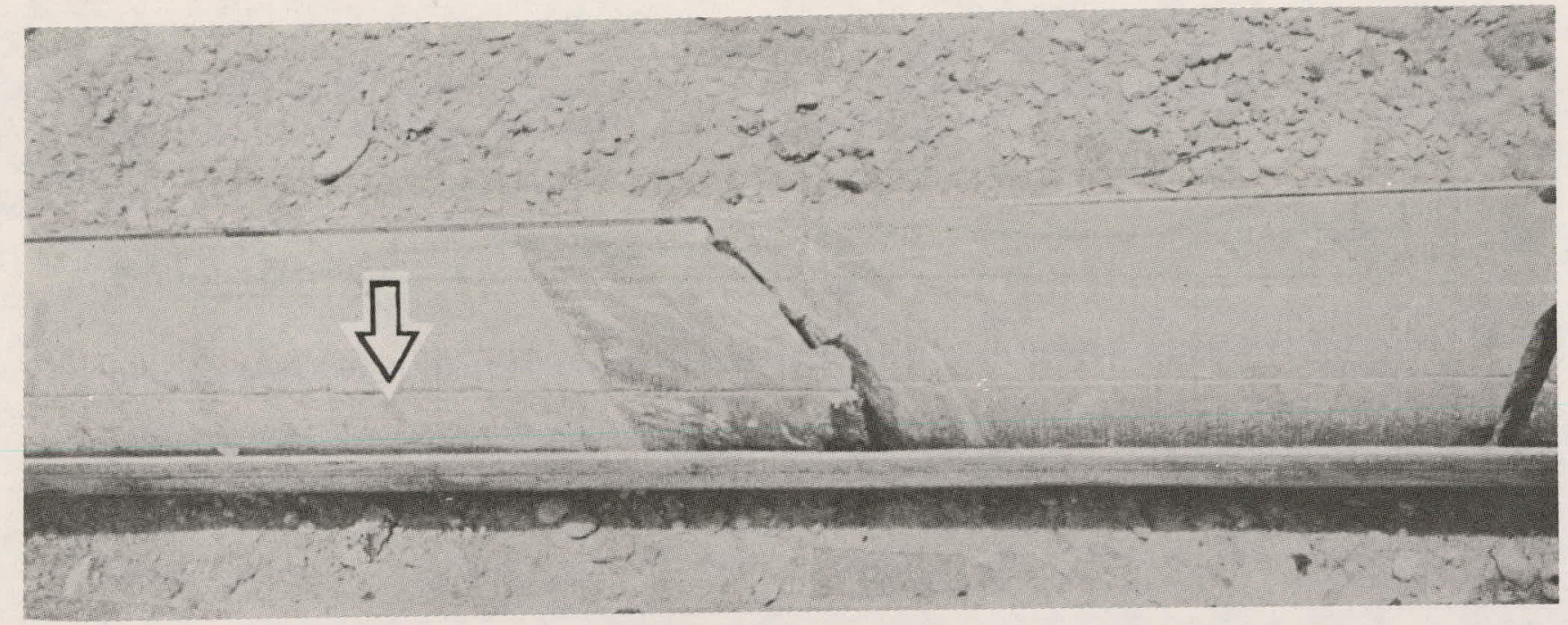

Figure 5

Reference Marks Scratched On Core

\section{Wireline Core Barrels}

Wireline Coring Systems provide added utility to the conventional double tube systems in situations where continuous coring over long intervals is desired (Figure 8). The inner barrel is detachably mounted in the outer barrel and can be retrieved to the surface through the inside of the drill pipe on a wireline. The obvious advantage of such a technique is that the drill string does not have to be removed from the hole in order to dump the core. In order to accomplish wireline remeval from the inner baírel, the largest diameter of the inner barrel system must be smaller than the minimum diameter in the drill string. This means that under normal circumstances, the core diameter will be quite small compared to conventional systems in the same size hole. Wireline cores generally provide only marginally adequate samples for proper formation evaluation. The small core size relative to hole size also means that considerably more rock must be removed by the bit, thereby leading to slower penetration rates and 


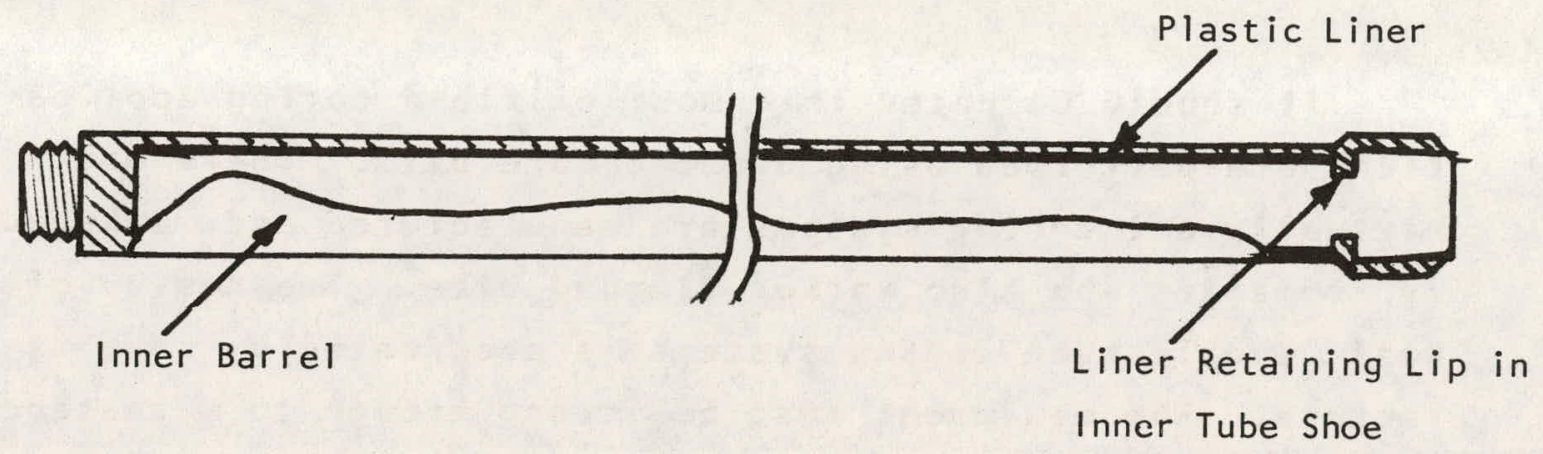

Figure 4

Plastic Liner in Inner Barrel

Oriented Coring

The most sophisticated addition to the conventional coring system is probably the core orientation system. This system is used when it is important to determine directional properties of the formation being cored. ${ }^{2}$ Reference scribe marks (Figure 5) are scratched into the surface of the core as it enters the inner tube (Figure 6). Above the core barrel in a non-magnetic drill collar is a multi-shot magnetic survey instrument which is rigidly attached to the top of the inner tube by a connecting rod (Figure 7). The survey instrument records the directional position of the scribe marks periodically during the coring operation. These periodic data points are later correlated with the proper depth position on the core. Core orientation, as well as most other available modifications to the standard coring system, add cost and complication to normal coring operations. They are, therefore, seldom used except for absolutely necessary situations. 


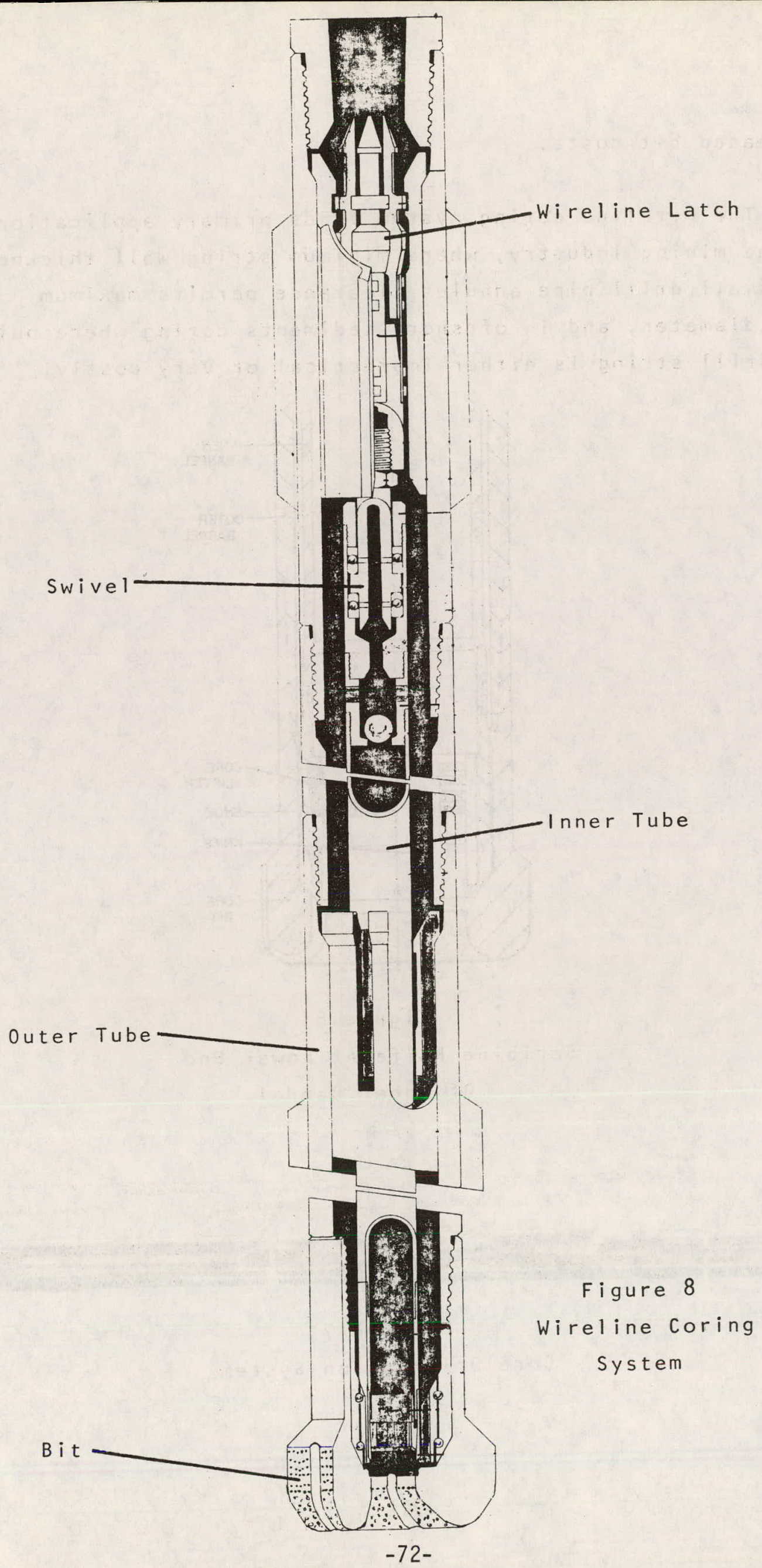


increased bit costs.

The wireline coring system finds primary application in the mining industry, where minimum string wall thickness and small drill pipe annulus clearance permits maximum core diameter, and in offshore sediments coring where pulling the drill string is either impractical or very costly.

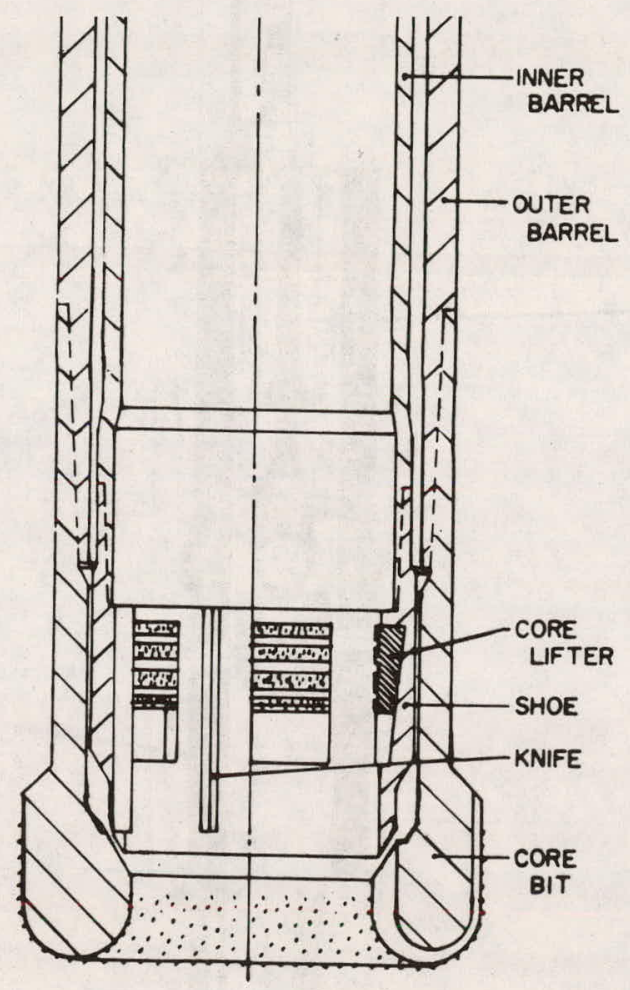

Figure 6

Scribing Knife At Lower End

of Inner Barrel

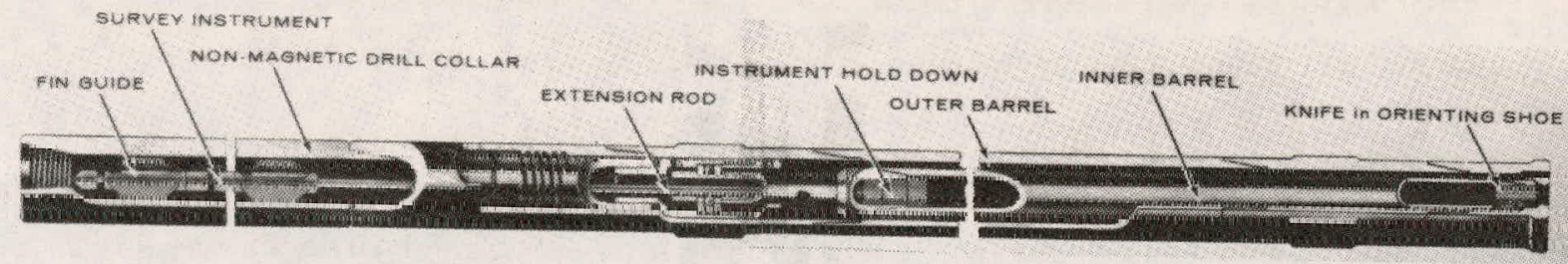

Figure 7

Core Orientation System 
The rubber sleeve core barrel is another fairly complicated special purpose tool. Developed by Jersey Production Research Co. ${ }^{3}$, this system permits the recovery of very soft, unconsolidated formations, conglomerates or badly fractured rock, which cannot be recovered using conventional coring systems (Figure 10). The basic improvement of the RSCB is the rubber sleeve itself, which is stripped onto the core immediately after it is cut, thus perserving its exact position in the formation. Once operation is begun, the top of the rubber sleeve is held in a fixed relative position with the formation so that even voids and lost core can be accounted for exactly. The rubber sleeve provides a protective seal around the core, thus reducing contamination from exposure to the drilling fluid. Additional design features isolate the flowing drilling fluid away from the core during the coring operation.

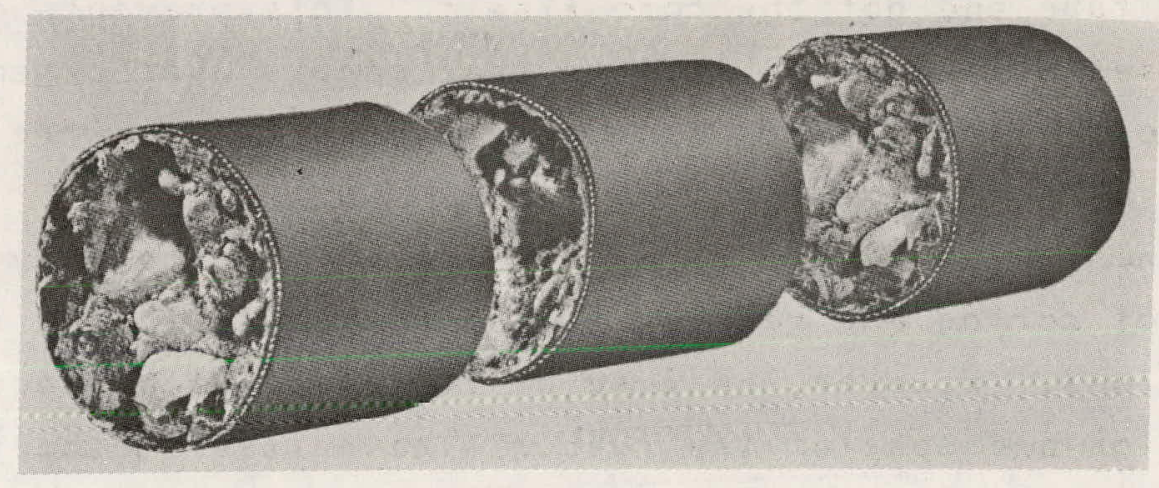

Figure 10

Unconsolidated Core In Rubber Sleeve 
During the trip into the hole and preparation for coring, the splined two-foot slip joint is locked in an open position (Fig. 1la). When ready to begin actual coring operations, a plug is dropped from the surface through the drill pipe to unlatch a ratchet tube (Fig. Ilb). From this moment until completion of the coring operation, the top of the rubber sleeve (which is attached to the bottom of the ratchet tube) will be held in its fixed position relative to the formation being cut. As the bit is rotated, cutting the core, the outer tube moves downwardly with bit load being applied by hydraulic pressure of the flowing fluid passing through a jet nozzle section. The rubber tube is stripped off of a carrying sleeve onto the core as the carrying sleeve advances downward with the outer tube and bit. After each two-foot interval of core is cut, the drill string is lowered, closing the two-foot spline and advancing the upper ratchet system on the ratchet tube as it is held in its fixed position by a second ratchet in the outer tube section (Figure llc). Since the top of the rubber sleeve is supported by this ratchet tube, the weight of the sleeve and core are suspended by the tube and not the core itself. This prevents core collapse, crushing and jamming that occurs when attempting to core similar formations with a conventional barrel.

The rubber sleeve core barrel provides the only present means of coring and recovering these unconsolidated types of formations. However, because of its complicated sequence of operation and cost of the rubber sleeve itself, the technique finds limited application. Typical rental costs are on the order of $\$ 50$ to $\$ 100$ per foot. Several features of the RSCB, such as the spline, spline locking mechanism and the hydraulic force for opening the spline joint appear to have potential application in an improved pressure coring system. 


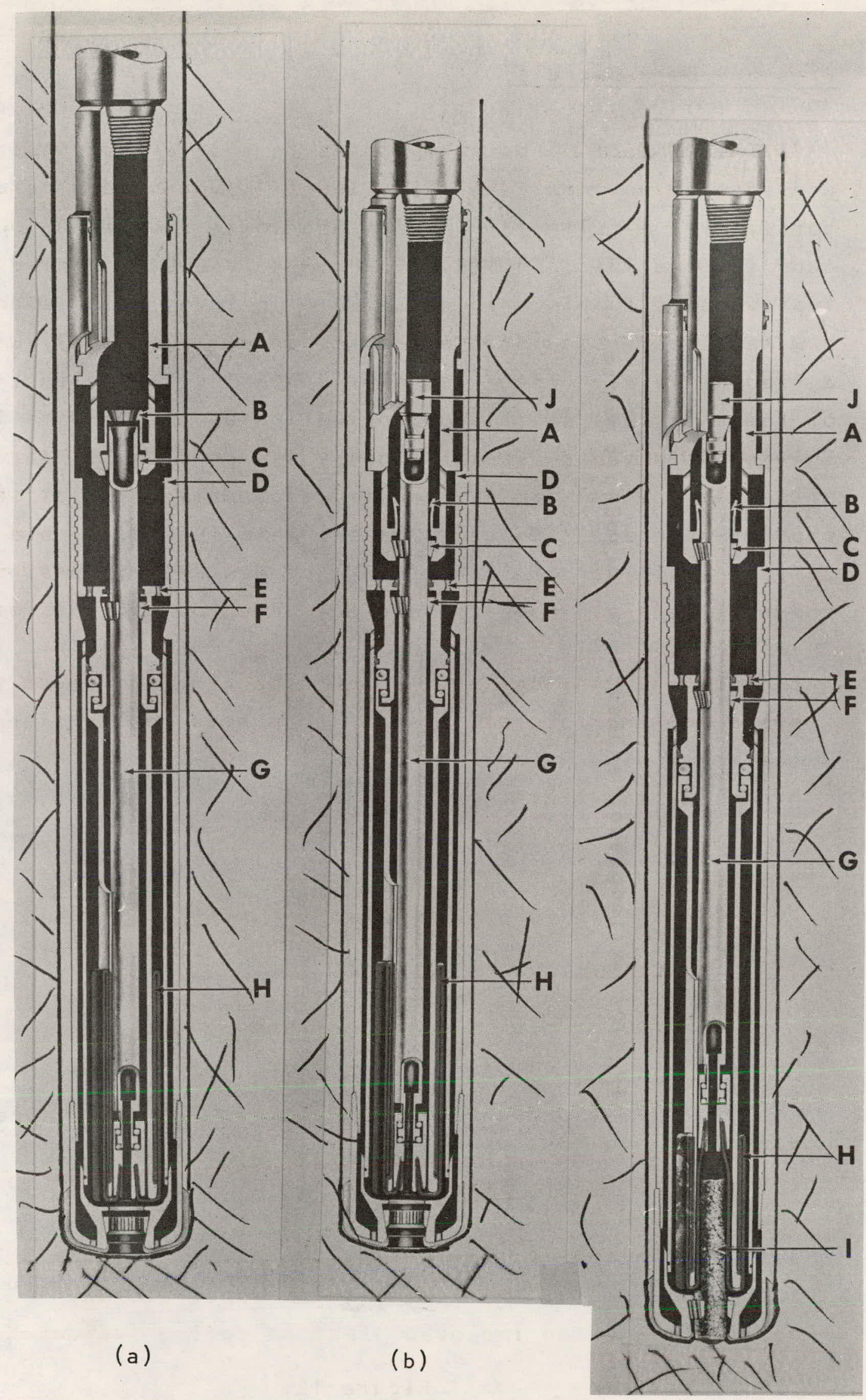

Figure 11 Rubber Sleeve Core Barrel (c) 
The concept of bringing cores to the surface under pressure is not new. In 1938, Sewe $11^{5}$ suggested a core barrel with a cylinder valve in the lower end of the outer tube (Figure 12). In 1941, 6 and $1944^{7},{ }^{7}$ Sewell recommended improvements to his original idea. In 1944, Auld 8 suggested a wire line version of a pressure barrel (Figure 13) with a flapper valve. There is no evidence indicating that any of these systems saw field application until the late 1950's. The Sewell patents were originally assigned to standard $0 \mathrm{il}$ of New Jersey and may have restricted application of the pressure concept. However, in the late 1950's, Humble 0 il Co., a subsidiary of Standard 0 il of New Jersey, designed and built a field operational tool based on concepts of sewell.

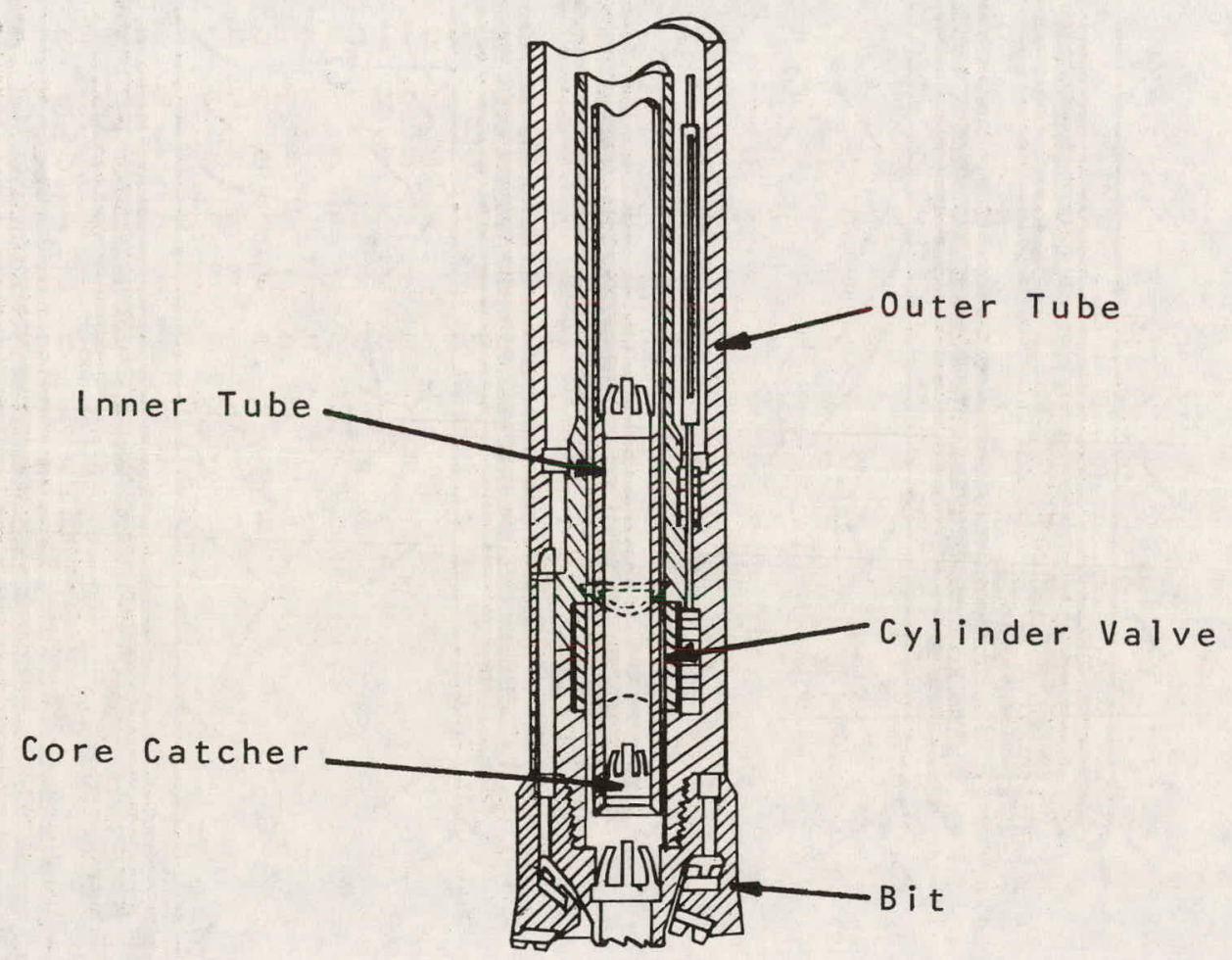

Figure 12

Sewell Pressure Core Barrel

(USP 2,216,962) 


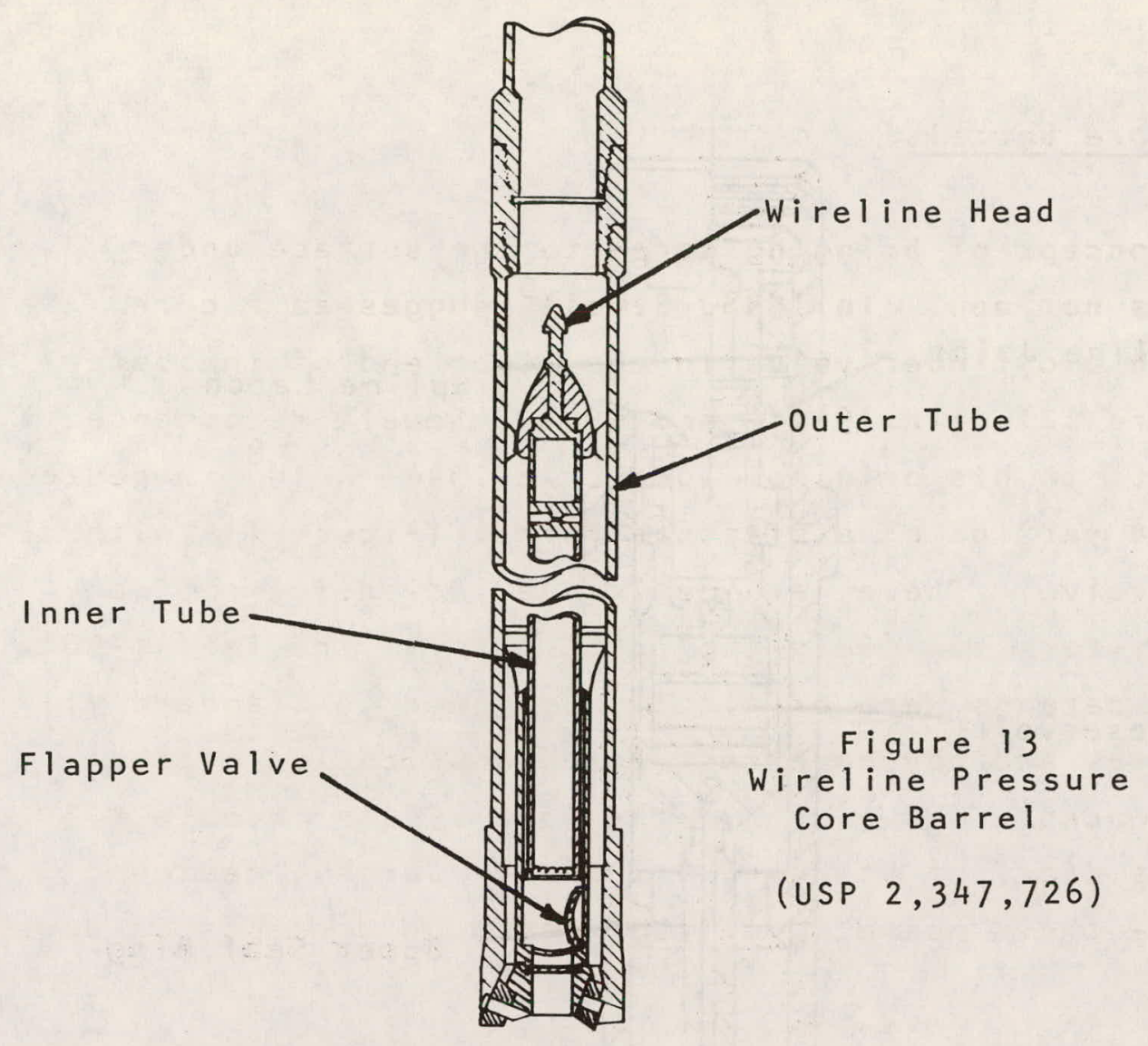

The Humble system saw field application within the Humble organization until the mid 1960's when marketing rights were licensed to Loomis Hydraulic Testing Co., Inc. Loomis has made the system available for commercial use, but the lack of technical personnel, a total lack of experience in coring and the apparent absence of financial incentive from industry, has resulted in no new developments being made on the original Humble system. It is used today in essentially the same form as the original design of the late 1950's.

\section{Loomis Pressure Barrel}

Specifications of the Loomis barrel (Figure 14) include a core diameter of $2-5 / 8$ inches and a length of $10 \mathrm{ft}$. Maximum working pressure for the system is 4,800 psi. The barrel has a maximum outside diameter of 6 inches and is, therefore, restricted to a minimum hole size of 7-7/8 inches under most drilling conditions. 9 


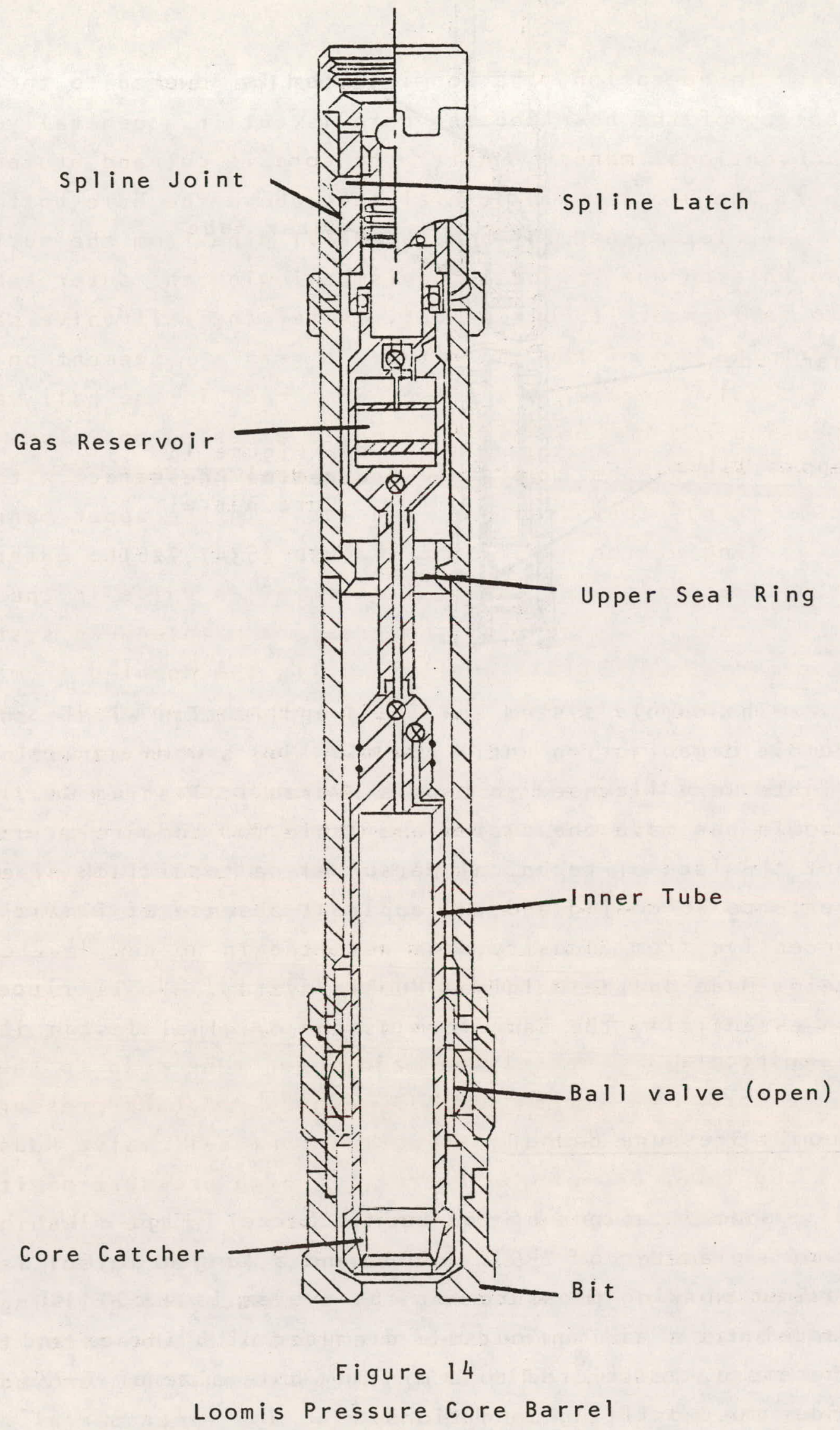


In operation, the Loomis sytem is lowered to the bottom of the hole and the core is cut in a generally conventional manner. After the core is cut and broken off, the bit is held several feet above the hole bottom. A ball is dropped through the drill pipe from the surface to unlatch the spline mechanism allowing the outer tube to fall under its own weight. After the ball valve passes over the end of the inner tube, a gear arrangement on the ball valve engages a corresponding rack in the ball valve housing and the ball is rotated to a sealed position. The upper end of the inner tube has a sealing surface with two 0 -rings that shoulders and seals in the upper barrel seal ring of the outer tube (Figure 15). As the outer tube reaches the extent of its travel, a valve in the inner tube head is opened from the pressure maintenance system located above. Drilling fluid fills the opening from the inner tube to the gas accumulator chamber which is separated from the mud by a sliding seal piston. An inert gas, such as nitrogen, was placed in the accumulator prior to the coring operation and pressure is maintained at a pre-set value by a pressure regulator. The pre-set pressure was calculated to be the same as the bottom hole pressure.

After the closing operation, the barrel is tripped out of the hole in the conventional manner, the bit is removed and the barrel head and outer tube down to the upper pressurc barrel seal is removed. A back pressure regulator is attached to a port in the ball valve housing at the lower end of the barrel. A high pressure positive displacement pump is attached to a port in the flushing head at the top of the inner barrel. Gelled Varsol is then pumped through under pressure to displace the drilling mud left between the inner tube and the outer tube after the coring operation. This drilling fluid must be removed so that the barrel can be disassembled and inner barrel removed 


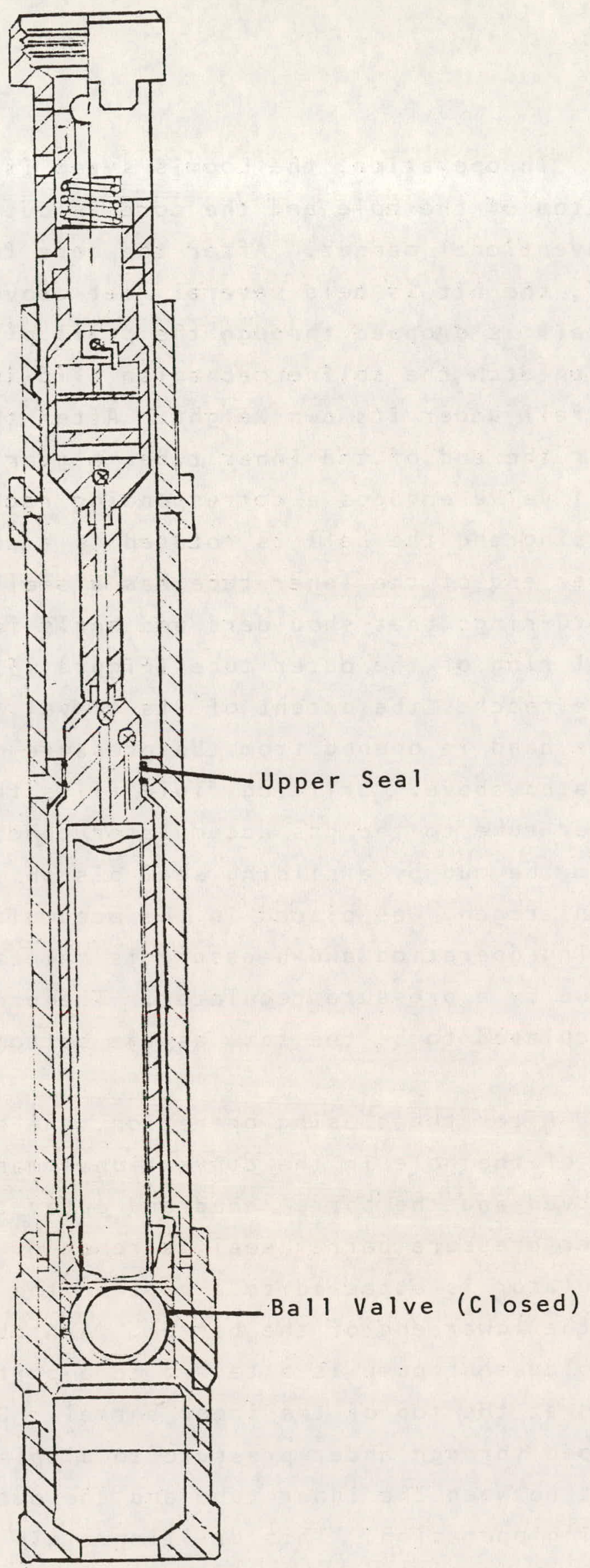

Figure 15

Loomis Barrel In Sealed Position 
after the core has been frozen. When the drilling fluid has been displaced satisfactorily, the barrel is placed into an insulated container and the core frozen, using dry ice. When frozen, the outer tube is removed and the inner tube is cut into manageable length sections with a standard pipe cutter and the core is broken off at each joint. Each of the sections is then placed into a marked insulated container with dry ice for transportation and storage at the lab.

In the 10 year period prior to 1975, the Loomis system apparently saw an average usage of about 8 cores per year. As a result of several tertiary recovery project evaluations, 10 to 15 pressure cores were taken during 1975 and to date approximately 30 pressure cores have been taken during 1976. With the exception of a recent carefully controlled program by Atlantic Richfield ( 18 of 19 cores recovered at the surface under pressure), previous applications of the Loomis system have been only marginally successful with an average of only about $50 \%$ of the cores cut being recovered at the surface under pressure.

\section{Shell/Christensen System}

In 1964, Shell Development Co. contracted Christensen Diamond Products Co. to design and build a pressure core barrel for a specific program which they had planned.

The specifications selected by shcll included a hole size of 5-1/2 inches and core length of 5 feet. The final design resulted in a core diameter of $1-3 / 4$ inches, a maximum working pressure of $5000 \mathrm{psi}$ and a nominal outer barrel diameter of 4-3/4 inches (maximum $005-1 / 4$ inches).

There was no public information concerning the Humble design at that time and, therefore, the Sewell patent provided the basic reference. On this basis and also the fact 
that principal project engineers for Christensen at the time (Rowley and Bridwell) were both former Jersey Production Research employees, it is no surprise that the Christensen design was basically the same as the Humble design (Figure 16).

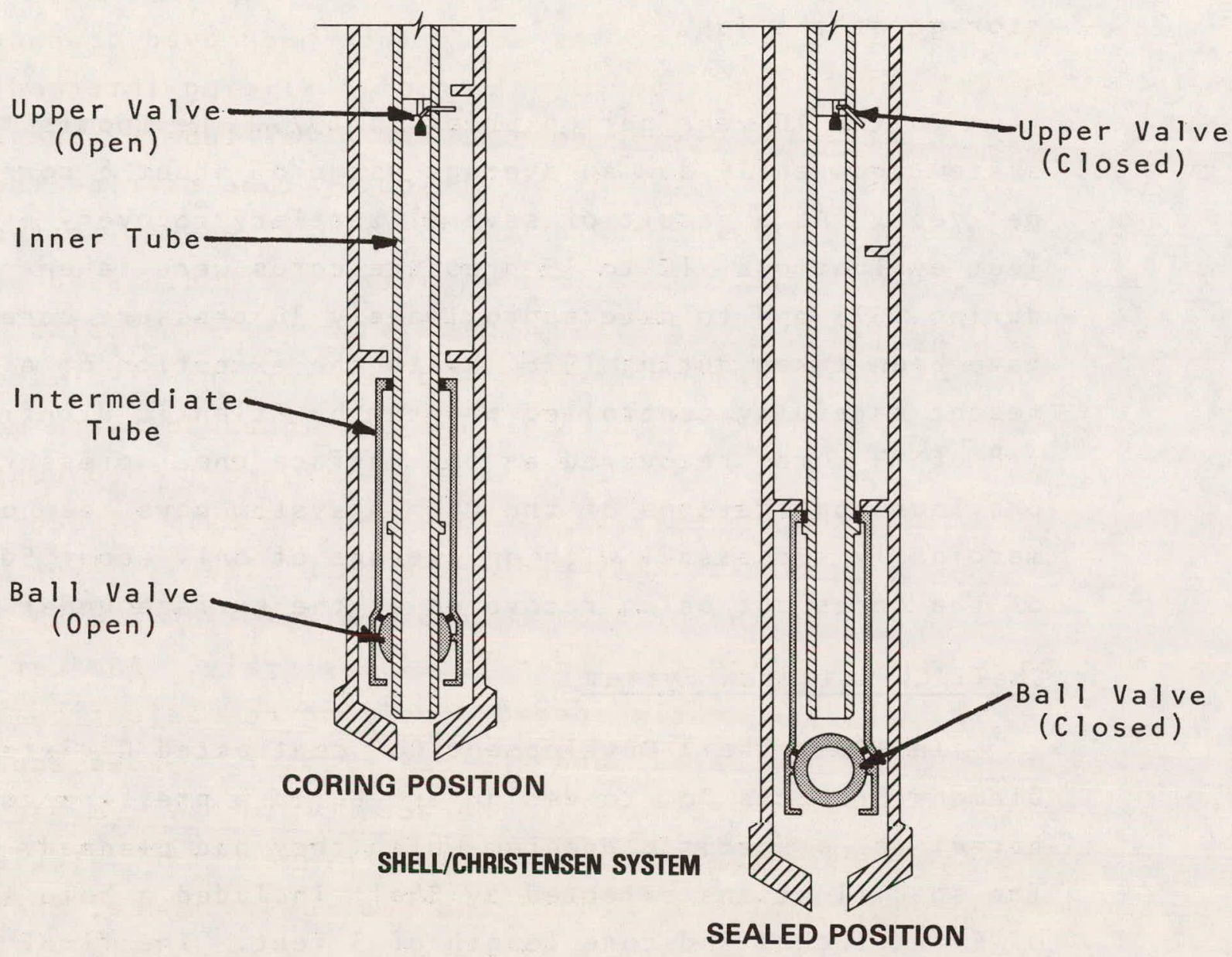

Figure 16

Shell/Christensen Pressure Core Barrel 
The operation of the barrel is nearly identical. The barrel is lowered into the hole and core cut in a near conventional manner. "After the core is broken off, the bit is heild several feet off bottom. A ball is dropped through the drill pipe from the surface to unlatch the spline mechanism and the outer tube"falls under its own weight. "Should there be an indication that the outer tube had not fallen or was not opening properly, provision was made to apply hydraulic force by pumping the drilling fluid through a set of nozzles: After the outer tube had moved downward a few inches; the upper shoulder of a sliding intermediate sleeve contacted a $r$ ing held in the outer tube by shear pins. Continued movement by the outer tube carried the intermediate tube downward until the ball valve located at the lower end of the intermediate tube had passed over the end of the inner tube. At this point, shear pins holding the slip ring sheared and further travel of the intermediate tube permitted. The continued downward movement of the outer tube brought a set of gears into contact with teeth on the ball value rotating the ball closed to the sealed position. At about the same time, a lever was tripped at the top of the inner barrel closing a plug valve and, thus, sealing the inner tube completely. Another valve was subsequently opened providing communication between the inner barrel and the gas pressure loaded equalization system. Pressure in the accumulator system had been pre-set at a value 50 to 100 pounds higher than calculated bottom-hole pressure. After the sealing sequence, the barrel was tripped to the surface in the conventional manner.

At the surface, the system was disassembled and the inner tube and pressure system were removed from the barrel. The analysis of all core on the project was handled by shell Development in their own lab and, therefore, they chose not 
to freeze the core. To insure that pressure was maintained on the system until time for analysis, a larger pressure maintenance system replaced the coring pressure system for transportation to the lab. The inner barrel systems were easily manageable without further breakdown because of their small size.

On the completion of the initial program lasting about, two years, Shell stored their pressure core barrel and it has not been used since. Shell. desired to take pressure cores during 1975 and it was decided to use the Loomis system instead of rebuilding their own system after storage of more than 8 years. Another deciding factor in the decision was that the Shell Development project engineer on the previous pressure coring program had since retired, leaving no one who was completely familiar with the shell/ Christensen system.

It can be seen from the previous discussion that a wide variety of coring equipment is available to meet exploration requirements. However, even though pressure coring systems are available they do not meet the requirements defined as the objectives of this true fluid coring project. 


\section{REFERENCES}

1. Drilling Manual, International Association of Drilling Contractors, Houston, Texas, Jan., 1975, p. AS-2.

2. Rowley, D. S., Burke, C. A., Manuel,T., "Oriented Cores In 1964," Paper presented at Michigan Basin Geological Society., Michigan State University, April 24, 1964, 17 pgs.

3. Hildebrandt and Bridwell, USP 2,927,776.

4. Christensen Diamond Products Co. Catalog (SD-668)

5. Sewel1, USP $2,216,962$.

6. Sewe 11, USP. $2,238,609$

7. Sewe 11, USP $2,343,805$

8. Auld, etal, USP $2,347,726$

9. Loomis Hydraulic Testing Co., Advertisement, 0 il E Gas Journal, March 1, 1971, p 


\section{LIMITATIONS OF PRESENT \\ CORING METTHODS}

Flushing

Pressure Reduction Bleed-off

Reliability

Core Size

Core Handling

References 


\section{LIMITATIONS OF PRESENT CORING METHODS.}

Previous sections of this report have discussed the current technology for obtaining true samples.of oil and gas formations: The most sophisticated of these techniques do, in fact, provide more accurate answers than those obtained by conventional day-to-day coring techniques. However, technology in present use still has serious limitations and does not achieve the desired capability of determining true unaltered ratios of formation fluids in the reservoir pore space. These limitations include: flushing of the core during the cutting operation, bleed-off during the trip out of the hole, reliability and effectiveness of coring equipment, and core handling requirements. Each of these factors is discussed in the section that follows along with the relative significance regarding the feasbility of obtaining true unaltered formation samples.

\section{Flushing}

Laboratory studies by Young and others before him clearly demonstrated the invasion of filtrates into. formation during drilling and coring operations. J Jenks was concerned with flushing during coring operations and at tempted to determine specifically those factors, that influenced the amount of flushing. He found that oil, including residual oil which is not mobil under normal water flooding pressure, can become mobil. and be stripped from the rock close to the working. bit under conditions frequently encountered in normal coring operations. ${ }^{2}$ In most coring operations, there is no provision for isolation of the core from the drilling fluid in the throat of the core.bit. In fact, as. shown in Figure 1 , the core must act as one side of the fluid flow channel. It is impossible to prevent some fluid invasion in flushing as long as this condition exists. 


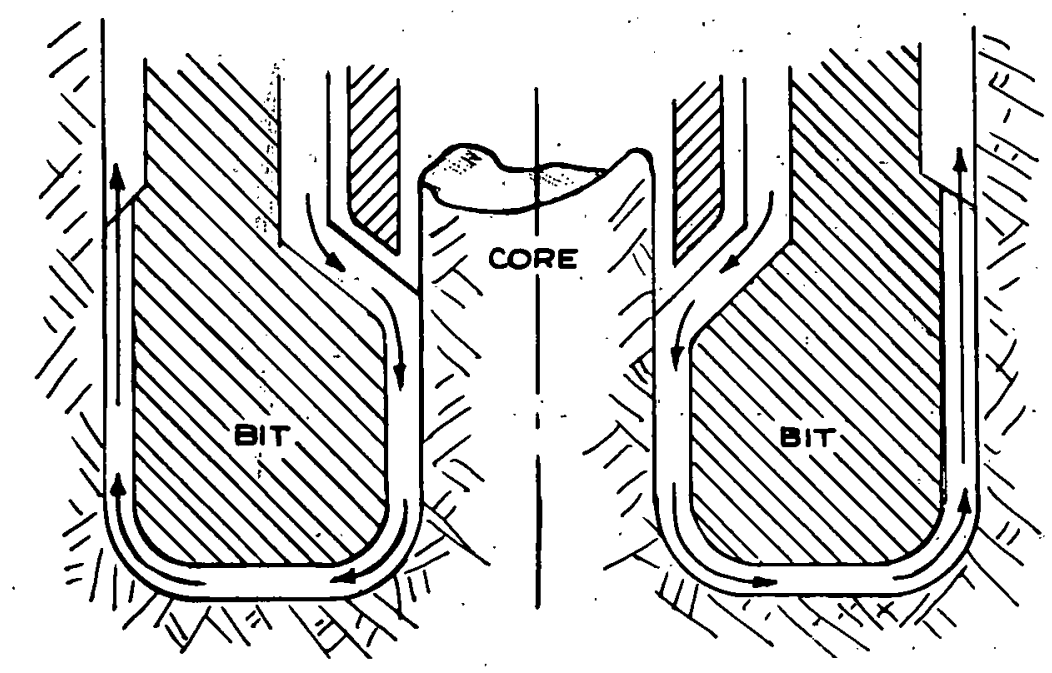

Figure' 1

Core Acting As One Side of Flow Channel

Jenks also found that the amount of flushing is increased by increased over-balance pressure in the borehole as shown in Table 1. Tables 2 and 3 show that larger cores result in reduced stripping as does shorter time exposure (faster drilling rate). Later drilling studies have confirmed these finds.

Early in the development of rotary coring techniques, this problem of flushing was recognized and many concepts were proposed for its elimination. In 1932, Johnston received a patent covering the concept of placing a heavy molten metal in the bottom of the hole to isolate the core from the drilling fluids, thus preventing flushing (Figure 2 ). ${ }^{3}$ By selecting a low melting point material, such as Woods'metal, lowering the mud temperature at the end of the coring operation would result in "freezing" of the molten metal, thus sealing the lower end of the inner tube. In 1941, Mounce suggested a similar technique whereby mercury or other heavy water insoluble fluid would be used (Figure 3). There is no known record of these concepts being placed into actual practice. 

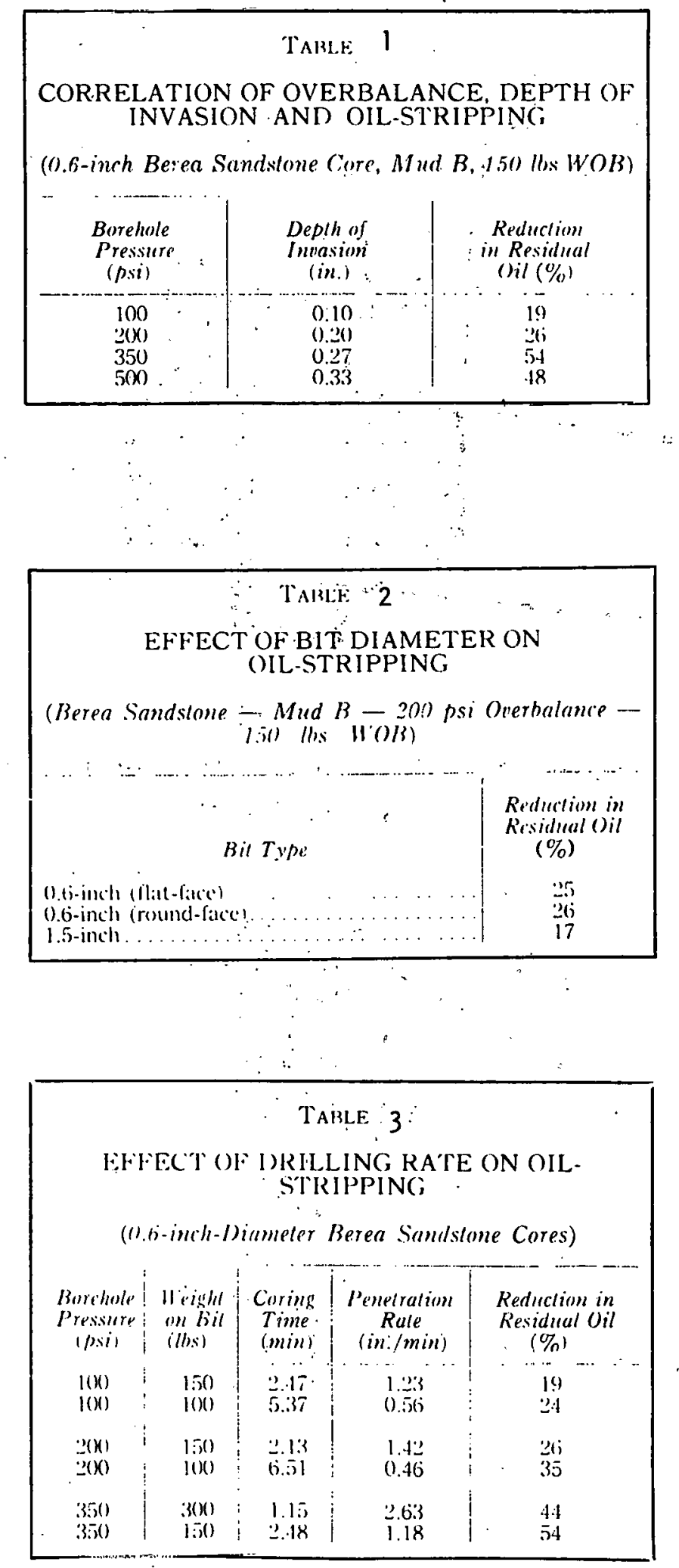


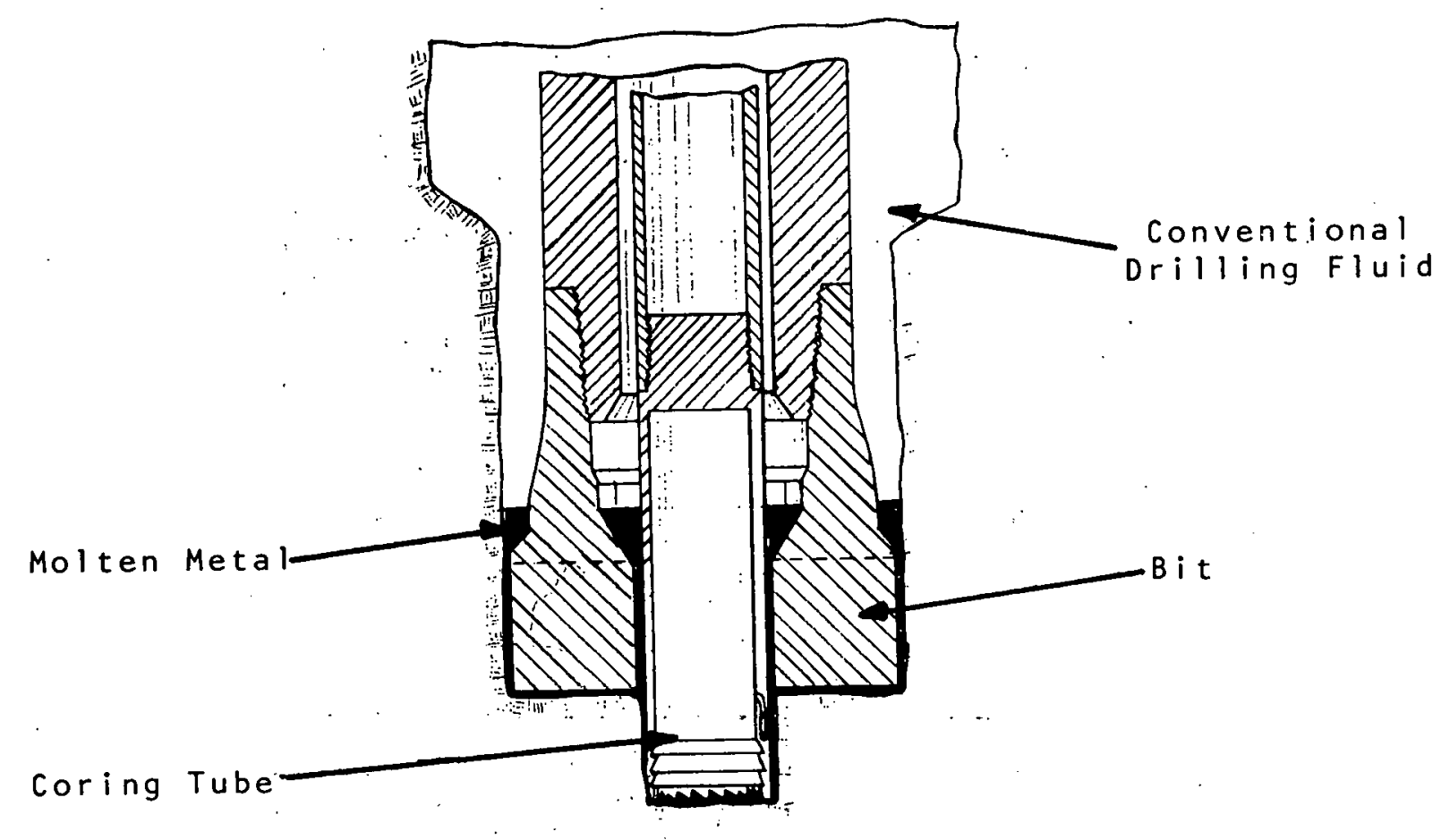

Figure 2

Use of Molten Metal To Isolate Core

(USP 2,146,263)

Conventional.

Drilling Fluid
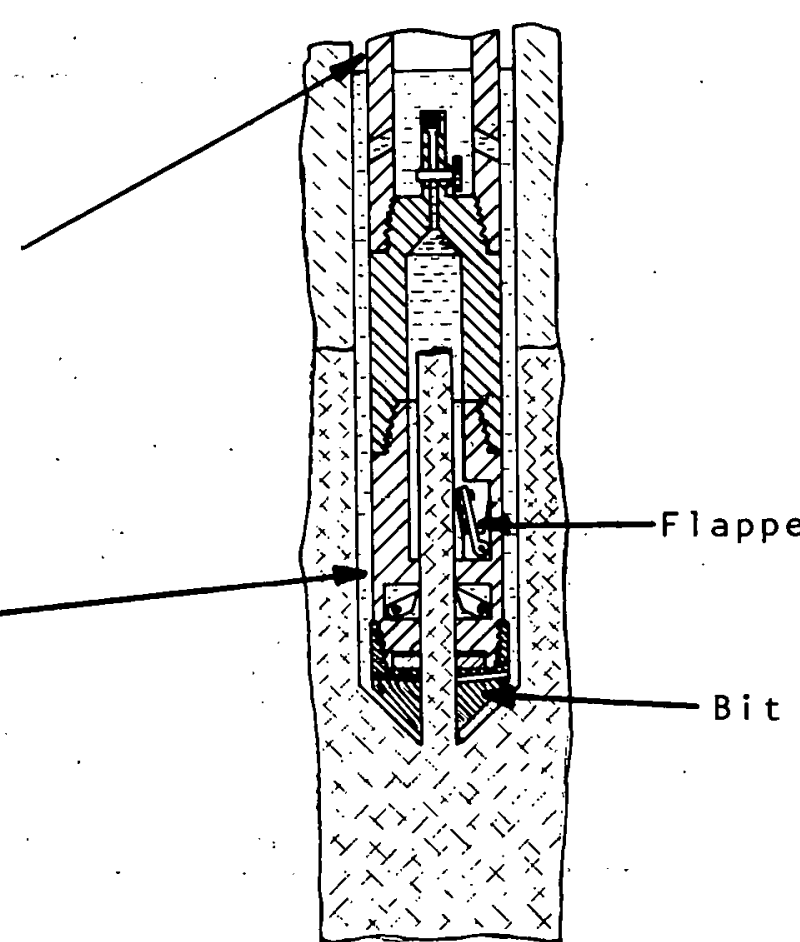

Figure 3

Use of Mercury to I solate Core

(USP 2, 264, 445) 
Later, in 1951, Smith suggested cutting small cores without fluid circulation (Figure 4). 5 other concepts similar to this are known to have been tried. However, the small, short core obtained in this manner is generally not satisfactory for most reservoir studies.

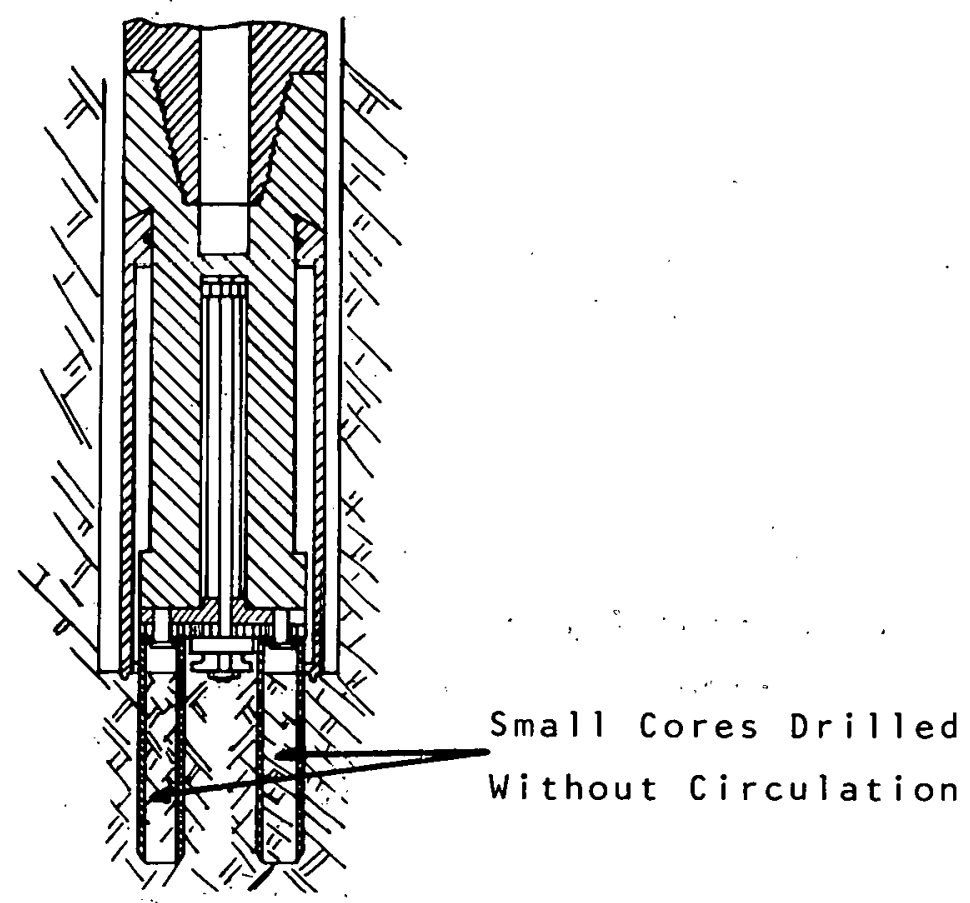

Figure 4

"Dry Drilling" Small Cores

(USP $2,541,785$ )

As work continued in an effort to eliminate flushing of the core, Cochren, in.1958, suggested filling the inner tube with a viscous fluid which would be expelled as the core was cut in such a way as to lubricate a pilot core bit (Figure 5). 6 The normal circulating fiuid would be by-passed through a reaming core head above so that the rinre would never be exposed to the conventional drilling filuid. The preferential viscous fluid was an asphalt, but thermal setting plastic or even a chemically setting material would be alternatives. In 1959, Williams suggested a similar approach except without allowance for iubrication of the pilot bit (Figure 6) 7 and Bridwell, 8 in 1962, suggested another similar system (Figure 7). There is no evidence that these techniques were tried or were successful. 


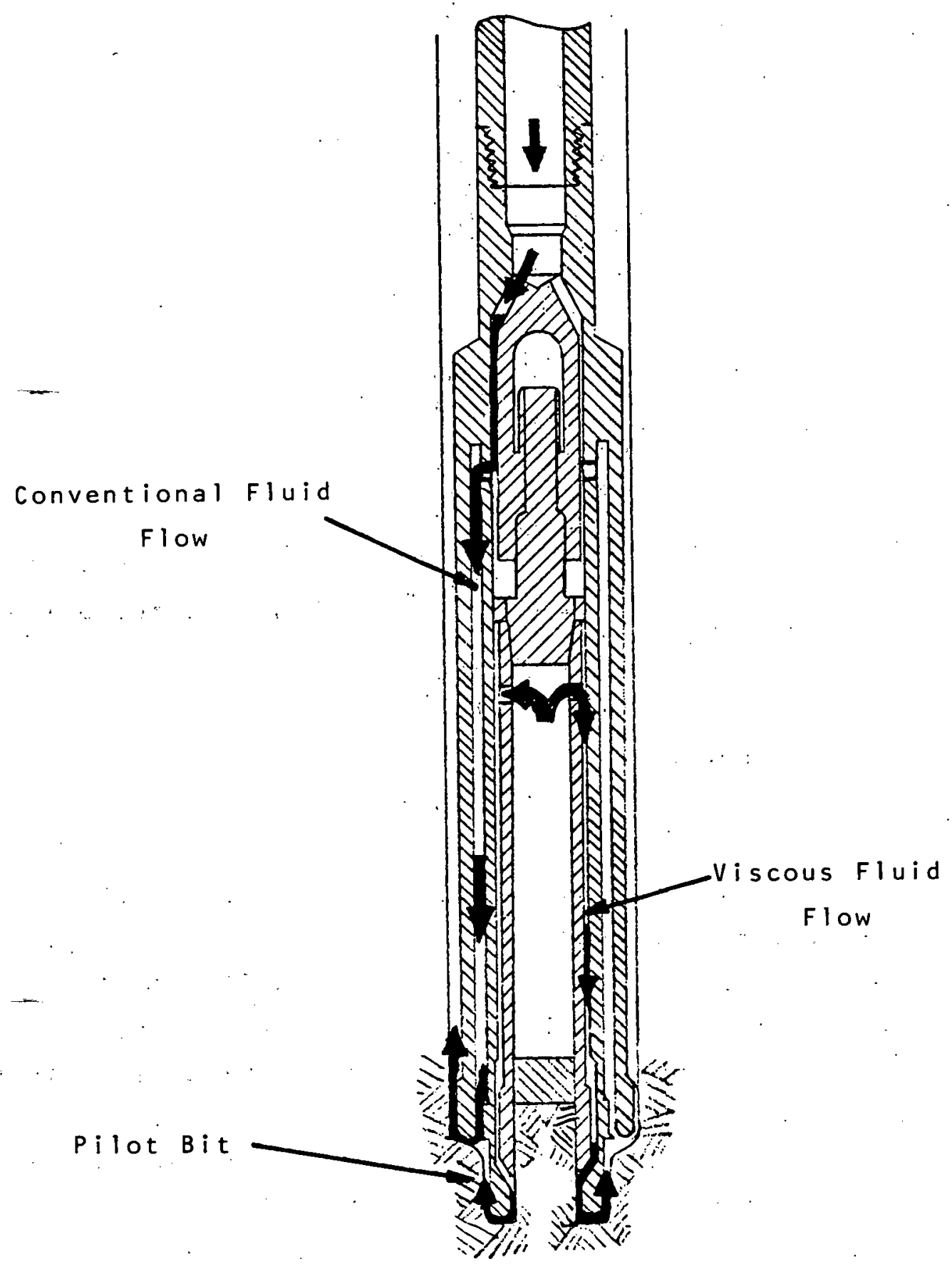

Figure 5

Use of Viscous Fluid To Isolate Core

And Lubricate Pilot Bit

(USP 2,862,691) 


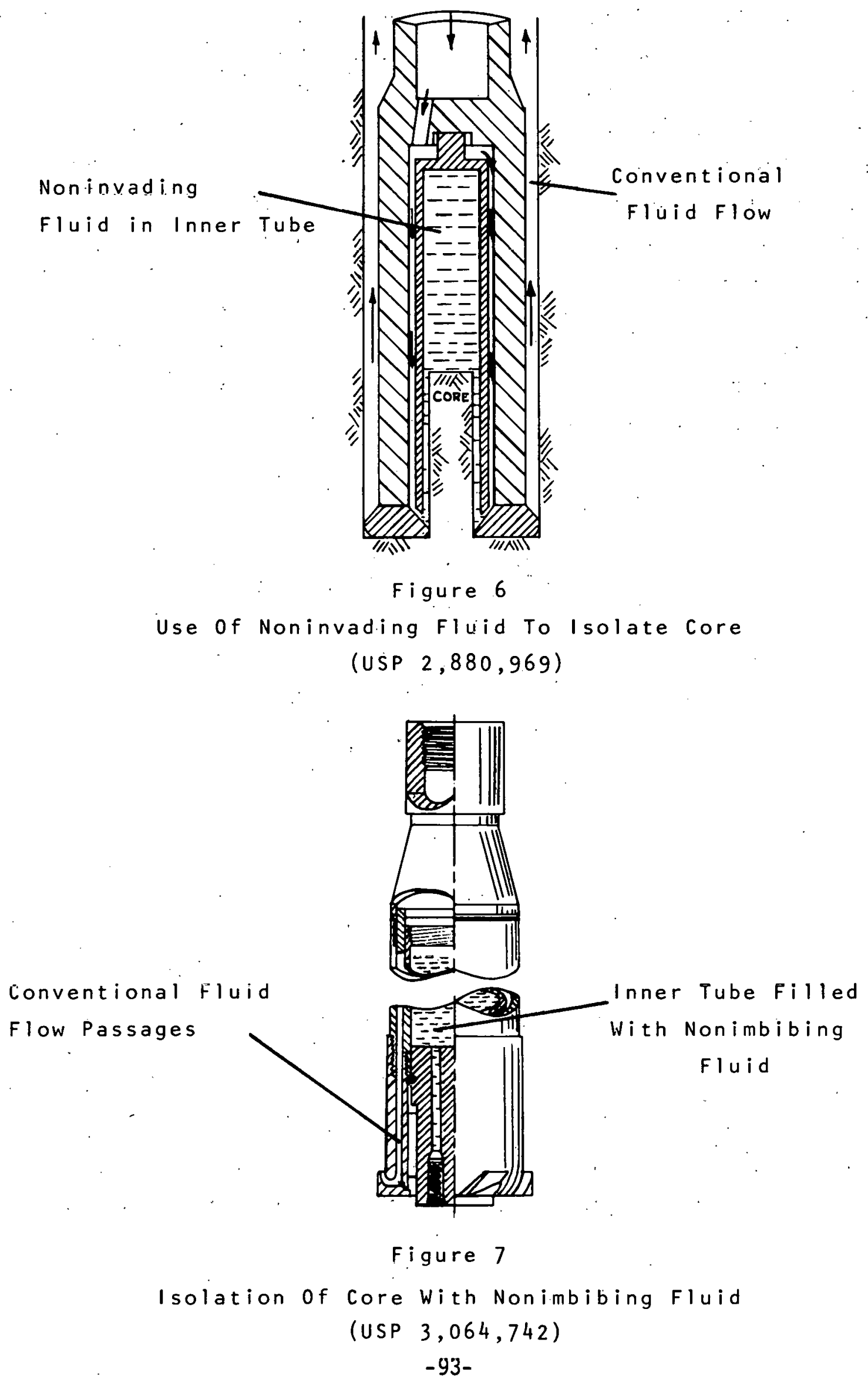


In 1963. Hildebrandt suggested a coring bit where the drilling fluid was isolated from the lower end of the inner tube by a sleeve and was discharged through the face of the core head tangentially (Figure 8 ). 9 . This bit design has been used for a number of years. in conjunction with the rubber sleeve core barrel. The use of tangential fluid discharge apparently results in substantially reduced washing away of soft, unconsolidated cores. While tangential discharge in itself does not appear to be particularly important to the reduction of fluid flushing, the concept that controlled bit shape and fluid discharge may achieve this objective does have significance to our study.

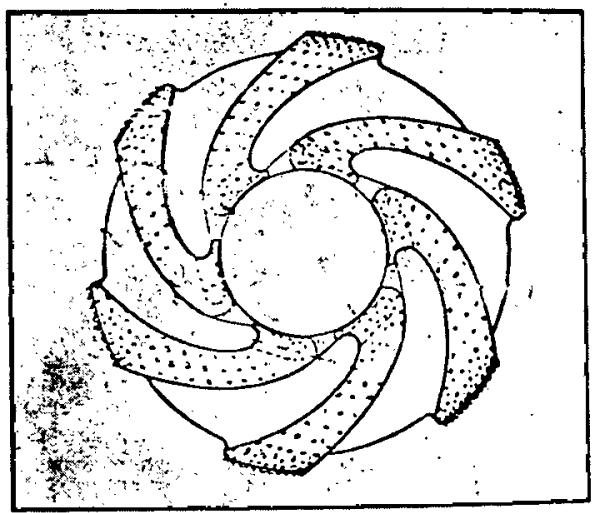

\section{Figure 8 \\ Tangential Discharge Core Bit (USP. $3,095,935$ )}

It appears that the techniques described above were either unsuccessful or impractical for normal coring operations. As a result, jersey Production Research Co. undertook a project in the early 60's to develop a non-flushing drilling fluid to be utilized during the coring operation. This project lasted about 5 years and was finally abandoned as unsuccessful. 
We have been unsuccessful in our attempts to gain access to the records of this project (these records are now property of Exxon Production Research). Correspondence from EPR management cite as their reasoning, "Our engineers feel that they have a good understanding of the fluid invasion process. They are confident that a practical TFC (True Fluid Coring) system cannot be developed if emphasis is primarily on controlling mud properties."lo Discussions with technical personnel. involved in the original project indicate that the quoted statement is, in general, true.

Theoretical analysis and analog modeling studies indicate that under normal coring techriques, it is likely that the core is flushed as much as several inches ahead of the bit face, as shown in Figure 9. Further study will be required.in order to verify concepts of controlled bit design and low filter loss drilling fluids for the reduction of invasion...and flushing.

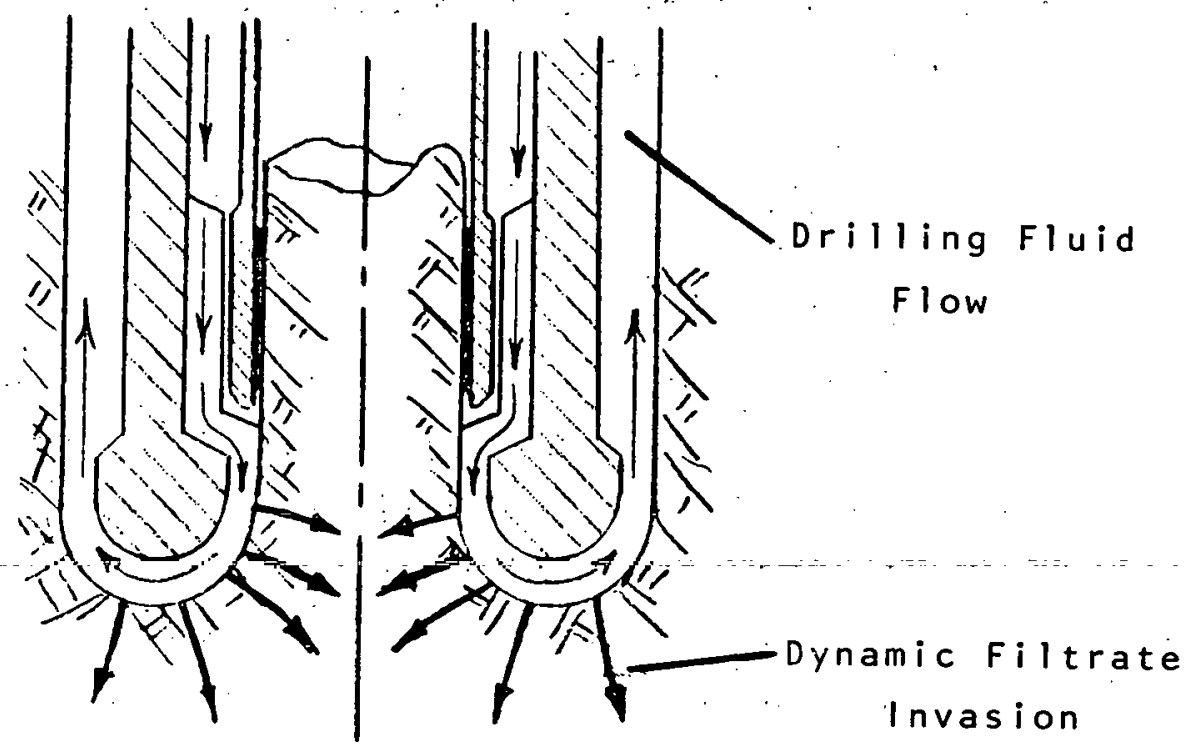

Figure 9

Flushing Ahead of Core Bit

Any new true fluid coring system design which does not utilize totally noninvading circulating. fluid must include a feature which isolates the cora from fluid invasion. 
Pressure Reduction Bleed-Off

: Under most new reservoir conditions and even under many depleted reservoir conditions, some of the hydrocarbon constituents normally in a gas phase at surface pressures will still be liquified under bottom hole pressures. The reduction of hydrostatic pressure during the trip out of the hole would result in these gasses coming out of solution and moving through the pore space of the core, carrying some of the liquid phases along. At the surface, even a coré cut without invasion or flushing would not be representative of true formation saturation because of this fluid.movement." The use of sealed barrels without pressure maintenance but trapping of all constituents is a potential solution. However; an effective reliable pressure coring system will probably be required in most cases. In the opinion of most industry personnel, there is not a great need, at this time, for maintaining formation temperature as well as pressure.

Reliability of Pressure Coring systems

The lack of reliability is a major limitation in the successful application of presently available pressure coring systems. The Loomis system is based on the system licensed from Humble 0 il and remains virtually unchanged from the original design of the early 1950's. Several design features of existing systems are sources of operational problems and should be redesigned in any new pressure coring system.

The ball valve appears to be the best solution for sealing the lower end of the inner tube. However, the complicated use of levers and gears to actuate the ball valve are a source of problems (Figure 10). When the outer 
tube is unlatched and falls to retract the inner barrel through the ball valve and, subsequently, to close the ball valve, there is a moment of sharp impact when the gears are engaged. This frequently results in damaged teeth and failure of the bali valve to close properly and seal. In the Loomis system, the upper end of the inner tube is closed by an o-ring sleeve shouldering inside the upper barrel seal. Both of the sealing surfaces and the 0-rings are exposed to the drilling fluid flow, during the coring operation. Some erosion can occur and foreign material, such as loss-circulation materials, can cake and build up around the o-ring surfaces, leading to problems in proper sealing when desired.

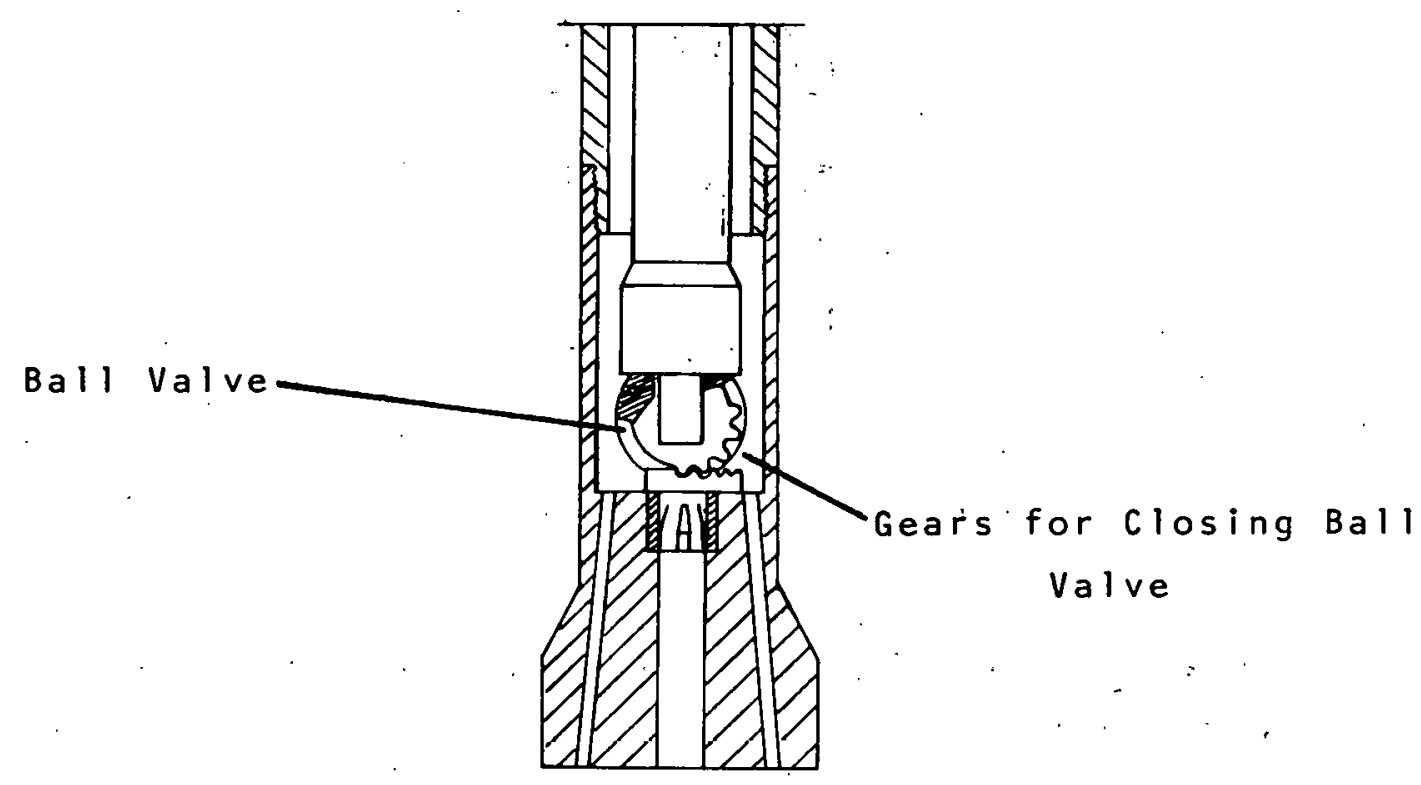

Figure 10

Gear Operated Ball Valve

On occasion, when core has been broken off, it has extended below the bottom of the inner tube and when the inner tube was retracted through the ball valve this extended core prevented closure of the valive (Figure 11). Care should be taken in the new design to provide for adequate clearance to insure proper operation of the ball valve. 


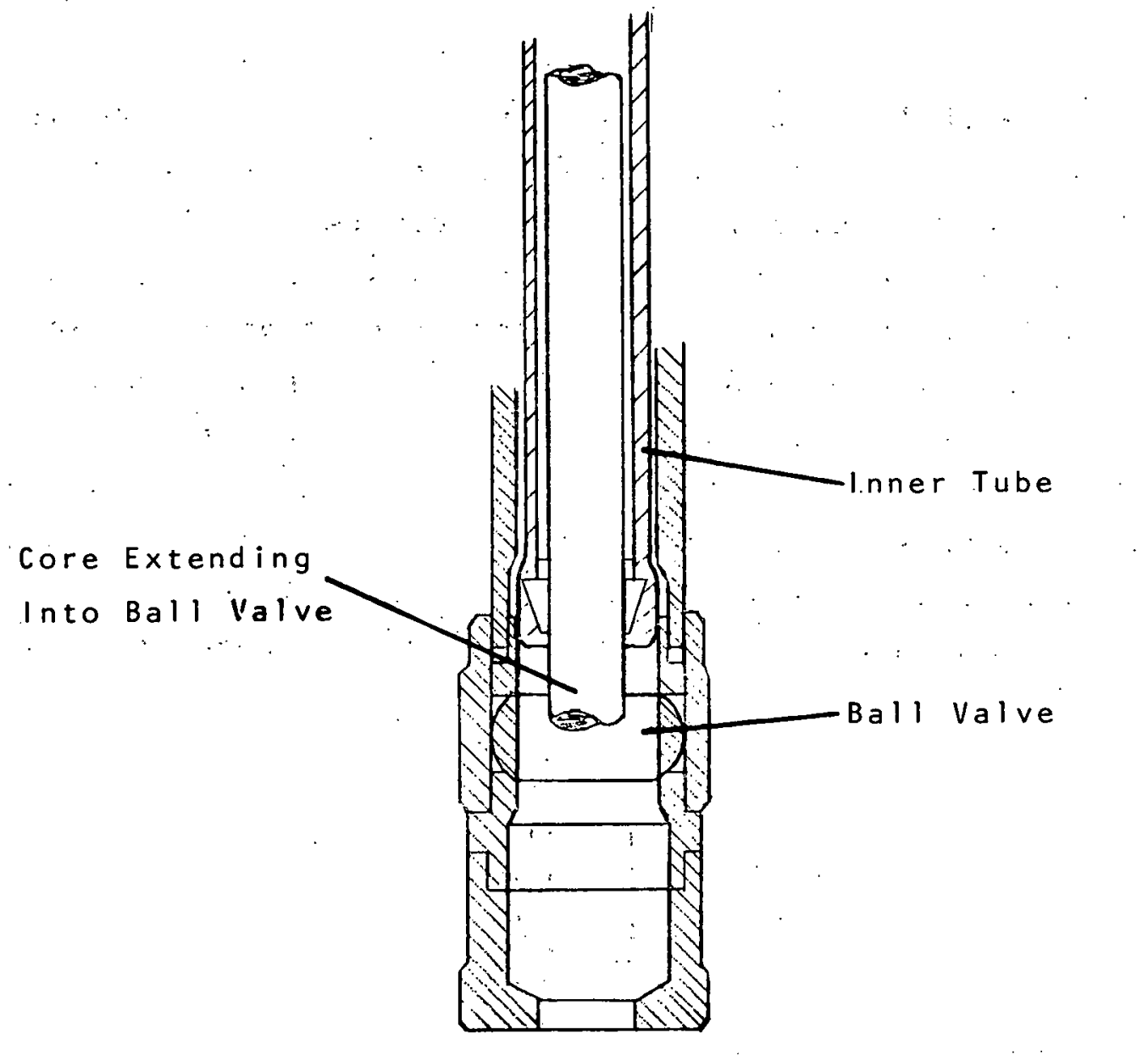

Figure il

$\therefore$ Ball. Valve Blocked By Core

The other pressure coring. system presently in existence was designed for Shell Development Co. by Christensen Diamond Products in 1964. The design work was carried out without the benefit of detailed knowledge of the then proprietory Humble barrel design. Several design features are certainly improvements over the Humble system, however, in general the Shell/Christsensen design is considerably more complicated. The same problems and limitations of gears operating the ball valve are present. I. n addition, several other shear pin rings and valve levers are a source of continual damage and failure. 


\section{Mud Displacement}

When the Loomis barrel is brought to the surface and disassembled for further handling, it is necessary to use a time-consuming technique in order to remove the drilling mud from the space between the inner tube and the outer tube. The present operating technique requires that a pressure regulating system be attached near the ball valve and gelled Varsol pumped, under pressure, into the annular space to remove this drilling fluid (Figure 12). If this drilling fluid is not removed prior to freezing the core, disassembly of the outer tube and removal of the inner barrel for handling is impossible. An improved system should either eliminate the necessity for this flushing operation or should at least reduce the volume of entrapped drilling fluid to reduce the time involved in its completion.

Flushing Fluid

Drilling Fluid P.umped in

Forced out

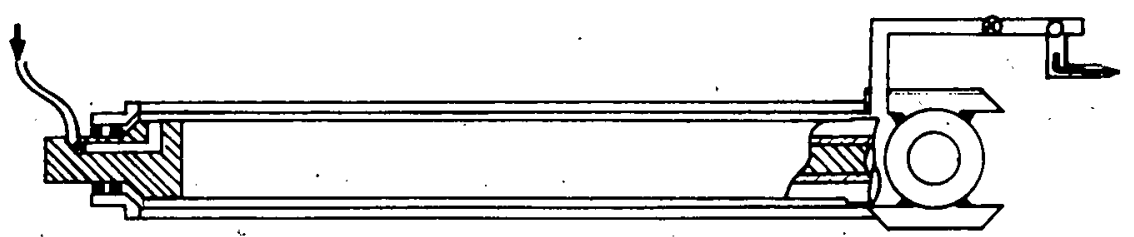

Figure 12

Displacement of Drilling Fluid Under Pressure

Once the core is frozen and the inner barrel removed and transported to the laboratory for evaluation, there is a problem in extracting the core from the metal tube. Present practice involves placing the frozen core in an endmill and carefully milling a longitudinal groove in the metal sleeve at 2 points diametrically opposed. Liquid nitrogen must be 
used as the coolant for the endmill and it is alsonecessary to do the operation quickly before the core can begin to thaw. While core Lab indicates that the operation is not difficult, it does represent an additional step in the analysis technique that should be eliminated, if possible.

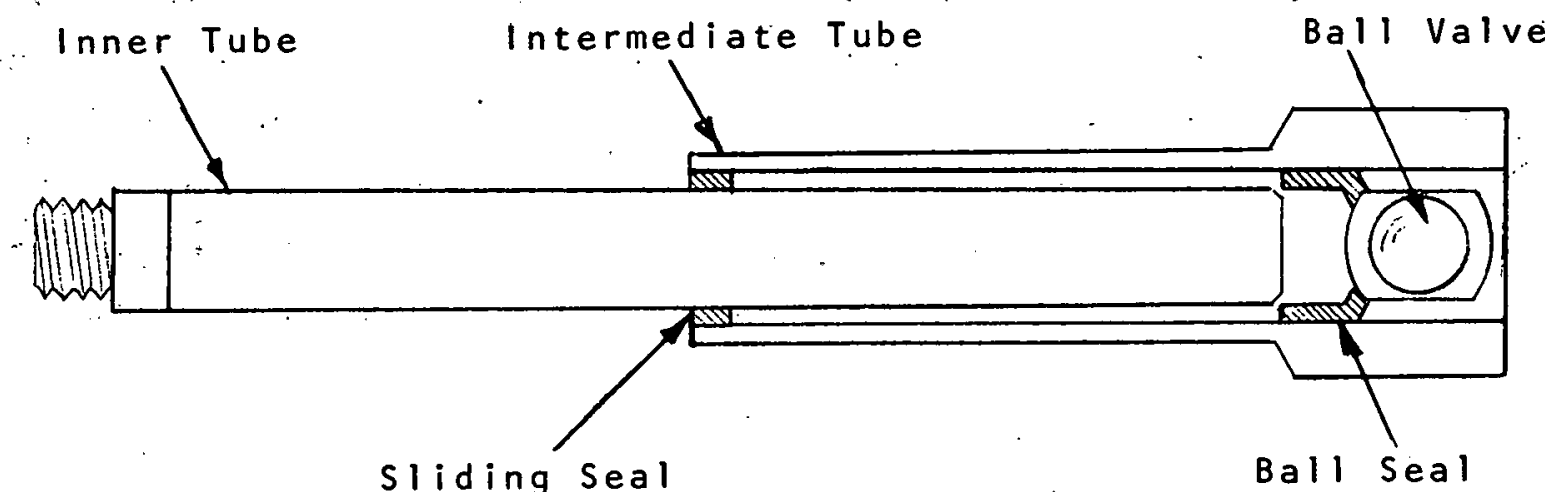

Figure 13

Shell/Christensen Sealed Inner Barrel

The use of a sliding intermediate sleeve with attached ball valve housing simplifies the problem of drilling fluid in the annular space between the inner and outer barrel since the volume is quite small. However, in order to achieve this feature, it was necessary to reduce the overail diameter of the ball valve itself (Figure 13). Since the inner tube containing the core must pass through the ball valve, the smaller diameter therefore required a much smaller and undesirable core size. It is considered very important that core size should not be less than 2-1/2 inches in diameter and any new system should be designed around this parameter. 
To meet specific program requirements at the time, the Shell/Christensen pressure barrel design was based on a very short 5 foot core length. This simplifies transportation and handling, but significantly increases time and costs when it is necessary to core an entire formation of any thickness. While it poses no problem to increase the overall barrel length and thus the core length, this is a factor that must be considered in any new design.

The Shell/Christensen system was $1 . i m i t e d$ to a $1-3 / 4$ inch core diameter. This is considered to be inadequate and most experts agree that the minimum diameter should be at least $2-1 / 2$ inches.

Although much longer and larger diameter cores are very desirable, these benefits are gained only with significant incresase in handling problems and decrease in system reliability, to say nothing of the physical limitations imposed by hole size and depth requirements of the drilling operation itself.

\section{Core Handling.}

While satisfactory procedures seem. to have been developed for handing the core from the freezing stage through prep: aration for final analysis, it is desirable to eliminate as many steps as possible. As discussed earlier, the core is locked inside the inner tube by freezing as a result of the drilling fluid entrapped in the annular space between the core in the inside of the inner tube (Figure 14). Once the inner tube is removed by the machining operation, it must be then placed inside a deepfreeze where the remaining 
layer of frozen mud must be manually chipped and scraped from the core surface (Figure 15). Even if this procedure can be completed quickly and easily, it does represent a period of time when the core is exposed to an uncontrolled atmosphere and, if at all possible, this procedure should be avoided.

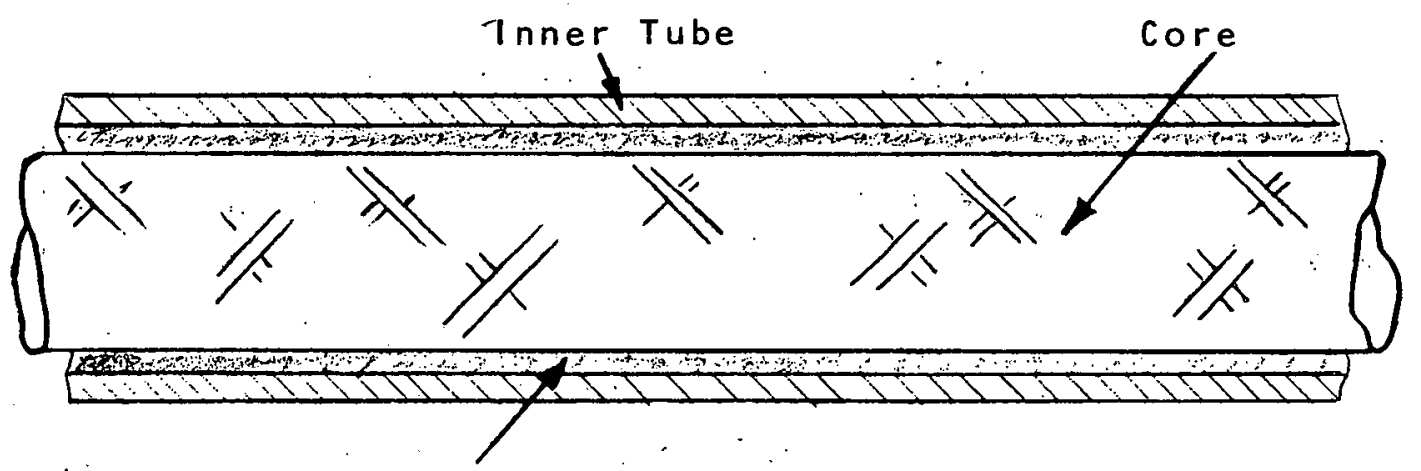

Mud Layer

Figure 14

Core "Locked" in Inner Tube By Frozen Mud Layer

With the exception of flushing ahead of the bit all of the limitations to present true fluid coring systems discussed above can be eliminated through understanding and careful design of a new system. The flushing problem is obviously very difficult and additional work. will be necessary to find a satisfactory solution. This is extremely important to the success of a true fluid program since no pressure core system, regardless of reliability and simplicity, will be of any benefit if the core is altered before entering the barrel. 


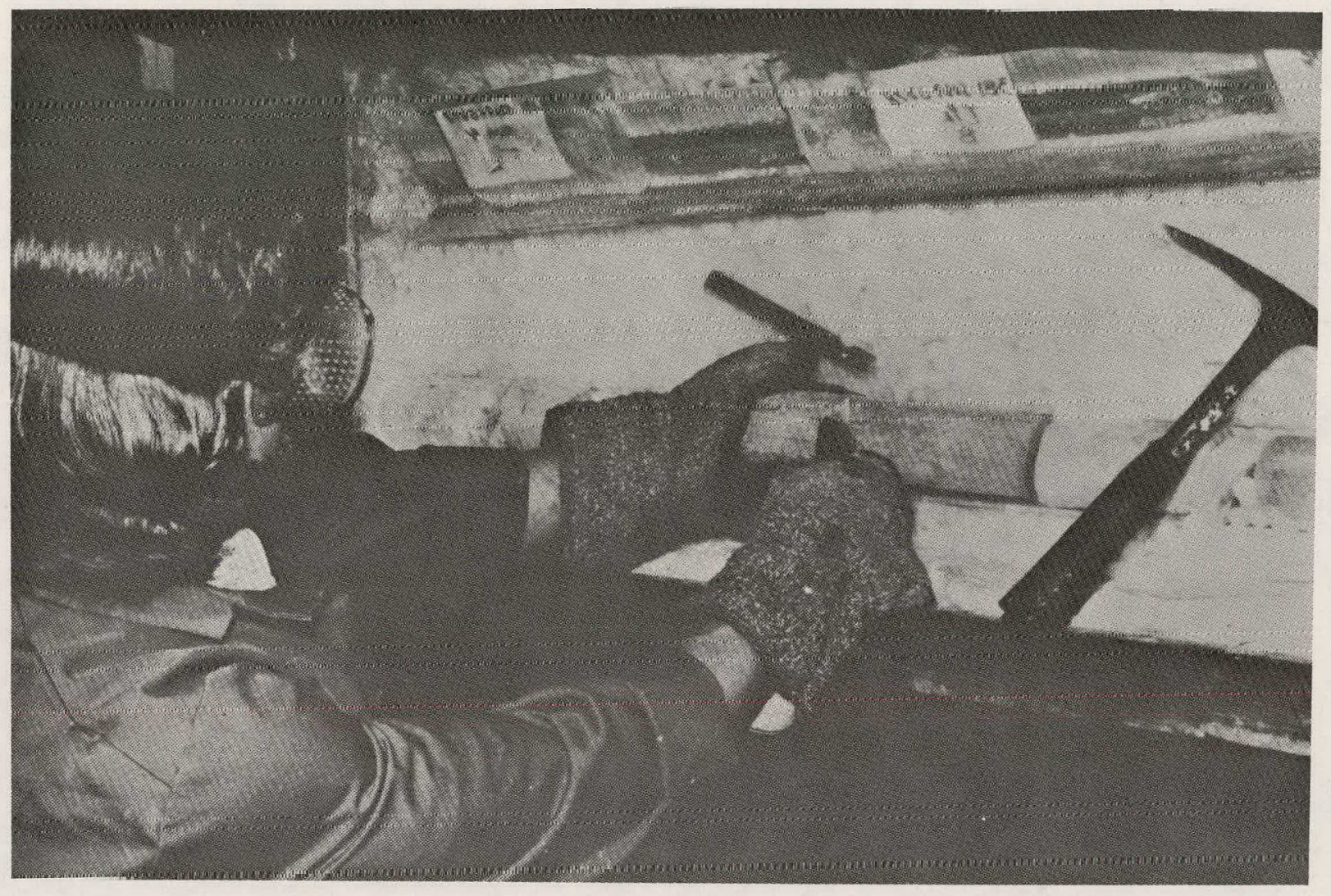

Figure 15

Frozen Mud Being Chipped From Core 


\section{REFERENCES}

1. Young, F. S., Jr., "Dynamic Filtration During Microbit Drilling," Petroleum Transactions, Society of Petroleum. Engineers, Sept., 1967, pp. 1209-1224.

2. Jenks, L. H., Huppler, J.D., Morrow, N.R., and Salalhiel, R. A., "Fluid Flow Within A Porous Medium Near A Diamond Bit," Reprint, The Journal of Canadian Petroleum Technology, Oct.-Dec., 1968, pp. 1-7.

3. Johnston, USP $2,146,263$

4. Hounce, USP 2, 264, 445

5. Smith, USP $2,541,785$

6. Cochren USP 2,862,691

7. Williams, USP $2,380,969$

8. Bridwell, USP $3,064,742$

9. Hildebrandt, USP 3,095,935

10. Welch, L.W., Jr., President, Exxon Production Research Co., Correspondence, Feb., 17, 1976. 


\section{SPECIFICATIONS FOR A TRUE \\ FLUID CORING SYSTEM}

Core Barrel Size

Core Diameter

Core Length

Pressure

Temperature

Coring Fluid

Monitoring 
V.I. SPECIFICATIONS FOR A TRUE

FLUID CORING SYSTEM

In addition to the capability of taking unaltered cores, any true fluid coring system must be capable of operation under typical field conditions. Design requirements, based on evaluation of typical coring situations and discussions with industry personnel are summarized in Table 1 .

TABLE 1

SUMMARY OF CORING SYSTEM

DESIGN SPECIFICATIONS

Parameter

Requirements

Core Barrel Diameter

Core Diameter

Core Length

Pressure Capability

Temperature Capability

Coring Fluid

Monitoring
6-1/4 inch nominal 0.D.

$2-1 / 2$ inch minimum

$10 \mathrm{ft}$. minimum

$20 \mathrm{ft}$. maximum

5,000 psi minimum

10,000 psi maximum

$275^{\circ} \mathrm{F}$ maximum

minimum modification to

normal drilling fluid

capable of signaliing

specific system failures

\section{Core Barrel Size}

Most applications for a true fluid coring system will occur in holes of 7-7/8 inches or larger. The core barrel should therefore be designed with a 6-1/4 inch nominal outside diameter. In order to achieve maximum core size 
it would be possible to mount the lower ball valve in

a sub at the lower end of the outer tube. It is an acceptable practice to use a larger diameter (up to 7-7/8 inches diameter) for such a sub located at the bottom of the barrel, provided the length is kept to about 18 inches or less.

Core Diameter

In order to minimize influences of fluid invasion and to provide adequate sample for analysis, it is desirable to obtain as large diameter of core as possible. The maximum size of core is limited by the outer tube size; however, it is felt that in no case should the core be less than 2-1/2 inches in diameter.

\section{Core Length}

A primary application for a true fluid coring system would be the evaluation of formations prior to tertiary recovery programs. In such applications; it is considered extremely important to be able to study the entire producing interval in order to evaluate differences in fluid saturations with depth. This would often require continuous coring of 1 to 2 hundred feet at a time. It is, therefore, necessary that as long a core be obtained on each run as is practical. Any new system should be capable of minimum core lengths of 10 feet with $20 \mathrm{ft}$. capability being even more desirable.

There are some applications where transporting core to the laboratory for analysis while maintaining sealed-in pressure (and without freezing). In these cases, it may be desirable to cut very short cores (e.g. 5 f.t.) to simplify handling problems. It should be noted that almost any system capable of handling longer cores can be modified to take short cores as well. 
It is thought that any true fluid coring system should be designed to seal in a minimum of 5,000 psi. This would permit operation in normally pressured reservoirs to a depth of about $11,000 \mathrm{ft}$. Although operation at higher pressures is not a typical.requirement, if possible any new true fluid coring system should be capable of up to 10,000 psi.

Reservoir gases remain in solution until pressure is reduced to the "bubble point" pressure.. If the 10,000.psi requirement cannot be reasonably incorporated into the pressure coring system, an alternate technique could be used. The pressure inside the sealed barrel could be allowed to reduce gradually during the trip out of the hole by releasing flow into a catch chamber through a pressure relief valve. The pressure reduction would cease and be maintained constant at a pressure slightly above the bubble point, thus. preventing the gases from evolving and altering the true fluid content of. the core.

\section{Temperature}

-High bottom hole temperatures are not anticipated for most true fluid coring application. Therefore, no great emphasis should be placed on achieving temperature capabilities in excess of normal elastomer limits of about 275 to $300^{\circ} \mathrm{F}$.

\section{Coring Fluid}

Although not absolutely necessary, it is desirable that any true fluid coring system be able to achieve satisfactory results with little or no modification to the conventional driliting fluids being used. 


\section{Monitoring}

Any highly advanced designed true fluid sampling system should be equipped with sensors and a telemetry system.

This system shoulld be capable of recognizing specific failures

in the operation of the equipment and provide aisignal to the surface to permit corrective actions, to be taken. 
VIII. CONCEPTS FOR IMPROVEMENT OF PRESENT TECHNOLOGY

Cutting

Eliminating Invsion

Sealing

Reliability

Core Transportation

Up and Out of the Hole

Down the Road

Core Analysis 
Many ideas have been proposed for methods of obtaining true fluid cores. Most of theșe ideas were discarded without attempt at application because they were technically impractical. 0 ther concepts failed because adequate technology for success did not exist at the time or because the concept of a totally integrated coring system was not developed. Some reasonable ideas were not tested or evaluated simply because of inadequate funding.

During this study, hundreds of ideas relating to true fluid cores have been evaluated. These many ideas have ranged from detailed design considerations for a small portion of a coring tool all the way to a very broad concept for an entire system. In the following chapter, these many concepts have been organized into several logical categories to reduce confusion and to simplify evaluation. These major categories are summarized in Table 1 and are discussed individually in greater detail below:

TABLE 1

CATEGORIES OF TRUE FLUID CORING CONCEPTS

Category Problem Addressed

Cutting

Invasion

Sea 1 ing

Reliability

Transportation

Analysis
Cutting speed; rock damage Elimination of fluid alteration

Maintenance of bottom hole pressure; core diameter

Simplified handling; improved reliability Pressure and temperature maintenance; reduction of disturbance

Reduced complexity; improved accuracy 
Many different methods of cutting cores quickly and without damage to rock properties are being considered. One idea is to use the Subterrene Corer being developed by Los Alamos Scientific Laboratories (Figure 1). Although this system which melts the rock can achieve high penetration rates, the concept is not considered feasible for several reasons. A tremendous amount of energy must be supplied from the surface in order to melt the rock. Even more importantly, it is felt that the high temperature operation of the system would immediately destroy true fluid ratios in the core obtained.

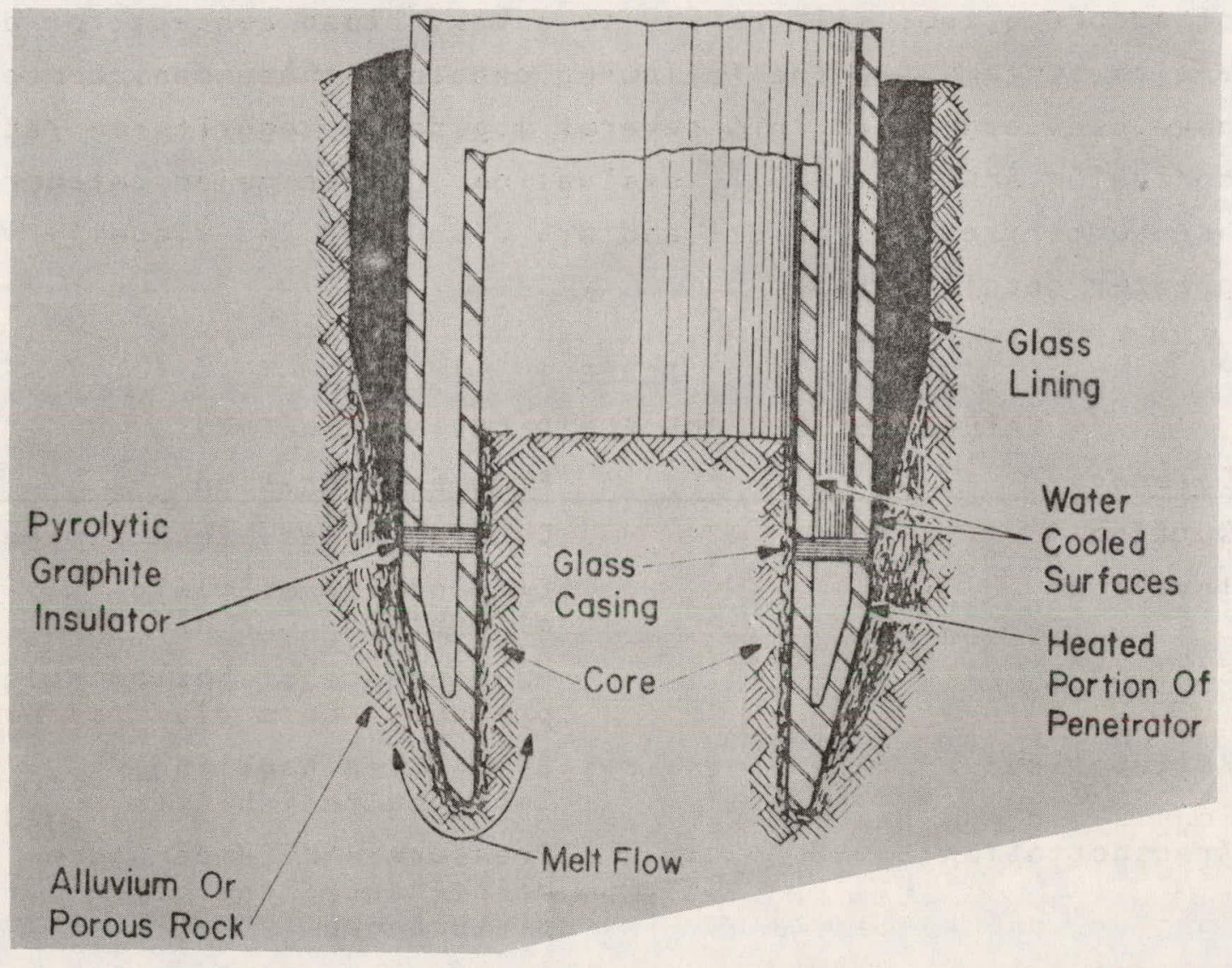

Figure 1

LASL Subterrene Corer 
The concept of firing bullets into the bottom of the hole, such as the Sandia Tround system (Figure 2), offers the likelihood of attaining high penetration rates, possibly without the use of damaging fluid circulation. However, it is very likely that the core would be fractured and fluid saturations disturbed.

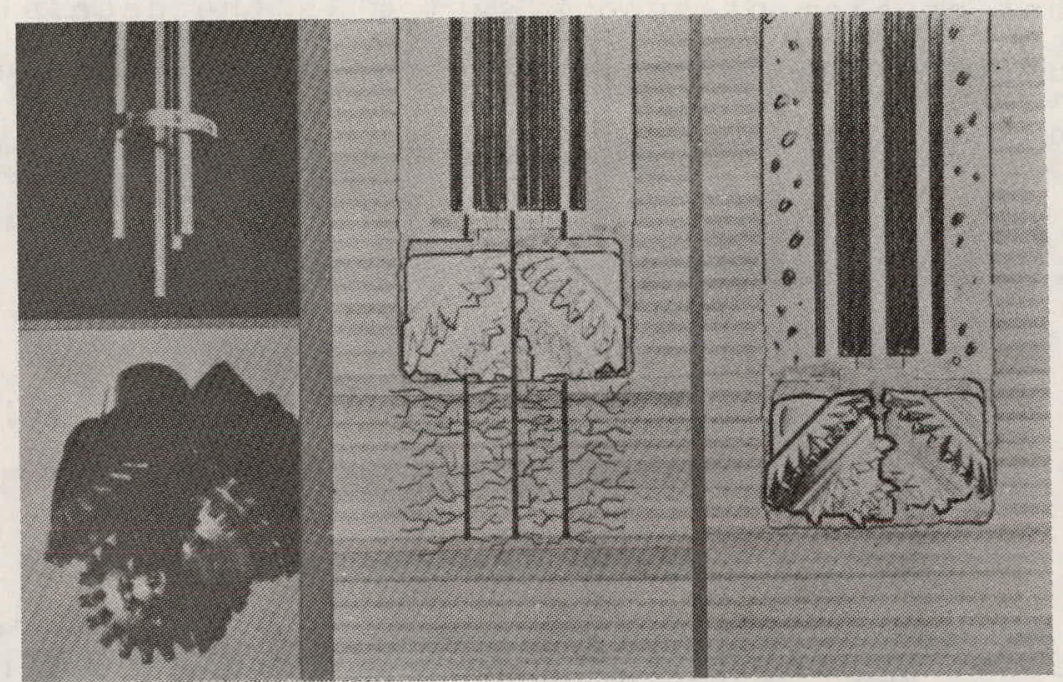

Figure 2

Sandia Tround Terra-Drill

Several techniques of single and multiple punch cores have been considered. In addition to the probable core damage, these techniques do not meet the requirement of desired core diameter and sample length.

Various methods of taking sidewall samples have been considered and the conventional punch core method was discarded for the same reasons as bottom hole punch coring. However, one concept does provide some very interesting possibilities. By lowering a small pressure coring system driven by a downhole mud or electric motor (Figure 3) on a wire line, it would be possible to alternately drill and take true fluid core samples. The curved tube opening from the 
drill collar to the hole annulus would be plugged during the drilling operation. While this concept does not provide a core of adequate diameter and length to satisfy the generally desired true fluid sample requirement, it could be used for sampling in existing wells of depleted reservoirs without requiring new holes to be drilled. This could provide valuable information at a greatly reduced cost. The primary development problem of such a system is the necessity of coring out into the formation far enough to reach uninvaded, unaltered reservoir rock.

Flexible Coring Tube

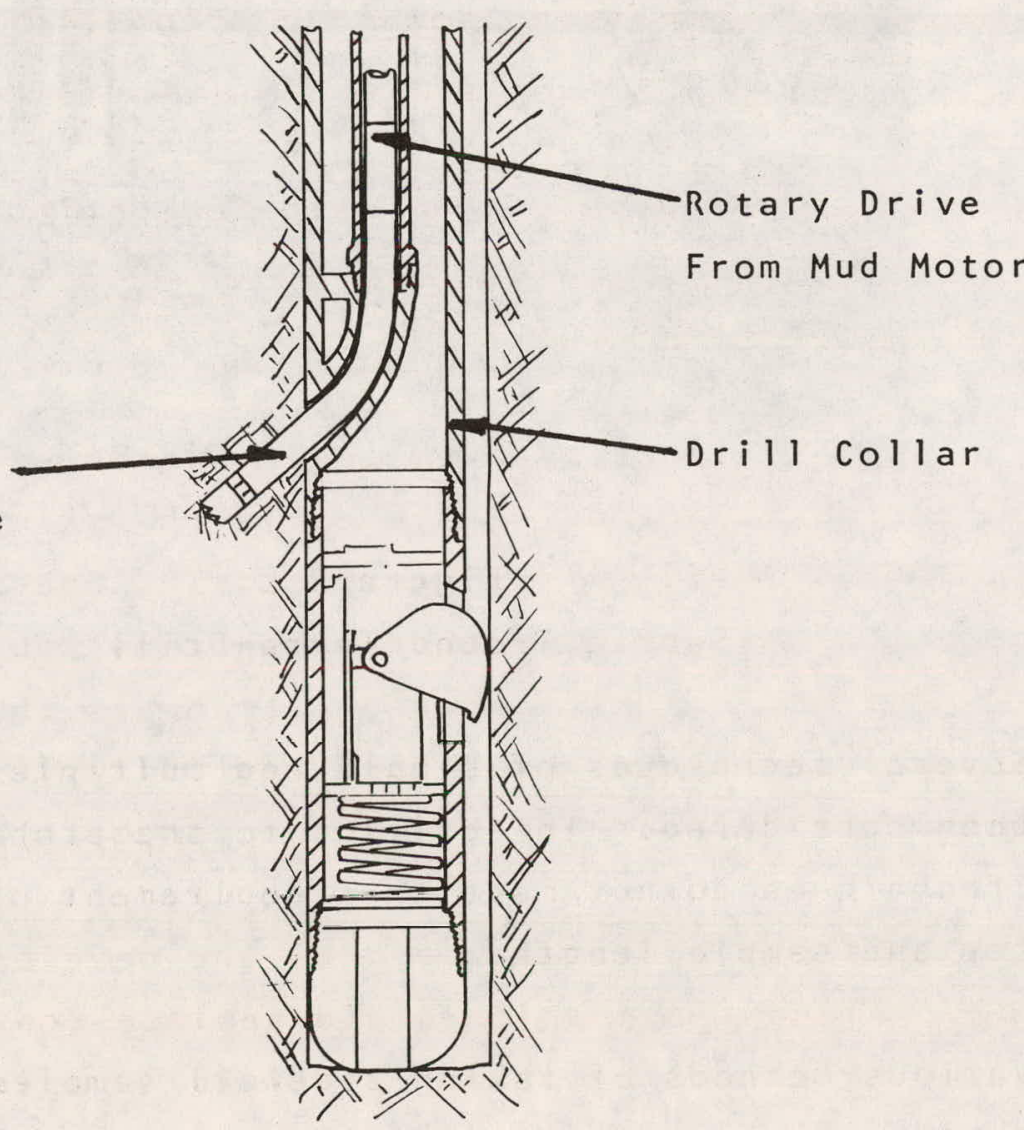

Figure 3

Sidewall Corer 
Roller cone bits generally penetrate at rates exceeding those achieved by the typical diamond bit in most formations. Their use, however, is likely. to be limited because of probable rock damage, problems of maintaining proper core gage and problems relating to prevention of fluid invasion.

The use of diamond coring bits on any new true fluid coring system seems to be the most logical approach. All of the justifications for using diamond bits in conventional coring techniques apply in this case also.

The idea of utilizing. downhole motors, either mud driven or electric, to provide rotary power for a true fluid system, has good merit. Their use should be given strong consideration especially for any highly sophisticated coring system.

\section{Eliminating Invasion}

The most critical problem to be overcome in the development of a true fluid coring system is the elimination of drilling fluid invasion during the coring operation. Successful development of all of the other subsystems would be of little value if the core is altered when it enters the system. It is felt that additional study and testing will be necessary to develop the most promising of the concepts being considered.

The most obvious idea would be the development of a special drilling fluid which could replace conventional drilling fluids and which would not permit fluid invasion. Such a non-invading fluid must necessarily maintain all of the other characteristics of a conventional drilling fluid in order to be useful. In addition, the problem is aggravated by the necessity of maintaining a hydrostatic head (probably greater than reservoir pore pressure) sufficient to prevent blowout. Previous attempts at developing such a fluid have proved very costly and generally unsuccessful. 
it is possible that a heavy liquid such as mercury could be spotted at the bottom of the hole to provide isolation of the formation being cored from conventional drilling fluid. It would still be necessary to maintain an undesirably high hydrostatic head to prevent blowouts and there is-a definite possibility that fluid invasion would still occur by mud filtrate leakage into the hole wall around and past the heavy liquid.

One interesting: concept would be to freeze the rock and fluids ahead of the coring bit, thus locking formation fluids in place. This would probably require the use of liquid nitrogen and a complicated system of insulated piping from the surface would be needed.

The use of an open hole packer to separate the reservoir rock from the normal drilling fluid looks very promising (Figure 4). The use of a packer would overcome the problem of excessive hydrostatic head since pressure below the packer could be adjusted to match formation pore pressures. The - primary problems involved for this concept include the necessary circulation of a non-invading fluid to cool and clean the bit, and the complex equipment required to set and release the packer system itself.: Open hole packers are routinely used in many drilling operations and the problems involved can probably be solved. 


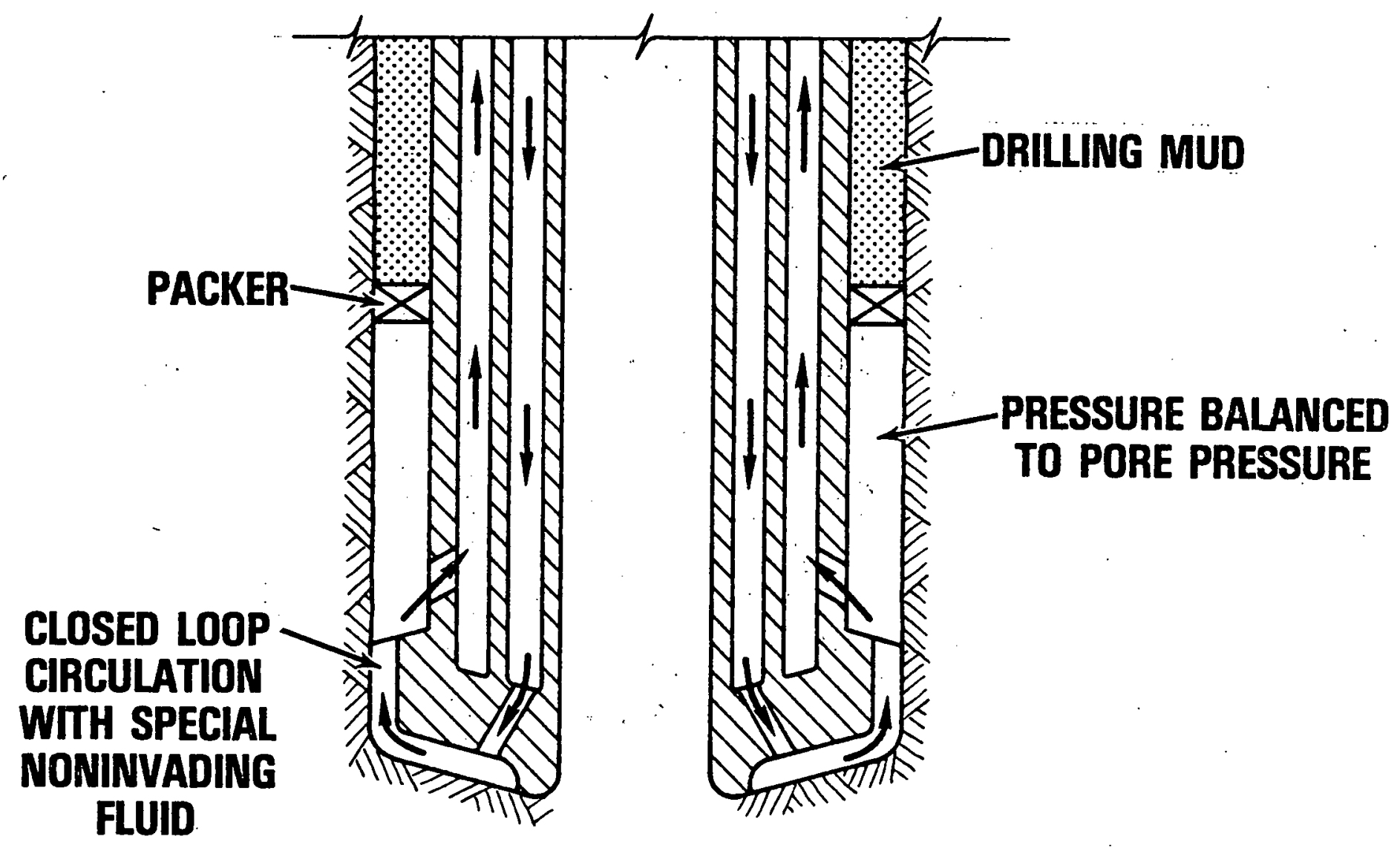

$$
\begin{gathered}
\text { Figure } 4 \\
\text { Open Hole Packer To Protect Reservoir }
\end{gathered}
$$


By using an "auger" type bit (Figure 5), it might be possible to drill below a packer without the use of an additional circulating fluid. Auger bits are used successfully on surface holes where the material being cut is unconsolidated, but it is doubtful that such a technique would work under bottomhole conditions and in hard rock formations.

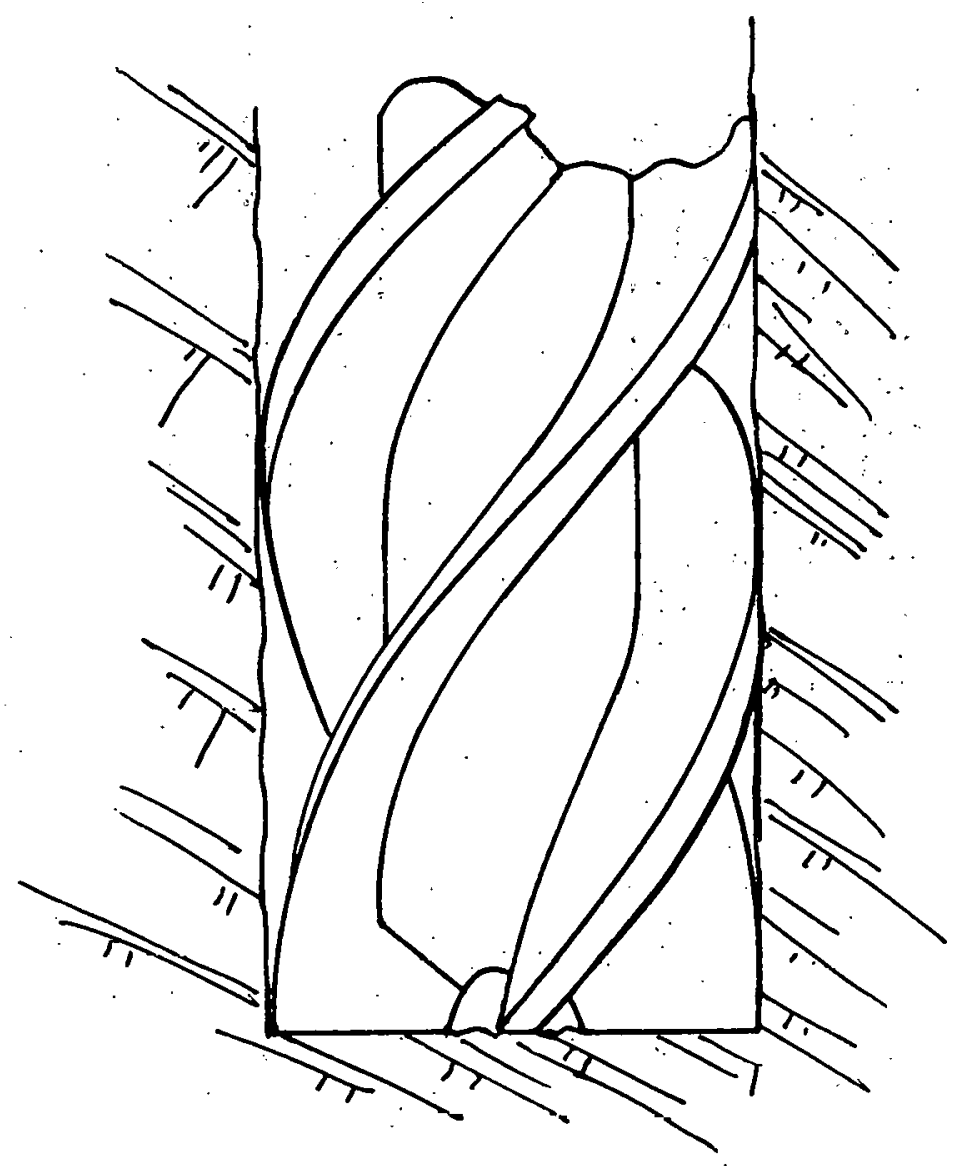

Figure 5

Dry Drilling Auger Bit

The best non-contaminating fluids that could be used are the produced förmation fluids. The main problem is how to withdraw sufficient fluid from the formation without causing alteration of the fluid saturation in the area being cored. It might be possible to use a formation fluid produced with. special handling to prevent alteration from an adjoining 
well. Handling of this fluid would be a problem and would not provide a universal solution (e.g. in a gas reservoir).

The most promising short-term solution to the problem of invasion includes the use of conventional drilling fluid but at a greatly reduced flow rate and a pilot-type coring bit (figure 6). If the majority of the drilling fluid was by-passed above the coring system to provide adequate maintenance of hole conditions and only a minimum.amount of fiuid necessary to clean and cool the bit allowed to cross the bit face, the problem of dynamic filtration (i.e. invasion) would be greatly reduced.

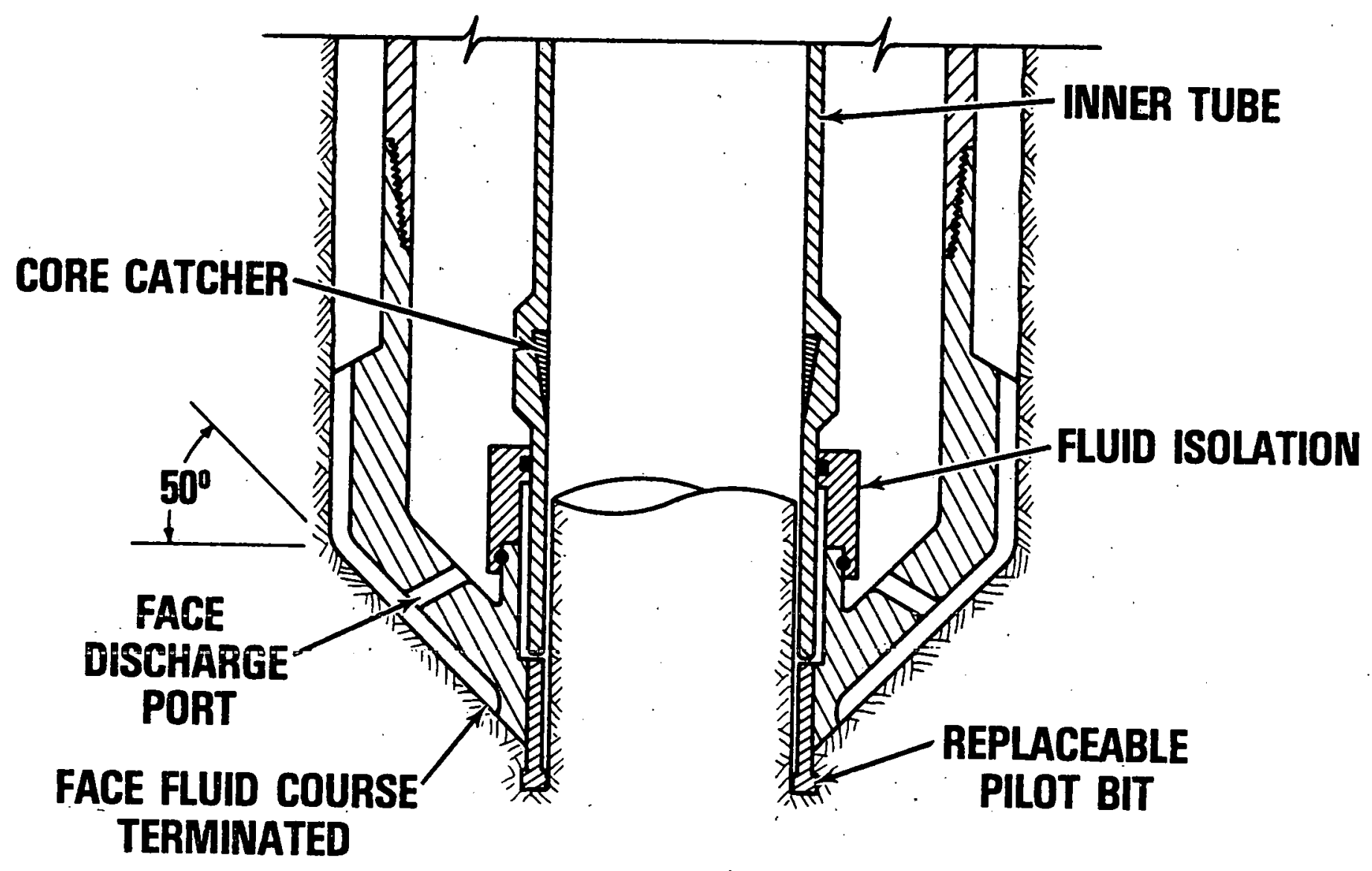

Figure 6

Bit Design to Reduce Invasion 
The pilot bit mentioned above should also include features to totally isolate the core from the circulating fluid by providing a rotating seal at the lower end of the inner tube system. It is thought that a replacable pilot bit extending ahead of the bit crown would further reduce the problem of fluid invasion.

If reduced fluid flow resulted in excessive bit wear caused by overheating, the bit could be cooled by circulation of a refrigerant inside the bit crown (Figure?).

REFRIGERANT

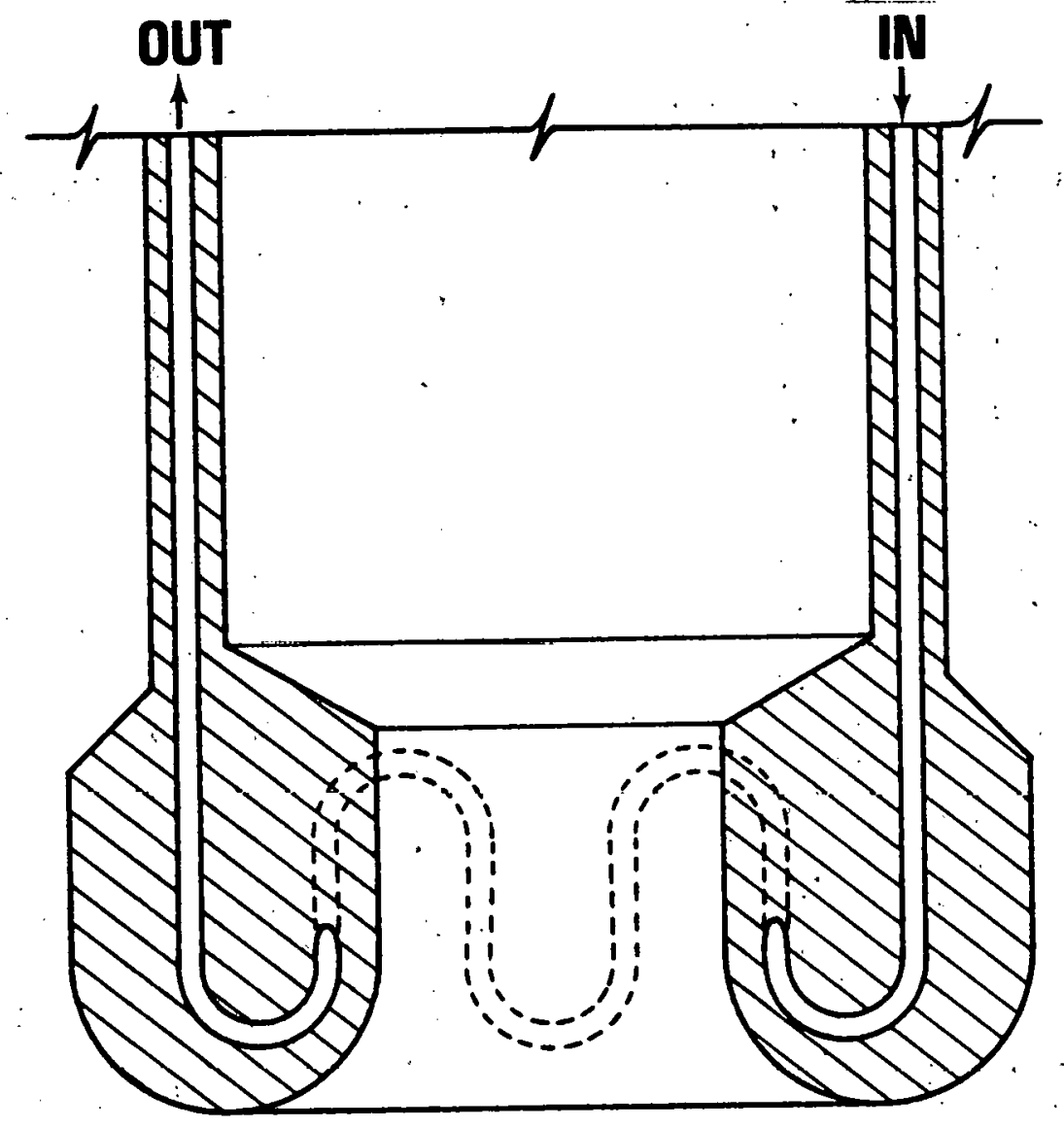

Figure 7

Refrigerant Cooled Bit 
Sealing

After a true fluid core has been cut, it is necessary to seal the inner tube system in order to maintain bottom hole pressure during the trip out of the hole.. While there is not a significant mechanical problem in sealing the lower end of the inner tube, the technique used is significant in that it controls the maximum core diameter that can be used.

The simplest method of closure and one which requires very little space in the open position is the flapper valve (Figure 8). The primary limitation with this concept is reliability of sealing. During the coring operation, with the valve in the open position, the sealing surfaces are exposed to rock cuttings and debris. It is felt that adequate positive closure and sealing would be difficult to achieve.

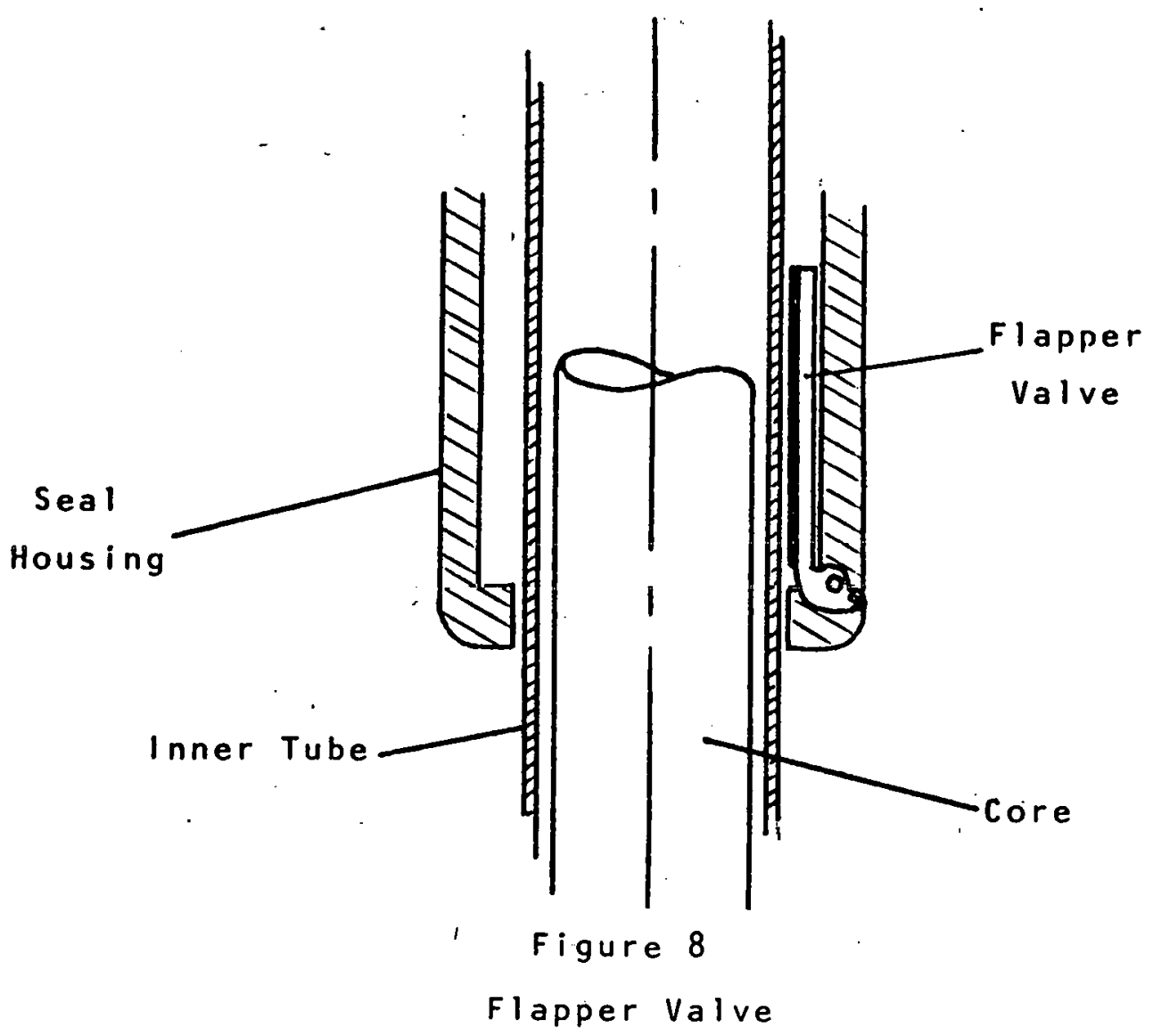

$-121-$ 
The Loomis coring system uses a ball valve. While careful design is necessary to obtain adequate core diameter, this approach appears to have the best reliability (Figure 9). The sealing surfaces are wiped clean by the rotating action of the valve and actual surfaces are never exposed to cuttings and debris. Previous problems with this sealing technique have generally not been related to sealing itself but have been more related to mechanical operations and closure of the valve.

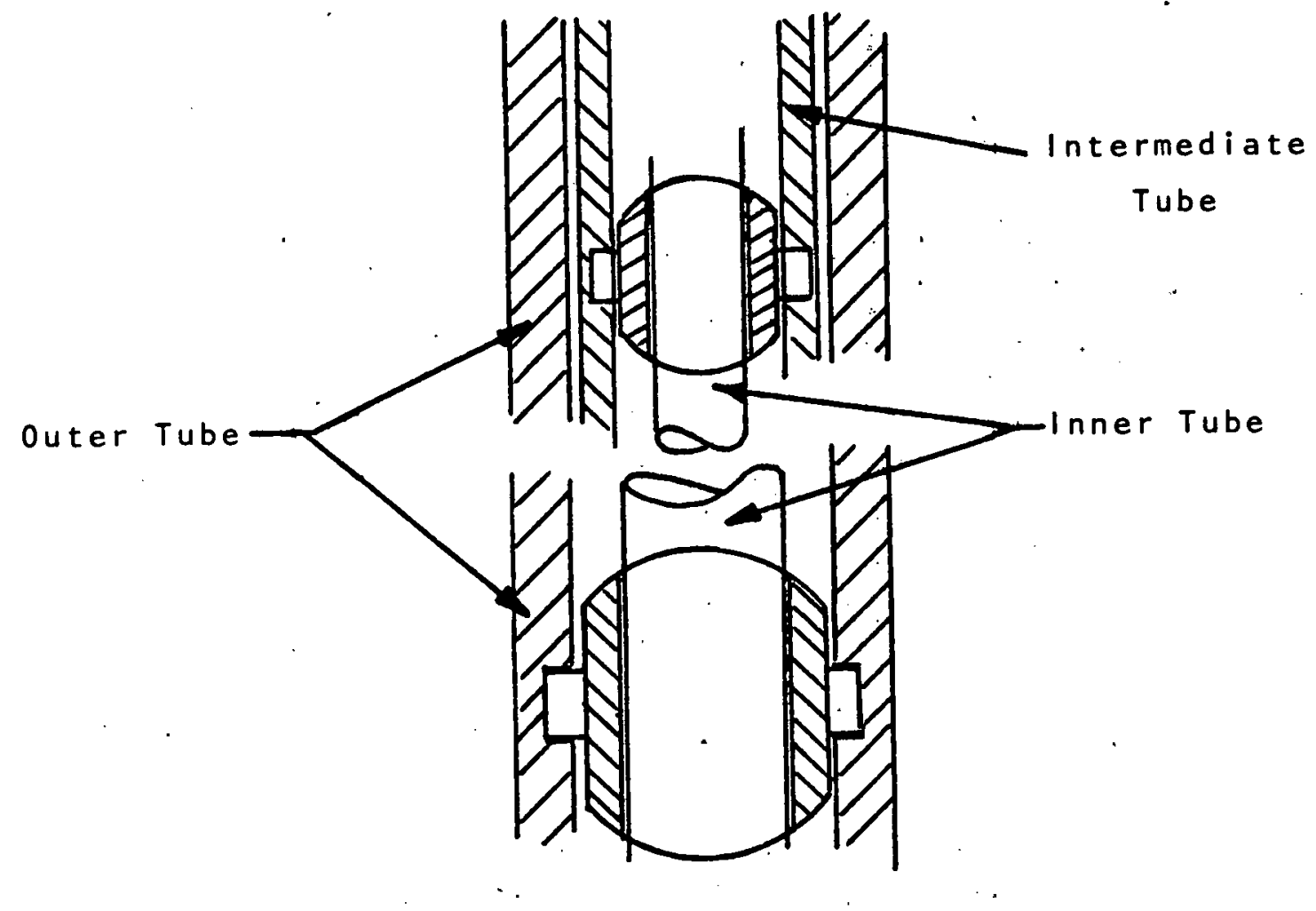

Figure 9

Ball Valve Design Controls Core Diameter

Additional concepts worthy of consideration include use of quick-setting "epoxies" to plug the lower end of the inner tube. Other concepts such as cone shape spring leaf closures and other complicated systems do not appear to have the reliability and safety under high pressures that is considered necessary. 
Improved Reliability and Ease of Handling

One possible step to improved reliability is the use of downhole instrumentation and controls to monitor and modify specific portions of the recovery operation. These improvements would reduce errors in functioning which cause failure to obtain a core sample, as well as provide better environmental control over the core such as maintaining downhole pressure and temperature around the core as it is raised to the surface.

Instrumentation and controls for the downhole environment could be electrical, mechanical, hydaulic, pneumatic or more probably a combination of these types of devices. All of the above equipment has specific advantages and disadvantages when applied to a well's hostile environment.

As a general design approach, the development of a highly reliable control system is the first criteria with accuracy and cost of a secondary importance. This is because the high costs of attempting to obtain this type of core make the cost of the unit less significant, but the need to obtain a core sample rapidly and reliably on each downhole trip of extreme importance. Accuracy is less important because the variability of strata over relatively short depths overshadows any small variations in the core's state.

There are two specific problem areas in core rerovery where the use of downhole controls could be of help. The first is controlling the closing of the main ball valve on the core chamber. This would involve limiting the torque on the valve to prevent damage to it; monitoring the valve's face to insure it is clear before allowing the ball to actuate; and signalling to the surface when the valve is closed so the core can be brought to the surface. The second is maintaining the core at its downhole temperature and pressure while it is brought to the surface. 
Three basic techniques can be used as a power source to close the ball valve. One technique previously used is to trip a heavy tube on the drill string and allow it to fall. A rack-and-pinion arrangement attached to the tube and valve rotates the valve's ball as the tube falls. This arrangement does allow control of the closing torque by varying the tube's weight, which is directly proportional to the torque. However, the impact load on the gears and their exposure to the downhole fluids does frequently damage them, which prevents proper actuation.

As an alternative option, the use of a hydraulic or pneumatic actuator could be considered (Figure 10). Fluid powered equipment is ideally suited for a high force, low energy application where there are extreme space requirements. A hydraulic (liquid media) system would probably be more desirable than a pneumatic (gaseous media) system because the relatively incompressible liquid media would minimize impact loading from the jerking of the ball valve as it closes. However, the use of gas as a power source would be very desirable as discussed later.

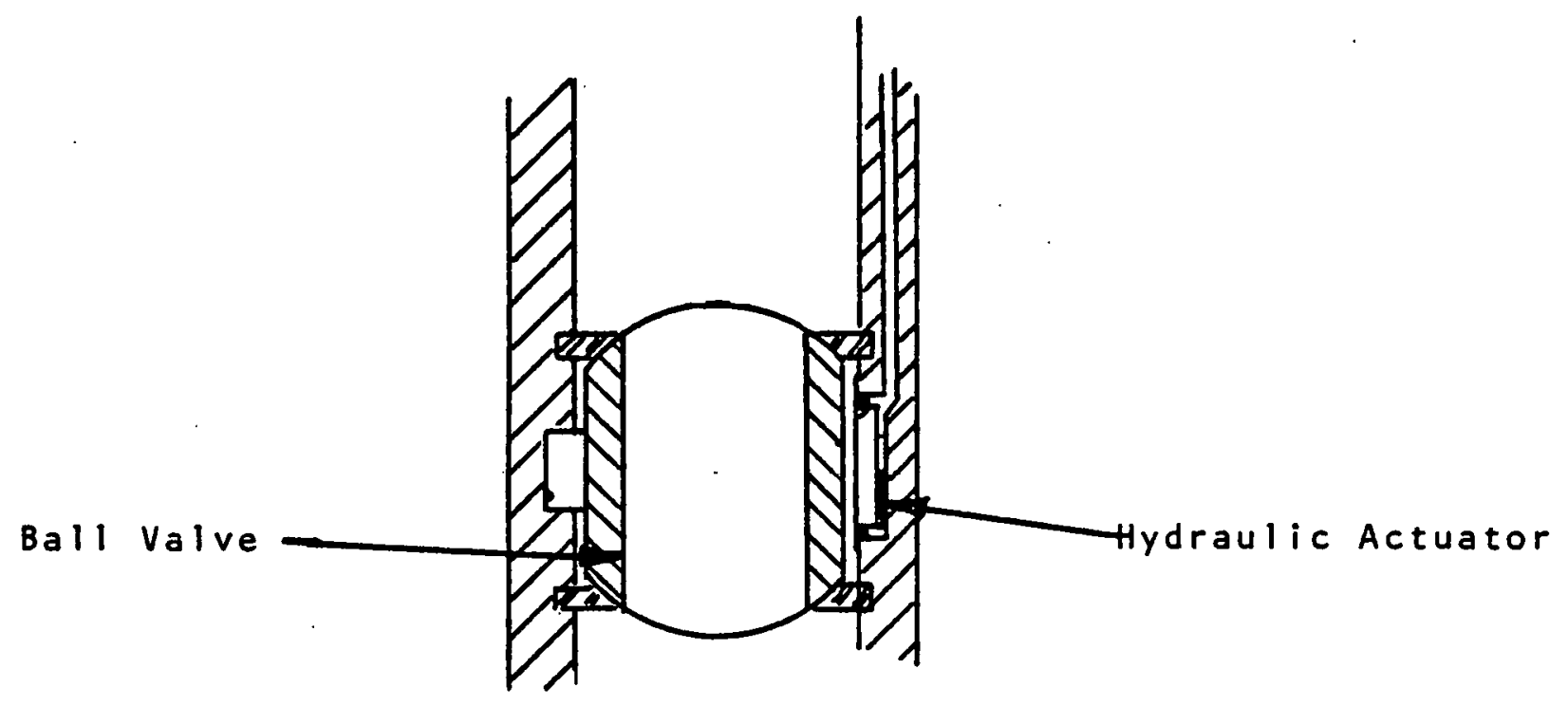

Figure 10

Hydraulically Actuated Ball Valve 
Hydraulic actuators would be used to close the ball valve. They could be vane type rotary actuators mounted on the side of the ball and direct coupled to its rotating shaft; or linear actuators mounted above the ball valve and connected to the ball's rotating shaft with a linkage. The rotary actuators would be most desirable because of their minimal moving parts and their direct coupling to the ball. Torque limiting of the closing would be accomplished by limiting the pressure difference across the actuators.

Because the actuation is a short term transient operation, the use of an accumulator for power storage would be very simple and reliable. A conventional hydraulic accumulator for this application consists of a pressure vessel, mounted on the core recovery system, partially full of hydraulic fluid. The remainder of the vessel is filled with compressed inert gas. A barrier consisting either of a sliding piston or a flexible rubber bladder is used to isolate the fluids. The gas stores the system energy and acts like a spring by keeping the hydraulic fluid at pressure.

One disadvantage to this concept is the pressure in the accumulator must be greater than the wellbore pressure, which for deep wells exceeds $10,000 \mathrm{psi}$. This requires high pressure accumulators and gas charging equipment which complicates the system. This can be prevented by dumping the hydraulic fluid into a second accumulator at a lower pressure than the first and thus isolating the system from the wellbore pressure. However, all hydraulic components. must be capable of sustaining the pressure difference between the hydraulic system and the wellbore which would make them considerably more massive. Also, a second accumulator would have to be mounted in the system.

As an alternative, the opposite of an accumulator could be considered. This might consist of a vessel mounted on the 
system and connecting it to the hydraulic control valve's low pressure side. The vessel would be sealed at atmospheric pressure and full of air. As the drill string is lowered downhole, a pressure difference will exist between the vessel and the wellbore. If the hydraulic control valve's pressure side is connected to the wellbore pressure, this pressure. difference would be used to operate the system,

In this configuration, all components would be at the wellbore pressure, except the vessel and low pressure side of the hydraulic valve. Actual drilling mud could be used as the hydraulic fluid or with the use of a barrier, hydraulic oil could be used, with wellbore mud pressurizing the oil.

The actuators would be controlled by a hydraulic valve mounted on the core recovery system. The activation of the hydraulic valve to close the ball valve could be accomplished with conventional techniques such as dropping a ball down the drillpipe to trip the valve open or use a mud pulse technique to actuate the valve.

Also, a downhole sensor that detects when a piece of core has been broken off and is held in the inner recovery tube could be used to automatically activate the ball valve without any communication from the surface. This sensor could consist of a "feeler whisker" set at the upper end of the inner tube. When the core moves up the inner tube, it would bend the whisker. The end of the whisker would be connected to a hydraulic switch that senses the bending and activates the hydraulic valve. The switch could be mechanically, hydraulically, or electrically coupled to the actuator's valve. An all mechanical coupling would have potential problems of reliability as well as the difficulty of packaging it in.a 
downhole system. A hydraulic switch could have some problems of reliability, but it would be relatively easy to couple to the hydraulic valve with hydraulic tubing. An electrical switch could be made to actuate most reliabily and would be quite easily coupled to the hydraulic valve; however, this would involve the added complexity of an electrical power source (batteries) downhole.

A third concept for closing the ball valve would be the use of an electrical motor for actuation. However, a motor and gear box with sufficient torque to actuate the ball valve would be very difficult to package for downhole operation.

All of the above valve closing concepts could be designed to not actuate if sensors detected a core or other obstructions in the ball valve. These sensors would consist of feeler whisker as discussed above. Also as discussed above, the sensor's switch could be either mechanical, hydraulic or electrical. If a falling tube is used for closing the valve, the switch could cause the retraction of shear pins that hold the tube. If hydraulic actuators are used, the switch could be tied to their hydraulic control valve as discussed; and for an electric drive, the switch could be connected to the motor's start switch.

For added reliability, the ball. valve's face sensors, as well as a sensor that detects full rotation of the ball, could be tied to a surface communication system to let operators know the status of the recovery operations. A system such as a mud pulse, or mud siren, could be readily used for this application. Communication to the surface, especially when the ball valve is clogged, would enable the operators to take corrective action when it is necessary and would inform them if the action was successful. 
Hydraulic systems could also be utilized to provide a positive opening force to insure relative movement between the outer tube and the inner tube (Figure 11). A similar téchnique could be used to provide hydraulic dampening (Figure 13) to reduce impact if outer barrel weight and/or other forces are used to provide relative movements. Another alternative is to use a simple set of fluid nozzles which use drilling fluid flow to provide hydraulic force to extend the outer tube (Figure 13). 


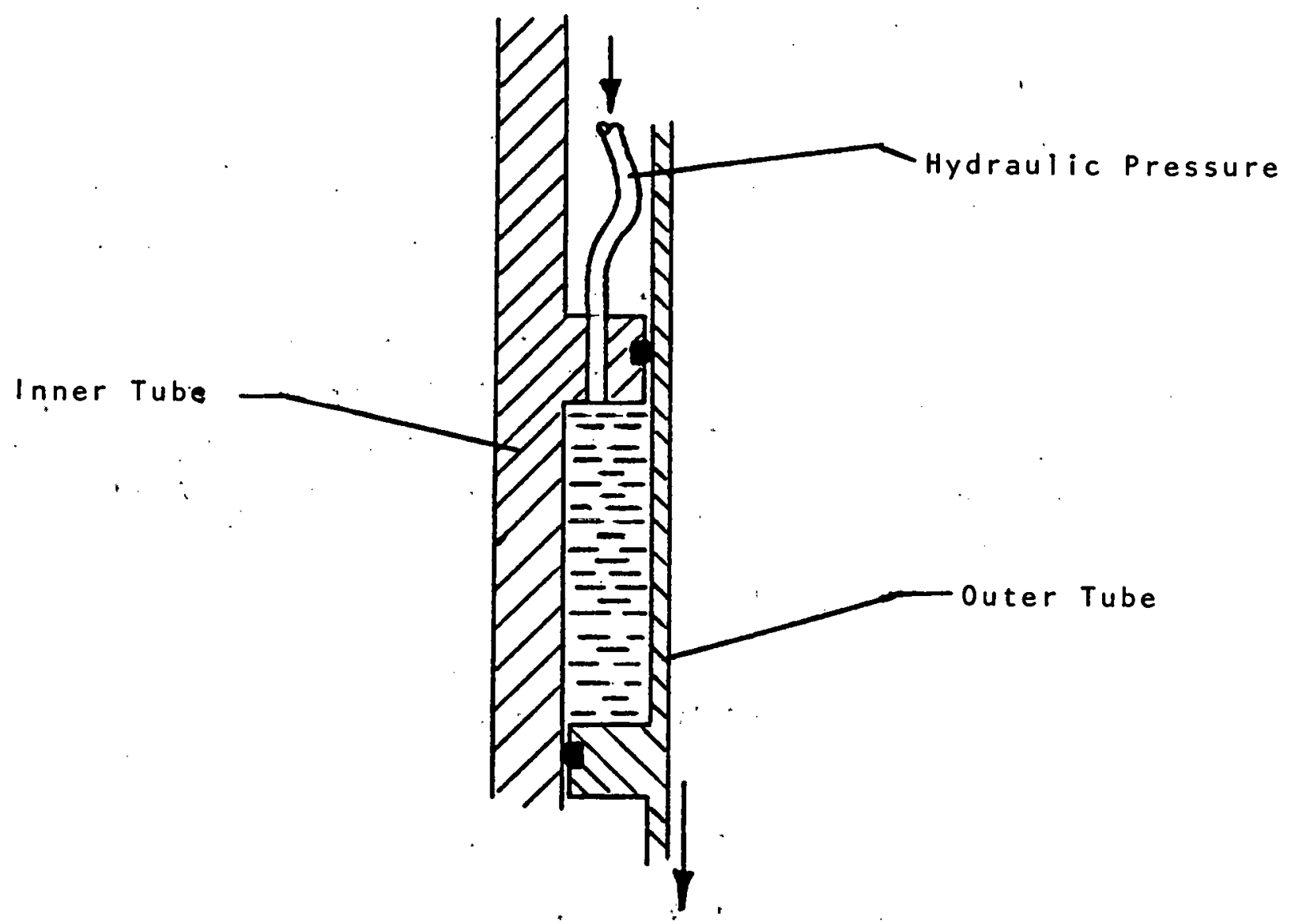

Figure 11

Hydraulic Extension of Outer. Tube

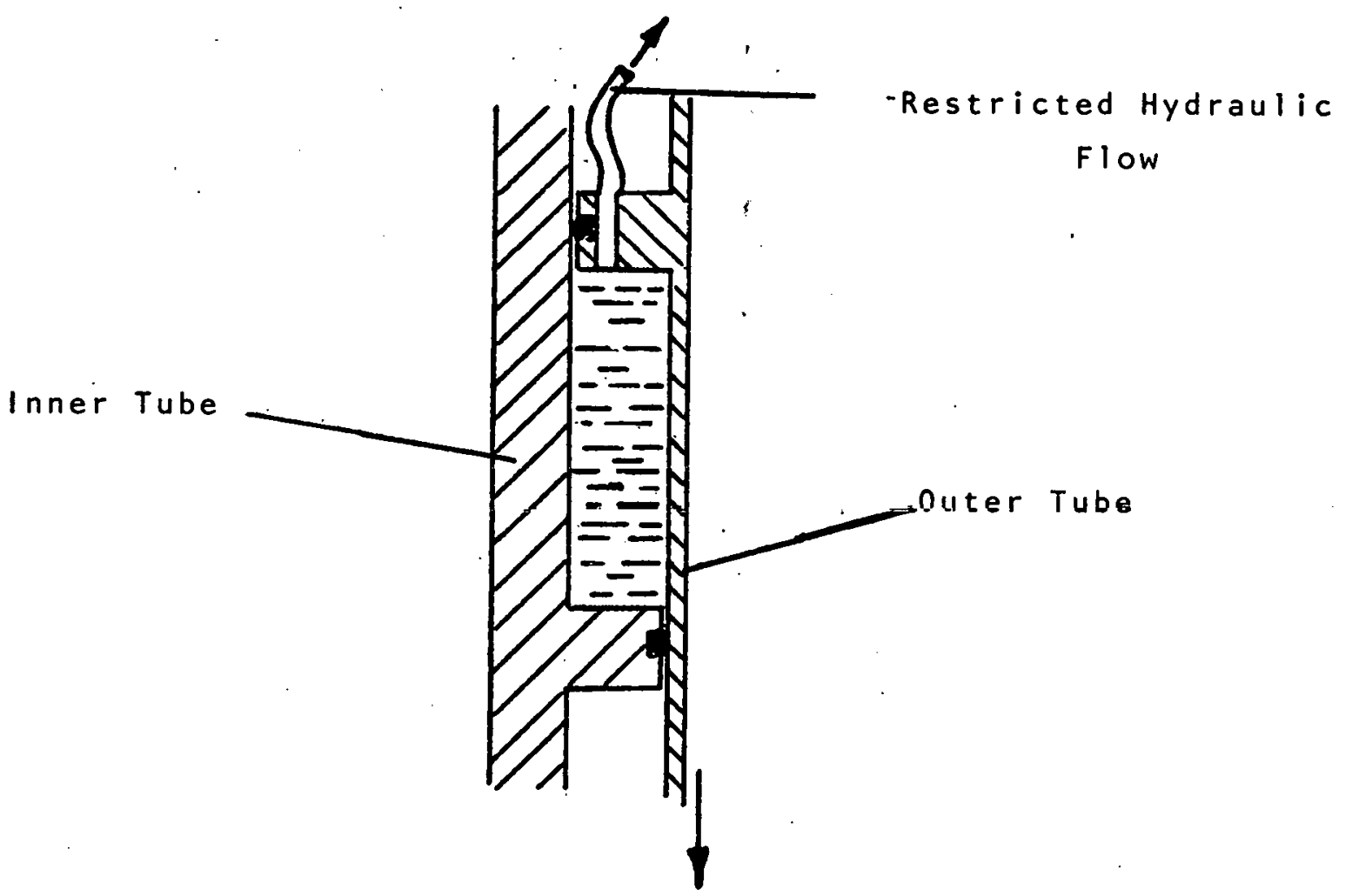

Figure 12

Hydraulic Damping of Outer Tube Movement 


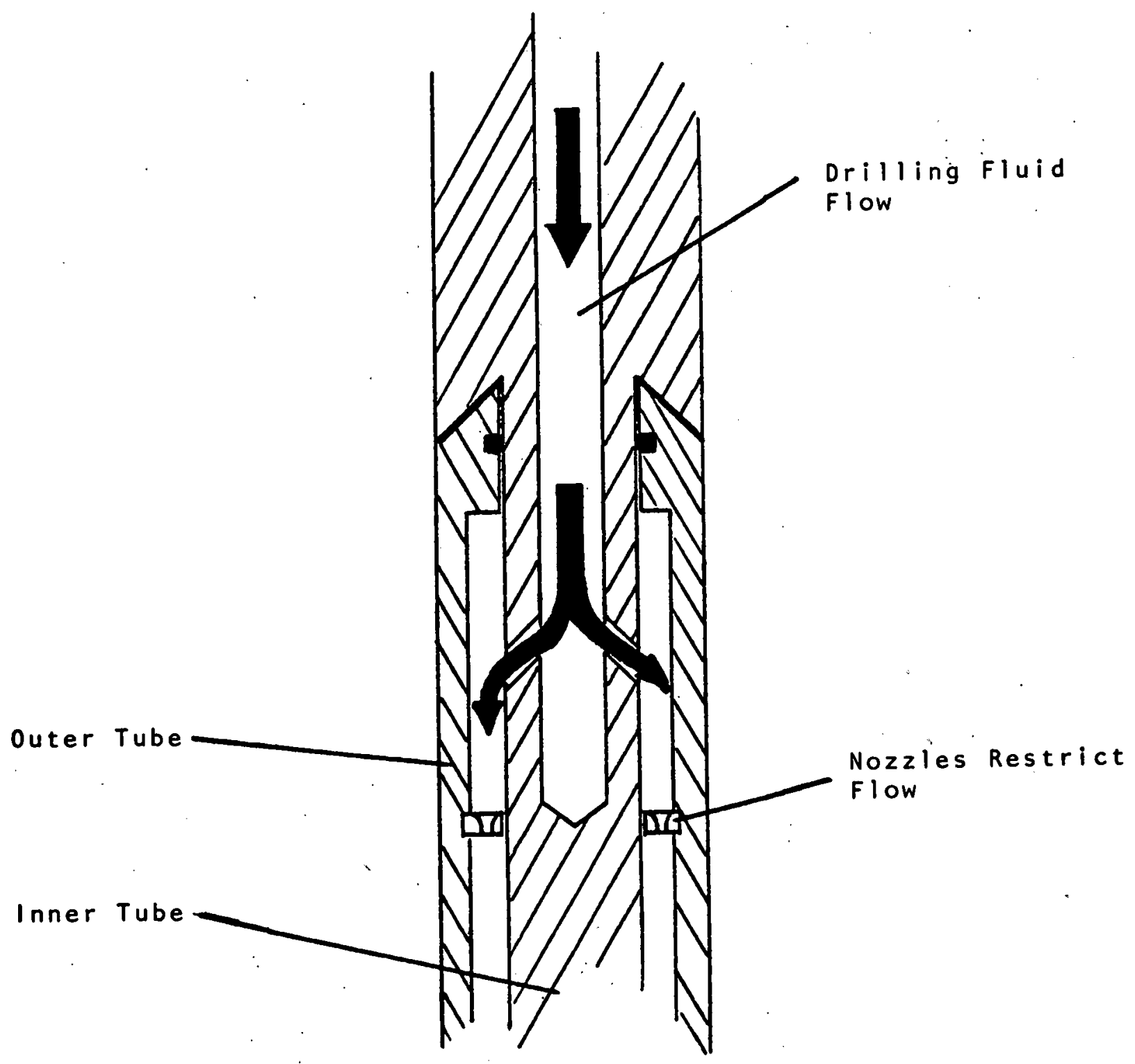

Figure 13

Fluid Nozzles Using Drilling Fluid

Energy To Extend Outer Tube 
The use of a non-invading and non-freezing gel inside of the inner tube and displaced by the core as it enters would simplify handling of the core under present techniques of freezing (Figure 14). The use of such a gel would eliminate the time-consuming and undesirable operation of removal of frozen drilling fluids from the core surface prior to analysis.

Surface handling and preparation for transportation could be further improved by reducing the problems involved in flushing drilling fluid from between the outer tube and the sealed core system. For example, an attachment could be designed to permit fiushing with the ball valve in an open position, thus reducing restriction of flushing fluid flow.

Handling of ten to twenty foot long cores at the surface is a significant problem. The present technique includes cutting the inner tube into short sections after the core is frozen. This inconvenient technique could be eliminated by designing an inner tube manufactured in short sections and designed for easy separation after the core has been frozen. 


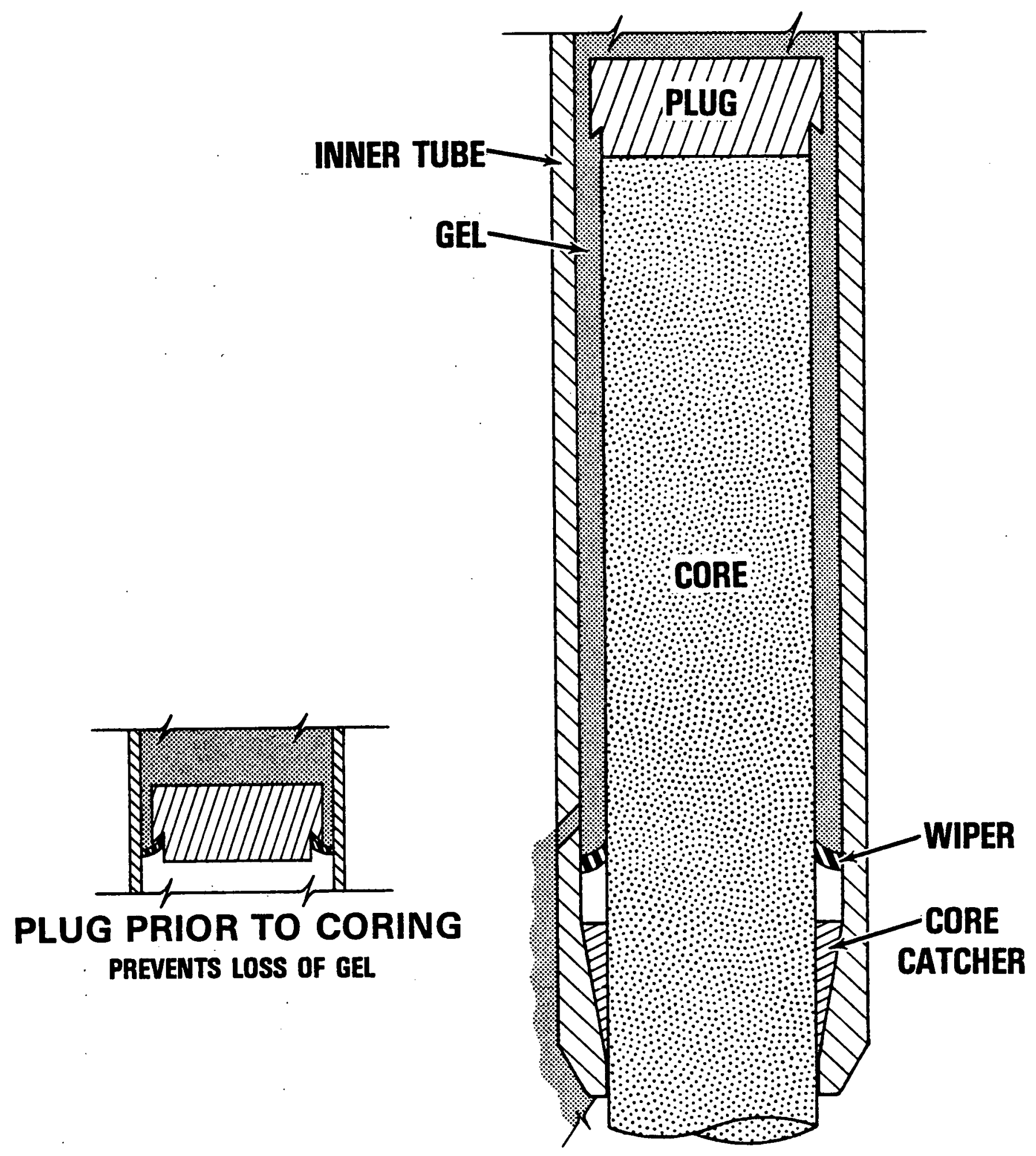

Figure 14

Non-Invading Gel In. The Inner Tube 
Core Transportation

The concepts of core transportation include all ideas that involve moving the core up the hole after it is cut and transporting the core to the lab for analysis.

The first part of this section discusses the consideratlons and concepts for "up and out of the hole." The second part of this section discusses moving the core "down the road."

Up and out of the Hole

Cores are normally recovered after the drill pipe is pulled out of the hole and the core barrel is then removed from the end of the pipe. Other concepts have been presented such as the one by Auld shown in Figure 15, where a wireline tool recovers the core barrel to the surface. This concept is less desirable because it is only able to recover a small core. It does allow continued coring without pulling the drillpipe, which gives a definite time and cost advantage.

Another concept for lifting the core is to reverse circulate or "float" it out of the hole and drop in another coring cartridge so that coring can continue. This 1968 concept by Elenburg is illustrated in Figure 16. With a tool such as Elenburg's, coring would be considerably faster, but would probably suffer from the same problem as the wireline retrlevable core; the core is too small. Also, with the complexity needed to encapsulate and trap the pressure in the core, an extremely complex tool would be required and reliability might suffer. 

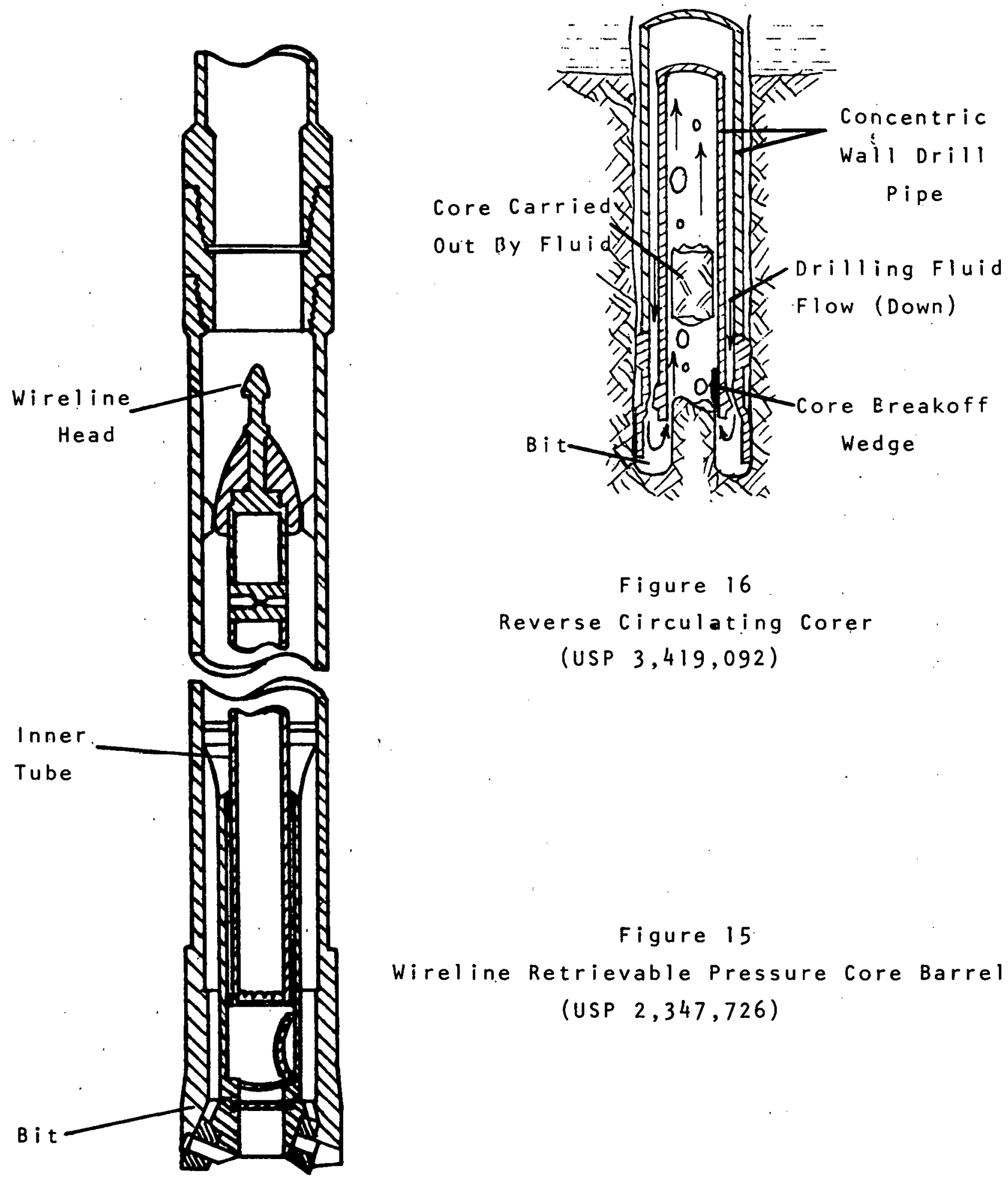

Figure 15

Wireline Retrievable Pressure Core Barrel (USP $2,347,726$ ) 
Another concept under consideration is to keep the core at reservoir temperature as well as pressure. This might preserve the formation wettability which has been shown to change during cooling - especially freezing the core. In general, the surface temperature and wellbore, as the core is withdrawn, is less than the sample's in situ temperature. Therefore, only sample heating will be considered. The most compact and easiest to control type of heaters for this application are electrical resistance. Exothermic chemical reaction type could be considered, but they require high pressure storage accumulators, as discussed above, as well as very accurate metering valves which would be difficult to make reliable. Resistance heaters of course do require the handling of electric powerdownhole and the packaging of batteries in the core recovery system. However, control of temperature would be quite straightforward with a simple instrument such as a bimetal switch.

The controlled temperature could be determined by measuring the downhole temperature and presetting the control before putting the system downhole. An alternative to eliminate the separate temperature measurements is to have the activation of the ball valve closure mechanism also "lock" the temperature control so it maintains the temperature it is at in the wellbore. This can be achieved by allowing the sensor to "float" at its null position until it is locked. At that point, it measures only deviation of temperature from the locked valve and applies heat to the sample until the deviation is nulled.

There are several reasons why the concept of temperature maintenance has been ignored to date. First, the cores would be extremely vibration sensitive and gravity segration would become a major problem or at least a dominant consideration. second, by using a simplified, finite element, heat transfer analysis as shown in Example 1 , we see that the amount of heat required could be tremendous. 


\section{Example 1 \\ Simplified Heat Loss From Core Barrel}

For a $10,000 \mathrm{ft}$, reservoir, keep the core at reservoir temperature while it is brought up the hole.

Reservoir Temperature $\left(T_{R}\right)$ is $300^{\circ} \mathrm{F}$ and the mud temperature $\left(T_{M}\right)$ at the surface is $100^{\circ} \mathrm{F}$.

\section{Assumptions:}

1) 10 increments for heat loss (1000 ft per increment)

2) $1 \mathrm{hr} / \mathrm{increment}$ or $10 \mathrm{hr}$ total time to come up the hole.

3) Conductivity (k) of core barrel is $26 \mathrm{BTU} / \mathrm{hr} f \mathrm{t}^{\circ} \mathrm{F}$

4) Core Barrel Length (L) $=30 \mathrm{ft}$

5) Outer and inner radii of core barrel are: $r_{0}=3$ in, $r_{i}=1$ in.

6) Mud temperature changes linearly from bottom to surface.

Heat loss equation:

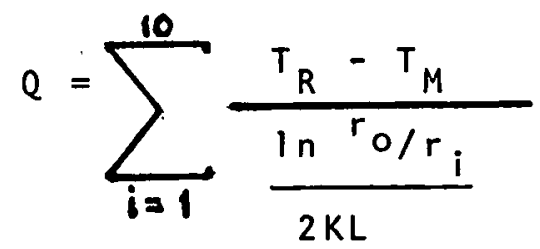


By figuring the average temperature difference in each $1000 \mathrm{ft}$ increment and summing, we find that the total heat loss would be :

$$
\begin{gathered}
Q=3,236,913 \mathrm{BTU} \\
\text { or } \\
Q=944 \mathrm{kw}-\mathrm{hr}
\end{gathered}
$$

The heat loss is equal to the amount of heat energy required to keep the core at a reservoir temperature of $300^{\circ} \mathrm{F}$.

For the particular case shown in Example 1 , the total amount of make-up heat would be about 3.2 million BTU, or $944 \mathrm{kw}-\mathrm{hr}$. No battery system could possibly supply this amount and a large cable to a surface power supply would be required. The drilling mud could be used to heat the core if it were kept near reservoir temperature in a zone around the core barrel as it was brought to the surface. This would require a pressurized mud system to prevent boiling at the surface. Continuous circulation during the trip out would also be required.

The opposite approach could also be used; that is, freeze the core at the bottom of the hole and bring it up frozen. In this case, pressure retention would be less important. One immediate problem with this concept is that a tremendous refrigeration system would be required or alternately an insulated pipe to the surface could supply liquid nitrogen or solid carbon dioxide to freeze the core. A problem exists if the mud also freezes in the hole, the possibility of sticking the tool and pipe might exist. 
Wellbore pressure could also be maintained on the core as it is removed from the hole. Conventional techniques are a pre-charged gas chamber and pre-set regulator valve. This provides a very reliable technique for pressure control. one possible improvement would be to use a small pressure chamber as a reference for control of the core tube pressure. When the ball valve is actuated, the reference chamber is isolated or "locked" to maintain the wellbore pressure.

The regulator valve would then sense the deviation of the sample tube and reference pressure and maintain the tube at the reference pressure. All of the above sensors and controls are mechanical or hydraulic. More sophisticated and compact equipment could be developed using electronic circuitry and transducers. However, the wellbore temperatures (often. in the $300-550^{\circ} \mathrm{F}$ range) would require some form of cooling of the electronics in order to protect the circuits. Also, the extreme vibration loads from drilling would pose considerable reliability problems.

A concept using a system of spot coring, which means core a section, continue drilling and core another section, would reduce the problem of handling. Then all sections of the cores would be sealed and brought to the surface. This would add to the coring tool's complexity, but would allow small sections of core to be taken economically through a thick formation.

At the surface, the core might be more easily handled by a sectioned inner barrel whereby pressure is maintained on each section. 
After the core is to the surface, it must be transported to the lab for analysis. One concept that should be considered is to bring the lab to the rig site. This would reduce core handli.ng and improve the dependability of results. No special transport trucks would be needed, but a specially equipped mobil van would be needed on site:

Presently, in preparation for transport, the cores are frozen and chopped into lengths suitable for people to handle and keep frozen during transport. A better idea would be a sectioned core barrel which would come apart but still remain sealed. This would add some complexity but might give a better chance of always having some good sections on each coring run. This, coupled with a non-freezing gel built into the core barrel container, would greatly simplify the eventual analysis. Frozen mud around the cores continues to be a problem when the cores are finally retrieved from their pressure containers. Core damage would be avoided if no frozen mud had to be chipped off and preparation labor costs would be reduced. 
If the cores are heated and handled hot, a short, convenient length is required. Also, vertical transport might be desired to minimize gravity segregation. Vibration in transit might be the biggest disadvantage because of its possible effects on the fluids, their positions and relative saturations in heterogeneous cores. With all of the other requirements of recovering heated cores mentioned previously, this concept will be tried only in a very expensive and sophisticated coring system.

A final concept to consider while transporting core sections is a standardized container with a built-in temperature controller which would maintain core temperature during transit and allow direct plug-in of power for changeover at the lab site. This would delete the need for special trucks or trucks with special chamber attached and would minimize handling as much as possible. This concept could be used to keep the cores frozen or at reservoir temperatures, whichever was most desirable.

\section{Core Analysis}

A concept which bears further study is that of analyzing the core at the bit as the core is taken. If it were possible to perform all or at least critical parts of the desired core analysis at the bit under bottom hole temperature and pressure conditions, the difficult task of sealing the core, transporting it to the surface under in-situ temperature and pressure conditions, transporting it under the same conditions to the analysis site, and then analyzing the core under pressure and temperature might be greatly simplified.

It is technically feasible to perform at least part of the tests on the core in the core barrel at the bottom of the hole as the core is cut. For example, core saturations 
could be determined through a combination of nuclear, sonic and electrical sensors, Such an in-situ determination of saturations might eliminate the necessity of transporting the core to the surface under pressure and temperature. A conventional core barrel might be used to recover the core for geological examination and measurement of permeability under restored core conditions. Also eliminated might be the need for high pressure, high temperature core analysis laboratory equipment.

Two important trade-offs must be considered:

1) Is it technically and economically more advantageous to perform the required saturation or other analyses at the bottom of the hole?

2.) Are results of such measurements sufficiently accurate to meet requirements?

Conventional wireline logging methods have been used for many decades to determine formation porosity and fluid saturations. These measurements are hampered, however, by the fact that these measurements must look from the hole out into the formation through mud, mud cake, mud filtrate and the invaded part of the formation in an attempt to make measurements which represent the true formation and its fluids. A logging system in which an unaltered sample of the rock is taken into a chamber with the proper type and configuration of sensors should be capable of providing accurate, reliable determinations of porosity and fluid saturations. Needless to say, the success of such a system is dependent on getting a true sample of the rock and its fluids. However, the same constraint is placed on the true 
fluid coring system even if the sample were transported to a remote laboratory for analysis.

Such a system might appear similar to the one shown in Figure 17. Data could be transmitted to the surface in real time or could be recorded downhole for later study. Most likely, however, the core would be recovered for correlation studies and for other measurements (such as restored 3-phase relative permeability) which could not be performed downhole.

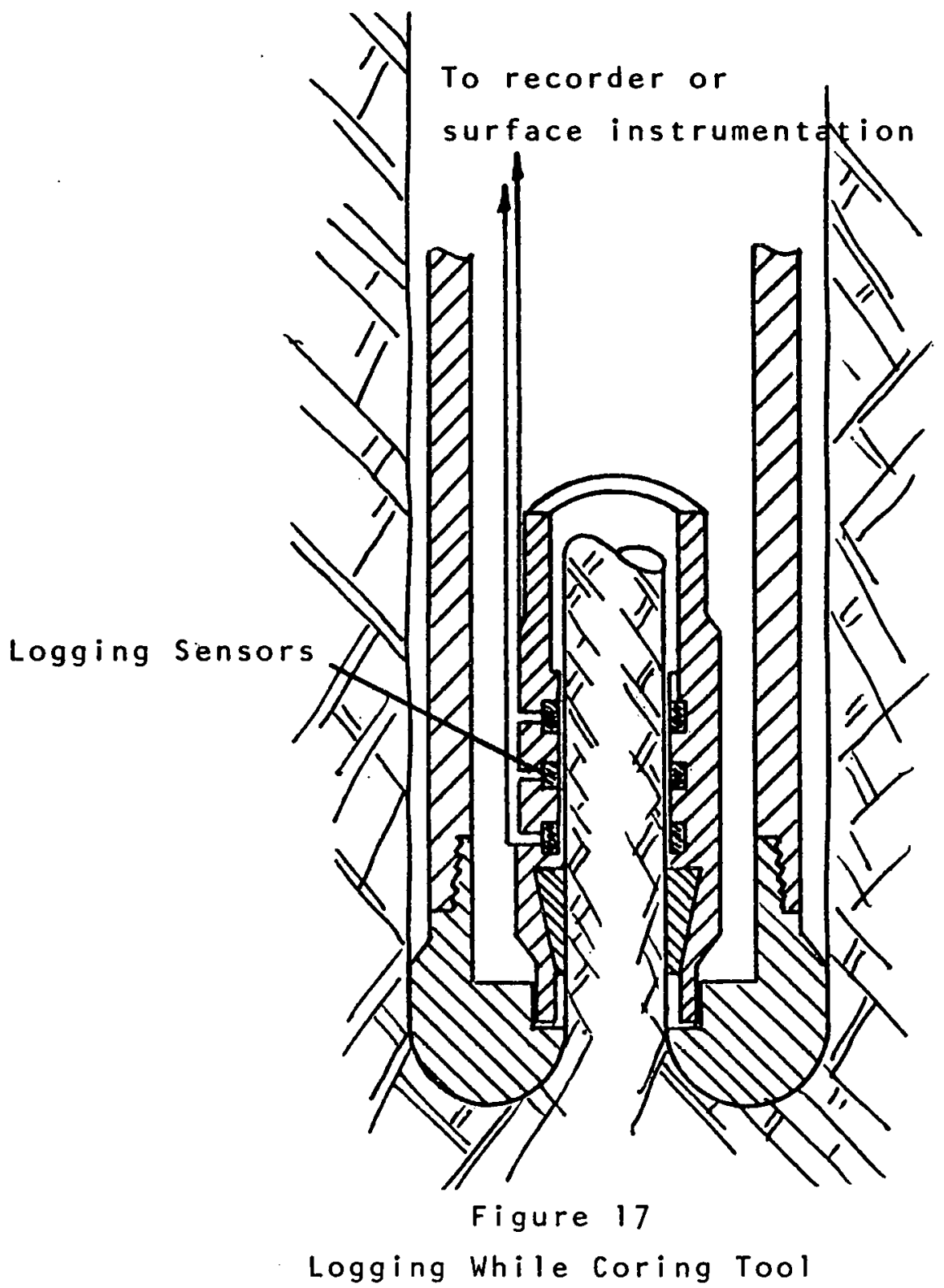


If results of this approach were accurate enough to eliminate surface requirements for actual core, it could be crushed and flushed to the surface after analysis (Figure 18). This would permit continuous coring through the entire zone of interest.

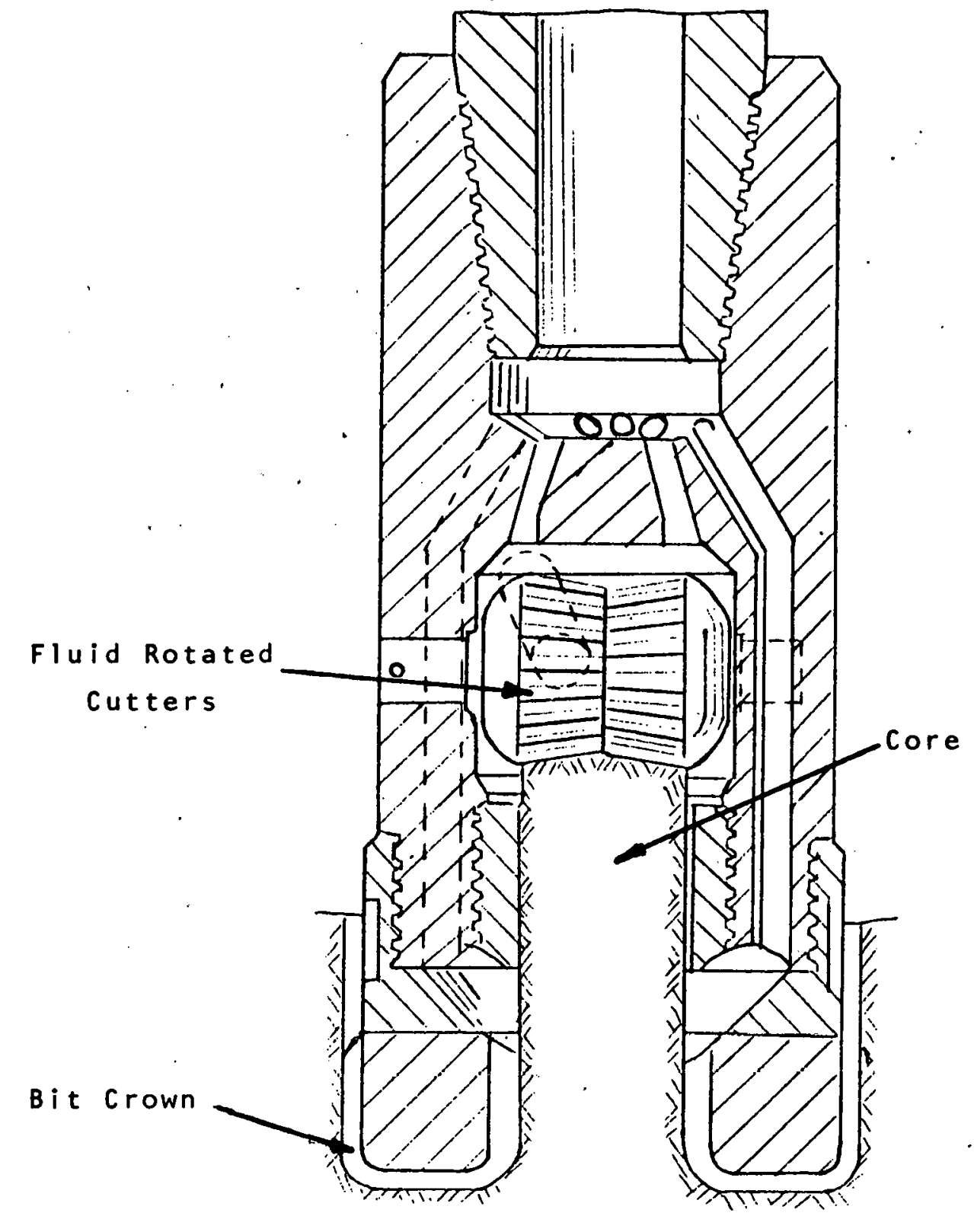

Figure 18

Turbine Core Disintcgrating Bit (USP 2,975,849) 


\section{FEASIBILITY OF A TRUE FLUID CORING SYSTEM}

The objective of this entire study was to determine the feasibility of obtaining unaltered true fluid samples of oil and gas reservoirs. After having examined the problem and many alternative solutions, we have determined that there is virtually no probability of obtaining completely unaltered samples. Any technique within the bounds of a practical bore hole size must alter the reservoir slightly. However, there is an acute need for accurate fluid saturation in reservoir production planning. This need is so great that $100 \%$ accuracy is not absolutely necessary and a system which approaches true results would be acceptable. It is felt that there is a very good probability that a system can be developed which will give results much improved over present techniques which cause flushing of $50 \%$ to $100 \%$. It is desirable to reduce flushing to less than $10 \%$.

The present Loomis pressure coring system is believed to give results approaching this accuracy under certain field conditions when the system functions properly. The design concepts for a Phase 1 True Fluid Coring System which can routinely and reliably achieve results approaching $90 \%$ accuracy is thought to be not only feasible but also within the practical normal economics of drilling operations.

The development of a Phase 1 system wili require several parallel effort programs requiring about 18 months from inception to field test of a prototype coring system. These parallel efforts include the design and manufacture of a prototype coring system, the laboratory evaluation of the influence of bit design on fluid invasion and the manufacture of an optimum bit design, and the evaluation of drilling fluid additives to reduce fluid invasion. No dramatically new technology 
development is required to develop this system. The fact that such a system has not already been built can be attributed to the lack of unified effort and economic incentive to develop such an integrated system.

Several very sophisticated system concepts appear capable of reducing flushing to the $2 \%$ to $5 \%$ range. Development of such a system would only be possible under an "unlimited funding" approach with the evaluation of alternatives, development of new technology, and design and development of prototype for field testing requiring a minimum of five years. While this type of accuracy is not needed at present, future needs and increased concern over maximum energy production may require that a very sophisticated coring system be developed. 


\section{$X$. PHASE $I$ SYSTEM}

The Phase 1 True Fluid Coring System is thought to be feasible. It should be capable of significantly improved results over currently available systems. This system (Figure 1) would cut and recover a core maintained under bottomhole pressure but not temperature, and would rely on the freezing technique to permit handing and transportation of the core to the analysis laboratory without pressure maintenance. The system would have the alternative capability of being manufactured to take a very short (e.g. 5 feet) core which could be maintained under pressure at the surface for special applications such as the tight gas sands where freezing might be detrimental to accurate analysis. The design parameters considered essential to this Phase 1 system are described below:

1) The inner tube system would be sealed at both top and bottom by hydraulically actuated ball valves.

2) The bottom ball valve should be mounted in an outer tube sub to permit maximum core size.

3) There should be a sliding intermediate sleeve to provide a sealed chamber between the lower end of the inner tube and the ball valve sub in order to minimize the volume of trapped drilling fluid and reducing the total weight of the equipment to be handled at the surface.

4) There should be a by-pass or dump valve provision either in the barrel or located immediately above the barrel to permit by-passing most of the drilling fluid without circulating through the bit. 


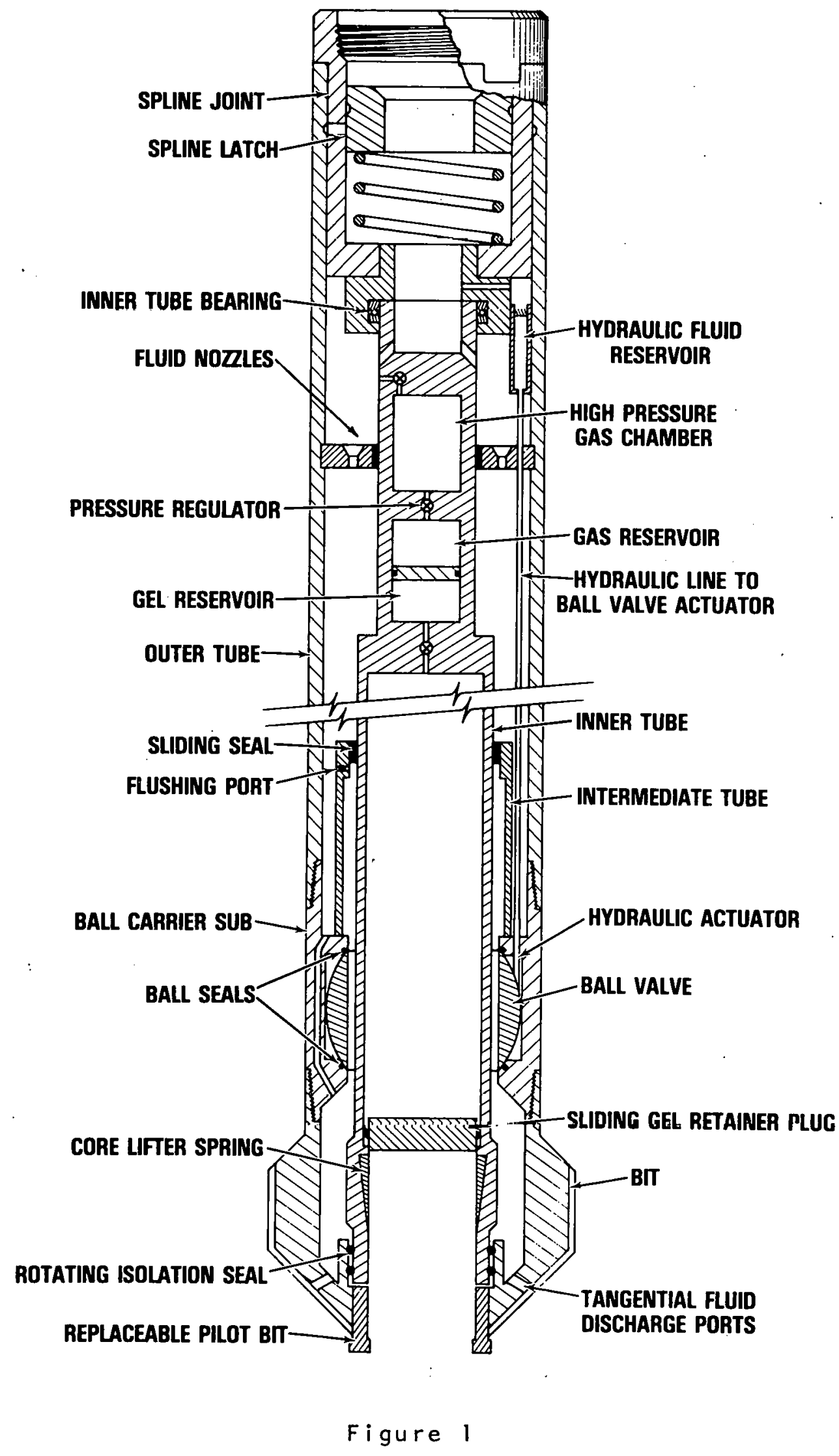

PHASE I PRESSURE CORING SYSTEM 
5) The coring bit itself should be designed with a tapered crown to direct the influences of dynamic fluid invasion away from the core. The bit should also include a replacable pilot bit to provide further isolation of the core from the drilling fluid.

6) The bit should utilize tangential face discharge of the drilling fluid to provide optimum cleaning at low fluid velocities.

7) There should be a viscous, non-invading gel inside the inner tube to be displaced by the core as it enters the inner tube. This gel should not freeze when the core is frozen with dry ice.

8) There should be a provision for a sliding plug to retain the gel in the inner tube until coring has started.

9) There should be flow channels provided to allow the extruded gel to clean and cool the pilot of the coring head.

10) There should be a sleeve in the core bit with a rotating seal at the lower end of the inner tube to provide complete isolation of the core from the drilling fluid at that polnt.

11) There should be fluid nozzels attached to the outer tube to provide a positive force assisting extension of the spline and retraction of the inner tube through the ball valve.

12) There should be adequate clearance between the lower end of the inner tube and the ball valve to insure that the ball valve will not be blocked by a core 
protruding slightly below the bottom end of the inner tube:

13) It is desirable that the system be designed with sensors to detect and provide surface indication in the case of critical operational failure (e.g. a fluid flow restriction would indicate failure of the ball valve to close completely).

14) Provision should be made for removal of trapped drilling fluids by flushing at the surface through the opened ball valve without loss of bottom hole pressure.

15) The inner tube should be designed in short 2-5 ft. sections easily separated at the surface after the core has been frozen to facilitate handling.

16) Since the core will not be locked inside the inner tube by frozen mud, an alternative system should be considered to permit the core to be hydraulically removed from the inner barrel after freezing for sectioning and placement into sealed containers which are capable of temperature maintenance during transportation to the lab. 


\section{PHASE 2 SYSTEM}

A highly sophisticated true fluid coring system can be built if adequate time and funds are provided. The practical value or even the necessity for such a system is dependent on the outcome of field trials of a Phase 1 system. For example, a Phase 2 system may be necessary to overcome the problem of fluid invasion during the actual coring operation. on the other hand, if bit design, fluid by-passing, and other concepts in the Phase 1 system substantially eliminate this invasion problem, the necessity for a Phase 2 system is not as great.

Since an advanced irue fluid coring system is envisioned essentially for the purpose of solving the invasion problem, any Phase 2 system must address this problem first. Several interesting alternative concepts have been proposed for handling the core and analysis. Regardless of the alternative taken, however, at least a portion of the system will be basically the same.

The basic system will include a core barrel run below a packer to isolate the reservoir rock from the conventional drilling fluid (Figure 1). A closed circulating system below the packer will utilize a special non-invading circulating fluid with the pressure of this fluid being balanced to match reservoir pore pressure, thus eliminating hydrostatic overpressures. The conventional fluid circulation above the packer will be maintained to condition the hole and to drive a mud motor providing hydraulic, mechanical and electrical power for operation of servo-controls and sensors in the coring system. Rotary power will be provided by the drill string from the surface or by a mud motor or an electrodrill (in which case, there would be direct communications with the surface and the need for downhole power generation would be eliminated). 


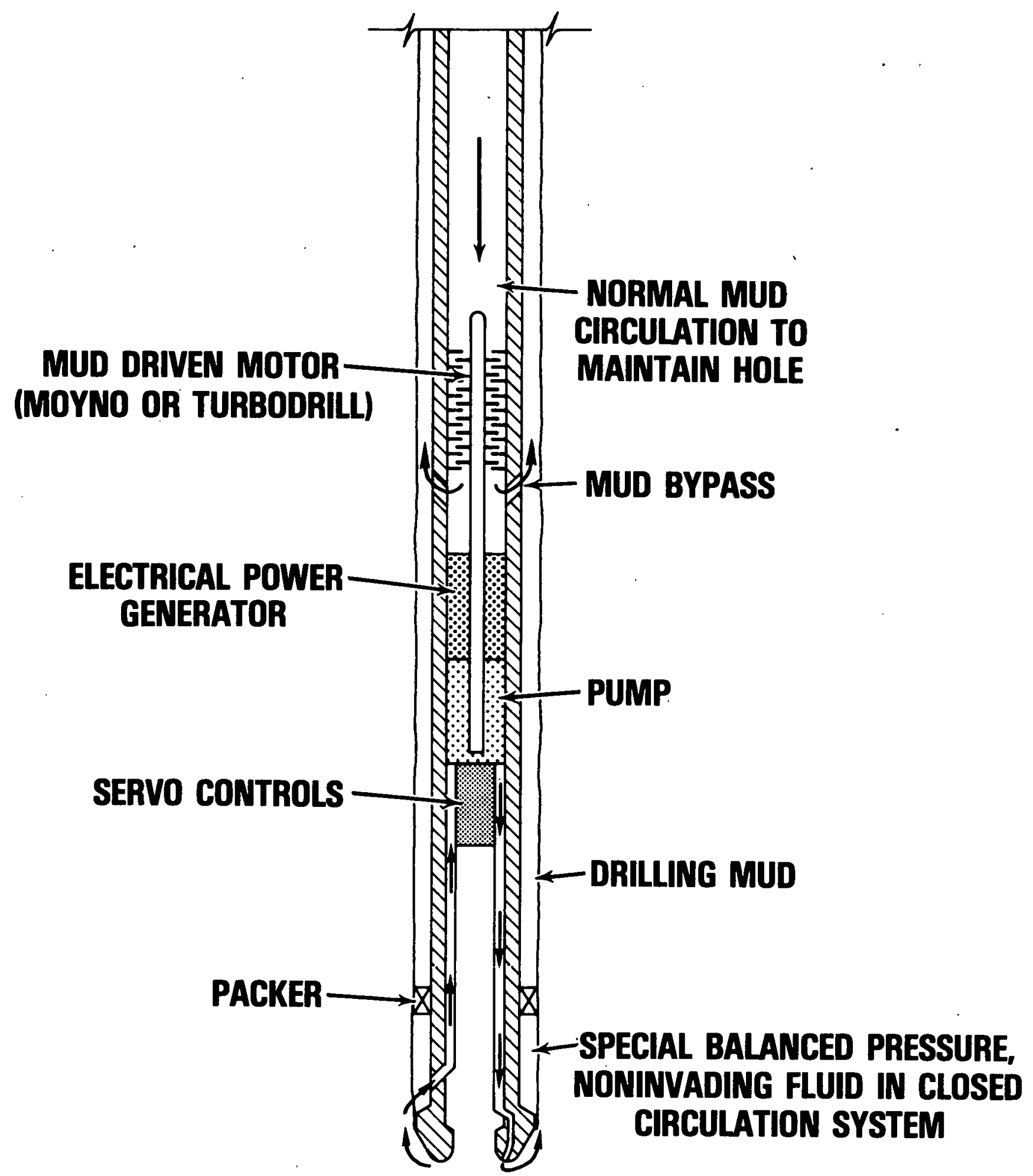

Figure 1

Advanced Pressure Coring System 
In one alternative, the core barrel would consist of a pressure coring system capable of maintaining pressure and temperature during the trip to the surface. Since the pressure and temperature conditions must be maintained at least through some point in the analysis cycle, it is probable there would be provision for on-site analysis in order to minimize the problems associated with maintaining pressure and temperature. The pressure coring system would very likely be an evolutionary design based on Phase 1 experiences.

With another alternative approach, logging sensors would measure reservoir properties as the core passes through the lower end of the inner tube. The coring system could be designed with or without pressure and temperature maintenance capabilities as required, With advances in logging techniques, this approach may supercede the other more normal coring schemes since accurate property measurement downhole would eliminate pressure maintenance and surface handing problems that greatly complicate the tools design. 
Final Report

\title{
A STUDY TO DETERMINE THE FEASIBILITY OF OBTAINING TRUE SAMPLES OF OIL AND GAS RESERVOIRS
}

\author{
Appendix
}

\author{
by \\ Charles E. Ward \\ A. Richard Sinclair \\ Maurer Engineering Incorporated
}

for

The Energy Research and Development Agency

Fossil Energy Division

Project No. EY-76-C-02-0035. ${ }^{*} 000$

Report No. BERC-0035-11

Attention: Mr. Ray Williams

December, 1976

TR76-24

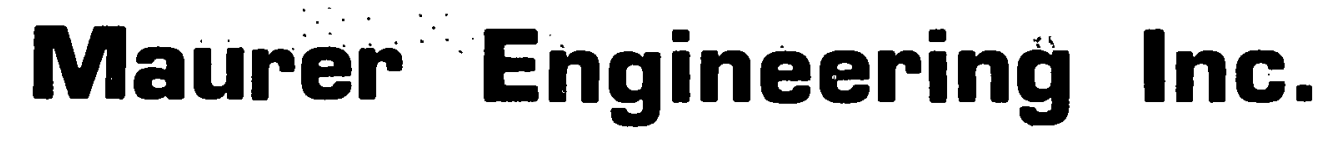

10301 NW FREEWAT SUITE 202 - MOUSTON, TEXAS T7092:(713)683-8227 


\section{APPENDICES}

APPENDIX A Conventional and Special Core Analysis

APPEHDIX B Patents

APPENDIX C Literature Search 
CONVENTIONAL AND SPECIAL CORE ANALYSIS PROCEDURES

1. Introduction

11. Pressure Core Analysis

A. Introduction

B. Retrieval and Transport

C. Laboratory Analysis

111. Conventional Core Analysis

A. Conventional (Plug-Type) Core Analysis

1. Summation of Fluids Method

2. Dean Stark (Solvent Extraction) Method

B. Whole Core (Full-Diameter) Core Analysis

C. Side Wall Core Analysis

D. Supplemental Tests

IV. Special Core Analysis

A. General Discussion

B. Sample Preservation, Packing and Shipping Procedures

C. Capillary Pressure Tests

D. Water Permeability

E. Formation Resistivity Measurements

F. Water Flood Tests

G. Relative Permeability

H. Overburden Permeability and Porosity

1. Residual Gas

J. Thermal Recovery Tests

K. Caprock Analysis

L. Rock Compressibility

M. Wettability Studies

N. Acoustic Velocity

0 . Surface and Interfacial Tension

P. Sieve Analysis 
Q. Sample Preparation and Selection

R. Petrographic Studies

5. Determination of Hydratable Clay Content

T. Pictures

U. Production Research

V. References 


\section{INTRODUCTION}

An important need for current and future planning is to be able to determine directly the oil or gas in place in a reservoir. This need exists both for new reservoirs, for the purpose of accurately determining the reserves of a company or the nation, and for depleted or partially depleted reservoirs for the purpose of establishing the efficiency of production practices or for studying the feasibility of secondary or tertiary recovery procedures. Current industry practice is to determine porosity and water saturation and calculate the volume of hydrocarbon in place by the difference of the pore volume and water volume of a formation. This places an important accuracy requirement on both the porosity and water saturation values. Two methods that may be described as direct are in use to determine residual oil saturation at floodout conditions, the log-inject-log method and the single well tracer ${ }^{2}$ method. Both of these methods have important limitations.

In addition to the need to know the quantity of oil or gas existing in a reservoir at any state of depletion, it is important to know the positions in the rock pores occupied by oil and water. The energy existing on the interfaces of the fluids and rock, or the surface kinetics, greatly influences the relative position of the fluids or the state of wetting of a formation. These characteristeristics, working together with the pore geometry, viscous character and relative quantities of each fluid, control relative permeability, and the quantity of residual oil remaining in the formation at depletion. It would be very desirable to know the wetting of the formation and contained fluids to be able to predict the amount of oil that can be produced and also for engineering analys is of secondary and tertiary recovery systems. However, 
the possibility of altering the surface kinetics or wettability, of the reservoir is always present with cur rently available coring techniques.

The oil and gas industry does not yet have a coring tool that will recover unflushed and unaltered core. Filtrate from the drilling fluid flushes and replaces some or most of the native pore fluids from the formation as the core is being cut. As the core is brought to the. surface, the gases dissolved in the residual. formation fluid expand and drive out a varying portion of the liquids in the formation pores after the cutting process is completed.

Flushing is generally believed to occur to a depth sufficient to flush cores up to $3 \frac{1}{2}$ inches in diameter across the complete face of the core. Larger diameter cores may have an unflushed portion at the center, (depending on permeability) but it cannot safely be assumed that the native fluids in the portion not fiushed by drilling fluid filtrate are in their in-situ positions and quantity. 3 In the majority of cases, where the permeability of the formation is greater than 1 to $5 \mathrm{md}$, the hydrocarbon saturations are reduced to residual values by filtrate when coring with water base mud. Flushing occurs slightly ahead of the coring bit except where low vertical permeability prevents it. Where vertical permeability is low, the cores may not be fully flushed to residual (minimum) hydrocarbon saturation values.

The liquids in the pores of core samples nearly always have some dissolved gas in them. As the confining pressure is reduced by bringing the core to the surface, a point is reached where the gas breaks out of solution. From that point on, the expanding gas drives liquid from the core until the relative permeability to gas is 
100 percent. The mobile fluid phase, usually a combination of drilling fluid filtrate and native formation water, is expelied by the expanding gas. The residual liquid oil provides most of the solution gas, and the oil shrinks significantly as the gas is liberated. Small quantities of liquid oil may be displaced by the expanding gas. Similar alterations occur if oil or gas drilling fluids are used. A pressure retaining core barrel, 4,5,6,7,8 designed to permit taking cores up to 10 feet in length, is in use in the industry that retains the fluids in the core as they exist in the core barrel at the bottom of the hole, after the core is cut. The flushing has occurred but the additional alteration of the fluid saturation caused by pulling the core to the surface is avoided. 


\section{A. Introduction}

In the body of the report, a detailed analysis of the pressure core analysis has been presented to shed light on what additional steps need to be taken to provide a true fluid core. Pressure core analysis has been a giant improvement over the conventional cores because it provided much additional information and at the same time caused much more care and planning to go into the coring process.

In this section of the appendix, a summary of the additional requirements and tests on pressure cores will be presented. Much greater detail of the entire pressure coring process is presented in the text. 


\section{B. Retrieval and Transport.}

Pressure cores are presently retrieved by either a Loomis or Shell-Christensen apparatus - with Loomis being the only pressure core barrel now in use. This double barrel captures the:core and a ball valve is closed which seals in the pressure as the core is retrieved to the surface. Reservoir formation pressure is maintained in the core; however, temperature is not controlied and will depend on mud temperature.

The pressurized core barrel is removed from the tool, cleaned and frozen to be ready to transport the core to the lab. After freezing, the core is sectioned and kept under frozen conditions as it is brought, usually by special truck, to a laboratory for analysis.

\section{Laboratory Analysis}

Much preliminary lab work is required before analysis can begin on the pressurized core. At the lab, the metal piressure barrel is removed, again under frozen conditions. Frozen mud is removed from the core by a laborious hand cleaning and shipping operation.

The cores are cut into $4^{\prime \prime}$ and 8 "cylinders to yield full diameter specimens, and plugs ( 1 "or $1-1 / 2$ ") are drilled from part of the core. All of these cores are sectioned or cut under controlled, frozen conditions. They are now ready for complete analysis.

Laboratory analysis begins with a complete description of the section of core to be analyzed. The following steps show what is required to get a permeability measurement: 
(1) The frozen full diameter sample is measured for length, diameter and weight and is placed in an air tight container. A quick (15 second) vacuum is applied to remove air surrounding thë sample within the container.

(2) The sample is then allowed to thaw overnight. Gas evolves during the thawing process and expands. The gas is trapped, and its volume is measured.

(3) Composition of the evolved gas is determined by chromatograph (when there is a need to know).

(4) Heat is applied to the core container to vaporize the oil and water - which are recovered in a calibrated receiving tube attached to the underside of the container. The receiving tube is submerged in liquid nitrogen, or a suitable coolant, to condense the vaporized fluids. See Figure 8 .

(a) $450^{\circ} \mathrm{F}$ and vacuum application is used in some processes. This effectively cleans and dries the core if oil gravity is $35^{\circ}$ API or above.

(b) $250^{\circ} \mathrm{F}$ and no vacuum will remove all water and some oil. The core must be weighed, oil extracted by an independent process and the core re-weighed to find the additional oil removed during this subsequent cleaning.

(5) After the core is cleaned and dried, the pore volume is determined using one of several suitable techniques. Porosity (pore volume divided by bulk volume) is then computed. 
(6) Permeability is determined on the clean, dry core.

Along with permeability, porosity and oil, gas and water saturations are the principal measurements that are made on unflushed, pressure-maintained cores. Of these measurements, the oil, gas and water saturation measurements are the most important since they would represent values that cannot be determined otherwise. Adequately accurate permeability and porosity values can be obtained from conventionally cut cores in most cases. Where a formation is unconsolidated, such as many in California, the analysis of pressure-maintained cores may yield more accurate porosity values.

It must be emphasized that the volume of oil determined to be present in unflushed, pressure-maintained cores would be the best possible evaluation of oil reserves, both for new reservoirs and for reservoirs at flood-out. The volume of gas produced from such cores and a compositional analysis of the gas would also be important and would be an early indicator of the quality of the oil, the gas-oil ratio, and the bubble point, or perhaps the dew-point if one exists. 
III. CONVENTIONAL CORE ANALYSIS

A. Conventional (Plug Type) Core Analysis

Conventional or plug analysis is the type most frequently employed. It involves the use of a relatively small sample of core to represent an interval of formation to be tested. It is used where the uniformity of the reservoir formation permits such a sample to accurately represent the interval.

(1) Core sampling and preservation. Analytical data can be no better than the sample from which they are obtained. Thus, it is essential that the samples be properly preserved until the analysis can be performed. Prior to sampling the core, pertinent field and reservoir information, when available, should be obtained by the analyst to assist in maximum utilization or core data. This may include such items as structure of the field and position of cored well on the structure, evidence regarding type of drive, any known contacts, gravity and viscosity of produced oil, original gasoil ratio, reservoir pressure and temperature, and chloride content of produced water. Mud data and coring conditions are recorded.

The frequency of sampling for conventional analysis is generally one sample per foot. Where the formations consist of laminated sand and shale, or shows other irregularities in lithology, more frequent sampling is desirable. About 200 to 300 grams of sample are ordinarily taken for analysis from the portion of each foot that appears to be most representative of the productive formation of that foot. For whole-core 
analysis, the sample interval is determined by the lengths of the segments of full diameter core available. The lengths of these samples can vary from 3 inches to 24 inches, and generally average about 12 inches. All of the sidewall sample recovered is used in the analysis if the sample is sultable.

Proper sampling, handling, and preservation of the core by trained personnel are essential for obtaining good data. Immediately upon removal from the core barrel, the core should be wiped (not washed) free of driliing mud. The representative samples of core should be selected and immediately placed in sealed containers, or quickfrozen. A $\log$ and description of the lithology of the core and visual characteristics such as fractures or staining, is made in as much detail as is pertinent.

The technique of quick-freezing has been found suitable and convenient for preservation of fluid contents if cores are to be transported elsewhere for analysis. Other methods, including the use of jars, cans, plastic tubing, plastic bags and even sealing in plastic, may be employed with good resultis provlded sultable precautions are taken against breakage, loss of fluids by evaporation or capillary action, and condensation in the container from low temperature in transit. The samples should not be immersed in oil, water, or drilling fluid if residual saturations are to 
be determined. Variations from the usual methods of transporting cores may be desirable in some cases where certain specialized measurements are to be performed.

(2) Basic measurements. The minimum basic measurements made on cores generally comprise the determination of porosity, permeability, and residual fluid saturations. In addition, various supplementary routine tests such as chloride content, oil gravity, vertical permeability, and the like, may be made as an aid to interpretation and evaluation.

POROSITY. Various techniques for measuring porosity are used by different laboratories. The methods are based on the determination of any two of the three quantities grain volume, void volume, and bulk volume. The grain volume and bulk sample. volume may be determined either by gravimetric or volumetric methods. The void volume may be measured by extraction of gas or air content, by saturation with a liquid or by calculation from Byole's law upon compression expansion of gas in the sample. Extraction may be accomplished by solvent extractors, solvent. flushing in a holder, solvent flushing in a centrifuge, vacumm distillation, or by a patented gas-driven solvent technique employing any of several suitable hydrocarbon solvents.

Care must be taken in drying the sample to insure complete drying, and at the same time to prevent dehydrations of clay minerals or similar materials. 
In addition, another method is in common use which may be described as a summation of fluids method. This involves determination of the oil and water content, then adding to the sum of these the gas content determined by injection of mercury into an adjacent fresh (not extracted) sample.

The Boyle's law type of porosimeter is capable of accurate grain volume determinations, with errors within $\pm_{2}$ percent, and with the particular advantage of normally using a much larger sample than the other techniques. The gas extraction method can yield good data if the measuring apparatus is kept clean, and if much care is exercised in its operation. it is generally agreed that the liquid saturation techniques yield low porosity values because of the inability to saturate samples completely with a liquid. Errors as great as 10 percent may be expected. The technique is convenient to use in many cases when samples are saturated with liquids for other tests.

PERMEAB ILITY. In principal, the determination of permeability is quite simple, involving only the measurement of the rate of flow of a fluid of known viscosity through a shaped sample under a measured pressure differential. Various forms of equipment and methods for sealing the sample are used. The sample itself is usually a small cylindrical plug, cut horizontally, or a rectangular sample which permits the measurement of both vertical and horizontal permeability. If 
the sample is friable it is mounted in wax or plastic.

Air is usually the fluid employed in permeability measurement becaus of its availablity and the simplicity and reproducibility of the measurement.

Because of this reproducibility, the measurements with air are frequently used as a basis of reference, even on so-called dirty formations which may exhibit some swelling or reduction of permeability when water is used as the testing fluid. On such formations, theoretically, water or reservoir brine should be the ideal fluid for measuring permeability, but in practice such measurements often give variable and erratic results. Air permeability measurements often give variable and erratic results. Air permeability measurements are normally corrected to an "equivalent" liquid permeability (the Klinkenberg correction).

Permeability as low as 0.01 millidarcy may be measured routinely, and permeabilities lower than 0.01 milldarcy can be measured if proper equipment and operating techniques are used. Reproducibility of measurements as low as $0.1 \mathrm{mill-}$ idarcy can be made within $\pm_{2}$ percent for most cores.

LIQUID SATURATIONS. The residual oil and water saturations are commonly determined by retorting by vacuum distillation, or by solvent extraction and distillation. If the retort method is used, the heating is generally in two stages. Water 
readings are taken after a definite time, as determind by calibration tests of the equipment; oil readings are taken after some additional clapsed time during which higher temperatures are reached. This is a rapid and efficient method for the determination of $l i q u i d$ content, and is capable of good accuracy by using appropriate corrections determined from blank and calibration tests. The water readings are taken early, on a plateau of the water recovery curve, so as not to include water of hydration which comes out at higher temperatures. Vacuum distillation is similar to the retort method except that the final temperature required is not so high. The extraction-distillation method (also know as the Dean-stark method) consist of first distilling the water from the core sample by refluxing it in a solvent which is immiscible with water but miscible with oil. The extraction of oil is completed by continued refluxing, after which the sample is dried, and oil calculated from total weight loss minus the amount of water recovered. This method is considerably slower than the retort method, but is also capable of good accuracy if the distillation and extraction are carried out for a long enough period.

\section{B. Whole-core (Full-Diameter) Core}

Whole-core analysis is employed where, because of the presence of fractures, vugs, or erratic porosity development, the volume of individual pore spaces may be relatively large in comparison to the plug samples used in the conventional analysis. It involves the use of essentially all of the core, in as large pieces as possible, recovered from the interval to be tested. 
Extraction or vacuum distillation methods are employed for the determination of fluid saturations. Horizontal permeability measurements are usually made in each of two perpendicular directions across the largest segment of whole core in the designated sample interval. In this case, the permeabilities are indicated by $K_{\text {max }}$ the value measured in the direction of principal fracturing, and $k_{90}$; the value measured at right angles. Sometimes, the horizontal permeability is a radial flow measurement, in which case this is made on a 4 to 6 inch length of faced.core. One type of whole-core analysis gives a nondirectional permeability obtained from the rate of penetration of water into the extracted sample, although in this case the estimated permeability is probably influenced by other factors such as porosity and relative permeability. Porosity is usually measured by the summation of fluid or Boyle's law techniques.

\section{Sidewall Core Analysis}

Sidewall core annalysis is the analysis of cores recovered by any of the sidewall coring techniques. The small sample size and the conditions under which they are taken limit the value of the measured data in reservoir evaluation.

Modifications of conventional core analysis procedures are necessary for the analysis of the small amount of material available from sidewall cores. Not infrequently the quality of the cores may be poor owing to excessive flushing of the sample or even infiltration of drilling mud solids. Soft samples may be compacted or crushed. This is true more often of percussion-type samples than of drilled samples. Nevertheless, allowance can be made if this condition exists, and sidewall core analysis thus frequently provides a means of obtaining useful information which cannot be obtained in 
any other way. The analysis techniques permit the usual determinations to be made on most samples.

\section{Supplementary Tests.}

The following more or less routine supplementary tests are made by the analyst when so instructed (except that oil gravity and fluorescence examination are frequently performed by the analyst for his own information). It is suggested that these tests be made more frequently, while the cores are still available, when there seems to be any possibility that they may be of value later on. Their cost is generally negligible compared to the amount already expended to obtain the core. In the following discussion, a, few remarks as to the significance and use of the tests are included.

CHLORIDE CONTENT. This is measured by crushing a core sample, leaching with water, and titrating with silver nitrate. The result is expressed in terms of parts of chloride per million parts of water present in the sample. It is useful as an indication of the degree of flushing of the core by drilling mud filtrate.

OIL GRAVITY. The gravity of the oil may be estimated by various methods on small quantities of oil extracted from a core. It is used as an indication of the quality of the producible oil and its viscosity, which enter into the recovery estimate.

VERTICAL PERMEABILITY. In formations showing even occasional horizontal laminations or bedding planes, the vertical permeability may be of a much lower order of magnitude than the horizontal permeability. Frequent measurements of vertical permeability are very useful whereever cross-bedding flow is likely to be important, as for example, 
in coning of gas or water, partial penetration of the well into an oil-bearing interval, perforation of only a part of the interval; or workover operations to reduce the gas or water flow from permeable strata.

It even appears conceivable that further development of computers in reservoir engineering may increase the application of vertical permeability measurements. This could, for example, permit more accurate calculations of the contribution of gravity drainage to recovery, the rate at which a secondary gas cap might be formed and gasoil ratios controlled, the conformance factor in water flood operations, the recovery efficiency in low-permeability reservoirs with induced horizontal fractures, and the like.

FLUORESCENCE. Examination of cores for color and uniformity of fluorescence under ultraviolet light is useful in certain cases, such as the determination of the relative amount of flushing in the center and at the outside of a core; in differentiating between dry gas, condensate and oil sands; or in indicating the presence or absence of oil in fractures, thereby giving evidence of the position of the oil-water contact in fractured dense formations. In some dirty sands the character of the fluorescence, whether uniform or mottled, may give a clue as to whether water-free or mixed production may be expected.

PERMEAB ILITY TO WATER. Test of the permeability of cores to fresh and salt water may be made if it is suspected that there may be any significant reduction in permeability by contact with water. Such effects, sometimes quite pronounced, may occur in sands containing appreciable amounts 
of swelling clays. It should be pointed out, however, that the determination of accurate values of permeability to water requires careful laboratory technique. The measurement is subject to many sources of experimental error which tend to give too. low values for permeability to water. Among these may be mentioned reduction of permeability by suspended mineral matter or algae, by a Jamin effect due to formation of minute gas bubbles released from solution or a change in wettability, and by a sort of checkvalve effect which has been observed, possibly from microscopic dislodged particles within the sample. Considering these factors, the magnitude of at least some of the reported "reductions" of permeability from routine water permeability tests, particularly where salt water is used, should be viewed with skepticism. Probably a better evaluation of the susceptibility of a formation to fresh water swelling may be obtained from a relatively small (but statistically sufficient) number of carefully conducted laboratory tests rather than more numerous "routine" tests which may be more subject to the above-mentioned errors.

It should be pointed out that damage to a well's productivity by drilling mud filtrate is not merely a matter of clay swelling or chemical reaction with fresh water, but also involves relative permeability effects, ie., a physical blocking of the flow of oil due to the presence of intiltrated water in the pores. This can occur even in perfectly clean sands; in fact, clean oil-wet sands are theoretically more subject to such effects than waterwet sands. 


\section{SPECIAL CORE ANALYSIS}

A. GENERAL DISCUSSION

1. Effect of Coring Fluids:

Most coring fluids alter saturations present in the core prior to the time the core is pulled to the surface. During pressure depletion, additional saturation changes occur. Techniques are available to remove extraneous fluids introduced during coring and on the trip to the surface, whether these extraneous fluids are oil, water or a ir.

In addition to saturation changes, wettability changes may also occur when surface active agents that are used to control coring fluid properties contact the rock. Coring with oil base or inverted oil emulsion mud may alter reservoir core wettability and may change wettability of water-wet samples to an oil-wet condition. Routine water. flood tests on cores that have been altered will not yield reliable results. Since these wettability changes do not always occur, it is advisable to preserve some samples and make laboratory tests to check wettability of the rock selected for special test.s. If the samples prove to be oil-wet, the test program can usually be altered to yield reliable values of capillary pressure and residual oil values after water flood. Gas-oil relative permeability tests can be determined on oil-wet systems by leaving out the connate water on restored tests or 
by testing fresh cores. Gas is a non-wetting fluid in any case and additives often do not influence gas-drive results if irreducible water is present in the cores.

Water base muds may also alter wettability in certain cases because of surface active agents added to the coring fluid, but wettability changes are less likely to occur in this system than with oil base or inverted oil emulsion muds. The water base fluid system is normally preferred if special tests are to be made. In some cases, cores have been taken using lease crude that has never been exposed to oxygen and that contains no surface active additives. This should be ideal in that no wettability change would be expected, no extraneous water would be introduced and water saturations measured on the routine core analysis would approach true irreducible water values present in the formation. Use of lease crude that has been exposed to oxygen is not desirable in that this fluid may also alter core wettability.

2. Fresh Versus Restored Cores:

Water flood performance and water-oil relative permeability tests should be made on rresh, preserved cores. Gas-oil relative permeability and singlepoint capillary pressure measurements can also be made on fresh samples.

The primary advantage of fresh core is that it has never been subjected to an extraction and drying 
process that might alter wettability of the rock.

Tests can be and are often made on weathered, dried cores. This may present problems in heavy oil reservoirs where crude that has dried on pore walls is difficult to remove. When this occurs, the samples are very likely to be oil-wet. Firing of the samples may be required to return the core to a water-wet state. High gravity crudes are less difficult to remove and samples usually clean adequately.

Cores that are relatively fresh and that have never dried completely prior to cleaning usually can be cleaned, restored and tested to yield reliable results.

3. Whole Core Versus Plug Analysis:

Plug analysis is recommended in homogeneous formations. This includes carbonates as well as sandstones. Plug samples can be taken from the center of the core and consequently contain less drililing mud and other fines.

Heterogeneous type formations are best tested using whole core. Fluids are flowed down the axis of whole-core samples; therefore, cores containing shale laminae are not suitable.

Heterogeneous type rock usually requires a "full diameter" core analysis technique. Samples that have been vacuum retorted are normally not suitable for 
special work. This means that special samples must be picked visually prior to analysis with no benefit of routine data in these cases.

Special flow studies on whole core require samples with parallel ends. Length should he eight inches long after trimming so special core analysis samples selected should be ten inches in length where possible.

Wholle cores analyzed by Dean-stark analysis or cleaned by solvent.can be used for special work as no oil is coked on the sides of pores. With this type analysis any test not requiring fresh core can be selected after review and study of the routine data.

4. Refined 0ils Versus Crude 0ils:

Use of crude oils in room condition tests are often unsatisfactory. The crude plugs the cores in many cases despite the filtering that precedes flow through the core.

Crude from wells with a water cut is often difficult to clean. Pressure filtering and centrifuging are many times not sufficient. Extra care is needed for crude oil preparation if unusual problems are found.

Refined oils are adequate for most tests and are recommended unless crude is specifically required. 
In those cases where crude is needed, it is recommended that tests be conducted at reservoir conditions with live oil containing dissolved gas. This often retards or prevents paraffin and asphaltene drop out that can plug pores.

5. Number of Samples:

A minimum number of samples has been recommended for each test. More samples may be required in heterogeneous rocks and where lithology varies widely. These cores should be selected to cover porosity, permeability and lithology ranges. Some engineers request that tests be made on samples from one permeability or porosity range as this is the "average" of their data.

It is recommended that rather than use this approach, a permeability or porosity spread be covered and cross plots made to give an average curve for any "average" parameter selected. Averages can vary as comparison of an arithmetic average, logarithmic average and harmonic average will show. Three cores of 100,10 and 1 millidarcy yield average values of 37,10 and 2.7 , respectively. Even when the type of average is firm, data on new wells may change "averages" previously computed.

6. Time Required:

Timing is partially dependent on the preparation stage when the new study arrives in the laboratory. 
Preparation may be delayed two weeks if a large number of low permeability and porosity cores must be cut and cleaned or if rubber-sleeve core requiring nitrogen drilling is being prepared. These type studies are sporadic and it is impossible to predict any reasonable time in advance.

The work in the laboratory also controls timing. The equipment is expensive and there is often a long time lag between ordering and delivery. Sufficient equipment is available to have excess capacity except on those occasions where multiple jobs all requiring a special test apparatus arrive at the same time.

Each test sample requires special individual attention. Results are checked, correlated with other data and questionable data are remeasured. Friable, shaly, vuggy and low permeability material require time consuming drilling or hand shaping, mounting and cleaning procedures.

At least two to three weeks time should be added to the timing of any friable or viggy samples. These samples are normally coated which slows cleaning. In addition, friable cores require solvent-type cleaning and, if 17 centipoises oil has been used (required for $\mathrm{Kg} / \mathrm{Ko}$ and $\mathrm{KW} / \mathrm{Ko}$ tests), cleaning time is often several weeks.

If a series of different tests must be performed on the same samples then the times must be compounded. This is often the cause of excessive time on studies. In those cases where timing is important, sufficient core should be made:available so that tests 
can be run concurrently on different samples.

In many cases, cores have been stored for long periods before the decision to have special core analysis is made. When the decision is made, the data is requested within short notice. The time to make tests is when the routine core analysis is completed. In this manner, special studies can be made without pressures because of timing and the information will be available whenever the decision to study the reservoir is made.

7. Unconsolidated Formations:

Rubber-sleeve core barrels now recover core from formations previously unsampled. Laboratory procedures to test this type of rock vary depending on the degree of core consolidation. Techniques now in use are discussed under sections "Overburden Permeability and Porosity" and "Sample Preparation and Selection."

\section{B. SAMPLE PRESERVATION, PACKING AND SHIPPING PROCEDURES}

Tests on homogeneous formations are normally made on one or one and one-half inch diameter cylindrical plugs approximately three inches long. Sufficient whole core should be available to drill samples of the above size. In heterogeneous formations, tests are made on whole-core samples. Whole cores should be eight inches in length and samples up to eleven inches in length can be tested. Wholecore diameters up to four and three-eighths inch can be used. 
Whole-core samples must have parallel ends prior to testing and samples must be cylindrical. Short broken cores are not suitable.

Samples for preserved core floods should be taken as soon as cores are removed from the core barrel. Coring flulds should be wiped (and not hosed) from the samples with a damp rag. Each sample should be wrapped in Saran wrap and then in aluminum foil. The core can then be packaged in wax or "seal peal." Each sample should be identified by number and $i t$ is advisable to place a paper tag outside the aluminum foil and beneath the coating that can be read by the receiving laboratory.

Temperature of the coating should be just above the melting point so that cores are exposed to minimum temperature. Several wax coats are required, if the cores are dipped, to prevent cracking during shipment. Cores can be placed in ice cream cartons with wax poured around the sample. This procedure is safer than dipping.. The samples should be insulated from each other to prevent damage and then placed in a strong container such as a wooden box. In some cases, individual samples have been placed in tin cans after first being coated with wax, and insulating material is placed between the sample and the can.

Wealhered core can be sent in any strong container containing sufficient insulation to prevent breaking of the cores during transit. Weathered cores should be marked so that they are easily identified on arrival in the laboratory. Samples that have previously been re orted using whole-core procedures are not adequate for water flood and most other special tests. An exception to this general rule are cores that have been cleaned by a Dean-Stark apparatus. In the 
latter case, residual oil is removed from the core during cleaning and no fluid remains on the sides of the pore spaces.

A cover letter explaining desired tests and sample identification should be placed in the shipping container. Information concerning shipping times should also be furnished so tracing operations can be initiated in the event the core does not arrive as expected.

\section{CAPILLARY PRESSURE TESTS}

1. Use:

Primary use of these data is to relate water saturation to permeability or porosity and height above an oil-water contact in the reservoir. This information is subsequently used to calculate hydrocarbons in place. Other techniques used to arrive at this information are use of oil-base core water saturations and calculations of water saturation from electric logs. Of the three, capillary pressure and oil-base cores are considered the standard by most reservoir engineers. The high cost of coring with oil-base mud makes capillary pressure tests the most practical and reliable technique for determining water saturation.

Conversion of capillary pressure data to height requires knowledge of reservoir oil (or gas) and water densities. Estimates must be made for (1) interfacial tension existing between reservoir fluids and (2) the wettability of the reservoir as 
reflected in the contact angle between rock and fluids. Reasonable values may be assigned for these parameters, and are presented under the equations section.

An important secondary use of capillary pressure data is to calculate pore sizedistribution information and relative permeability characteristics. A brief discussion of the former is included. See Relative Permeability Tests for a discussion of the latter.

2. Method:

(A) Restored State

(1) Water saturated samples for air-water or oil-brime tests and oil saturated cores for air-oil tests are placed on a semi-permeable diaphragm, and a portion of the contained liquid is displaced with the appropriate fluid of air or oil. Liquid saturations are measured after equilibrium saturation has been reached at each of several successive pressure levels. Reservoirs with closure greater than 100 feet have one additional high pressure-saturation value determined in the centrifuge.

(2) Three Phase Capillary Pressure Tests These require a water saturated sample. The water is reduced to irreducible and the voided pores are saturated with oil. 
The oil may then be displaced by gas

to simulate a gas cap advance, or

displaced by water to simulate water

encroachment.

(B) Centrifuge

Cores are saturated with water (or oil) and spun under air or oil at increasing speeds. Average liquid content at each speed is calculated from observations of liquid spun out (liquid volume out is read with a stroboscope while the centrifuge is in motion). The average saturation data are operated on mathematically to establish a water saturation versus pressure curve. In reservoirs of large closure it is necessary to transfer the cores to a high speed centrifuge for data at a pressure of several hundred psi. This is the best technique for unconsolidated core mounted in metal jackets.

(c) Mercury Injection

The test specimen is evacuated and mercury is injected in measured increments into the core at increasing pressure levels. In this type of test the mercury represents the non-wetting phase, equivalent to oil or gas in the reservoir. This is recommended chiefly for samples of low permeability.

(D) Calculation of Connate Water as a Function of Both Height Above Water and Permeability (or Porosity)

This correlation requires sufficient capillary pressure data so that average curves can be drawn 
for selected permeability or porosity ranges.

This correlation allows the user to relate

his routine core analysis permeability and/or

porosity information to oil-water level data and

calculate the reservoir water saturation versus

height. It is one way to use the basic

capillary pressure data.

(E) Calculation of Pore Size Distribution

This allows calculation of pore entry radi from capillary pressure data. Equations have been presented by Burdine et al for calculation of a distribution function used to calculate relative permeability of cores. This distribution function is no longer used in our relative permeability calculations but is used as a rock type correlation tool: Equations for pore size calculations are presented in the equations section.

3. Type of Tests:

(A) Single-Point - Used primarily to obtain "irreducible minimum" values at high pressure levels, although any requested lower pressure can be used. Recommended only for zones of very. permeable tormation with thick oil columns or reservoirs containing no bottom water. Centrifuge technique is not recommended for this test.

(B) Two-Point - Used in conjunction with complete curves. These data assist in obtaining an accurate correlation of water saturation as a function of height and permeability by supplementing the complete curve data. Centrifuge data are not suitable for this test. 
(c) Complete-Curves - Saturations measured at 6 or more pressure levels to define the saturation over the entire range of pressure. (Mercury injection yields approximately.twenty data points and is best test if pore size distribution is to be studied.)

4. Type of Samples:

(A) Restored state tests can be made on permeability plugs through whole core sizes.

(B) Centrifuge is restricted to samples with maximum diameter of one inch and length of $1-1 / 2^{\prime \prime}$.

(C) Mercury injection is restricted to permeability plugs. The 1-1/2" plugs are necessary for low permeability and porosity rock.

5. Minimum Number of Samples Recommended:
(A) Single-points - 8 to 10

(B) Complete study: Eight complete curves and eight two-points for homogeneous formation; 16 complete curves and 32 two-points for heterogeneous formation. Correlation of saturation versus height and permeability normally not obtainable when less than eight complete and eight two-point curves are measured.

6. Special Information Needed:

(A) For single-point - (1) maximum height of productive reservoir above water level, (2) density of the 
reservoir oil (or gas), (3) a sample, the composition, or the chloride content of the formation brine.

(B) For complete study - "Same as single-point"

7. Average Minimum Time Required:

(A) Single-point - 4 weeks

(B) Complete study - 6 to 8 weeks

8. Data Reported:

(A) For both single-point and complete curves as measured by réstored state, centrifuge or mercury injection a tabular presentation of measured laboratory results is given. A graphical presentation of saturation versus permeability (or porosity) in single-point study is furnished when requested. A graphical presentation of water saturation versus pressure is given for all methods of complete curve measurements.

(B) Correlation of data to yield connate water versus height and permeability (or porosity) - Graphical and tabular presentation of connate water saturation as a function of permeability (nr porosity) and height above the water table is presented.

(c) Calculation of pore size distribution - Data gives pore entry radii corresponding to each capillary pressure and the distribution function as a function of the average pore radii over the $\Delta R$ investigated. See equations. 
9. Key Equations:

The following data and equations are presented -

- Typical Interfacial Tension and Contact Angle Constants

- Capillary Pressure Conversion to Height

- Example Equations for Conversion of AirMercury (A-Hg) Capillary Pressure Data to Air-Brine (A-B) Data

- Example Equations for Conversion of Air-Brine Capillary Pressure Data (PCA-B) to Height above Free Water Level

- Pore Size Distribution Equations Including Pore Entry Radi Calculation and Distribution Function Calculation

TYPICAL INTERFACIAL TENSION AND CONTACT ANGLE CONSTANTS

\begin{tabular}{|c|c|c|c|c|}
\hline System & $\begin{array}{c}\Delta \\
\text { Contact Angle } \\
\end{array}$ & $\begin{array}{c}\text { Cosine } \\
\text { Contact } \Delta \\
\end{array}$ & $\begin{array}{c}\gamma \\
\text { Interfacial } \\
\text { Tension } \\
\end{array}$ & $Y$ Cosine $\Delta$ \\
\hline \multicolumn{5}{|l|}{ Laboratory } \\
\hline Air-water & 0 & 1.0 & 72 & 72 \\
\hline 0ll-water & 30 & 0.866 & 48 & 42 \\
\hline Air-mercury & 140 & 0.765 & 480 & 367 \\
\hline Air-oil & 0 & 1.0 & 24 & 24 \\
\hline
\end{tabular}

Reservoir

Water-oil

30

0.866

30

26

Water-gas

0

1.0

$50 *$

50

*Pressure and temperature dependent. Reasonable value to depth of 5000 feet. 
CAPILLARY PRESSURE CONVERSION TO HEIGHT

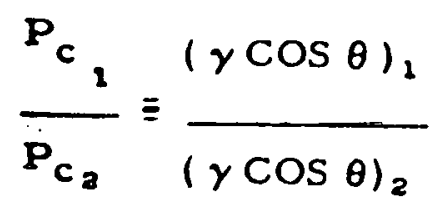

Therefore: $P_{c_{2}}=\frac{P_{c_{1}}(\gamma \cos \theta)_{2}}{(\gamma \cos \theta)_{1}} \ldots \ldots \ldots$ (1)

Then:

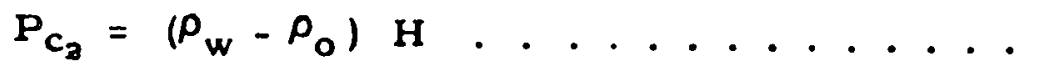

or:

$H=\frac{P_{c_{a}}}{\rho_{w}-\rho_{0}} \ldots \ldots \ldots \ldots$

where: $\quad$ subscript 1 refers to Lab data or values subscript 2 refers to reservoir data or values $\underset{\gamma}{\mathrm{P}} \mathrm{c}=$ capillary pressure, psi

$\gamma=$ interfacial tension

$\theta=$ contact angle

$\rho_{\mathrm{w}}=$ water density, psi/ft.

$\rho_{\mathrm{o}}=$ oil density, psi/ft.

$\mathrm{H}$ = height above zero capillary pressure, ft.

Technique: (1) Convert lab $P_{c}$ to equivalent reservoir $P_{c}$ with eq. (1).

(2) Calculate height above free water zone with eq. (3). 
EXAM PLE EQUATIONS FOR CONVERSION OF AIR-MERCURY (A-Hg) CAPILLARY PRESSURE DATA

TO

$$
\text { AIR - BRINE (A-B) DATA }
$$

$\frac{\mathrm{Pc} \mathrm{A}-\mathrm{Hg}}{\mathrm{Pc} \mathrm{A-B}}=\frac{(\gamma \cos \theta) \mathrm{A}-\mathrm{Hg}}{(\gamma \cos \theta) \mathrm{A}-\mathrm{B}}$

$P c A-B=P c A-H g \quad \frac{(\gamma \cos \theta) A-B}{(\gamma \cos \theta) A-H g}$

PC A-B = PC A-Hg $\frac{72}{367}$

$P C A-B=\frac{P C A-H g}{5.1}$ 
EXAMPLE EQUATIONS FOR CONVERSION OF AIR-BRINE CAPILLARY PRESSURE DATA (PC A-B) TO HEIGHT ABOVE FREE WATER LEVEL

Convert Laboratory Pc Air-Brine to Pc at Reservoir Conditions

Pc Reservoir Conditions $=($ Pc A-B $) \frac{26}{72}$

$=(\mathrm{Pc} A-\mathrm{B}) \quad(0.361)$

Convert Pc at Reservoir Conditions to Height (H)

Given:

$$
\begin{aligned}
& \rho_{w^{*}}=\text { water gradient in psi/ft }=0.44 \\
& \rho_{\mathrm{o}}{ }^{*}=\text { oil gradient in psi/ft }=0.33 \\
& H=\frac{\text { Pc Reservoir Conditions }}{\rho_{w}-\rho_{0}} \\
& =\frac{\text { Pc Reservoir Conditions }}{(0.44-0.33)}
\end{aligned}
$$

Substitute for Pc Reservoir Conditions

$$
\begin{aligned}
& H=\frac{(P c A-B)(0.361)}{(0.11)} \\
& H=(P c A-B) \quad(3.3)
\end{aligned}
$$

* At initial reservoir conditions of pressure and temperature. 
Pore Entry Radil Calculation

$$
R 1=\frac{2 \gamma \cdot \cos \theta^{\circ} c}{P c}
$$

Distribution Function Calculation

$$
\overline{D(R 1)}=\frac{V_{1} \cdot 10^{4}}{\Delta R}
$$

Where:

$$
\begin{aligned}
& \text { R1 = Pore radi1, microns (average value at midpoint of } \Delta R \text { ) } \\
& \text { Pc = Capillary pressure in laboratory, psi } \\
& \gamma \quad=\text { Interfactal tension, dynes/cm } \\
& \theta \quad=\text { Contact angle, degrees } \\
& D(R I)=\text { Distribution function (as a function of } R 1 \text { ), } \mathrm{cm}^{2} \\
& \text { Vi = Incremental volume of mercury injected } \\
& \text { (fraction of total pore volume) } \\
& \text { C }=\text { Conversion constant equal to } 145 \cdot 10^{-3} \\
& \Delta R \quad=\text { Incremental change in radius over which } V_{1} \text { was determined }
\end{aligned}
$$


CORE LARORATORIES. INC:

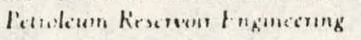

OALLAS TE.XAS
Pinge

File:
Company

Well

Field
Fomation

(inisty .

sitate

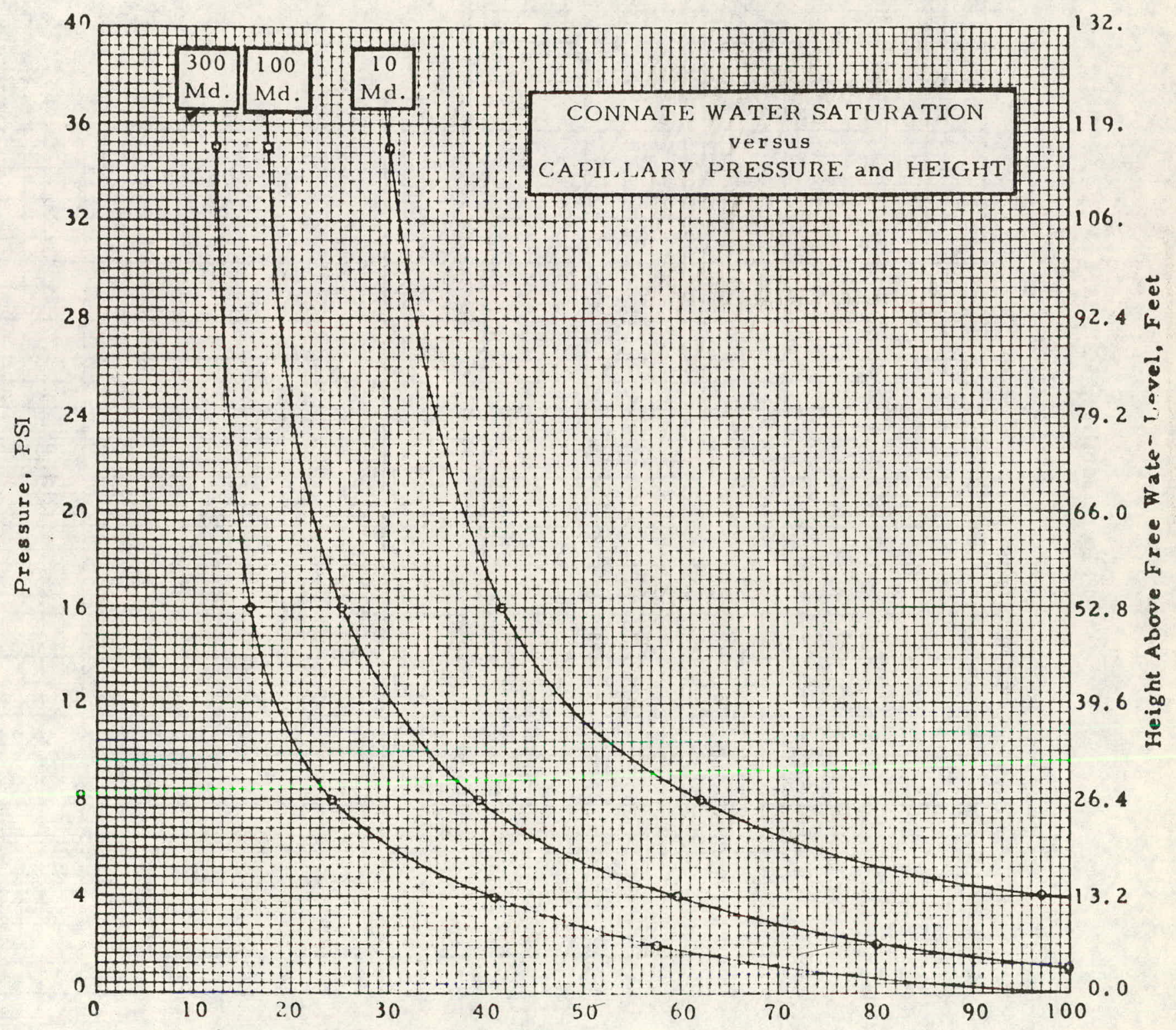

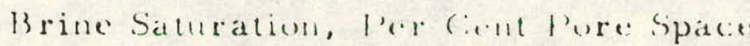


CORE LABORATORIES. INA Petruieum kesenur Engineering

OALLAS TEXAS
Fise ol

Fil::

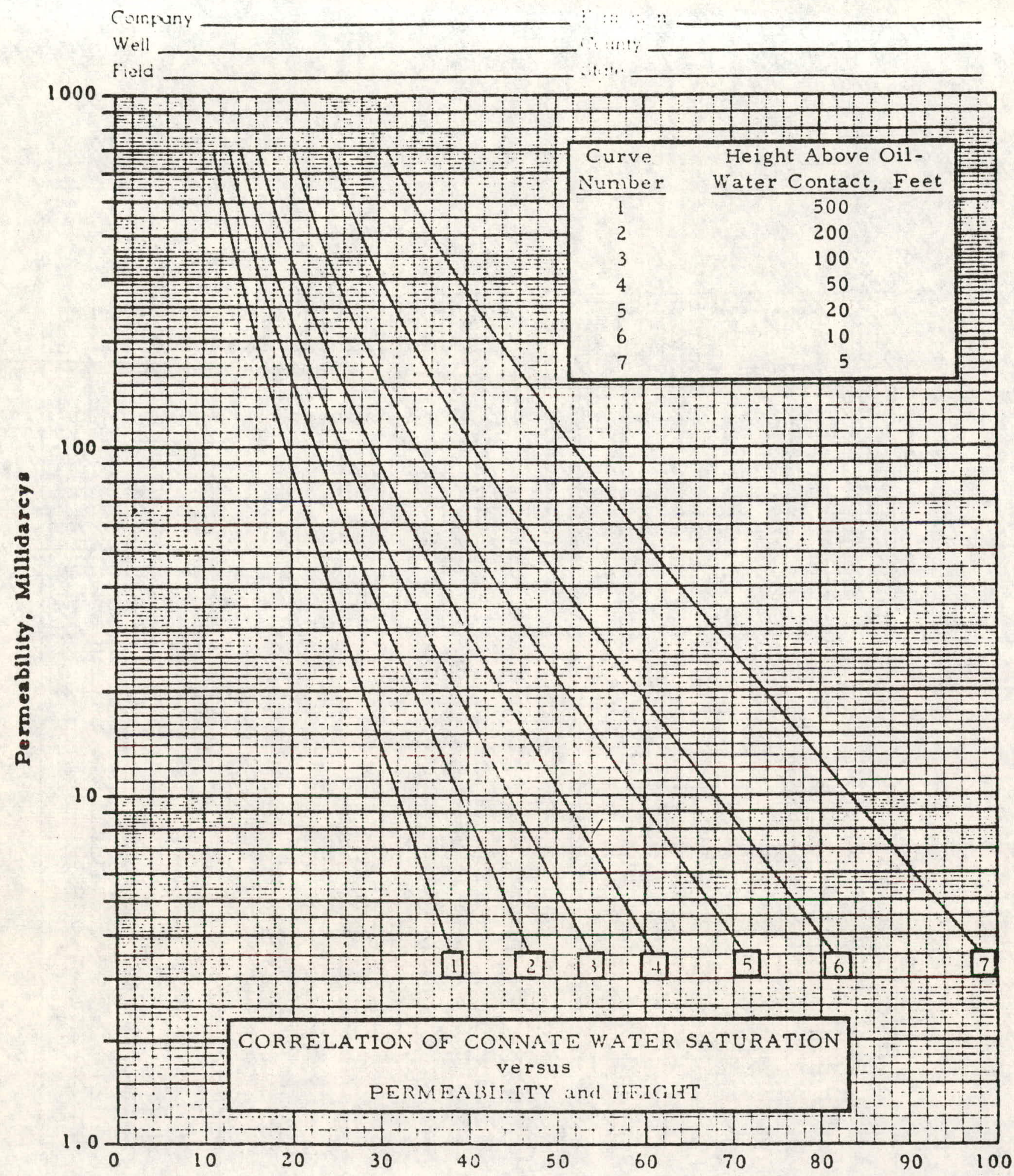

Water Satumition, Per Cent Pore Space 


\section{WATER PERMEAB ILITY}

1. Use:

This test is the best indicator of formation sensitivity to various brines. It is used to evaluate damage to a formation that would occur from various drilling filtrates and/or injection waters. A loss of permeability may be due to (1) swelling clays such as montmorillonite or (2). particle movement and subsequent pore blockage by fines or clays such as kaolinite. This test offers insight into the permeability reduction mechanism and can often differentiate between swelling and blockage.

Supporting tests that can be run are the benzidine dye test used on all test plugs and the determination of per cent and/or types of clays present. See Hydratable clay Content section.

2. Method:

Tests consist of direct measurement of permeability during the flow of water through a saturated sample. Fresh water or brine of any desired composition can be used. Permeability to water as a function of throughput is normally recommended. If samples indicate permeability reductinn, flow througl, the sample in a reverse direction is made to differentiate between swelling. clays and particle movement. A sharp increase in permeability on the reverse flow test indicates moving particles. The reverse flow dislodges the particles from pore necks where they have accumulated and temporarily causes increased permeability. 
Tests indicate that the presence of residual oil in the sample may retard the swelling of clays in some instances and give results closer to reservoir behavior. Results on fresh cores are sometimes more difficult to evaluate because of the relative permeability effect caused by the residual oil in the sample. This difficulty is overcome by first running a base permeability to the formation water and then following this with the proposed injection water. Comparison of these values indicate sensitivity.

In most cases, fresh core tests are recommended, but restored cores are adequate. In both instances the base permeability to formation brine should first be determined.

It is essential in all cases to duplicate the history and/or follow the proposed reservoir sequence of water injection. Cores tested with one water may be damaged and suffer a residual effect that may alter subsequent test data on the core. When various injection waters are to be evaluated, duplicate samples of essentially equal permeability are required.

3. Type of Tests:

(A) Specific permeability to air and to water Used to obtain only an equilibrium permeability after a given quantity of water has flowed through the core. For example, permeability after $100 \mathrm{cc}^{\prime} \mathrm{s}$ or pore volumes of injection. Its primary value is to supplement throughput data. 
(B) Permeability as a function of throughput Permeability is determined at various injection fluid volumes to give insight into permeability reduction versus pore volumes injected.

4. Type of Samples:

Permeability plugs or larger that are fresh or weathered.

5. Minimum Number of Samples Recommended:

Three to ten with each liquid being evaluated.

6. Special Information Needed:

(A) To evaluate damage by drilling fluid - water sample, analysis, or approximate chloride content of both reservoir water and mud filtrate.

(B) To evaluate damage by water injection in water flood - water sample, water analysis, or chloride content of reservoir water and. proposed injection waters.

7. Average Minimum Time Required:

Four - six weeks depending on core and complexity of study.

8. Data Reported:

Measured air and liquid permeability values (as a function of throughput when applicable) and liquid/air permeability ratios are reported in tabular form. 
A graphical plot of permeability to air versus

permeability to water when sufficient data are available or on specific request may be given.

9. Key Equations - Not applicable 
CORE LABORATORIES. INC

Perroleum Reservoir Engineering

DALLAS. TEXAS
Page

File of

Company Formation Well County.

Ficld iliste

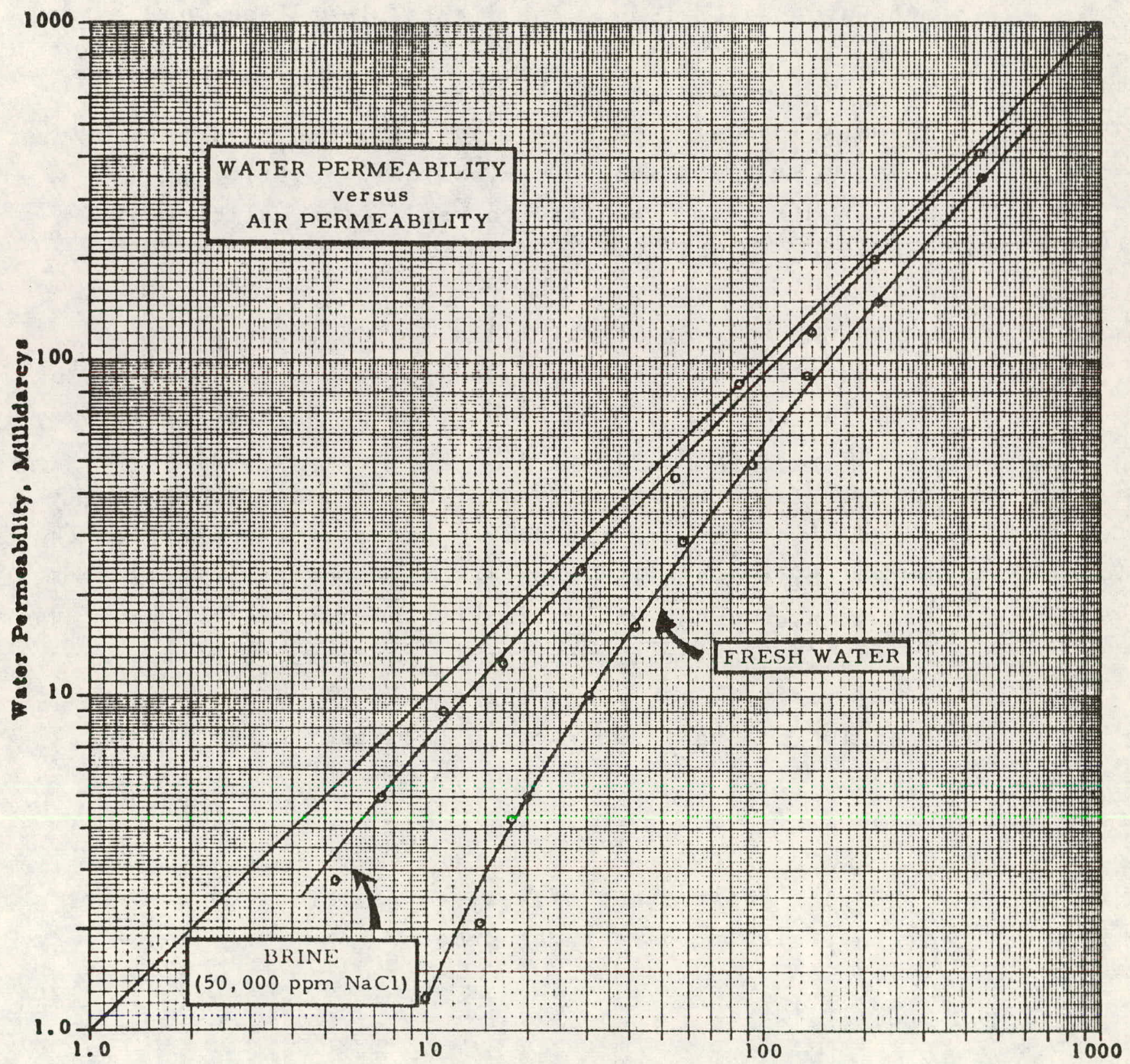

Air Permeability, Millidarcys 
E. FORMATION RESISTIVITY MEASUREMENTS

1. Use:

These measurements define for a given formation parameters used in electric log calculation of porosity and water saturation. They therefore refine log calculations and remove the necessity of relying on constants presented in the literature. Although many formations can be described by published constants, sufficient deviations occur so that resistivity measurements are required to verify the validity of published values.

The "B" factor allows improved log interpretation in shaly sands. Equation $9 c$ shows the formation factor (Fa) for any one sample to vary with the resistivity of the saturating brine. For clean sands "B" has a value of zero, and the formation factor is a constant. In shaly sands the clays conduct electricity and effect the Fa value, especially in waters that are relatively fresh. Depending on what variables are known in Eq. 9c knowledge of the "B" factor can assist in calculation of a proper water resistivity or the resistivity of a shaly formation when 100 per cent saturated with water.

2. Method:

Direct measurement of resistivity of a 100 per cent or partially brine-saturated core. $\Leftrightarrow$

3. Type of Tests:

(A) Formation resistivity factors (FF) - Ratio of resistivity of a 100 per cent brine saturated sample 
to the resistivity of the saturating brine. Reported as a function of porosity, these tests evaluate "a" and " $m$ " in equation FF $=a / f m$ defined under 9 below.

(1) Room condition tests at atmospheric pressure and room temperature are normally run. If porosities are less than 10 per cent, overburden pressure tests are recommended.

(2) Overburden pressure tests may indicate significant differences in the formation factor - porosity relationship for a low porosity formation $(<10 \%)$ or for formations at great depth subjected to large net overburden conditions. The cementation constant " $m$ " is normally higher under overburden pressure conditions. The compressibility of rock is small, and even though porosity changes only slightly under overburden, the reduction in pore size causes measurable differences in electrical resistivity.

Several tests to define FF versus confining pressures equal to $1 / 2$ the depth are normally obtained. Equipment limitations are approximately 8000 psi.

(B) Resistivity index (RI) - Ratio of the resistivity of a partially saturated sample to the resistivity of the 100 per cent brine saturated samplc. Reported as a function of brine saturation, these tests evaluate " $n$ " in formula presented in section 9. 
Tests are made at room conditions. While it would be advantageous to measure resistivity ratios under overburden pressure conditions, we have not successfully mastered the lab techniques. It is necessary to desaturate the samples and yet not evaporate any water from the core. This is to prevent a change in the salt content and hence resistivity of the saturating brine. Flowing oil through the core will accomplish the desaturation, but a thin film of oil between the sample and the electrode forms that breaks the electron flow and results in erroneously high resistivities.

(C) Calculation of "B" Factor - Formation factors are determined in the laboratory with four different salinity saturating brines. These data are plotted and extrapolated to yield the value of $\mathrm{F} .01^{\circ}$ Equation $9 \mathrm{c}$ is solved using the measured data, to yield "B". Note: This calculation requires 4 formation factor tests per core; with their related cost. The charge for the calculation of "B" is additional to formation factor charges.

Experiments are now being made to evaluate "B", which is related to clay content and cation exchange capacity, in a more direct manner than just discussed. Hopefully this will furnish an additional technique for calculation of "B" at less expense to the client. This method involves cleaning, determination of porosity and then reduction of the sample to grain size. It is 
washed with chemicals and put in a water siurry where the conductance of the slurry is measured during a titration with magnesium sulfate.

4. Type of Samples:

Room condition tests use small permeability plugs, or larger, including whole cores.

$$
\text { Overburden tests require } 1 " \text { or } 1-1 / 2^{\prime \prime} \text { cylindrical }
$$
plugs.

5. Minimum Number of Samples Recommended:

Formation factor, resistivity index and "B" factor should have a minimum of ten samples tested. Overburden FF are run at several pressures equal in maximum value to $1 / 2$ the formation depth. Resistivity indices should be run on a minimum of three saturations on each sample.

6. Special Information Needed:

Resistivity, water sample, water analysis or chloride content of formation water. Depth of formation and original reservoir pressure.

7. Average Minimum Time Required:

(A) Formation resistivity factors - Four weeks. Tests are repeated until stabilized FF values are obtained.

(B) Resistivity indices - dependent upon amount of associated capillary pressure or other 
tests requiring desaturation. Normally 4

additional weeks after formation factor

tests are completed.

(C) "B" factors - currently require several months.

New technique should reduce this to several

weeks.

8. Data Reported:

(A) Tabular and graphical presentation of formation factor versus porosity and resistivity index versus saturation. Normally a composite plot containing all FF and a composite plot showing all RI data are presented. Calculations of "a", " $m$ " and " $n$ " are made and the mathematical relationships of porosity to formation factor and resistivity index to water saturation are given.

The value of "B" for each core is presented in tabular form.

9. Key Equations:

(A) Formation factor

$$
F F=\frac{a}{f^{m}}=\frac{R o}{R w}
$$

where:

$$
\begin{aligned}
F F= & \text { formation resistivity factor } \\
f= & \text { porosity (fractional) } \\
m= & \text { cementation factor (ranges from } 1.8 \\
& \text { to } 2.5)
\end{aligned}
$$




$$
\begin{aligned}
\text { Ro }= & \text { resistivity of } 100 \text { per cent brine } \\
& \text { saturated sample } \\
R w= & \text { resistivity of saturating brine } \\
a= & \text { FF value at fractional porosity of } \\
& 1.0 \text { Value of "a" can range from } \\
& 0.6 \text { up to } 1.42
\end{aligned}
$$

(B) Resistivity index

$$
R I=\frac{R t}{R o}=\frac{1.00}{S w^{n}}
$$

where:

$$
\begin{aligned}
R I= & \text { resistivity index } \\
R t= & \text { true resistivity at a given water } \\
& \text { saturation } \\
\text { Ro }= & \text { resistivity of } 100 \text { per cent brine } \\
& \text { saturated sample } \\
S W= & \text { water saturation (fraction of pore } \\
& \text { volume) } \\
n= & \text { saturation exponent (ranges from } \\
& 1.4 \text { to } 2.2 \text { ) }
\end{aligned}
$$

(C) "B" factor

$$
F a=F_{.01}(100 R w)^{B} \log (100 R w)
$$

where:

$$
\begin{aligned}
\mathrm{Fa}- & \text { apparent formation resistivity } \\
& \text { factor measuled wilh various } \mathrm{kW} \\
& \text { brines } \\
\mathrm{F} .01= & \text { formation factor when sample is } \\
& \text { saturated with brine of } 0.01 \text { ohm- } \\
& \text { meter solution. This value is } \\
& \text { normally found by extrapolation } \\
& \text { of Fa measured with various salinity } \\
& \text { brines in the core } \\
\mathrm{RW}= & \text { resistivity of saturating brine } \\
\mathrm{B}= & \text { constant of negative sign related } \\
& \text { to clay content in a core }
\end{aligned}
$$


CORE LABORATORIES. INC.

Petroleum Reservon Finginering

DALLAS. TEXAS
Pri

File
Comprany

Well

riend (i), 11

1. 31,

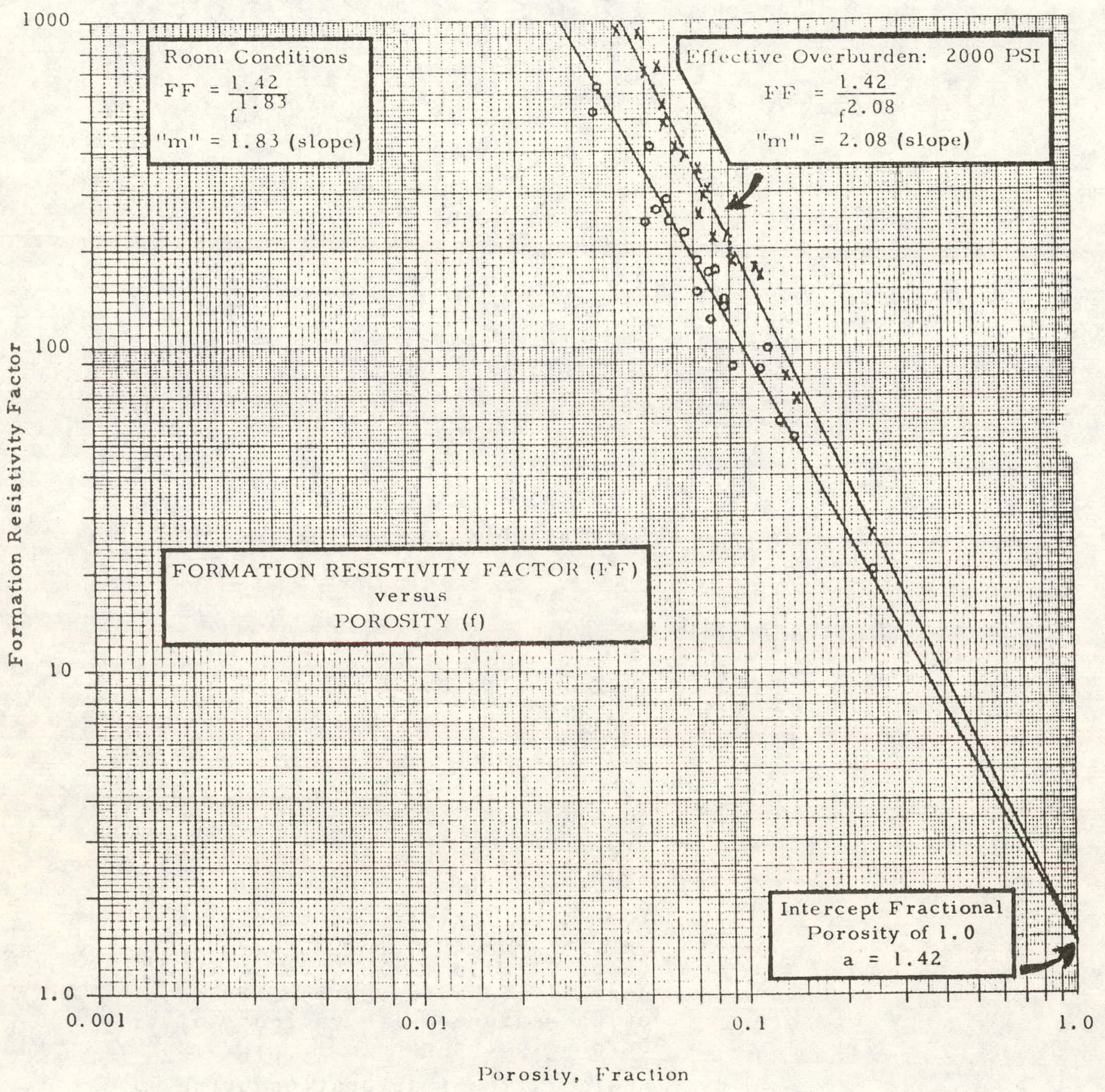


CORE LABORATORIES. INC

Perroleum Reservoir Engineering

DALLAS. TEXAS
Page

File
Company
Formation
We!l
Field
Siate

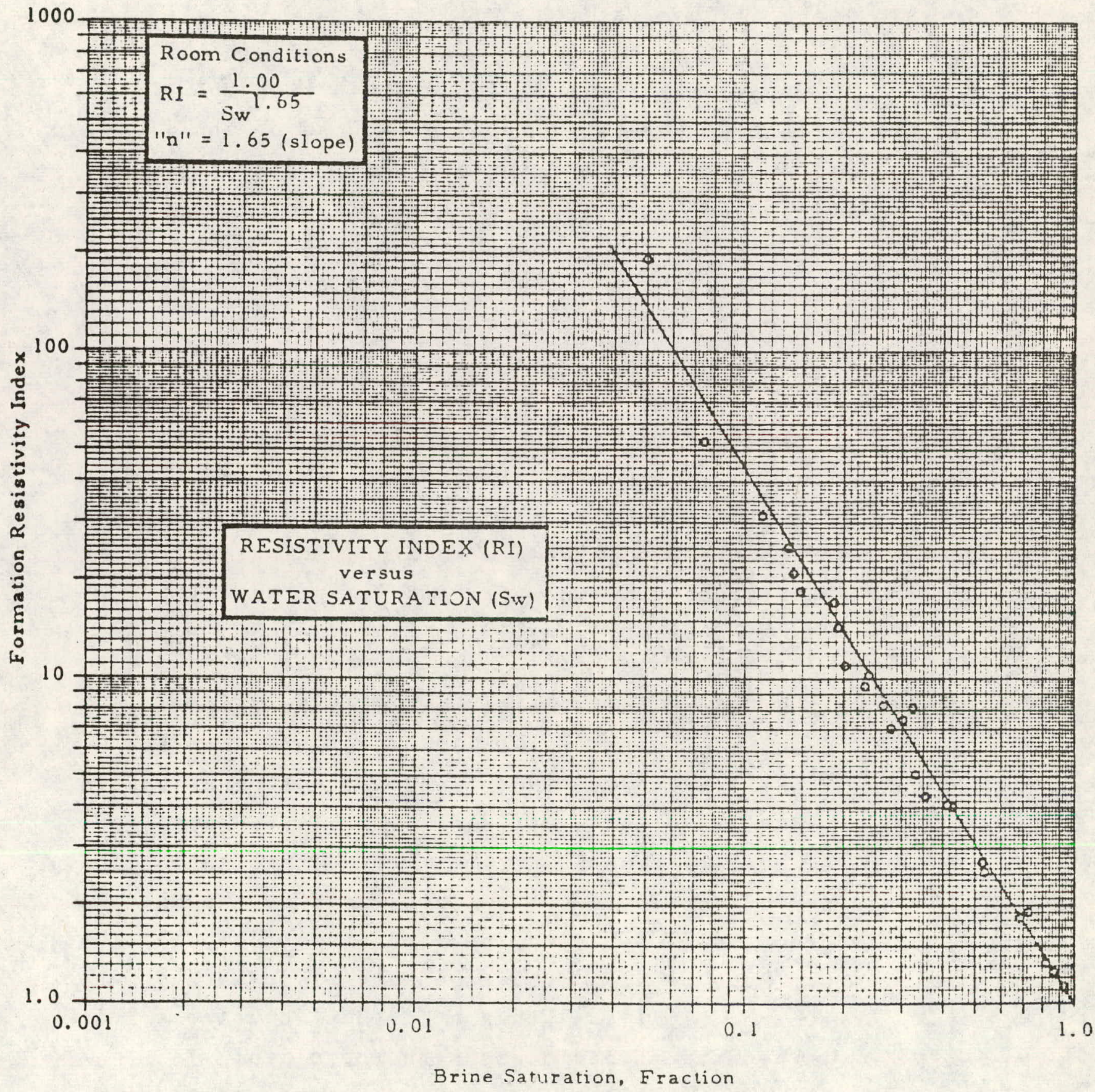




\section{F. WATER FLOOD TESTS}

\section{0il Reservoirs}

\section{(A) General Observations}

These tests are designed to furnish the effective permeability to oil ahead of the flood front, residual oil content after water flood, and the effective permeability to water behind the flood front. These data are used with permeability distribution and injection pattern efficiency to make predictions of reservoir performance.

Several tests may be run in the laboratory to furnish the required information. These tests vary in complexity and ease of application from the Basic Flood through Water Flood Susceptibility (WFS) test to water-oil relative permeability $\left(K_{W} / K_{0}\right)$ measurements.

Performance relating oil recovery to pore volumes of water injected and to water-cut is usually desired. These data are not developed in the Basic Flood tests, and are reported only for the Water Flood Susceptibility measurements. The performance data can be calculated by the user from the $K_{W} / K_{0}$ using the fractional flow equations, but many persons requiring water flood performance are not familiar with use of these equations. It is necessary to discuss with the client his proposed calculation technique when recommending types of water flood tests. Unless a definite 
requirement for $K_{w} / K_{0}$ is expressed, WFS tests can be recommended with confidence.

(B) Reservoir Condition Versus Room Condition Tests

Basic flood and WFS tests can be made under reservoir conditions of temperature and pressure using live reservoir oil. This is an improvement over room condition techniques. where tests are made at atmospheric conditions with refined laboratory oils. Use of the live crude exposes the rock to compounds present in the oil that might influence wettability, and establishes a plug environment as close as possible to reservoir conditions.

Those cases where reservoir condition tests cannot be performed, room condition Basic flood and WFS tests are in many cases satisfactory substitutes. These tests require refined oils specifically selected so that the laboratory oilwater viscosity ratio equals the oil-water ratio existing under reservoir conditions.

(c) Fresh Preserved Core Versus Restored Core Tests

It is desirable to perform all flood tests on fresh core samples when possible. Drying and cleaning of the samples prior to analysis may alter the wetting properties of the formation, thereby altering flood performance. Exposure to air for a sustained length of time may invalidate fresh core tests. It is essential that cores for fresh floods be stored under air free conditions. Samples 
brought to the field laboratory that are exposed six to eight hours during routine analysis often suffer from water evaporation and exposure and may not be suitable for fresh flood tests. Where possible, fresh core should be preserved immediately after removal from the core barrel by wrapping with Saran wrap and foil, and then dipping in paraffin or plastic.

(D) Tests on Cores Simulating High Reservoir Oil-Water Viscosity Ratio

Water flood tests are normally carried to water cuts in excess of 99.9 per cent. During Basic Flood and WFS tests several hundred pore volumes of injected fluid are required to reach 99.9 per cent water cut when oil greater than four or five centipoises viscosity is present. Basic Flood tests yield only the residual oil value at the terminal condition of the laboratory test when several hundred pore volumes of water are injected. Much of the oil recovered in the laboratory is at a water cut and at injected volumes greatly in excess of field conditions. Most field water floods have only one or two pore volumes of fluid injected and become uneconomic at water cuts in excess of 95 per cent.

The Basic flood test may indicate optimistic recovery values and is not recommended for reservoirs with viscous oil. WFs tests or $K_{w} / K_{0}$ tests are recommended in these cases as performance as a function of injected water volume is presented or can be calculated. 
(E) Comments on $\mathrm{K}_{\mathrm{w}} / \mathrm{K}_{\mathrm{o}}$

(1) Unsteady State Technique

Water-oil relative permeavility tests normally require that a viscous oil be used.

This results in a high oil-water viscosity ratio and forces an early breakthrough of the water phase with a long subordinate production phase (where both oil and water flow). The unsteady state $K_{w} / K_{o}$ measurement technique employed requires both oil and water flowing before $k_{w} / k_{0}$ can be calculated.

On certain occasions where the actual reservoir oil-water viscosity ratio is low, $k_{w} / K_{0}$ residual oil saturations obtained with viscous oil in the samples are higher than obtained when comparison flood tests simulating the reservoir viscosity ratio are made. Equal saturations would probably be reached if the $K_{w} / K_{0}$ tests could be extended to infinite pore volumes of injection. This is not feasible, and where the absolute residual oil at essentially 100 per cent water cut $(99.99 \%)$ is required, Basic Flood tests simulating the reservoir oil-water viscosity ratio conditions can be used to furnish supporting residual oil values for the $\mathrm{K}_{\mathrm{w}} / \mathrm{K}_{0}$ tests.

Where the reservoir oil-water viscosity ratio equals five to ten, it is usually possible to calculate $K_{W} / K_{0}$ data from a WFS test. 
Requests are often made for $K_{w} / K_{0}$ data under reservoir conditions. As noted above, if the reservoir oil-water viscosity ratio is high a reservoir condition WFS test can be made and $K_{w} / K_{0}$ can be calculated from the data. Where the reservoir oil-water viscosity ratio is low, normally a late water breakthrough and small subordinate production period is observed, and $K_{w} / K_{0}$ can be calculated for only a limited water saturation range and in some cases not at all. Use of refined viscous laboratory oils at reservoir conditions of temperature and pressure is not recommended. This is easy enough to do in the laboratory, but the main advantage of using reservoir crude is lost. Therefore, unless the oil-water viscosity ratio is high, reservoir condition $k_{w} / k_{0}$ over a large saturation range is often not available. Sometimes calculated points at the terminal conditions of the low oil-water viscosity ratio reservoir flood can be extrapolated over the saturations prior to water breakthrough to yield additional data.

(2) Steady State Technique

Low viscosity refined oil is used in these tests and all work is done at room conditions of temperature and pressure. This service is currently under development and is discussed more fully under Water-0il $\left(k_{w} / k_{0}\right)$ Relative Permeability.

2. Gas Reservoirs

Water flood tests on gas reservoirs furnish residual 
gas after water encroachment into a gas saturated zone.

These data are needed for (1) natural gas reservoirs with water drive, and (2) for gas storage projects in aquifers where a portion of the gas injected into the reservoir is trapped and is unrecoverable as production occurs and the gas bubble shrinks.

Residual trapped gas is a function of the initial gas in place. Where a water-gas saturation profile exists in the reservoir, several tests should be made on a given core for various initial gas saturations. This will define a curve of initial versus trapped gas for a given permeability rock. This applies to naturally occurring gas reservoirs with a long initial water-gas transition zone and all aquifer storage projects. In most naturally occurring gas reservoirs, the large density difference between water and gas results in a negligible gas-water transition zone and trapped gas tests at irreducible water are all that are needed.

\section{Basic Flood}

(A) Use:

Data from this. test are used in Stiles and Dykstra-parsons type calculations that require values of oil permeability at connate water and water permeability at residual oil to predict water cut versus cumulative oil recovery.

Test data do not yield oil recovery versus water cut and pore volumes of fluid injected as given in Water Flood Susceptibility test. 
(B.) Method:

(1) Room Condition Tests

a. Extracted Cores - Extracted and dried cores are saturated with brine. These samples are restored to reservoir oil and water contents by centrifuge, capillary pressure cell, dynamic displacement or evaporation of brine and subsequent saturation of voided proes by oil. Test fluids are selected so that the reservoir oil-water viscosity ratio is reproduced in the laboratory test. Effective permeability to oil in the presence of connate water is determined and the cores are then water flooded to 99.9 per cent water cut. Total oil produced is recorded Permeability to water in the presence of residual oil is then determined.

b. Fresh cores - Fresh core is evacuated shortly under oil and then flushed with oil to remove all gas. Extraneous water introduced during coring is displaced by centrifuge, capillary pressure cell or dynamic displacement. The reservoir oilwater viscosity ratio is reproduced in the laboratory test. Effective permeability to oil is measured. The samples are then flooded, as above. Fluid contents are measured by distillation and air permeability and porosity on the clean dry sample are determined. Saturations present in the core at initiation of flooding are calculated by material balance. 
Reservoir Conditions Tests

a. Extracted Cores - Procedures are the same as for room condition extracted cores through the determination of effective permeability to oil in the presence of connate water. After this measurement the cores are placed in a controlled temperature environment and raised to reservoir temperature. Pressure on the system is increased to exceed the saturation pressure of the live oil. The laboratory oil within the sample is then displaced by live crude. The core is soaked at temperature and pressure for approximately 24 hours. One additional pore volume of oil is flushed through the core to displace the soak oil and the sample is then water flooded to 99.9 per cent water cut. 0 il and water are flashed through a back pressure regulator and measured at room conditions. Total oil produced is determined. Permeability to water in the presence of residual oil is measured. Pressure on the system is reduced to atmospheric and oil and water produced during pressure blow down are measured. Produced oil volumes are corrected to reservoir volumes using an appropriate flash formation volume factor.

b. Fresh Cores - Procedures are the same as for room condition fresh floods through measurement of the oil permeability in the presence of connate water. The samples are then placed in the temperature environment and raised to reservoir temperature. 
Pressure on the system is increased to exceed the saturation pressure of the live oil. The tests then follow the same procedures as for reservoir condition extracted core floods through the completion of the pressure blow down. The sample is then removed from the holder. Fluid saturations are measured by distillation. Air permeability and porosity are determined on the clean dry sample. Saturations present in the core at initiation of flooding are calculated by material balance, after room condition oil and water volumes have been corrected to reservoir volumes using an appropriate flash formation volume factor.

(c) Type of Tests:

(1) Room Conditions ( $P$ lug and Whole Core)

a. Extracted cores

b. Fresh cores.

(2) Reservoir Conditions (Plug and Whole Core)

a. Extracted cores

b. Fresh cores

(D) Type of Samples:

(1) Room Conditions - Whole core or $1-11 / 2$ " diameter plugs only.

(E) Minimum Number of Samples: - Four to eight.

(F) Special Information Needed:

(1) Room Condition Tests (Extracted or Fresh Cores) 
a. Oil viscosity at reservoir conditions existing at time of flood.

b. Injection water viscosity at reservoir conditions existing at time of flood.

c. Salinity (chloride) of (a) formation water and (b) injection water, including sodium, calcium and magnesium content, if available. These data are extremely important as any reaction between rock and water will effect the test results.

d. Height above water at which the major portion of the reservoir exists. Water-oil contact, crest of structure and gasoil contact will help. These data are to assist in calculating capillary pressures to use when restoring interstitial water saturations in the cores. If these data are unknown, irreducible waters will be established.

e. If reservoir overlies a water-oil contact; the oil reservoir density in $/ \mathrm{ft}^{3}$ or gradient from a pressure traverse in psi/ft is needed in conjunction with item 4. The water gradient is also desired.

f. If oil and water viscosity are not know, reasonable estimates can be made if following information is furnished.

- Lhloride content of water (from water analysis or resistivity of sample).

- Reservoir temperature.

- Reservoir pressure at (1) original and (2) current conditions.

- Original oil solution gas-oil ratio. . 0 il gravity (can be determined from s ample). 
(2) Reservoir Condition Tests (Extracted or Fresh Cores)

a. Water and reservoir information required

on room condition tests is needed. This

includes data on connate and proposed in-

jection water.

b. Oil data including viscosity and flash

formation volume factor will be developed

in the Reservoir Fluid Laboratory for a

charge of approximately $\$ 400$.

c. 0 il samples, either bottom hole or separator

products, for recombination are required.

Associates key sampling data are needed as

follows.

. Bottom Hole Samples

-Bottom hole temperature $\varepsilon$ its associated depth.

-Bottom hole pressure $\varepsilon$ its associated depth.

- Perforation interval.

- Sampling depth.

- Recombination Samples

-Bottom hole temperature $\varepsilon$ its associated depth.

-Bottom hole pressure $\varepsilon$ its associated depth

-Gas-oil ratio $\&$ whether oil is stock tank or separator barrel.

- Pressure \& temperature base used in GOR calculation.

- Specific gravity \& specific gravity factor ( $f g$ ) used in GOR.

- Compressibility factor ( $\left.f_{p v}\right)$ used in GOR.

d. Sufficient oil to flow 3 to 5 pore volumes of fluid through each flood sample are required. For each plug sample, $100 \mathrm{cc}$ of reservoir fluid sample is normally sufficient. Whole core volumes vary widely because of sample length and porosity and must be evaluated at time of study initiation. 
(G) Average Minimum Time Required - Six to eight weeks

(H) Data Reported: - Tabular data including air permeability, porosity, connate water, effective permeability to oil at connate water saturation (ahead of flood front), oil recovered by flood, residual oil saturation and effective permeability to water at residual oil (behind the flood front).

(1) Key equations: - Not applicable 
4. Water Flood Susceptibility

(A) Use:

Data can be used in Stiles and Dykstra - Parsons type calculations that require values of oil permeability at connate water and water permeability at residual oil.

0 il recovery is determined as a function of pore volumes of water injected and water cut. These data furnish a graphic display of expected reservoir performance in those areas of the reservoir swept by water and as such. offer more insight into flood performance than do Basic Floods.

Method:

(1) Room Condition Tests

a. Extracted cores - Same as Basic Flood except incremental production and rates of flow of oil and water are recorded.

b. Fresh cores - Same as Basic Flood except incremental production and rates of flow of oil and water are recorded.

(2) Reservoir Condition Tests

a. Extracted cores - Same as Basic l:Flood except incremental production and rates of flow of oil and water are recorded.

b. Fresh cores - Same as Basic Flood except incremental production and rates of flow of oil and water are recorded.

(C) Type of Tests: - Same as Basic Flood.

(D) Type of Samples: - Same as Basic Flood. 
(E) Minimum Number of Samples: - Four to eight.

(F) Special Information Needed: - Same as Basic Flood.

(G) Average Minimum Time Required - Six to eight weeks.

(H) Data Reported: - Oil recovery as a function of injected water volumes and water cut are presented in tabular and graphical form in addition to air permeability, porosity, connate water, effective permeability to oil at connate water saturation (ahead of flood front), oil recovered by flood, residual oil saturation and effective permeability to water at residual oil (behind the flood front).

When $K_{W} / K_{j}$ is calculated from WFS, tabular and graphical presentation of the $k_{w} / k_{0}$ ratio curve and individual relative permeability to water $\left(k_{w} / K\right)$ and to oil $\left(k_{o} / K\right)$.

(1) Key Equations: - Not applicable. 


\section{G. Relative Permeability}

Darcy's Law as originally written applies to a porous medium where a single fluid completely saturates the rock. When two or more fluids are present, they compete for flow space within the rock and the concepts of effective permeability and relative permeability have been introduced to properly account for this multiphase condition.

The following definitions apply:

(1) Specific Permeability - Refers to permeability (Ks) when a single fluid at 100 percent saturation is present. Units are darcys or millidarcys.

(2) Effective Permeability - Applies to the permeability of each phase at specified saturations when two or more fluids are present. Examples are effective permeability to water $(\mathrm{KW})$ and effective permeability to oil (Ko). Units are darcys or millidarcys.

(3) Relative Permeability - Equals Effective Permeability at specified saturation divided by Specific Permeability; i.e. Kro $=\frac{K o}{K s}$ - Fraction or percent.

(4) Relative Permeability Ratio - Relative Permeability to one phase divided by Relative Permeability to second phase at a common saturation; i.e. Krw/Kro $\mathrm{Kw} / \mathrm{Ko}$ - Dimensionless.

The effective permeability and the relative permeability require that the saturation of the phases be known before much practical use can be made of the data. The saturation present is dependent on the wetting characteristics of the rock and the saturation history of the sample. In general, laboratory samples 
should follow the same sequence of saturation changes during preparation and test that the reservoir has undergone.

Relative permeability requires that the effective permeability be made relative to some base permeability. In most cases this base is the specific air permeability that has been corrected for klinkenberg effect. An exception to this rule is that in Canada the base is normally the oil permeability existing at connate water saturation.

The base of air permeability is most often used since core analysis permeabilities are air permeability values. These are grouped and average into permeability or porosity ranges. and used as the correlating tool. It is convenient to have these correlating values as the base in the relative permeability calculation.

Relative permeability values reported can be shifted to a new base by use of equation (3) above. This does not change the relative permeability ratio values only individual phase relative permeability. The base values for Special Core Analysis samples are reported on the bottom of the tabular data sheets so that they are easily available and part of the permanent data recont.

1. Water-0il $\left(K_{w} / K_{0}\right)$ Relative Permeability

(A) Use: These data are preferred by many engineers evaluating water flood performance. Reservoir performance relating oil recovery as a function of water cut and porevolumes of water injected (similar to water flood susceptibility data) can be calculated using fractional flow equations for any set of 
oil-water viscosity conditions. An example is included under section (1). When used in the fractional flow formula in conjunction with capillary pressure data, it offers insight into water cut versus height above the water-oil contact, and often assists in explaining injectivity difficulty into disposal wells.

(B) Method:

(1) Unsteady State Tests (Normal system used in water floods)

a. Room Conditions - Extracted cores-

identical with water flood susceptibility

(WFS) procedures except a viscous re-

fined oil ( 17 centipoises) is used

to yield a high oil-water viscosity

ratio and force an early breakthrough of

water. On request crude oil can be sub-

stituted for the refined oil. Crude often

partially plugs the samples during res-

toration and during oil permeability mea-

surements and is not recommended except

in unusual circumstances.

When the oil-water viscosity ratio exceeds

5 to 10 in the normal WFS test, $k_{w} / k_{0}$ values can often be calculated from the WFS data.

Fresh Cores - Identical to fresh core Water Flood Susceptibility procedures except a viscous refined oil (17 centipoises) is used to yield a high oil-water viscosity ratio and force an early breakthrough of water. As noted above, crude oil can be used but is not recommended. 
b. Reservoir Conditions - Extracted cores Water-oil relative permeability is calculated from extracted core Water Flood Susceptibility Tests. If the reservoir oil-water viscosity ratio exceeds 5 to 10 , the $k_{w} / K_{0}$ relationships can often be calculated. There is no benefit to be gained from testing refined oil at reservoir temperature and pressure as it is the reaction between actual reservoir oil, water and rock that is desired.

Fresh cores - Water-oil relative permeability is calculated from fresh core reservoir condition WFS tests.

\section{(2) Steady State Tests}

a. Room Conditions - Extracted cores Samples are prepared as for room condition water flood tests through measurements of an oil permeability at connate water. The sample will then be placed in the steady state apparatus and will have a selected water-oil ratio flowed through it. Flow will continue until. capillary equilibrium is obtained and the effluent ratio equals the injection ratio. This is verified by a constant pressure drop across the core which is monitored on a chart recorder. Rate of flow will be monttored and effective permeability to oil and water will be calculated.

The sample is removed from the apparatus, weighted, returned to the apparatus and 
the water oil ratio is increased. The. procedure is repeated for five to six ratios and will take approximately one week per core. Water saturation in the core when when equilibrium was obtained at each ratio will be calculated from the weight changes that occurred and known densities of the water and oil.

Fresh cores - Samples are prepared as for fresh room condition water floods through permeability to oil determination at connate water. The steady state process as described above is then followed. At the conclusion of the test, fluid contents are determined by distillation. Air permeability and porosity on the cleaned and dried core are measured and saturations present in the core at each wateroil ratio are calculated by material balance.

(3) Calculated from pore size distribution (capillary pressure data). Equations are last resort technique since water flood is an imbibition process and drainage capillary pressure curves are often all that are available. Imbibition capillary pressure data can be utilized, but question exists .. as to the proper tortuosity to use for the imbibition case.

(C) Type of Tests:

(1) Unsteady State Technique

a. Room Condition (Extracted or fresh core)

b. Reservoir Condition (Extracted or fresh core) 
(b) Type of Samples

(1) Unsteady State Technique

a. Room conditions - Whole Core or 1", 1-1/2" 2" plugs with 1-1/2" preferred.

b. Reservoir conditions - Whole core of $11 / 2$ "

(2) Steady state apparatus limited to $1-1 / 4$ " diameter cylindrical plug.

(E) Minimum Number of samples: - Three to five.

(F) Special Information Needed:

(1) Unsteady State Technique

a. Room conditions (Fresh or extracted cores)

Requires composition, chloride or resistivity of formation water. Requires composition, chloride or resistivity or injection water.

b. Reservoir Conditions - $k_{w} / K_{0}$ is calculated from the reservoir condition Water Flood Susceptibility data. See Water Flood section for details of test and information required.

(2) Steady State - No special information is required.

(G) Average Minimum Time Required - Eight Weeks.

(H) Data Reported - Permeability to air, permeability to oil at connate water saturation, porosity, connate water, residual oil, oil recovery, permeability to water at residual oil. Graphical and tabular presentation of relative permeability to oil, relative permeability to water, and water-oil relative permeability ratio as a function of water saturation.

(i) Key Equations - Presented are (1) equations relating 
CORE LABORATORIES. INC. Petroleum Reservoir Engineering

DALLAS. TEXAS
Page

File of

Company

Formation

Well County

Field State

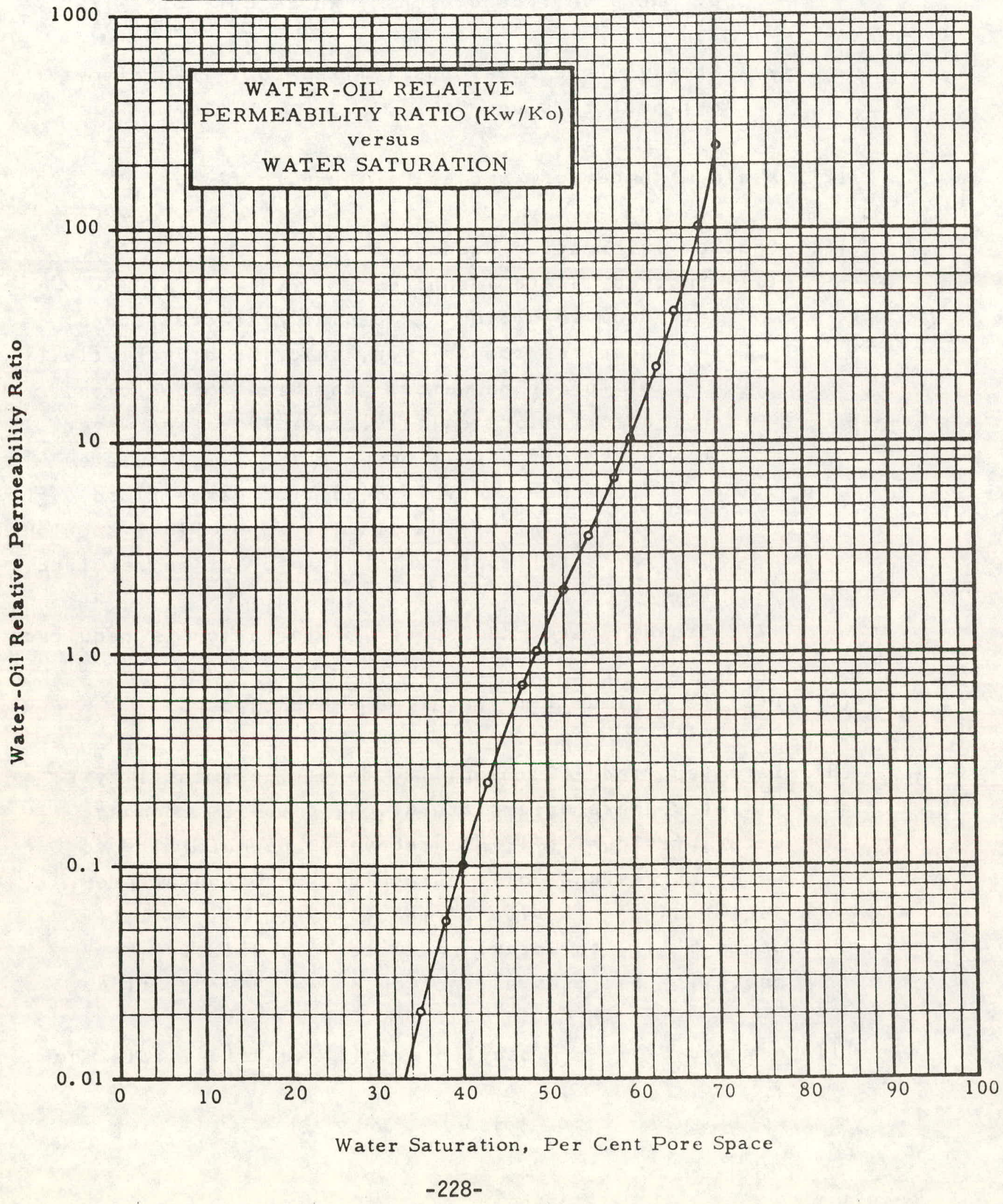


CORE LABORATORIES. INC Petruleum Reservoir Engineering

DALLAS. TEXAS
Page

File

Company

Formation

Well County

Field State

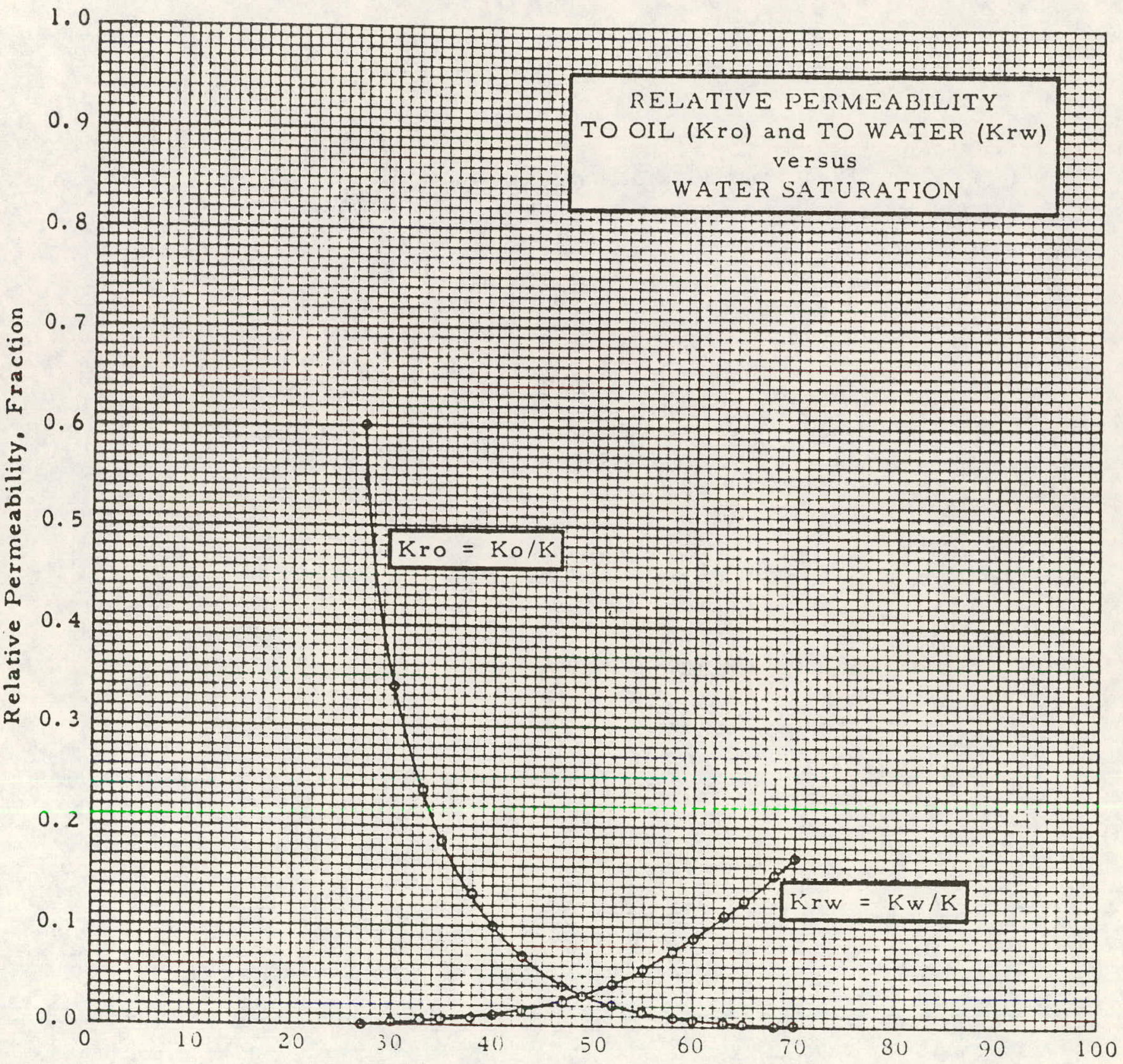

Water Saturation, Per Cient fure Space 
RELATIONSHIP OF WATER-OIL RELATIVE PERMEABILITY AND FRACTIONAL FLOW

$$
\begin{aligned}
& Q_{0}=\frac{(K r o \cdot K a)(A)(d P)}{(\mu o)(L)} \\
& Q_{w}=\frac{(K r w \cdot K a)(A)(d P)}{(\mu w)(L)}
\end{aligned}
$$

Fractional Flow of Water $=\frac{\text { Water }}{\text { Water }+0 i 1}=f w$

$$
\begin{gathered}
f w=\frac{Q w}{Q o+Q w} \\
f w=\frac{\frac{(K r w \cdot K a)(A)(d P)}{(\mu w)(L)}}{\frac{(K r o \cdot K a)(A)(d P)}{(\mu o)(L)}+\frac{(K r w \cdot K a)(A)(d P)}{(\mu w)(L)}} \\
f w=\frac{\frac{K r w}{\mu w}}{\frac{K r o}{\mu o}+\frac{K r w}{\mu w}}
\end{gathered}
$$

Now Divide Through By $\frac{K r w}{\mu w}$ and

$$
\begin{aligned}
& \mathrm{fw}=\frac{1}{\frac{\mathrm{Kro}}{\mu \mathrm{o}} \cdot \frac{\mu w}{\mathrm{Krw}}+1} \\
& \mathrm{fw}=\frac{1}{1+\frac{\mathrm{Kro}}{\mathrm{Krw}} \cdot \frac{\mu w}{\mu_{0}}}
\end{aligned}
$$


EXAMPLE CALCULATION OF FRACTIONAL FLOW

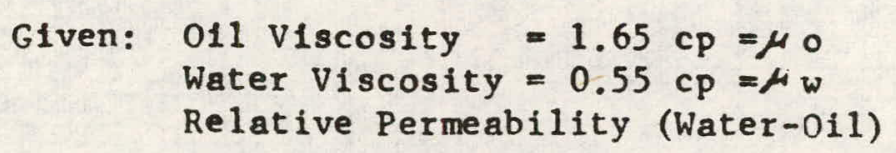

\begin{tabular}{|c|c|c|c|c|c|c|c|c|}
\hline $\begin{array}{l}\text { (1) } \\
\text { Sw } \\
\end{array}$ & $\begin{array}{r}(2) \\
\text { Kro } \\
\end{array}$ & $\begin{array}{l}\text { (3) } \\
\mathrm{Krw} \\
\end{array}$ & $\begin{array}{l}(4) \\
\mathrm{Krw} \\
\mathrm{Kro}\end{array}$ & $\begin{array}{r}(5) \\
\mathrm{Kro} \\
\mathrm{Krw} \\
\end{array}$ & $\begin{array}{l}(6) \\
\frac{\mu w}{\mu o}\end{array}$ & $\frac{\mathrm{Kro}}{\mathrm{Krw}} \cdot \frac{\mu \mathrm{w}}{\mu \mathrm{o}}$ & $1.0+(7)$ & $\begin{array}{r}(9) \\
\mathrm{fw} \\
1.0 /(8) \\
\end{array}$ \\
\hline .27 & 0.60 & 0.0 & 0 & & 0.333 & & & 0.0 \\
\hline .30 & .34 & .002 & .0059 & 170 & 0.333 & 56.5 & 57.5 & .017 \\
\hline .40 & .10 & .01 & .10 & 10. & 0.333 & 3.33 & 4.33 & .231 \\
\hline .49 & .03 & .03 & 1.0 & 1. & 0.333 & .333 & 1.33 & .751 \\
\hline .60 & .009 & .09 & 10.0 & .1 & 0.333 & .033 & 1.03 & .968 \\
\hline .65 & $.003=$ & .125 & 40.3 & .025 & 0.333 & .0083 & 1.008 & .993 \\
\hline .70 & .001 & .17 & 230.0 & .0043 & 0.333 & .00143 & 1.001 & .996 \\
\hline
\end{tabular}

Where:

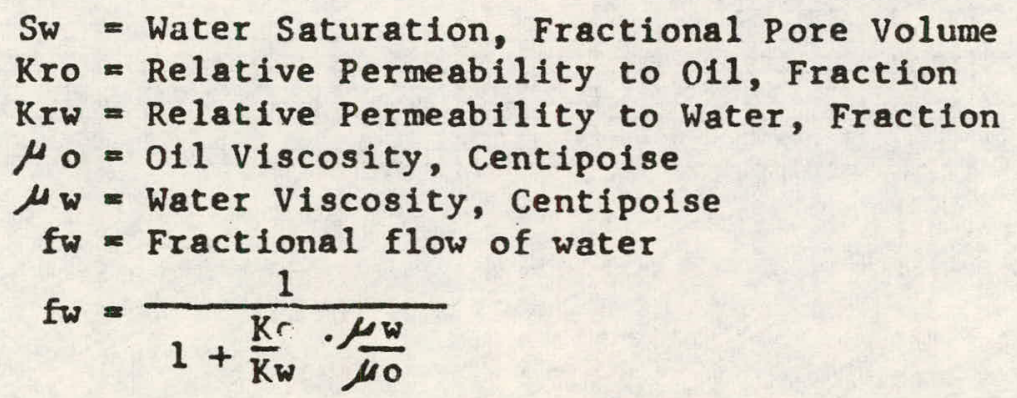


CORE LABORATORIES. INC.

Pernoleum Resenvar Engineering

DALLAS. TEXAS
Page

File
Company
Formation
Well County
Field State

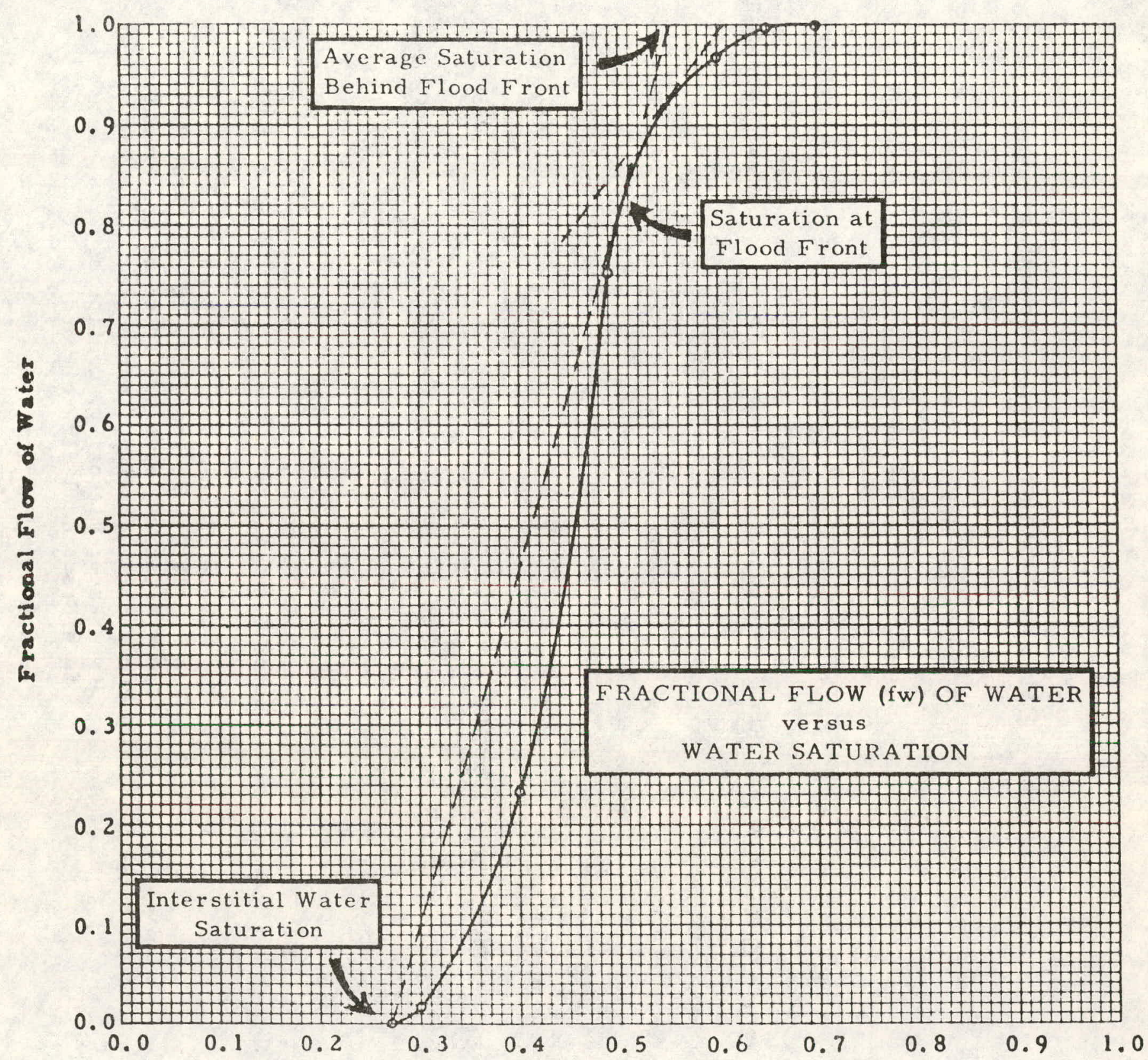

Water Saturation, Fractional Pore Volume 
EXAMPLE CALCULATION OF WATER FLOOD PERFORMANCE CALCULATED USING $\mathrm{KW} / \mathrm{KO}$ AND FLUID PROPERTIES OF MUDDY SAND

(1)

Sw 1

End Face

0.270

.505

.550

.600

.650

.700
(2)

Sw2

Average

0.270

.554

.607

.646

.677

.700
(3)

(4)

Cumulative Oil Produced (Fractional PV) Sw2-Cw

fw @ Sw1

0

.829

.925

.965

.994

1.00

\section{0}

.284

.337

.376

.407

.430
(5)

(6)

(7)

Qi

Water Injected

(Pore Volumes)

Sw2-Sw1 (1.0-fw)

1.0

(5) $/(6)$

$$
0
$$

.760

$.057 \quad .075$

1.31

$.046 \quad .035$

.006

4.5

0.0

\section{Where:}

Swl = Water Saturation at Producing Well-Fraction of Pore Volume

Sw2 - Average Water Saturation Between Producing and Injection Well - Fraction of Pore Volume

$\mathrm{fw}=$ Fractional Flow of Water

$C_{w}=$ Interstitia- Water Saturation (Initial Water in Reservoir at Start of Water Injection)

fo $=$ Fractional Flow of 0 il $=(1.0-\mathrm{fw})$

Qi = Cumulative Water Injected, Pore Volumes 
CORE LABORATORIES. INC

Purrileun Rescrvour Engucering

DALLAS. TEXAS
Pacje of

File

Formation

Company

Well

Field County State

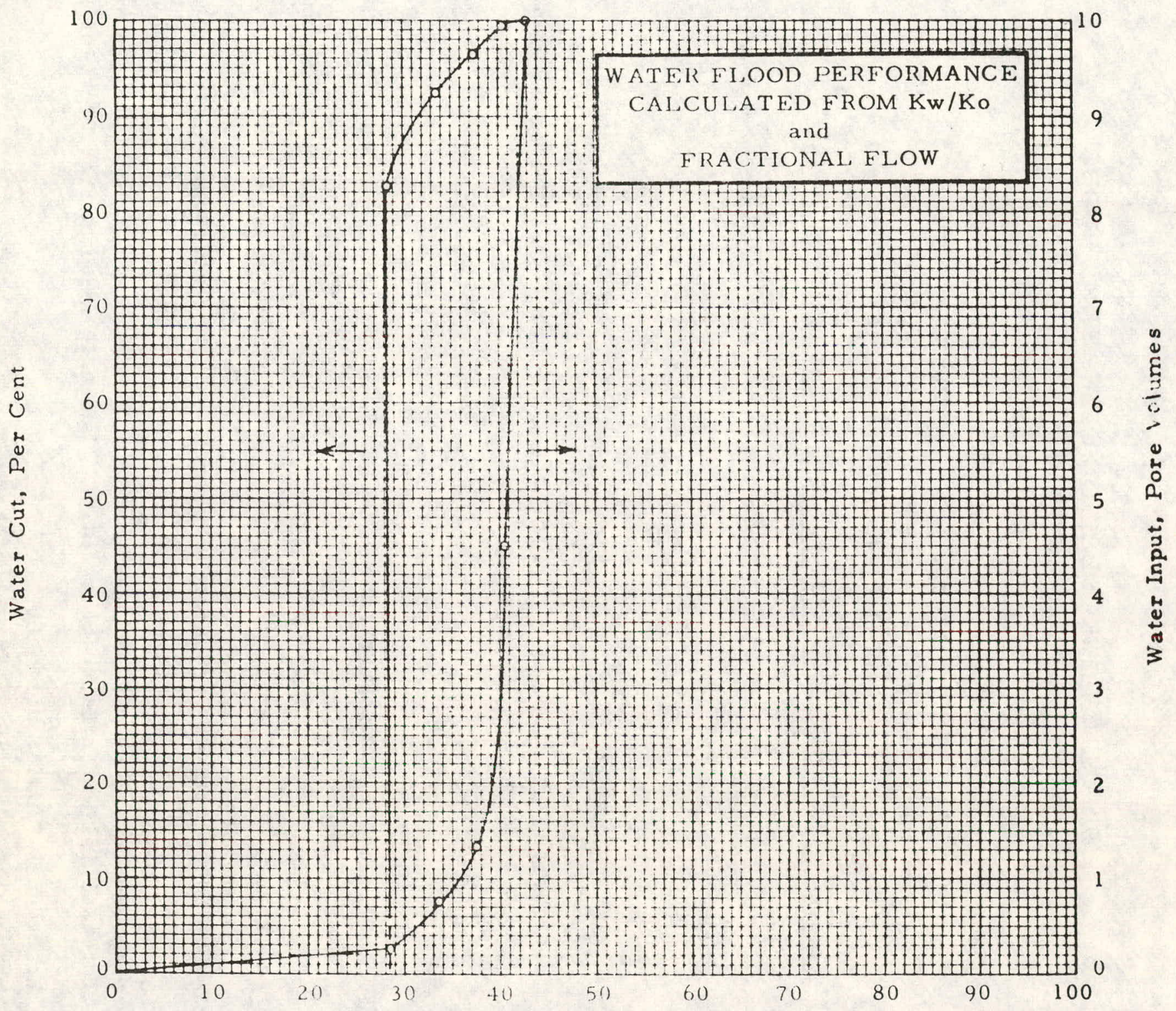

Ci! Recowery, twr Cint Pure Spate 
$K_{w} / k_{0}$ to fractional flow of water which is in reality water cut at reservoir conditions in the producing well bore; (2) example calculation of fractional flow of water using $k_{w} / k_{0} d a t a$ for Muddy sand; (3) plot of fractional flow of water versus water saturation; (4) calculation of water flood susceptibility from fractional flow data of Muddy sand (5) plot of water flood susceptibility.

2. Water Floods on Cores Containing Trapped Gas

(A) Use: These tests are made to simulate water flooding of a pressure depleted oil zone where flood pressures are so low that free gas that occurred due to pressure drop and production will not go back into solution in the oil. In this situation the trapped gas will affect relative permeability and residual oil values.

(B) Method: Extracted and dried samples are saturated with brine. They are restored to initial oil and water saturations as discussed in basic floods. They are then gas flooded to the current reservoir gas saturation. The cores are subsequently flooded with oil to simulate the formation of an oil bank and to establish a trapped gas saturation. Water is then injected and performance is monitored as in a WFS test. These tests are normally made at elevated prcssuites to minimize qas snlubility in the ull and water.

(c) Type of Tests: - Extracted cores at room temperature but elevated pressure.

(D) Type of Samples - Whole core, 1-1/2" or 2" diameter cylindrical plugs. 
(E) Minimum Number of Samples - Four to eight

(F) Special Information Needed

(1) Same data as room condition Basic Flood.

(2) Gas saturation in reservoir at time of initiation of water flood.

(G) Average Minimum Time Required:- Eight to ten weeks.

(H) Data Reported: Tabular and graphical oil recovery versus water cut and water volumes injected. Initial gas and final trapped gas saturations are given as well as oil permeability at trapped gas saturation.

Tabular data also include air permeability, porosity, connate water, effective permeability to oil at connate water saturation (ahead of flood front), oil recovered by flood, residual oil saturation and effective permeability to water at residual oil (behind the flood front).

(1) Key Equations - Not applicable.

3. Gas $0 i l(\mathrm{Kg} / \mathrm{Ko})$ Relative permeability

(A) Use - These data are used in conjunctionıwith fluid properties and material balance equations to predict pressure, gas-oil ratio and production performance for solution gas-drive reservoirs. $K_{g} / K_{0}$ is also required for gas-cap advance, gravity drainage, productivity decline, gas coning and fractional flow equations. 
(B) Method:

(1) Gas drive (also called Welge or unsteady state method) with no connate water - Gas displaces, at a high rate, the viscous oil from an oil saturated core with no connate water present. Rates and volumes of effluent are measured throughout the test. Relative permeability is calculated by digital computer using equations by Johnson, Bossler and Naumann "Calculation of Relative Permeability from Displacement Experiments" AlME Transactions, Vol 216 (1959). Tests are normally made at room conditions temperature and pressure on extracted and restored cores.

(2) Gas drive with connate water present - $\mathrm{Kg} / \mathrm{Ko}$ tests should be run with connate water in most cases. This is particularly important in sands containing hydratable clays and in low permeability rock. This test allows only two mobile phases; so when water is present, it must be at an immobile saturation. This deviates from reservoir conditions in those cases where both oil and free gas are present and the reservoir is close to the oil-water contact so that water also flows. Tests can be made on fresh core but normally are madc on extracted, restored roree.

(3) Relative permeability can be calculated from pore size distribution data. See section on Relative Permeability Calculated from Pore Size Distribution.

(c) Type of Tests: 
(1) Restored core tests with or without connate water at room temperature normally using a viscous (17 centipoises) refined oil.

(2) Fresh core tests can be made if requested and normally a viscous refined oil is used.

(D) Type of Samples - Whole core or cylindrical plugs $1 ", 1-1 / 2 "$ or $2 "$ in diameter.

(E) Minimum Number of Samples - Three to five.

(F) Special information Needed:

(1) When no connate water is requested no special information is needed.

(2) With connate water requires composition, chloride content or resistivity of formation water.

(G) Average Minimum Time Required: - Eight weeks

(H) Data Reported: Permeability to air, permeability to oil at connate water saturation, porosity, connate water, tabular and graphical data of relative permeability to gas, relative permeability to oil, and gas-0 11 relative permeability ratio as function of l lquid saturation.

(1) Key Equations: - Example of fractional flow is given in Water-0il Relative Permeability Section and similar equations apply in gas-oil system.

4. Gas-Water $\left(k_{g} / K_{w}\right)$ Relative Permeability

(A) Use - These data are used for calculation of gas bubble formation in gas storage projects where gas displaces aquifer water from a zone originally 
CORE LABORATORIES, INC.

Pecrolium Rescrvour Engincerung

DALLAS TEXAS
Page of

File

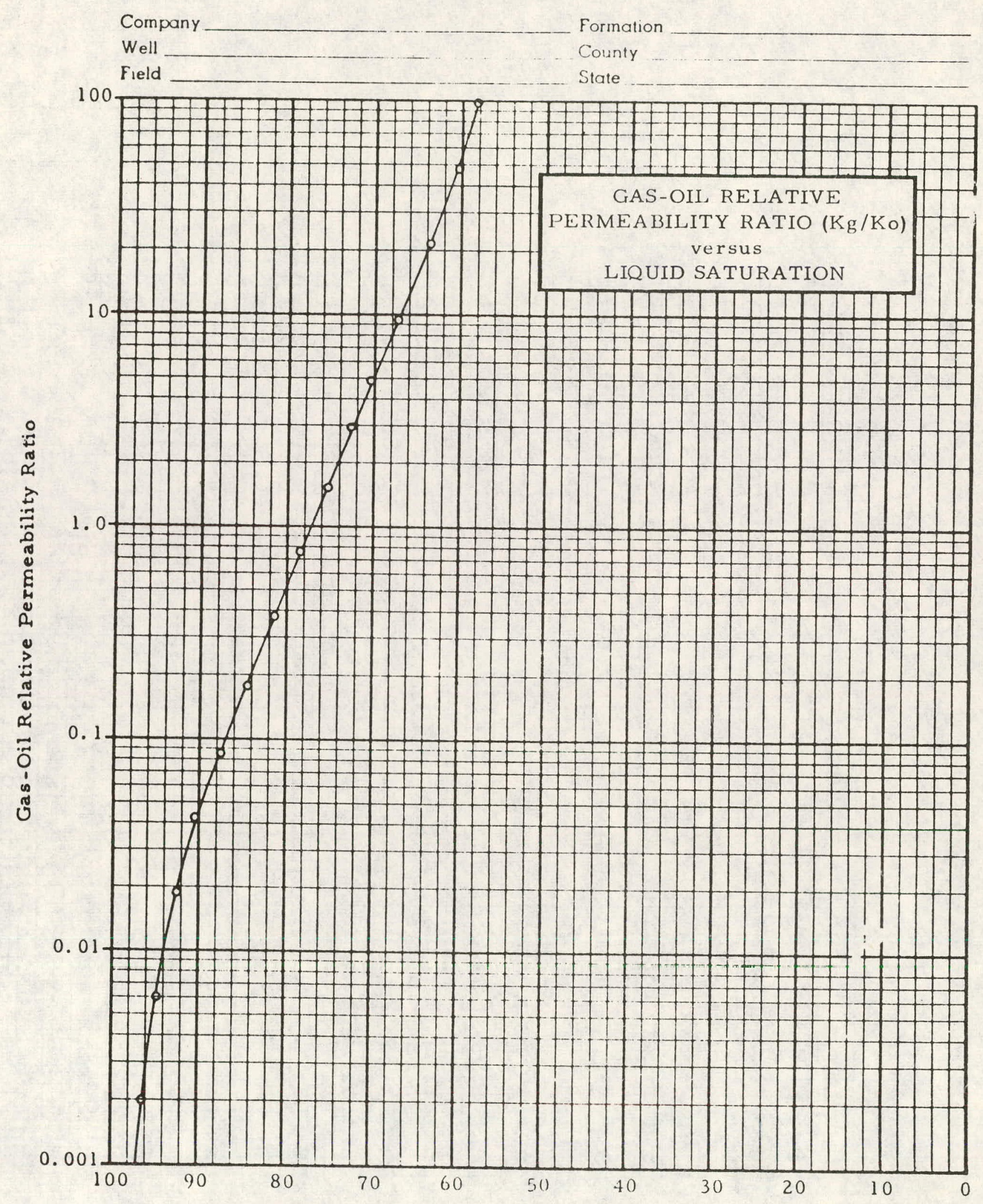

Liquid Saturation, Per Cent Pore Space 
CORE- L ABORATORIES. INC.

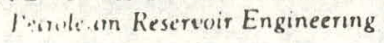

DALLAS. TEXAS
Page

File of

Company Formation

Well County

Field State

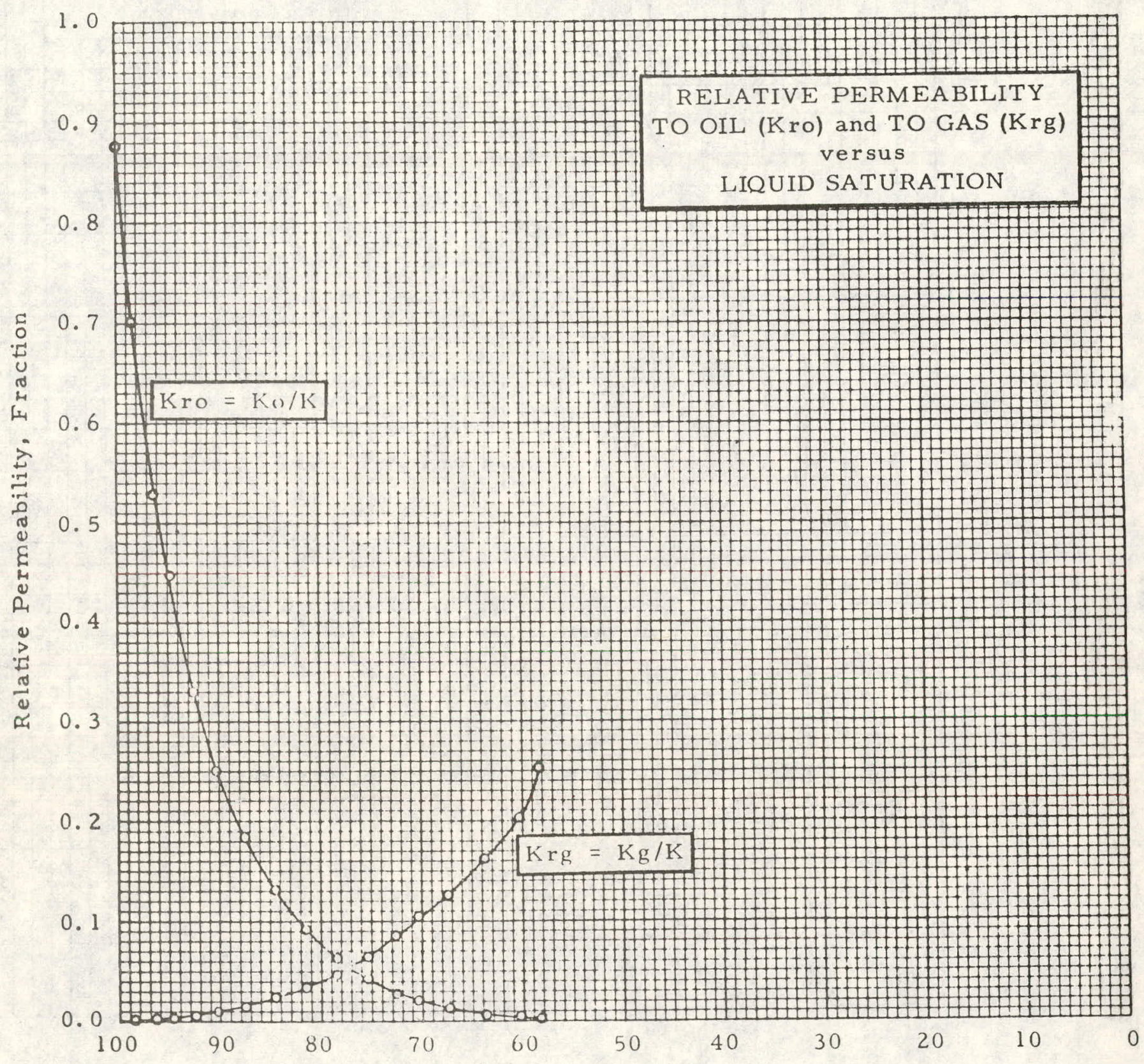

Liquid Saturation, Per Cent Pore Space 
100 per cent water saturated. Also used for gravity drainage and theoretical productivity calculations in gas storage wells.

(B) Method:

(1) Gas drive (Welge or unsteady state method) Gas displaces, at a high rate, water from a 100 per cent water saturated core. Rate and volume are measured throughout the test. Relative permeability is calculated by digital computer using similar equations to $\mathrm{K}_{\mathrm{g}} / \mathrm{K}_{\mathrm{o}}$ calculations. (2) $K_{g} / K_{w}$ can be computed from pore size distribution data derived drom capillary pressure test. See section on calculation of Relative Permeability from Pore Size Distribution.

(c) Type of Tests - Gas-drive tests are normally made on restored core at room temperature. Fresh samples could be used if requested.

(D) Type of Samples - Cylindrical plugs 1", 1-1/2" or $2^{\prime \prime}$ in diameter or whole core.

(E) Minimum Number of Samples - Three to five

(F) Special Information Needed - Composition, chloride content, or resistivity of formation water.

(G) Average Minimum Time Required - Eight weeks

(H) Data Reported - Porosity, permeability to air and to water. Tabular and graphical presentation of relative permeability to gas, relative permeability to water, and gas-water relative permeability ratio as function of water saturation. 
CORE LABORATORIES. INC.

Petrolewm Reservor Engineering

DALLAS. TEXAS
Page

File of

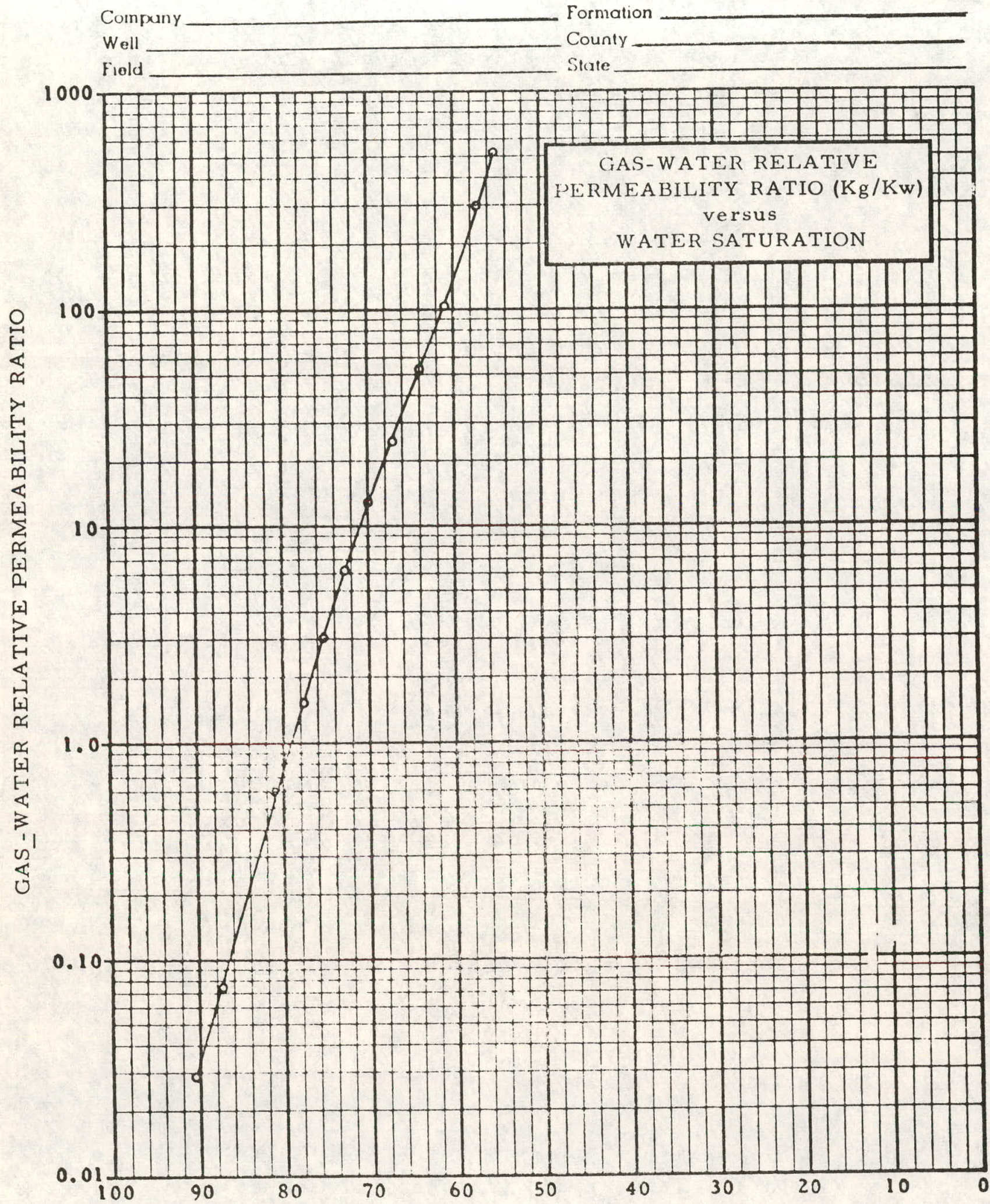

WATER SATURATION, PER CENT PORE SPACE 
CORE LABORATORIES. INC.

Pernoleum Reservoar Enginering

DALLAS. TEXAS
Page

File ol Formation

Company County

Well State

Field

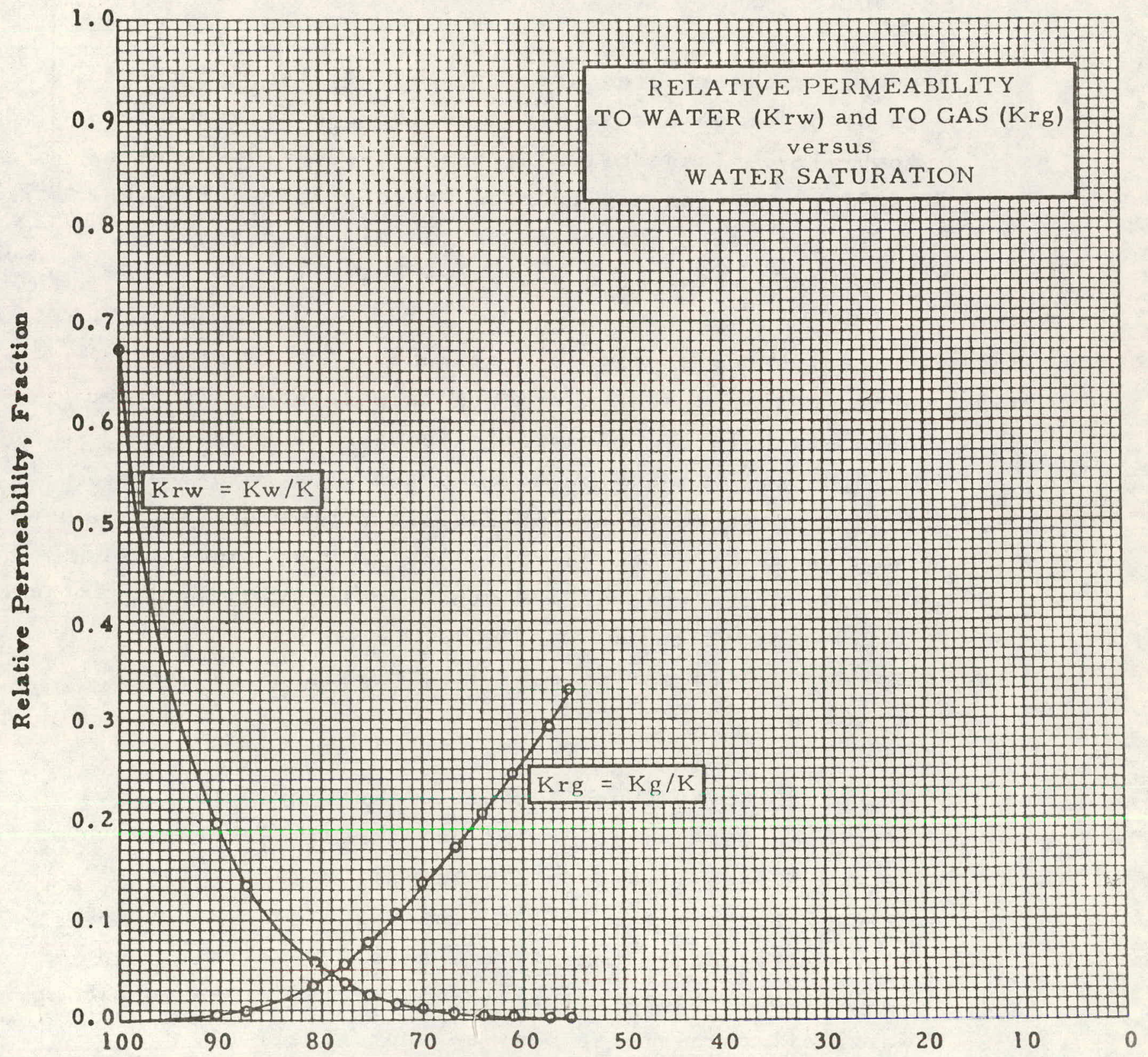

Water Saturation, Per Cent Pore Space 
(i) Key Equations - Example of fractional flow is given in Water-oil Relative Permeability Section and similar equations apply in gas-water system.

5. Relative Permeability Calculated From Pore Size Distribution.

(A.) Use: Capillary pressure data can be used for the calculation of pore size distribution and relative permeability. These calculations were developed for a capillary drainage situation where a non-wetting phase (gas) displaces a wetting phase (oil in gas-oil system and water in a gas-water system).

Gas-drive tests discussed elsewhere are recommended where possible, but there are cases where calculated data are helpful. Examples are when rock samples are too small for flow tests but adequate for capillary pressure tests, or capillary pressure data have been run in preceeding years and rock no longer esists for gas-drive testing. Another application is in extremely tight reservoirs where flow tests are impractical but mercury injection capillary pressures can be obtained.

As noted above, these terhniques were primarily developed for gas-oil relative permeability since this is a drainage situation. Water-oil data can be calculated, but the latter contains a great uncertainty since water encroachment into an oil reservoir is an imbibition process rather than drainage. The resulting water-oil data are at best an approximation.

One additional use of these data is in gas-condensate reservoirs where oil saturation builds up as pressure drops, causing a reduction in gas well productivity. 
The normal gas-drive $\left(k_{g} / k_{0}\right)$ flow test does not yield relative permeability at the high gas saturations (low liquid saturation) needed for gas condensate reservoir calculations. The calculated relative permeability furnishes relative permeability values for gas saturations of 100 per cent to zero and can be used for engineering approximations.

(B) Method - Experimental and theoretical work were carried on simultaneously by Burdine and Purcell. Equations utilized are a combination of the two calculation techniques. Burdine's contribution was in the handling of the tortuosity factor. Purcell's integration of $1 / \mathrm{Pc}^{2}$ has been adopted as the most practical. This calculation requires that a complete capillary pressure curve be available. Mercury injection complete curves are preferable because of the multiplicity of points and good definition. See Equations Section (1).

(c) Type of Tests - Not applicable

(D) Type of Samples - Requires core suitable for capillary pressure test. Permeability plugs, 11 or $1-1 / 2 " d i a-$ meter satisfactory. Low porosity cores require 1-1/2" sample for accuracy. Maximum plug length is approximately 2 ".

(E) Minimum Number of Samples - Three to five.

(F) Special Information Needed - Calculation from pore size distribution requires knowledge as to approximate height in feet above oil-water contact at which top of the oil column exists. Also requires reservoir oil 
gradient and water gradient in psi/ft so proper water saturation in reservoir at top of zone can be estimated from capillary data. This is needed in cases where little closure exists and the total oil zone is close to the water-oil level with a reservoir water saturation greater than irreducible.

(G) Average Minimum Time Required - Two to three weeks in addition to time to run capillary pressure.

(H) Data Reported - Capillary pressure data used in calculations are reported. Tabular and graphical presentation of relative permeability to wetting phase (oil in gas-oil system and water in gas-water system) and non wetting phase (gas in gas-oil system and gas in gas-water system).

(1) Key Equations - See next page. 


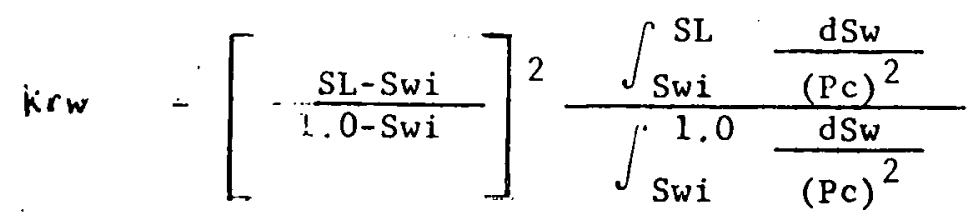

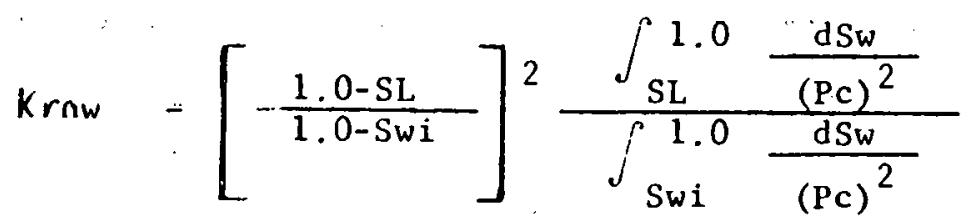$$
\frac{K_{B}}{k_{0}}=\frac{K r \xi}{K r o}=\frac{K r n w}{K r w}
$$

\section{Where:}

$$
\begin{aligned}
& \text { Krw - Kelalive peliluability to wetting phase (Krw \& Kro) } \\
& \text { Krnw - Kelative permeability to mon-wetting phase (Krg) } \\
& \text { Swi -. Minimum comble water saturation } \\
& \text { SL = Tolal liquil saturation = (1.0-gas saturation) } \\
& \text { PC - lapillary pressure } \\
& \text { Sw - Welling phase saturation from Pc curve }
\end{aligned}
$$

\section{Note:}

Equations as wrilten apply to case where initial water in saniple: is at ireducible (Swi). 
H. Overburden Permeability and Porosity

(1) Use - The advent of rubber sleeve cores taken in formerly unrecoverable unconsolidated formations has been the primary factor in development of this service It has been observed in competent formations that water present in the pore spaces during overburden test lubricate the sand grains and/or soften the matrix yielding greater compression than when cores are tested in the dry state. This has not proven to be important a factor in many of the unconsolidated sands and the service offered herein is performed on clean, dry cores.

Air permeability and porosity under overburden conditions are necessary for approximation of reservoir condition values when the core is unconsolidated.

Relaxation of the grain contacts occur during coring, movement to the surface, or during the removal of the core from the rubber sleeve. This results in erroneously high values of permeability and porosity unless a correction is made for this relaxation prior to the time the physical parameters of the core are determined. 
One technique used to minimize disturbance of the sand grains during preparation is to freeze the rubber sleeve and drill the test plug using liquid nitrogen. $1 t$, is then mounted while in the frozen state and ready for further testing. A more common method is to insert a punch through a window cut in the rubber sleeve and extract a core sample which is displaced into a thin wallo metal. sleeve with screens over the end to minimize grain loss. The sleeve is seated to the sand (containing residual fluids) by squeezing at a selected overburden pressure. After the sample has been cleaned it is then ready for overburden measurements.

Increased overburden pressure causes a reduction in porosity and permeability. The net overburden pressure on the formation that causes compression of the rock can be calculated by assuming the overburden gradient due, to rock weight is $1.0 \mathrm{psi} / \mathrm{ft}$ and the internal gradient due to hydrostatic pressure is $0.5 \mathrm{psi} / \mathrm{ft}$ (fresh water is $0.433 \mathrm{psi} / \mathrm{ft}$ ). This results in an approximate expression that yields the net pressure (frame) causing compaction and states this frame pressure is equal to ( $1.0 \mathrm{psi} / \mathrm{ft}-0.5 \mathrm{psi} / \mathrm{ft}$ ) $x$ depth in feet. This simplifies to the expression that net overburden pressure equals one-half the depth. For example, the laboratory overburden overburden pressure used to masure permeability and 
porosity should be approximately 5000 psi if the formation were 10,000 feet deep.

Boundary loading conditions causing compression of the rock in the laboratory differ from those in the reservoir. One investigator states that a better approximation in the laboratory is to use one-fourth the depth rather than one-half. On a study conducted by an engineering and consulting lab, it was

found that a factor slightly greater than one-fourth the depth was valid. Either the one-fourth or onehalf approximation is better than applying no correction. The greatest reduction in permeability and porosity is often seen with the first 500 psi overburden pressure and use of either one-fourth or one-half the depth often yields little difference in results. The best approach to the problem is to measure both permeabilility and porosity at several overburden pressures so that the trend can be determined.

\section{Method:}

(A) Air Permeability - Samples (consolidated cores or unconsolidated samples mounted in thin wall metal sleeves) are first cleaned and dried. Lengths and areas are determined where appropriate. The samples are placed in tariaxial holders and subjected to a low overburden pressure (approximately 100 psi). Flow of air through the core is measured using the standard permeameter. Overburden pressure is never removed between measurements and is incrementally increased until the maximum pressure is obtained. 
The overburden pressure limitation is approximately 6000 psi due to equipment.

(B). Porosity (Boyle's Law) - Cores are prepared as discussed under Air Permeability. At selected overburden pressures helium is injected into the pore space and pore volume is read from the helium porosimeter gauge. Overburden pressure is then increased and pore volume is again determined. Several pore volume measurements are made at each pressure to assure that equilibrium has been reached and no further compaction of the pore space is occurring. Overburden pressure is never removed from the sample during the test and is increased until maximum pressure is obtained. $1 \mathrm{t}$ is assumed the pore volume reduction also reflects a corresponding and equal reduction in bulk volume.

Permeability and Porosity, these two tests are often measured in conjunction with oneanother. At any given overburden both permeability and pore volume are determined. Overburden is increased and the measurements are repeated as discussed above.

\section{Type of Test}

(A) Single overburden - Permeability and/or porosity can be determined at a single designated overburden pressure.

(B) Multiple overburden - Permeability and/or porosity are usually determined at a number of overburden pressures. These type tests are recommended as the decrease of porosity and permeability gives insight into the sensitivity of these parameters to overburden pressures. Anomalous data can also be identified more easily. 
4. Type of sample - All tests can be made on 1 or $1-1 / 2$ inch diameter cylindrical plugs. Unconsolidated cores are jacketed with thin wall metal sleeves of 1 or $1-1 / 2$ inch. with screens over the ends to inhibit grain loss.

5. Minimum Number of Samples:
(A) Permeability - 10
(B) Porosity - 10
(C) Permeability and Porosity - 10

6. Special Information Needed: - Coring procedures and handling prior to arrival are helpful.

7. Average Minimum Time Required:
(A) Permeability - 6 weeks
(B) Porosity - 6 weeks
(C) Permeability and Porosity - 6 weeks

8. Data Reported:
(A) Permeability-permeability at each overburden
(B) Porosity - porosity at each overburden
(C) Permeability and Porosity - value of both at each overburden.

9. Key Equations: - Not applicable. 


\section{RESIDUAL GAS}

\section{Use}

These tests furnish trapped gas saturation after waterdrive. Data are needed for gas storage projects in aquifers and for naturally occurring gas reservoirs that are underlain by water. Trapped gas may represent appreciable pore space and should be accounted for in reservoir calculations.

Trapped gas is often a direct function of initial gas saturation and in aquifer storage projects this relationship must be developed by running tests at various initial liquid saturations. Naturally occurring gas reservoirs typically have a short gas-water transition zone and tests with irreducible water in the core will suffice.

2. Method:

(A) Imbibition Tests

(1) Liquid saturation comparable to Irreducible Water - Cleaned and dried cores are saturated with water or toluene. The samples are saturated with water in most cases where swelling clays exist and where the cores have nover boon contocted with vil; i.e., a gas scorage aquifer. originally 100 per cent water saturated. In cases where oil has once been in the cores, toluene is superior to water as the saturating wetting phase in that it strongly wets the core and reduces wettability difficulties. When toluene is used, it takes the place of the water and the test simulates the case of a strongly water-wet reservoir system. 
The saturation of the wetting fluid is reduced to a desired value by evaporation. The sample is weighed and then suspended from a balance under the saturating liquid. As the fluid imbibes into the core and displaces gas, the sample changes in weight. Weight is plotted as a function of time until equilibrium is reached in the sample. The residual gas is determined. from the weight plot at a point on the curve indicated by a change in slope where diffusion processes are minimum. This gives one value of residual gas for one initial gas saturation.

(2) Multiple Liquid Saturations- If trapped gas is required for liquid saturations in addition to irreducible, the sample is again 100 per cent liquid saturated and the evaporation process is repeated to establish a different liquid saturation. The imbibition process is again performed to establish a second residual gas. This process is repeated for various initial saturations as requested.

(B) Dynamic Displacement - Cleaned and dried cores are saturated with water. A reduced water saturation is established by centrifuge, capillary pressure cell or evaporation. The voided pores contain air for the test. The core is then placed in a core holder. Mean pressure on the system is increased to about $500 \mathrm{psi}$ and gas saturated water is injected into the core at a low pressure differential. Gas produced is measured at the elevated pressure and residual gas can then be calculated by material balance. 
3. Type of Tests

(A) Imbibition

(1) At irreducible Liquid Saturation

(2) At multiple Liquid Saturations

(B) Dynamic Displacement

4. Type of Samples

(A) Imbibition Tests - l" or 1-1/2" cylindrical plugs preferred. Tests can be made on irregular shaped cores.

(B) Dynamic Displacement - 1" or $1-1 / 2^{\prime \prime}$ cylindrical plugs.

5. Minimum Number of Samples:

(A) Imbibition Tests - Four to eight

(B) Dynamic Displacement - Four to eight

6. Special Information Needed

(A) Imbibition Tests

(1) At irreducible Liquid Saturation - If water is used, i rreducible can be established by centrifuging cora. Connate water salinity, composition or resistivity is required. If toluene is used, information on irreducible water saturation must be furnished.

(2) At multiple Liquid Saturations - If no liquid values are furnished, several saturations 
will be selected. If water. is used, the salinity, composition or resistivity is required.

(B). Dynamic Displacement - Salinity, composition or resistivity of connate water is required.

7. Average Minimum Time Required.

(A) Imbibition Tests - Six to eight weeks

(B) Dynamic Displacement - Eight weeks

8. Data Reported

(A) Imbibition Tests - Tabular data include air permeability, porosity, connate water, initial gas and gas recovered.

(B) Dynamic Displacement: - Identical data to imbibition tests.

9. Key Equations - Not applicable. 


\section{J. THERMAL RECOVERY TESTS}

Thermal recovery is primarily used to increase production from low API gravity reservoirs containing viscous oil. A valid thermal prospect typically has low primary production recovery and is often a poor risk for more conventional secondary recovery operations such as water flood.

Addition of thermal energy to the reservoir results in expansion of the oil in place and a dramatic reduction in oil viscosity. An example of the latter would be reduction of viscosity from 1000 centipoises to 1 centipoise by raising reservoir temperature from $100^{\circ} \mathrm{F}$ to $500^{\circ} \mathrm{F}$. This oil viscosity reduction is the principal factor yielding increased recoveries.

Several types of tests may be run in the laboratory to assist engineers in selection of the proper thermal recovery process to use. These include (1) hot water injection (2) steam injection and (3) in-situ combustion. Each process offers advantages in certain situations and is likely to be unsatisfactory in others. Fewer people have practical experience in thermal operations than in routine water flood operations and it is therefore highly desirable that each prospect be studied critically in making a final selection of the most promising process.

$$
\text { In general, most thermal projects are relatively }
$$
shallow and both hot water and steam injection are conducted at depths less than 2500 feet. A rule of thumb of 1000 barrels of oil per acre-foot as a minimum volume to support a thermal operation can be used. Steam and hot water injection require thick sands (greater than 50 feet) to minimize heat loss while 
in-situ combusion may operate satisfactorily in sands less than 50 feet in thickness.

\section{Hot Water Flood}

(A.) Use - These data are used to predict oil recovery by injection of hot water. Recovery in this case is enhanced by (1) viscosity reduction of the crude and (2) thermal expansion of the oil. Effective permeability to oil in the presence of connate water and water permeability at residual oil are given, in addition to other information: These data may be used with permeability distribution and injection.pattern efficiency to make predictions of reservoir performance. Equations such as those proposed by Marx and Langeheim are used to investigate the cumulative heated area, the thermal invasion rates and to derive the economic limits for hot water injection. These. equations require a residual oil value which is furnished by the hot water flood test.

In addition, Water Flood Susceptibility tests, using hot water as the injection fluid, present oil recovery as a function of pore volumes of water injected and water cut. A graphic display of reservoir performance in a given strata swept by water is presented and thereby offers more insight into flood performance than do Basic flood tests.

Hot water floods are normally made on heavy oils that have little or no gas in solution in the reservoir. Crude oil is normally used in these tests and floods are made at the temperature 
proposed for injection. In these cases, the viscosity of the crude oil used in the laboratory test will approximate the viscosity of the crude in the reservoir when brought to the injection temperature. These floods therefore approach reservoir condition floods where no reservoir pressure is present.

(B) Method:

(1) Basic Flood

a. Extracted cores - Extracted and dried cores are saturated with formation brine. Connate water is established by centrifuge, capillary pressure cell, dynamic displacement or evaporation. "Voided pores are then saturated with crude oil. The samples are placed in an air bath and the temperature is elevated to that of the hot water flood. Permeability to oil is determined. Hot water is injected and total oil recovery is recorded for the Basic Flood test. Permeability to water in the presence of residual oil is also determined.

b. Fresh cores - Plugs drilled from fresh core are evacuatcd under oil aind lien flushed with oil (may require elevated temperatures) to remove free gas. Extraneous water introduced during coring is displaced by centrifuge, capillary pressure cell or dynamic displacement. Effective 
permeability to oil is measured and the temperature of the samples is elevated and the samples are flooded, as above. After the water flood, residual contents are measured by distillation. Air permeability and porosity are determined on the clean sample. Saturations present at the start of the flood are calculated by material balance.

\section{(2) Water Flood Susceptibility}

a. Extracted cores - Same procedure as Basic Flood with addition of incremental water cut, injected volumes and oil recovery measurements.

b. Fresh cores - Same procedure as Basic Flood with addition of incremental water cut, injected volumes and oil recovery measurements.

C. Type of Tests:

(1) Basic Flood tests at desired temperature and atmospheric pressure for end point permeabilities and saturations. Tests are made on fresh or restored cores.

(2) Water Flond susceptibility tests at desired temperature and atmospheric pressure for end point values of permeability and saturations in addition to incremental oil recovery versus water cut and injected volumes. Tests are made on fresh or restored cores.

D. Type of Samples:

(1) Basic Flood (fresh or restored core) - Whole core or cylindrical plugs $1 ", 1-1 / 2 "$ or $2^{\prime \prime}$ in diameter. 
(2) Water Flood Susceptibility (fresh or restored core) Same as Basic Flood except 1-1/2" or larger are preferred.

(E) Minimum Number of Samples: - Three to five.

(F) Special Information Needed: - The following data are needed for fresh, restored $p l u g$ and whole core floods. A sample of the crude oil and the composition; chloride content or resistivity of formation water and injection water are required. Also required are formation temperature and temperature of the hot water flood. Information as to the approximate height above the oil-water contact of the centroid of the oil column is helpful in establishing the magnitude of the connate water on the restored flood samples.

(G) Average Minimum Time Required: - Eight weeks.

(H) Data Reported:

(1). Basic Flood - Tabular values of porosity, permeability, connate water, permeability to oil at connate water, oil in place, residual oil, oil recovered, permeability to water at residual oil.

(2) Water Flood Susceptibility - Incremental oil recoverty versus injected water volumes and water cut are given in tabular and graphical form in addition to the data reported for the Basic Flood.

(i) Key Equations - Not applicable. 


\section{Steam Floods}

(A) Use - These test furnish data as to the susceptibility of a formation to steam injection. The laboratory test simulates a frontal drive displacement mechanism and not the "huff and puff" technique where steam is injected into and produced from the same well in cycles.

0il recovery in a steam flood process results primarily from (1) steam distillation of the crude, (2) thermal expansion of the crude and (3) viscosity reduction. Other less important factors that may have some influence on recovery are gas-drive effects and solvent extraction. The oil properties are of maximum importance in these tests and it is therefore essential that crude oil be used during steam displacement tests.

The Marx and Langenheim equations require residual oil values after steam injection and are often used to calculate thermal invasion rates, heated area and economic limits of steam injection. This equation requires a valid value for residual oil which. is furnished in the laboratory steam flood.

\section{(B) Method:}

(1) Extracted cores - Extracted and dried cores are saturated with formation brine. Connate 
water is established by centrifuge, capillary pressure cell, dynamic displacement or evaporation. The voided pores are saturated with crude oil. Permeability to oil is determined. Samples are then placed in an air bath and the temperature elevated to that used for steam flooding. This procedure simulates conditions in that portion of the reservio that has been increased to the steam temperature.

Other variations of this flooding technique may be accomplished by elevating the temperature of the sample only to reservoir temperature and then heating it further by steam injection. This laboratory technique has the disadvantage that in low permeability cores the rate of steam injection through a sample may be so slow that a true steam flood is never reached in the laboratory and at best a hot water flood is performed on the core. In most cases, it is advantageous to raise the temperature of the sample to that of the injected steam prior to or during the actual injection of the steam. After the desired temperature has been reached, steam of approximately 80 per cent quality is injected into the core. 0 il recovered and condensed water volumes are monitored.

Flow rates and heat losses cannot be precisely scaled to reservoir conditions and therefore the incremental recovery data are only a qualitative indication of reservoir performance. The final quantitative value of residual oil after steam flooding is 
secured by distillation of the tested sample.

(2) Fresh cores - Plugs drilled from the fresh core are evacuated under oil and then flushed with oil to remove free gas when the oil is available and of low enough viscosity that it can be flowed through the cores. In many cases, this is not feasible because the oil viscosity is so high and/or oil from the formation to be steam flooded is not available. Data reported in the literature indicate that the residual oil after steam flooding is independent of the initial saturation in most cases. This means that floods can be made on samples as recovered from the core barrel. Once the sample has been placed in the steam flood apparatus and brought to to temperature, the flooding procedure is the same as discussed under extracted cores above. After flooding, the residual oil content in the test core is determined by distillation. Porosity and permeability of theclean core are determined. Where possible, the saturations present at the start of the flood are computed by material balance. In most cases, an adjacent plug to the steam sample is secured and analyzed to yield water and oil saturations that are assumed to be initially present in the steam flood core. When this is done, it is indicated on the summary data sheet.

Emulsions often form in the produced fluids and it is difficult to separate the produced crude oil from the condensed water. In most cases these emulsions can be broken by the addition of chemicals and/or centrifuging to yield recovery as a function of injected 
volumes. Even where this cannot be accomplished, reliable values of the residual oil saturation at the conclusion of the steam flood are obtained by distillation.

(c) Type of Tests: - Tests are made on fresh or restored cores and are not "huff and puff" but displacement type tests. Water used in forming the steam must be distilledbecause of equipment limitations. This prohibits addition of chemicals to a furnished field water to evaluate possible damage to the sample from chemical carry over.

The maximum steam temperature that can be sustained for any length of time is $500^{\circ} \mathrm{F}$. Steam flood tests often approach one day testing time and difficulty is experienced with the "0" rings and other equipment at temperatures approaching $550^{\circ} \mathrm{F}$. In most cases, steam flood tests are limited to approximately $500^{\circ} \mathrm{F}$.

(D) Type of Samples - Cylindrical plugs one and one-helf inches in diameter are preferred. Whole core can be tested in some cases but equipment is not designed for delivery of large steam volumes that are typically required for whole core steam floods.

(E) Minimum Number of Samples - Three to five.

(F) Special Information Needed: - Similar data is required for fresh, restored, $p l u g$ and whole core analysis. An actual sample of the crude is required for restored core tests although not needed for fresh core tests. 
CORE LABORATORIES. INC. Perodoum Reserwor Engineming

Page of

DALLAS. TEXAS

File

Company

Formation

Woll County

Fiold State

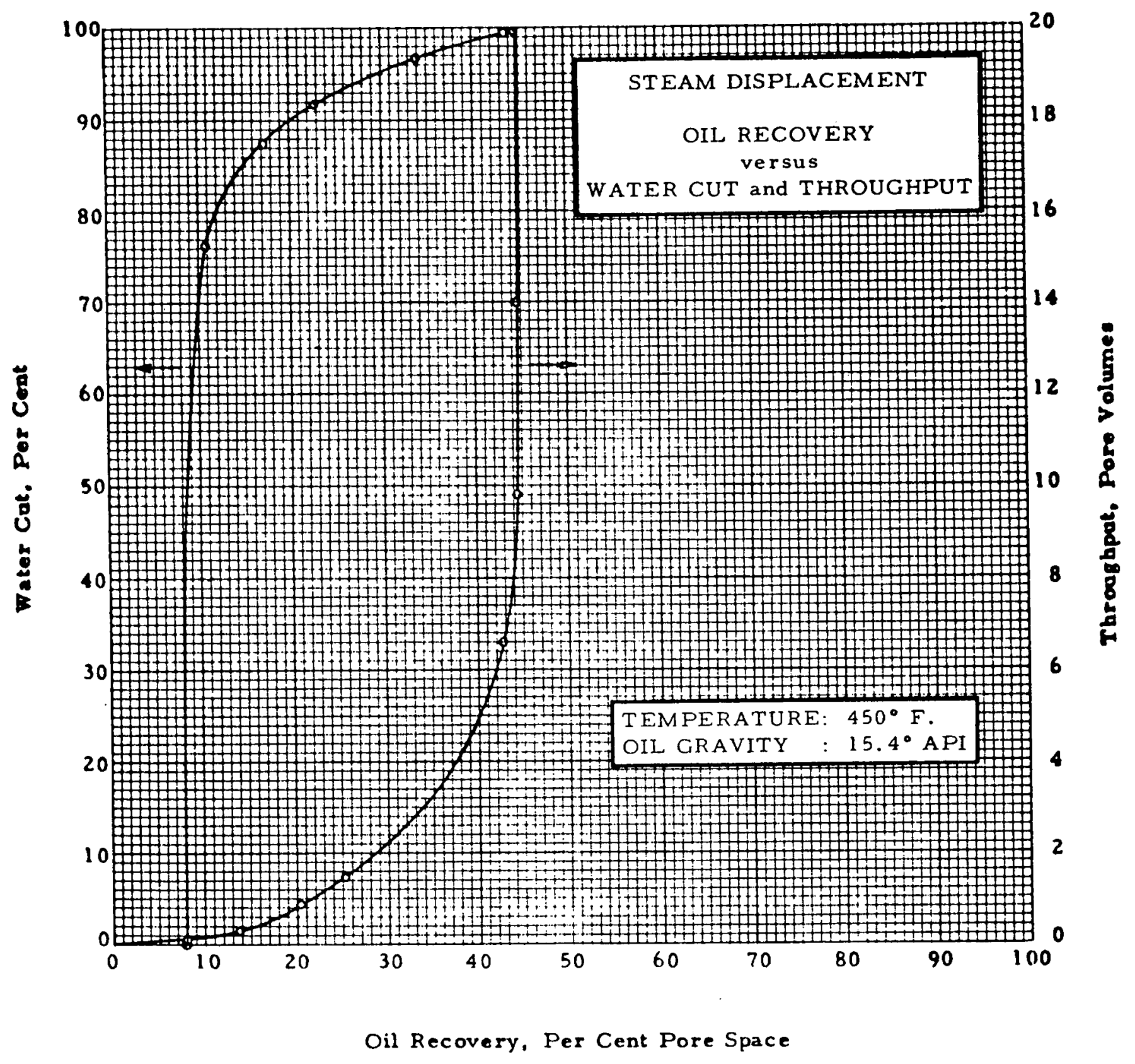


The desired temperature of steam injection must be furnished although the maximum temperature can be estimated from the formation depth. This is accomplished by assuming that the maximum injection pressure is that which will not fracture the formation. This fracture pressure can be estimated by multiplying an overburdenpressure gradient of one psi/foot of depth times the depth in feet. The temperature of the steam can then be found from the relationship of steam temperature and pressure corresponding to the calculated fracture pressure.

(G) Average Minimum Time Required: - Six to eight weeks

(H) Data Reported: - Incremental oil recovery and water cut versus throughput volumes (condensed water volumes) are given in tabular and graphical form. Tabular values of porosity, permeability, initial water, oil in place, oil recovered and residual oil are presented.

(1) Key Equations - Not applicable.

3. Steam Soak

(A) Use - These data are used to evaluate changes in permeability and porosity of cores after exposure to steam vapor for extended periods of time. Chemicals may be added to the system so that their effects on the rock can be evaluated. For example, steam soaking certain formations with ammonia may inhibit clay swelling in some cases and result in better injectivity in the formation.

(B) Method: - Porosity and air permeability are determined on the clean dry core. The core is then evacuated and pressure saturated with a prescribed 
salinity fluid (normally fresh water). Permeability to the saturating fluid is determined. If clays are present, liquid permeability is normally lower than the klinkenberg corrected air permeability. The core is then placed in a high temperature and pressure autoclave and soaked in steam vapor for one week at temperatures comparable to the proposed steam flood. After removal from the autoclave, porosity and air permeability are remeasured. The sample is again saturated with liquid and its liquid permeability is redetermined.

The soak may then be repeated with a desired chemical. permeabilities are remeasured and comparison to initial nonchemical values give insight into changes occurring within the sample after exposure to the. chemical.

(c) Type of Tests: - These tests are static soaks of extracted core (no dynamic flow of steam through the core) by steam vapor.

Temperature and pressure restrictions of the equipment are approximately $700^{\circ} \mathrm{F}$ and 3200 psi, respectively.

(D) Type of Samples: - This test is limited to one inch, one and one-half inch or two inch diameter cylindrical plugs.

(E) Minimum Number of Samples: - Three to five. 
(F) Special Information Needed: - Chemicals to be and the soak temperature are required. Any data pertaining to swelling clay are helpful, if available.

(G) Average Minimum Time Required: - Six weeks

(H) Data Reported: - Porosity, permeability to air and water prior to and after steam soak are presented.

(1) Key Equations - Not applicable.

4. Fire Tube

(A) Use - These tests furnish data required to evaluate the feasibility of the in-situ combustion process as a method of producing crude oil. In essence, the process consist of (i) gas injection to establish permeability to air (2) propagation of the combustion front through the reservoir. These three steps are also accomplished in the laboratory tests.

Primary data required from the laboratory analysis are the pounds of fuel per unit volume of pack consumed during the burn and the standard cubic feet of air required to burn one pound of fuel. The former concerns recovery, since oil burned is unrecoverable, and the latter influences quantity and cost of surface facilities required to inject needed air volumes.

(B) Method:

(1) Fresh core - Tests are normally made on fresh core as recovered from the barrel. The rock must be reduced to grain size and packed in the thin walled combustion tube that is ap proximately five feet in length and two inches 
in diameter. This tube is placed within a larger metal cylinder approximately eight inches in diameter. The annulus between the two is packed with insulating material. The outer tube is swiveled in the middle and can be rotated about the axis perpendicular to its length. This allows access to the combustion tube while serving as a holder and blow-out preventer.

A clamp heater is installed on the upper end of the combustion tube to give ignition when a run is started. Nitrogen is injected into the tube to establish permeability to gas and at the start of injection the heater is turned on. When the temperature reaches approximately $450^{\circ} \mathrm{F}$, the nitrogen supply is terminated and air is injected. Combustion occurs at this point and the heater is then turned off. Typical combustion temperatures range from $800^{\circ} \mathrm{F}$ to $1300^{\circ} \mathrm{F}$.

A thermocouple well is centered within the small tube and runs its full length. This allows the combustion front to be tracked during the burn. Temperatures are monitored throughout the test and recoreded automatically on a strip chart. During the burn, air is injected at a desired flux rate. Pres sures on the injection face and downstream end of the tube are monitored. Combustion gases are metered and samples are taken at intervals. These samples are subsequently analyzed by chromatograph.

(2) Extracted core - Technique for extracted cores is the same as for fresh cores except for sample preparation. See discussion under Type of Samples. 
(c) Type of Tests: - Evaluation is limited to the forward combustion process and the equipment is not suitable for the reverse combustion process.

Initial design of this equipment was for injection of air alone. Some data indicate simultaneous injection of water with air may give better performance and result in less fuel being burned. The modification of the tube could be accomplished to allow water injection if warranted on a particular project.

(D) Type of Samples - Rock must be reduced to grain size prior to analysis. Rubber sleeve cores are excellent for these tests. Rock used should be from the reservoir being evaluated as grain size, shale and clay content affect fuel consumption. The core may be fresh and burned with saturations found after coring.

An analysis of the sample used in packing the fire tube is made so saturations in the tube prior to burning are known. Very heavy oil $\left(11^{\circ}\right.$ to $12^{\circ}$ API) with high oil saturations may necessitate having to reduce this saturation prior to burning. Experience indicates the formation of an oil bank in front of the burning front. With very viscous crudes the permeability to air is reduced such that sufficient air to sustain combustion cannot be injected. The fire Llieu smulders and eventualiy goes out.

In rare cases, the core may be cleaned and then have oil and water added to arrive at desired saturations. These components would be premixed and then tamped into the tube. This process might be required where oil base coring fluids were used that contaminated the fresh samples. This contaminant could be removed 
by washing the rock grains with solvent and then resaturating with a sample of crude oil and water.

Approximately 13 pounds of mix are required for one tube pack. Sufficient core for several tube mixes should be sent to the laboratory in the event that alternates are needed during the testing phase.

Cores taken with oil base fluids are not desirable. Filtrate lossduring coring may flush natural hydrocarbons. A fire tube test on contaminated samples would not yield reliable fuel consumption values.

(E) Minimum Number of Samples: - One

(F) Special Information Needed - Information on current saturation of oil and water in the reservoir is desired as well as the reservoir pososity. If swelling claysare known to be present, this information is helpful.

(G) Average Minimum Time Required: - Five weeks.

(H) Data Reported: Composition of the effluent combustion gas, in terms of carbon monoxide, carbon dioxide, oxygen and trace hydrocarbons, pounds of fuel burned per unit volume of sand pack, standard cubic feet of air required to burn a pound of fuel, gravity of the produced oil, $\mathrm{pH}$ of the produced water, pack porosity, oil and water saturations prior to burning, temperature at the combustion front and air flux rate.

(1) Key Equations - Equations for laboratory calculations and application of Fire Tube data to reservoir evaluation are presented in Producers Monthly of May, 1961 in an article entitled "How to Engineer an In-Situ Combustion Project" by T.W. Nelson and J. S. McNeil of Socony Mobil oil Company. 
5. Steam Distillation of Crude

(A) Use - These data assist in evaluating the additional oil recovery in a steam injection project by the single recovery mechanism of steam distillation of the crude. It may also give insight into the texture of the heavy crude remaining after the light ends are removed during steam distillation. This has proven important in some cases where the heavy material remaining after steam flooding would not flow and caused partial plugging of the formation.

(B) Method: - A known volume of stock tank oil is placed in a pressure vessel and steam is bubbled through the oil. The light hydrocarbons are removed during this steam distillation process. Hydrocarbons remaining after steam distillation are determined.

(c) Type of Test - Only one type of test described above is available with temperature limited to approximately $700^{\circ} \mathrm{F}$. Demand for this service has been low for the past several years and the equipment has consequently been disassembled.

(D) Type of Sample: - Approximately 400 cubic centimeters of crude oil are required.

(E) Minimum Number of Samples: - One.

(F) Special Information Needed: - The temperature of the steam distillation is required.

(G) Average Minimum Time Required: - Four weeks.

(H) Data Reported: - The volume recovered by steam 
distilliation as per cent of initial charge and gravity of the residual crude are given

(i) Key Equations - Not applicable. 
K. Caprock Analysis

1. Use - The development of gas storage reservoirs requires information on both the caprock overlying the storage zone and the properties of the storage zone itself. Where depleted reservoirs are used for gas storage, data on the caprock are often not required as the caprock ability to hold fluids has been proven. Where aquifers are to be used as storage projects this confidence does not exist and matrix permeability to water and threshold permeability in the range of $1 \times 10^{-6}$ millidarcys. In addition, the pressure (threshold pressure) at which gas will first penetrate into a sample containing 100 per cent water should approach or exceed 1000 psi.

As the gas bubble forms in the aquifer it displaces water. At the top of the storage zone, gas is prevented from escaping by the overlying water saturated caprock. The pressure in the gas bubble increases as it grows and it is pressured by injected gas. It is the ability of the matrix caprock to prevent the non-wetting phase (gas) from entering and hence escaping vertically that is tested in the laboratory threshold pressure test.

The tests discussed herein define matrix properties of the caprock. Geologic features such as faulting or fracturing near the crest of the structure may void a storage reservoir prospect that has excellent matrix properties.

The required analysis of the gas storage zone may be made with a variety of tests normally used for gas or oil rescrvoir craluation. 


\section{(2) Method:}

A. Permeability (down to $1.0 \times 10^{-6}$ md) - Samples should be 100 percent water saturated for this test. If drying has occurred during shipment to the laboratory the cores are placed under water and evacuated to resaturate the voided pore spaces.

The sample is placed in a trialxial core holder and subjected to a squeeze pressure equal to 1500 psi. Water comparable to that found in the underlying storage zone is flowed through the core until equilibrium flow is obtained. Testing and adjusting may take several hours to a day or longer since the rock tends to compress under the overburden pressure and must stabilize before permeability can be determined. Fluid flow through the core is monitored on a pipette.

B. Threshold (entry) pressure - The liquid source for permeability measurement is removed and gas is introduced on the face of the sample. Gas flow into the core is attempted at increasing pressure levels. Flow from the core is again monitored by pipette. The pressure at which gas first penetrates the largest pores is designated as the threshold pressure and is accompanied by an appreciable increase in flow rate from the core.

(3) Type of Tests - Permeability and threshold pressure tests may be determined independently, but a proper analysis requires both. Flow is down the vertical axis of whole core and plugs are drilled vertically for these tests.

(4) Type of Samples

A. Permeability (down to $1.0 \times 10^{-6}$ md) - Full diameter 
core is preferred although a plug type analysis will yield reliable data in homogeneous caprock. Plugs are usually restricted to $2^{\prime \prime}$ diameter samples drilled in a vertical direction from the whole core.

B. Threshold (entry) pressure - Same as permeability samples.

5. Minimum Number of Samples

A. Permeability (down to $1.0 \times 10^{-6} \mathrm{md}$ ) - one sample per foot or more is required if whole core has broken at 1 ithologic changes.

B. Threshold (entry) pressure - Same as permeability.

6. Special Information Needed:

A. Permeability (down to $1.0 \times 10^{-6} \mathrm{md}$ ) - Water from storage zone beneath caprock, analysis of this water or salinity.

B. Threshold (entry) pressure - No special data needed.

7. Average Minimum Time Required:

A. Permeability (down to $1.0 \times 10^{-6} \mathrm{md}$ ) - Depends on availability of whole core holders also used for waterflood and the number of samples to be tested. Normal for 20 feet of core -8 weeks.

B. Threshold (entry) pressure - For 20 feet of core 8 weeks. 
8. Data Reported:

A. Permeability - Sample permeability in millidarcys is given.

B. Threshold (entry) pressure - Pressure at which gas enters the core is given. If no penetration of gas has occurrediat pressures of $1000 \mathrm{psi}$ the test is terminated and data presented states threshold pressure is greater than 1000 psi.

9. Key Equations: - Not applicable. 


\section{Rock Compressibility}

1. Use: - These data are used to compute the reduction in pore volume that occurs within the por a sace of the reservoir during pressure depletion. This pore reduc: tion is the result of a change in balance between the overburden pressure (caused by weight of the overlying sediments) and the internal reservoir pressure normally established by hydrostatic gradient. The pressure difference between oberburden and internal pore pressure is referred to as "effective overburden" or "frame" pressure.

During pressure depletion operations the internal pressure of the reservoir drops. Since overburden pressure remains constant the frame pressure is increased. The effect of increasing frame pressure is to reduce the bulk volume of the reservoir while at the same time the the sand grains within the pore spaces expand because of the internal pressure drop. These two volume changes tend to reduce the pore space and hence the porosity of the rock.

Often these data trend both with porosity and the frame pressure existing on the system. Compressibility typically docrcascs as porosity increases, and also decreases as frame pressure increases. Typical values of rock compressibility range from $3 \times 10^{-6}$ to $25 \times 10^{-6}$ pore volume/pore volume/psi. This means that for each million barrels of pore space a reduction of 3 to 25 barlels wuld occur for each psi of reservoir pressure drop. 
Although these values are small they become important in reservoirs that are undersaturated when calculations are made to define oil-in-place or aquifer constants that will be used to predict future pressure performance. The sum of the rock compressibility and of the water compressibility can be as great as the oil compressibility and of the water compressibility can be as great as the oil compressibility and ignoring of the rock and water compressibility data will yield optimistic values for oil-in-place and aquifer strength. Inclusion of this compressibility data is especially important during the early life of a field when little history exists and the match of the past performance of the reservoir is based on limited history.

\section{Method:}

(A) Hydraulic Loading of Corè Sample - Hydraulic loading (pressure applied equally on all sides and ends) is easily accomplished in the laboratory, but for a given frame pressure it results in greater rock compressibility than in the reservoir. Laboratory data must be reduced in magnitude prior to application. (See Key Equations).

Extracted and dried samples are jacketed with heat shrinkable plastic tubing that conforms to the cylindrical surface and overlaps attached end-butts. The jacketed sample is placed in a core holder, and hydraulic pressure of 200 psi is applied. Pore volume is measured by helium injection.

The sample is evacuated and saturated with water while maintained under 200 psi hydraulic pressure. It is connected to a water filled high-pressure 
pipette graduated in 0.001 cc divisions. A mercury slug is placed in the pipette to assist in monitori ing the pore volume changes during the test. The .. system is placed in an air bath maintained at a constant temperature of $90^{\circ} \mathrm{F}$. After stabilized conditions of pressure and temperature are reached at the effective overburden pressure of 200 psi, the position of the mercury slug is noted. The external and internal pressures are then elevated to the levels specified, and movement of the mercury is recorded.

Pore volume at each effective overburden pressure is determined by applying the corrected incremental pore volume change to the reference pore volume. Pore compressibilities are calculated by graphically differentiating the plot of porevolume versus effective overburden pressure.

(1) Technique One - External confining pressure is raised to a value equal in magnitude to the reservoir depth times 1 psi per foot: Internal pore pressure is maintained at $200 \mathrm{psi}$ less than external as the latter is increased. After obtaining maximum pressures, internal pressure is dropped to a selected value. The change in pore volume results in water movement from the core which is monitored on a micropipette. Water expansibility within the pore spaces is accounted for.

(2) Technique Two - Internal pressure is elevated to approximately 200 psi with external pressure increased to approximately 400 psi. The external pressure is raised to selected values, with internal pressure remaining constant at 200 psi. Reduction in pore volume is indicated by water movement from the pore space which is monitored on a micropipette. Water expansibility is not a factor as internal pressure remains coristant. 
(3) Technique Three - Techniques above apply to consolidated sandstones and carbonates. Cores so poorly consolidated that they have been mounted in thin-walled metal sleeves..are tested with a less complicated procedure in which the external pressure is varied while the internal pressure is maintained at atmospheric: conditions.

(B) Uniaxial Loading of Core Sample - Uniaxial loading is accomplished by maintaining a constant cross-sectional area of the core and allowing only vertical deformation due to end loading. Vertical deformation is measured by dial indicator. These boundry conditions are more representative of those in the reservoir and do not require data conversion. Samples contain air in the pore space so water expansibility presents no problems. Temperature is at ambient conditions. Pore volume at each effective overburden pressure is determined by applying the corrected incremental change to the reference pore volume. Pore compressibilities are calculated by graphically. differentiating the plot of pore volume versus effective overburden pressure.

3. Type of. Tests:

(A) Single frame pressure - Compressibility is calculated at a single effective overburden (frame) pressure. This case is applicable for gas storage reservoirs where pressure within the formation is expected to fluctuate only within several hundred pounds.

(B) At three or more frame pressures - In this test compressibility is, evaluated at three or more frame pressures so that the trend with net overburden pressure 
can be established. This is applicable to those conditions where internal reservoir pressure continues to decline during the production history and the frame pressure continually increases. In many cases internal pressure may drop several thousand psi. Since compressibility varies as a function of frame pressure, a single value will not adequately define rock compressibility when operating conditions show such a wide variance in pressure change.

4. Type of Samples: - One and one-half inch diameter cylindrical plugs are recommended for the hydraulic loading technique. One inch samples may suffice in hard, nonvuggy rocks and are required for the uniaxial loading system. samples must be extracted prior to analysis. Pressure limitations are approximately 10,000 psi for uniaxial loading, and 10,000 psi overburden and 9,000 psi pore pressure for hydraulic loading.

5. Minimum Number of Samples Recommended: - Three to eight samples are needed so as to cover the porosity range exhibited.

6. Special Information Needed: - Data required are depth of the formation and the internal reservoir pressure. Information as to expected pressure drops to be encountered during the production history of the reservoir are helpful in designing the test program. Salinity of the formation brine is also helpful. The laboratory tests normally require saturation of the samples with a fresh to low salinity brine. This is an adequate procedure in essentially all cases but information on formation water is desirable. 
CORE LABORATORIES. INC.

Penoderm Resmoir Engimaring

DALLAS. TEXAS
Page of

File
Company

Woll

Field
Formation

County

State

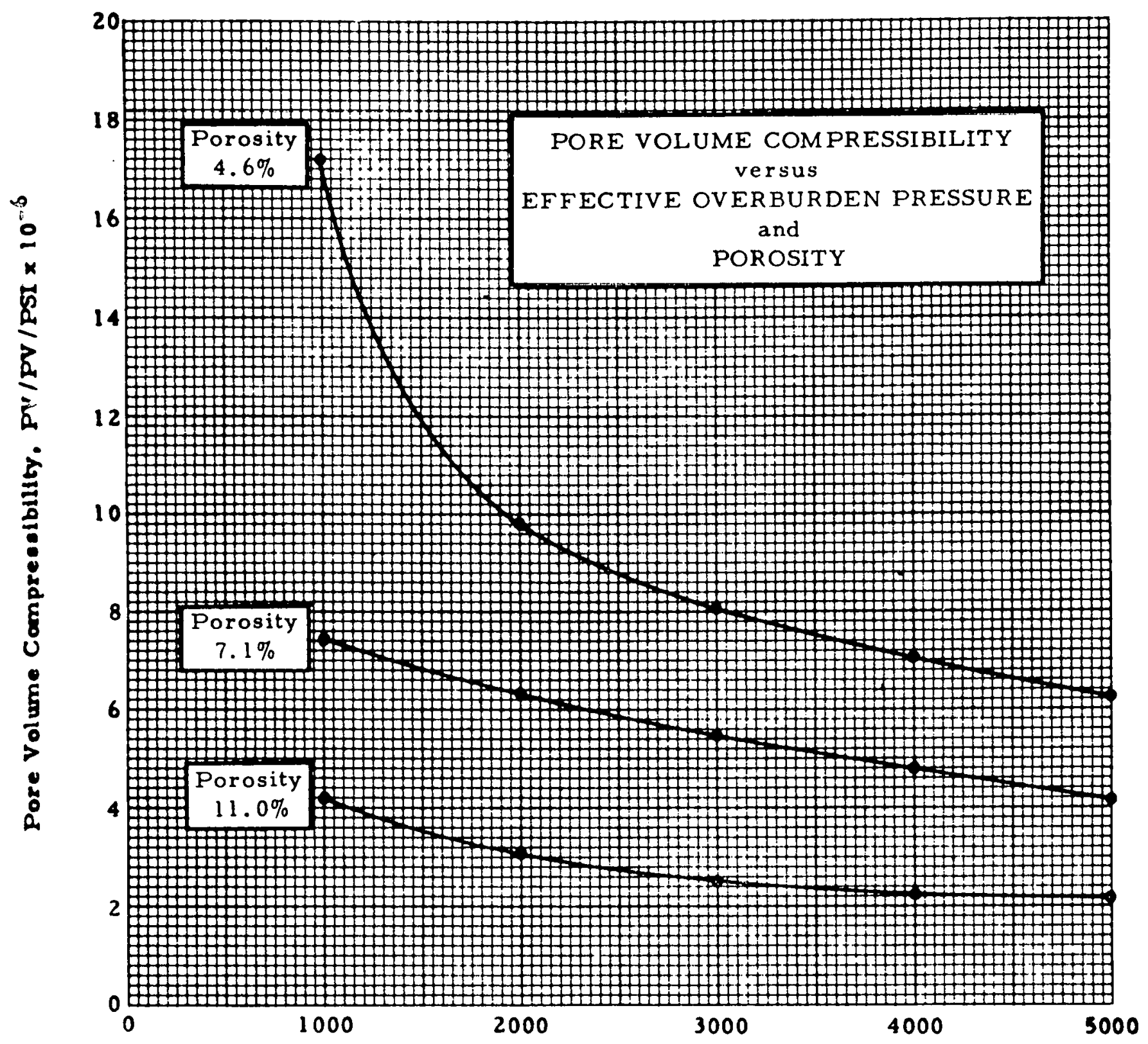

Effective Overburden Pressure, PSI 
7. Average Minimum Time Required: - Four to eight weeks depending upon the type and number of cores tested.

8. Data Reported: - Pore volume compressibilities, pore volume, bulk volume and porosity at various effective overburden pressures are reported in tabular form. Converted (reduced) compressibilities to reflect boundary conditions are also reported when the hydraulic loading technique has been used.

9. Key Equations: - Conversion of hydraulic load data to uniaxial loading is presented in the paper "prediction of Formation Compaction from Laboratory Compressibility Data" by $D$. Teeuw, Society of Petroleum Engineers Journal, 1971, Volume X1, No. 3, pages 263-271. 


\section{WETTABILITY STUDIES}

1. Use: - Wettability studies give an indication of the reservoir rock wettability at the time of test in the laboratory. This indication may or may not be representative of actual reservoir wettability. Special precautions must be observed during both the coring and transporting of the rock to optimize the chance of securing a reliabile rock sample that will yield true reservoir wettability. The latter is what is desired in most tests of this nature.

0il-wet rocks are often characterized by low connate water and poor water displacement. The normal capillary forces that attract water into small pores to displace oil are not operative in water flood of an oil-wet reservoir and the water tends to sweep the large pores first. High water cut may be experienced with low oil recovery. This means that oil-wet reservoirs are often poor prospects for water flood and this latter consideration is one factor that makes determination of wettability important.

A complex relationship exists between minerals comprising the rock, the oil composition and coring fluid additives. These common additives often reverse rock wettability in certain rock and fluid systems. Tests on rock of this altered wettability will yield performance non-representative of the reservoir. Use of water with no surface active additives or reservoir oil that has never been exposed to oxygen may yield a practical solution to the coring fluid. 
Exposure of the core to air may cause a reversal in wettability, but more often has a less drastic effect that moves the rock surfaces from a strong water-wet condition to a neutral wettability. To circumvent this the cores should be plunged under de-gassed water immediately after removal from the core barrel. Another technique is to select samples, quickly wrap them in Saran and several layers of aluminum foil and wax them at the well site. This will assure their proper protection whtil received in the laboratory.

2. Method:

(A) Imbibition at room conditions - A sample is drilled from the core using water as the lubricant. The core is then evacuated under water to reduce gas and flushed with water to residual oil. The plug is placed under oil processed to remove surface active agents and imbibition of the oil is monitored. Water displaced during imbibition is measured and is equal to oil imbibed.

After equilibrium has been obtained, which may take several weeks in low permeability core and is indicated by no further water displacement, the plug is flushed with oil to reduce the remaining water to an irreducible value. The sample is then placed under water and water imbibition is monitored by observing oil displaced. The fluid that imbibes into the sample is the wetting phase. At equilibrium conditions the core is removed and cleaned. its porosity and permeability are determined. 
In some cases two adjacent plugs are drilled and tested simultaneously. One prepared plug is placed under water and the second is placed under oil. This reduces total time of testing but requires additional core and offers the disadvantage the both oil and water wettability are not checked on the same piece of rock.

(B) Imbibition at reservoir conditions - This test is requested on only rare occasions and varies widely depending on reservoir rock fluids and conditions. Test procedures must be designed for each situation. The follwoing is presented as only a guide to procedure. Normally a cylindrical plug will be drilled from the preserved core using water as the lubricant. It will be evacuated under water and then flushed with oil to irreducible water. It is then placed in a special test apparatus that is brought to reservoir conditions of temperature and pressure. Live reservoir fluid (preferable a bottom hole sample) is used to fill the pore spaces not occupied by water. Water is then introduced to the face of the sample under a zero-to very slight pres. sure head and the volume of water imbibed into the core is monitored. This tests is extremely complicated and the final technique selected will depend on the actual test conditions and fluid.

(C) Other Methods - A simple drop test is often made as a check of wettability. This can be very misleading and is a qualitative measurement only. Drops of oil and water are placed on a fresh broken surface of the core. The fluid that is imbibed is a wetting 
phase. while the fluid that rolls off or forms a ball that does not wet the surface is the non-wetting phase. Drop test data that conflict with submersion imbibition test data may be obtained. When this occurs, the drop test data are believed invalid.

3. Type of Tests:

(A) Imbibition type at room and reservoir conditions. (B) Drop tests on fresh broken surfaces of the core.

4. Type of Samples:

(A) Imbibition tests at room and reservoir conditions can best be made on cylindrical plugs 1 , or $1-1 / 2$ inches in diameter. It is possible to make room condition imbibition tests on irregular shaped samples although this prohibits flushing of the cores as described above.

(B) Drop tests require only enough rock to give a fresh break and adequate surface for drops of fluid.

5. Minimum Number of Samples:

(A) Three to five samples for imbibition tests and these should cover lithology and depth interval as oil may vary with depth in reservoirs of large closure.

(B) Drop tests should also cover lithology and depth.

6. Special Information, Needed:

(A) Imbibition tests at room conditions - No special information required.

(B) Imbibition tests at reservoir conditions - Require 
reservoir fluids, temperature and pressure of reservoir.

(c) Drop tests - No special information required:

7. Average Minimum Time Required:

(A) Imbibition at room condition - 6 - 8 weeks.

(B) Imbibition at reservoir conditions - 8-10 weeks.

(C) Drop tests - l week.

8. Data Reported:

(A) Imbibition at room conditions - Total oil and total water imbibed as per cent of pore volume.

(B) Imbibition at reservoir conditions - Fluid imbibed and other pertinent information will be furnished.

(c) Drop tests - Fluids imbibed will be noted as well as others observations made during the test.

9. Key Equations - Not applicable. 
1. Use - These tests evaluate the relationship between porosity and acoustic velocity and thereby refine porosity values calculated from the down hole acoustic logging tool. Literature relationships presented for limestone and sandstones are average or representative values for these types of formation. In many cases a formation has a porosity-velocity relationship that varies from these average values. In some cases no correlation of acoustic velocity and porosity exists. Tests should be run to verify ..and/or replace literature average relationships.

2. Method: Direct measurement of acoustic travel time under overburden conditions through a vertical sample completely (or partially if desired) saturated with brine (or light oil). Samples should be saturated - even for cores from gas wells as the saturated condition approaches closely the condition in the vicinity of the bore hole.

3. Type of Tests - Acoustic tests are made under conditions of confining pressure. Tests have shown that the pressure difference between overburden pressure and fluid pore pressure is the pressure that controls acoustic velocity. Tests at various confining pressures are made to define the curve of acoustic velocity versus confining pressure. Maximum pressure used is equal to $1 / 2$ the depth. Equipment limitations are approximately 8000 psi for plugs and 20,000 psi for whole core tests.

4. Type of Samples - One inch diameter cylindrical plugs or selected whole core sizes. All tests samples should be vertical to simulate the down hole tool performance and 
properly account for shale and/or other laminations.

5. Minimum Number of Samples Recommended: - Ten.

6. Special Information Needed: - Formation water sample, analysis, resistivity or chloride content. Depth of formation and current reservoir pressure.

7. Average minimum Time Required: - Six weeks

8. Data Reported: - Tabular presentation of acoustic velocity versus confining (net overburden) pressure for each sample. Composite plot of transit time versus porosity for all samples at one selected overburden pressure.

9. Key Equations: $-\frac{1}{V}=\frac{f}{V_{L}}+\frac{1-f}{V m}$

$\begin{aligned} V \quad= & \text { Velocity in saturated porous medium } \\ & \text { (measured in laboratory) } \\ f \quad= & \text { Porosity, fractional } \\ V_{L} \quad= & \text { Velocity in liquid in pores } \\ V_{m} \quad= & \text { Velocity in matrix rock }\end{aligned}$


0. SURFACE AND INTERFACIAL TENSION

1. Use:

Surface tension and interfacial tension data assist in understanding the recovery mechanism of additives that change rock wettability or alter fluid interfacial tensions. An example is caustic flooding where interfacial tension can be dropped to zero with greatly increased oil recovery in some oil-water systems. The amount of caustic required to yield this interfacial tension reduction can be found by interfacial tension measurements on solutions of various strength.

2. Method:

(A) Surface tension (atmospheric pressure only)

(1) Room temperature-The fluid to be tested is placed in a clean dry beaker. A platinum ring is lowered into the fluid. It is then slowly raised and a DuNouy Tensiometer is used to determine the force required to break the ring free from the surface of the liquid.

(2) Elevated Temperature - The same procedure is followed as for the room condition test except that the temperature of the fluid is elevated to the desired value prior to determination of surface tension.

(B) Interfacial tension (atmospheric pressure only)

(1) Room temperature. - The more dense of the two fluids to be tested is placed in a clean dry beaker. A platinum ring is lowered into the fluid. The second fluid is then poured over the first. The ring is slowly raised and a 
DuNouy Tensiometer is used to measure the force required to pull the ring through the interface of the two fluids.

(2) Elevated temperature - The same technique is used except temperature of the fluids is elevated to the desired value.

3. Type of Tests: - Not applicable.

4. Type of Samples:

(A) Surface Tension

oil samples not contaminated by emulsion breakers or other additives and that have had a minimum exposure to oxygen are required. Water samples should be from a clean sampling point and free from chemical contaminants. Pit samples are. not satisfactory.

(B) Interfacial Tensions - Same as Surface Tension

5. Minimum Number of Samples:

(A). Surface Tension

One test per fluid investigated per chemical additive is required.

(B) Interfacial Tension

One per set of fluids per additive if applicable. 
DuNouy Tensiometer is used to measure the force required to pull the ring through the interface of the two fluids.

(2) Elevated temperature - The same technique is used except temperature of the fluids is elevated to the desired value.

3. Type of Tests: - Not applicable

4. Type of Samples:

-

(A) Surface Tension

oil samples not contaminated by emulsion breakers or other additives and that have had a minimum exposure to oxygen are required. Water samples should be from a clean sampling point and free from chemical contaminants. Pit samples are not satisfactory.

(B) Interfacial Tensions - Same as Surface Tension

5: Minimum Number of Samples:

(A) Surface Tension

One test per fluid investigated per chemical additive is required.

(B) Interfacial Tension

One per set of flulds per additive if applicable. 
6. Special Information:

(A) Surface Tension - Temperature required if tests at elevated temperature.

(B) Interfacial Tension - Same as Surface Tension

7. Average Minimum Time Required:

(A) Surface Tension - One week

(B) Interfacial Tension - One week

8. Data Reported:

(A) Surface Tension - Value in dynes/centimeter.

(B) Interfacial Tension - Value in dynes/centimeter.

9. Key Equations: - Not applicable 


\section{P. SIEVE ANALYSIS}

1. Use:

Sieve analysis data yield grain size distribution and can be used to gain insight into transportation prior to deposition. It is also used to assist in screen or slotted liner selection when completing poorly consolidated formations. The grain size found at the cumulative ten percentile point is normally used as the screen size.

2. Method:

A clean dry sample is reduced to grain size. This measurement should be restricted to friable cores since breaking up of hard formations may cause fines and/or larger pieces that do not represent a true grain size. The grains are then placed on the topmost (largest mesh) of a nest of screens. The screens are vibrated and the grains pass through the screen nests until they are caught on a mesh size slightly smaller than the grain. Grains that collect on each screen are weighed. The smallest. size screen used is usually 350 mesh.

3. Type of Tests: - Not applicable

4. Type of Samples:

Normally restircted to friable sandstones. Fifty to 100 grams desirable.

5. Minimum Number of Samples:

This test may require one sample per foot or one per lithologic change depending upon the use. Samples should cover the cored interval. 
6. Special Information: - Not required

7. Average Minimum Time:

One to two weeks

8. Data Reported:

$$
\begin{aligned}
& \text { Graphical and tabular data showing cumulative } \\
& \text { per cent of sample (by weight) for various grain } \\
& \text { (screen) sizes. A medium grain diameter is given as } \\
& \text { well as a calculated sorting coefficient. }
\end{aligned}
$$

9. Key Equations:

Sorting Coefficient $=\frac{A}{B}$ where $A$ equals grain diameter @ 25 percentile and B equals grain diameter (e) 75 percentile. 
CORE LABORATORIES INC

Petrulcum Reserewer Engincering

DALLAS, TEXAS
Pripe _..._...... of ___

File:
Compuny

Well

Field
Formenturn

(i) anty

Situte

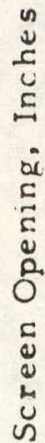

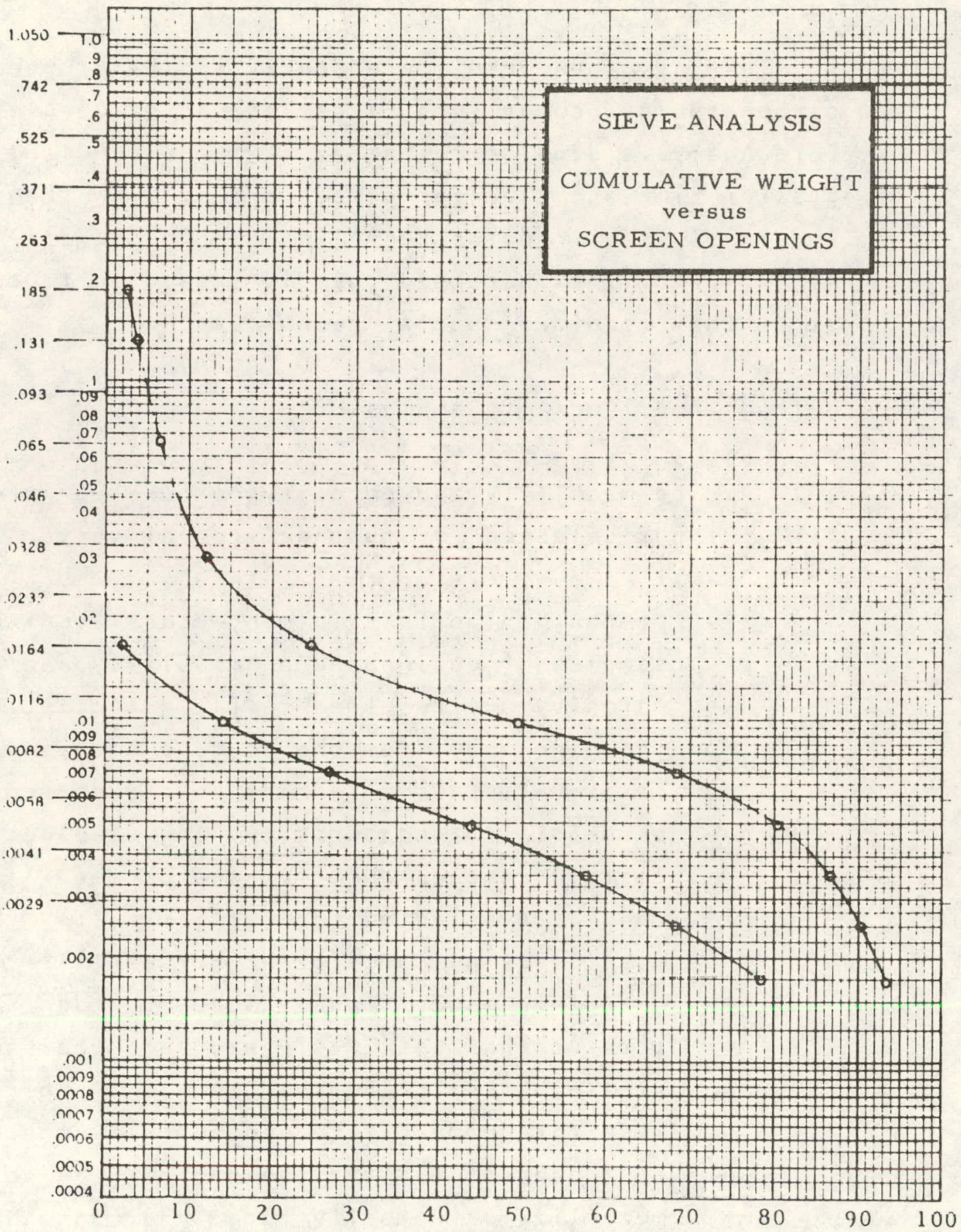

Cumulative Weights, Per Cent of Total Weight 


\section{Q. SAMPLE PREPARATION AND SELECTION}

I. Use:

Testing of unconsolidated cores and heterogeneous carbonates now comprise a large segment of special Core Analysis studies. These rock types require greater time and care for sample preparation than previously required for consolidated sandstones. A portion of the increased cost is passed on to the study that requires special techniques.

2. Methods and Types of Samples:

(A) Air permeability and porosity on cores prepared but not selected for further special tests.

(1) Overburden tests - In many cases a suite of samples of designated permeability and/or porosity are required to fit a statistical grouping made from the routine core analysis data. After samples have been prepared and permeability and porosity have been determined, certain samples that fit the permeability range are selected for further tests. In most cases no porosity or permeability charge is made if a single overburden pressure has been designated and the samples are selected for further tests. A charge is made for permeability and porosity measurement on those samples that do not fit the permeability or porosity range and consequently are not selected for additional testing. 
(2) Room condition tests - As above, samples of designated permeability and/or porosity are often requested. When plug tests are made on core that has been analyzed by wholecore techniques many samples are often drilled to find a few of specified permeability. No charge for permeability or porosity is made for cores that fit the desired permeability and porosity range and are selected for special tests. Charges are made for prepared plugs that do not fit the requested ranges and are not needed further. A single page 1 isting porosities and permeabilities of samples. that were prepared but not selected will be given in a report.

(B) Mounting (friable or vuggy cores)

(i) Plug size cores

a. Metal jackets and screens are used to mount unconsolidated core. A hollow punch is inserted into a window cut in the rubber sleeve. When the punch is withdrawn a sample is trapped in the punch. Thls sample is then ejected from the punch by a plunger and forced into the metal jacket. Screens are placed over the ends of the sample and held in place by folding the thin lip of the jacket over the screen edge. These samples are subsequently squeezed under simulated overburden pressure to seat the jacket to 
the sample. The cores are then cleaned and dried. Pore volume is measured by helium injection. Grain volume is measured in a matrix cup. Corrections are made to the measured pore volume by subtracting pore space in each screen. Corrections are made in grain volume calculations by subtracting the volume of the metal sleeve and the metal in .the end screens. Bulk volume equals corrected pore volume plus corrected grain volume. Corrections in length are made for the screen and 1 ip thickness of the metal jacket. Area is calculated by dividing bulk by length.

b. Consolidated but friable plugs are often mounted in plastic. One inch or $1-1 / 4 \mathrm{inch}$ cores are cast up to $1-1 / 2$ inch diameter in epoxy mounting. Grain loss is minimized by this process. In preparation for mounting, cores are cleaned and dried and each core has its bulk volume and pore volume determined. Its length is also measured. The core is then placed on a clay base within a tefion mold. Epoxy is poured around the core. When the epoxy has set the core is removed and the ends are trimmed to remove any plastic and/or clay. Pore volume and length are again measured. It is assumed that porosity is the same in the trimmed core as was found originally. A new bulk volume is then calculated from the new pore 
volume and from this and knowledge of the length an effective cross sectional area can be determined for flow tests.

(2) Whole core

Whole core has often been slabbed prior to arrival and requires mounting to give a cylindrical shape suitable for testing. Vuggy cores must also be mounted. In some cases fiber glass is first bonded around the core to cover but not fill the vugs. The sample is then cast in epoxy to a larger cylindrical size. The plastic must be thick enough to prevent pressure imposed on the boot (to hold the core during testing) from breaking the plastic and flowing into the vugs. When this occurs the boot punctures and the test is ruined.

Mounting of whole cores in plastic is not an easy process. In many cases the thermal expansion of the plastic and of the rock is sufficiently different so that the sample and/or its mount pull apart during the heat curing process that is required. Cores that have been mounted also present problems in cleaning. Most cleaning processes work most efficiently when the entire circumterence of the core is available for penotration by solvent. The impervious sheet surrounding the sample adds additional time to cleaning procedures.

(C) Special Handling Required Because of Rock Type or Texture

Special procedures such as hand shaping of plugs that are too friable to drill with water, oil or air, require excessive time and a premium is charged for this and other similar services. In those cases 
where liquid nitrogen is required to drill plugs in a frozen state the cost of the nitrogen is charged to the study.

Rubber sleeve cores also pose special problems. When an analysis is made of this unconsolidated material a window is first cut into the sleeve and samples are extracted for permeability and porosity determination. If additional tests are being made on these cores, each window that has been cut into the sleeve must be taped to preserve the core. This is time consuming and in some cases additional charges are made to cover the cost of this extra handling. Use of windows to select samples is not a good process. In many of the reservoirs from which poorly consolidated sands come lithology varies within small intervals. If one only has a small window to observe the core these changes will not be noted. A much better process is to split the rubber sleeve such that the full core is revealed. In this manner representative samples can be secured. This presents problems, however, with unconsolidated rock which falls apart when the sleeve is split. Special waxing procedures must sometimes be employed and in many cases the rubber sleeve has been cast in a wooden box in wax, cut open, and samples removed. The cut portion is taped closed and wax is again used to seal the box. This is an excellent way to store the cores for a long period of time but is expensive and time consuming. In other cases samples must be pulled, wrapped in saran and aluminum foil and waxed. 


\section{R. PETROGRAPHIC STUDIES}

1. Use:

Both mineral description of samples and diagenesis study require that thin sections of samples be made and studied under a petrographic microscope. The minerals present in the rock are identified and, the texture of the sample is studied. The degree of rounding and sorting of the grains as well as the grain and pore sizes can give clues as to the depositional characteristics and also yield supporting data as to why permeability is reduced in water sensitive rock.

A diagenesis study includes a discussion of the changes in composition and texture that occur in a rock sample at relatively low temperatures after deposition has occurred. This study yields insight as to the type of environment in which the sediment was deposited and on the order of accumulation of minerals present in the sample. Examination of metamorphic rock for example, may reveal that the change in rock character was due to high pressures after deposition and not due to temperatures associated with an igneous mass. The latter of course would indicate that d well was near base rock and would have little chance of encountering a hydrocarbon pay.

2. Method:

Thin sections are made on each sample of rock to be analyzcd and studied under a petrographic microscope. Optical techniques are available for identification of various minerals. 
3. Type of Tests:

Mineral descriptions and diagenesis studies may be done independently of each other.

4. Type of Samples:

Representative samples should be secured for each foot of rock to be analyzed. Unlike other tests, a regular shaped plug i.s not required. Tests may be made on an irregular shaped sample although it is desirable to have the piece large enough so that the core may be oriented as it was in the reservoir. For example, thin sections can be made in both a horizontal and vertical plane and this difference in orientation could be very important in some cases. A $l^{\prime \prime} \times l^{\prime \prime}$ piece of rock would normally suffice for a test sample.

5. Minimum Number of Samples:

Rock character often changes with depth as varying depositional environment may have occurred during the time the sediments were deposited. For this reason samples should be taken throughout the vertical interval for these tests. A detailed study might require one sample per foot or in other cases one every ten feet might be adequate. The data have very little value unless sufficient samples are taken to establish a trend in changes that are occurring in the rock matrix. 
6. Special Information Needed:

Orientation of the sample sent as to its horizontal and vertical position in the reservoir is required. Any supplmentary information concerning possible injection problems or plugging of wells or other data that would indicate the presence of specific minerals expected would be helpful.

7. Average Minimum Time Required:

Time to make this study is a direct function of the number of samples to be tested. Thin sections can normally be made within a week. After a trend in any mineral changes occurring is established a minimum of two cores a day can be studied.

8. Data Reported:

(A) Mineral description - The per cent and identification of minerals including cementing material is given. Textural properties of clastic samples such as estimated porosity, median grain diameter, degree of rounding and sorting, and other textural properties observed are presented. For chemical. biochemical, and biogenic rocks, a per cent estimate of porosity and the insitu characteristics of the rock as well as characteristics resulting from tidisportation are presented. 
(B) Diagenesis - Data include a discussion of the type of environment into which the sediment was deposited, the order of accumulation of minerals present including order of cement, and discussion of the alteration processes to which the sample was exposed after deposition.

9. Key Equations: - Not applicable 
S. DETERMINATION OF HYDRATABLE CLAY CONTENT

1. Use:

The primary value of these tests is the detection of water sensitive rock in petroleum reservoirs. These tests may also be used to supplement liquid permeability measurements where sensitivity has been indicated. Total swelling clay minerals can be separated and a quantitative measurement of weight per cent of the total clay can be determined. In addition, this total clay can be broken down into weight per cent of slightly swelli.. clays such as calcium-montmorillonite and highly sw: i: clay minerals such as sodium-montmorillonite. The actual clay type is not identified as to calcium or sodium but only as slightly swelling or highly swelling.

2. Method:

The test procedure is a centrifuge separation based on the hydrated grain densities of the swelling clay minerals. The samples to be tested are cleaned of all hydrocarbons and organic residues. The cores aredried at low temperature and then pulverized to separate the clay coatings from the sand grains. The samples are again dried and then treated with silicone to make the grains slightly oil wet and yet not impair water vapor transmission. The treated rock is then mixed with water which causes the swelling clay particles to expand. This in turn lowers their densities. Calcium-Montmorillonite and other slightly swelling clays have a grain density of less than $1.85 \mathrm{gms} / \mathrm{cc}$ and sodiummontmorillonite has a hydrated grain density of less 
than $1.59 \mathrm{gms} / \mathrm{cc}$. All non-swelling, water-insoluble minerals have grain densities of 1.9 or greater: It is this fact that makes it practical to separate the rock samples as to their swelling characteristics.

The rock-water slurry is centrifuged over a non-water miscible heavy liquid of selected density while stirring the mixture. This keeps the grains dispersed and allows individual sample grains to segregate by density difference. The hydrated clays remain in the water above the interface and these are decanted and dried to a constant weight. The swelling clay fraction is then calculated as a per cent of sample dry weight.

3. Type of Tests:

(A) Total swelling clay - Includes all swelling clay minerals.

(B) Highly swelling clay - An additional test is required to differentiate between total swelling clays and highly swelling clays. In some cases it is desirable to know the per cent of highly swelling clays as small volumes of these minerals can cause rather dramatic water sensitivity and permeability reduction problems. In some cases, small quantities of highly swelling materials in conjunction with large quantities of slightly swelling materials causes excessive permeability damage. The relationship of the highly and slightly swelling clays is very complex. 
4. Type of Samples:

Irregular shaped samples can be used for these tests. The amount of sample required is roughly based on the per cent of swelling clay. In all cases $50 \mathrm{gms}$ of sample will be adequate. This amount is required when small percentages of clay are present. When the clay content approaches 5 to 20 per cent only 5 gms of material are required.

5. Minimum Number of Samples:

Minimum of four to six samples should be tested for any given reservoir. If lithology changes greatly over the production interval, additional samples are required. Since clay content often varies with depth within a given formation, it is advantageous to select samples to cover the depth interval. Unless the minimum four samples are available, this analysis is not performed.

6. Special Information Needed: - None

7. Average Minimum Time Required:

This test requires the use of a centrifuge and the time to perform this type of analysis is thelefore dependent upon the availability ur the centrifigal equipment. Total time to complete and report the data is estimated at 4 weeks.

8. Data Reported:

(A) Total swelling clay content as a per cent of dry weight of the core. 
(B) Highly swelling clay content as a per cent of the dry weight of the core is given for this test. When both total and highly swelling clays are requested, the difference, which is equal to the slightly swelling clays, is also reported.

9. Key Equations - Not applicable 
T. PICTURES

1. Use:

Color pictures furnish a permanent record of the test samples and in many cases aid in understanding test results when the actual rock is not available for study. They are of particular value in carbonates where vugs may dominate flow characteristics.

2. Method:

Color pictures are taken with a split frame camera so that two images (typically an end view and a side view) of the core are presented on a single print. These can be mounted in the back of the special core Analysis report. The size of the print $\left(3-1 / 2^{\prime \prime} \times 5^{\prime \prime}\right)$ allows two prints to be placed on a single report page.

3. Type of Tests: - Not applicable

4. Type of Samples:

Whole core or permeability size plugs used in tests. Pictures have generally been restricted to whole core carbonate samples.

5. Minimum Number of Samples: - Not applicable

6. Special Information Needed: - Not applicable

7. Avorage Minlmum lime Required:

Four weeks

8. Data Reported: - Not applicable

9. Key Equations: - Not applicable 


\section{U. PRODUCTION RESEARCH}

Some labs offer fee cost facilities which are available to perform semi-research work on a variety of flow problems. These include evaluation of sodium hydroxide (caustic) floods, carbonated water, surfactants, polymers and other water flood or work-over additives.

Tests can be made under simulated conditions or reservoir temperature and pressure using live reservoir oil. The methods used will depend on the evaluation requested.

When possible, cost estimates are made by following quoted prices for more routine type studies to which a fee is added for unusual procedures, time factors or other precautions demanded for proper handling of the material. In other cases, a per hour or per diem rate may be quoted. 


\section{REFERENCES}

1. Murphy, R.P. and Owens, W.W.: "The Use of Special Coring and Logging Procedures for Defining Reservoir Residual Oil Saturations," SPE Paper 3793, Improved 0 il Recovery Conference, April 16, 1972, Tulsa,. Oklahoma

2. Dalton, R.L., Deans, H.A., Shallenberger, L.K., and Tomich, J.F.: "Single-Well Tracer Method to Measure Residual 0 il Saturations," SPE Paper 3792, Improved 0 il Recovery Conference, April 16, 1972, Tulsa, Oklahoma.

3. Muskat, M.: Physical Principles of 0 il Production, McGrawHill, (1949), 158-160.

4. Sewell, Ben W.: "The Carter Pressure Core Barrel," API Drilling \& Production Practices (1939).

5. Mullane, J.J.: "Pressure Core Barrel," API.Drilling E Production Practices (1941).

6. Hagedorn, A.R. and Blackwell, R.J.: "Summary of Experience with Pressure Coring," SPE Paper 2962, presented at $47 \mathrm{th}$ Annual Fall Meeting SPE-AIME, October 8-11, 1972, San Antonio, Texas.

7. Loomis Hydraulic Testing Company, P.0. Box 6408, Pasadena, Texas. 77506 .

8. Bobek, J.E., Mattax, C.C., and Denekas, M.0.: "Reservoir Rock Wettability --lts Significance and Evaluation,": J.Pet. Tech. (1958) No. 213,213 . 
9. McCaffery, F.G.: "The Measurement of Interfacial Tensions. and Contact Angles at High Temperature and Pressure," J. Can. Pet. Tech. (1972) 11, No. 3, 26.

10. Colpitts, G.P. and Hunter, D.E.: "Laboratory Displacement of $0 \mathrm{il}$ by Water Under Simulated Reservoir Conditions," J. Can.Pet. Tech. (1964) 3, No. 2,66 .

11. Odeh, A.S. and Cook, E.L.: "Discussion-Effect of Temperature on Waterflooding," J.Can. Pet. Tech. (1965) 4. No. 4, 242 .

12. Edmondson, T.A.: "Effect of Temperature on Waterflooding,": J.Can. Pet. Tech. $(1965)$ 4, No. 4, 236 .

13. Davidson, L.B.: "The Effect of Temperature on the Relative Permeability Ratio of Different Fluid Pairs in Two Phase Systems," J.Pet. Tech. (1969) No. 8, 1037.

14. Poston, S.W., Ysrael, S., Hossain, A.K.M.S., Montgomery, D. F., and Ramey, H.J., Jr.: "The Effect of Temperature on Relative Permeability of Unconsolidated Sands," Soc. Pet. Engineers J. (1970) 10, No. 2, 171 . 
PATENTS

SERIAL NO. TITLE INVENTOR ASS I GNEE

\begin{tabular}{|c|c|c|c|}
\hline $1,952,170$ & Sample Taking Apparatus & $\begin{array}{l}\text { G. A. Humason, } \\
\text { et al }\end{array}$ & $\begin{array}{l}\text { Reed Roller } \\
\text { Bit Co. }\end{array}$ \\
\hline $2,146,263$ & $\begin{array}{l}\text { Method of Coring to Preserve } \\
: \text { Fluid Content }\end{array}$ & N. Johnston & - \\
\hline $2,214,551$ & $\begin{array}{l}\text { Method and Apparatus For Taking } \\
\text { Samples }\end{array}$ & C.R. Edwards & - \\
\hline $2,216,962$ & Pressure Coring Device & B.W. Sewell & $\begin{array}{l}\text { Standard } 0 \text { il } \\
\text { Devel. Co. }\end{array}$ \\
\hline $2,238,609$ & Pressure Coring Barrel & B.W. Sewell & $\begin{array}{l}\text { Standard } 0 \text { il } \\
\text { Devel. Co. }\end{array}$ \\
\hline $2,256,552$ & Retrievable Formation Tester & H.E. Drake & - \\
\hline $2,264,449$ & Method and Apparatus For Coring & W.D. Mounce & $\begin{array}{l}\text { Standard } 0 \text { il } \\
\text { Devel. Co. }\end{array}$ \\
\hline $2,343,805$ & Pressure Core Barrel & B.W. Sewell & $\begin{array}{l}\text { Standard } 0 \mathrm{il} \\
\text { Devel. Co. }\end{array}$ \\
\hline $2,347,726$ & $\begin{array}{l}\text { Wire Line Pressure Retaining } \\
\text { Core Barrel }\end{array}$ & $\begin{array}{l}\text { D.W. Auld, } \\
\text { et al }\end{array}$ & $\begin{array}{l}\text { Phillips Pet. } \\
\text { Co. }\end{array}$ \\
\hline $2,364,088$ & Core Drilling & $\begin{array}{l}\text { H.C. Miller, } \\
\text { et al }\end{array}$ & $\begin{array}{l}\text { United States } \\
\text { Government }\end{array}$ \\
\hline $2,373,323$ & $\begin{array}{l}\text { Process and Apparatus For } \\
\text { Pressure Core Drilling }\end{array}$ & G:A. Macredy & - \\
\hline $2,541,785$ & Coring Device & D.M. Smith & The Texas Co. \\
\hline $2,587,231$ & Boring Tool & W. Schierding & - \\
\hline $2,703,697$ & $\begin{array}{l}\text { Process and Apparatus For Well } \\
\text { Coring }\end{array}$ & R.D. Walker & - \\
\hline $2,830,667$ & $\begin{array}{l}\text { Pressure-Operated Bottom-Hole } \\
\text { Drill Stem Tester }\end{array}$ & J.E. Walstrom & $\begin{array}{l}\text { California } \\
\text { Research Corp. }\end{array}$ \\
\hline $2,862,691$ & Coring Bit Assembly & C.D. Cochran & $\begin{array}{l}\text { Jersey Prod. } \\
\text { Research Co. }\end{array}$ \\
\hline $2,880,969$ & Apparatus For Obtaininq Unaltered & P.S. William3 & $\begin{array}{l}\text { Jeisey Prod. } \\
\text { Research Co. }\end{array}$ \\
\hline $2,927,776$ & Coring Apparatus & $\begin{array}{l}\text { A. B. Hildebrandt, } \\
\text { et al }\end{array}$ & $\begin{array}{l}\text { Jersey Prod. } \\
\text { Research Co. }\end{array}$ \\
\hline $3,064,742$ & Obtaining Unaltered Core Samples & H.C. Bridwell & $\begin{array}{l}\text { Jersey Prod. } \\
\text { Research Co. }\end{array}$ \\
\hline $3,095,935$ & Coring Bit & $\begin{array}{l}\text { A. B. Hildebrandt, } \\
\text { et al }\end{array}$ & $\begin{array}{l}\text { Jersey Prod. } \\
\text { Research Co. }\end{array}$ \\
\hline $3,138,214$ & Bit Force Applicator & H.C. Bridwell & $\begin{array}{l}\text { Jersey Prod. } \\
\text { Research Co. }\end{array}$ \\
\hline
\end{tabular}




\begin{tabular}{|c|c|c|c|}
\hline $3,146,837$ & $\begin{array}{l}\text { System For Obtaining True Core } \\
\text { Samples }\end{array}$ & H.C. Bridwell & $\begin{array}{l}\text { Jersey Prod. } \\
\text { Research Co }\end{array}$ \\
\hline $3,329,220$ & $\begin{array}{l}\text { Apparatus For Drilling Core } \\
\text { Samples }\end{array}$ & R.K. Dyer & $\begin{array}{l}\text { Sinclair } \\
\text { Research Co. }\end{array}$ \\
\hline $3,635,295$ & $\begin{array}{l}\text { Apparatus For Drilling A Small } \\
\text { Borehole Downwardly From The } \\
\text { Bottom of a Large Borehole }\end{array}$ & J.H. Cobbs & $\begin{array}{l}\text { Fenix } \varepsilon \\
\text { Scisson, Inc. }\end{array}$ \\
\hline $3,804,184$ & Core Drilling Apparatus & $\begin{array}{l}\text { M.T. Gusman, } \\
\text { et al }\end{array}$ & - \\
\hline $3,837,412$ & $\begin{array}{l}\text { Downhole Electrical Core Drilling } \\
\text { System }\end{array}$ & W.B. Driver & - \\
\hline $3,839,899$ & $\begin{array}{l}\text { Method and Apparatus For } \\
\text { Determining Parameters of Core } \\
\text { Samples }\end{array}$ & J.M. McMillen & Mobil oil Corp. \\
\hline $3,898,815$ & $\begin{array}{l}\text { Pressure and Volume Compensating } \\
\text { System For Reciprocating Oil } \\
\text { Field Drilling Tools }\end{array}$ & J.W: Young & $\begin{array}{l}\text { Dresser Ind. } \\
\text { Inc. }\end{array}$ \\
\hline $3,898,895$ & $\begin{array}{l}\text { Method of Attaching Teeth To An } \\
\text { Earth Drilling Tool }\end{array}$ & T.L. Taylor & - \\
\hline $3,921,733$ & $\begin{array}{l}\text { Method of Drilling A Borehole } \\
\text { Using Gelled Polymers }\end{array}$ & R.L. Clampit & $\begin{array}{l}\text { Phillips } \\
\text { Petro. Co. }\end{array}$ \\
\hline
\end{tabular}




\author{
APPENDIX C \\ LITERATURE SEARCH \\ ON \\ CORING EQUIPMENT
}

Petroleum Abstracts for the period January, 1965 to the present were searched for permanent literature on certain coring equipment. Approximately 120 references were located. Titles of these references are tabulated in the attached list which also includes the abstract number for that reference. Abstracts for each of these references are found in the following sections grouped as $l$ isted on the index tabs. 


\section{LITERATURE SEARCH}

․ CORING EQUIPMENT

PETROLEUM

ABSTRACTS NO.

TITLE

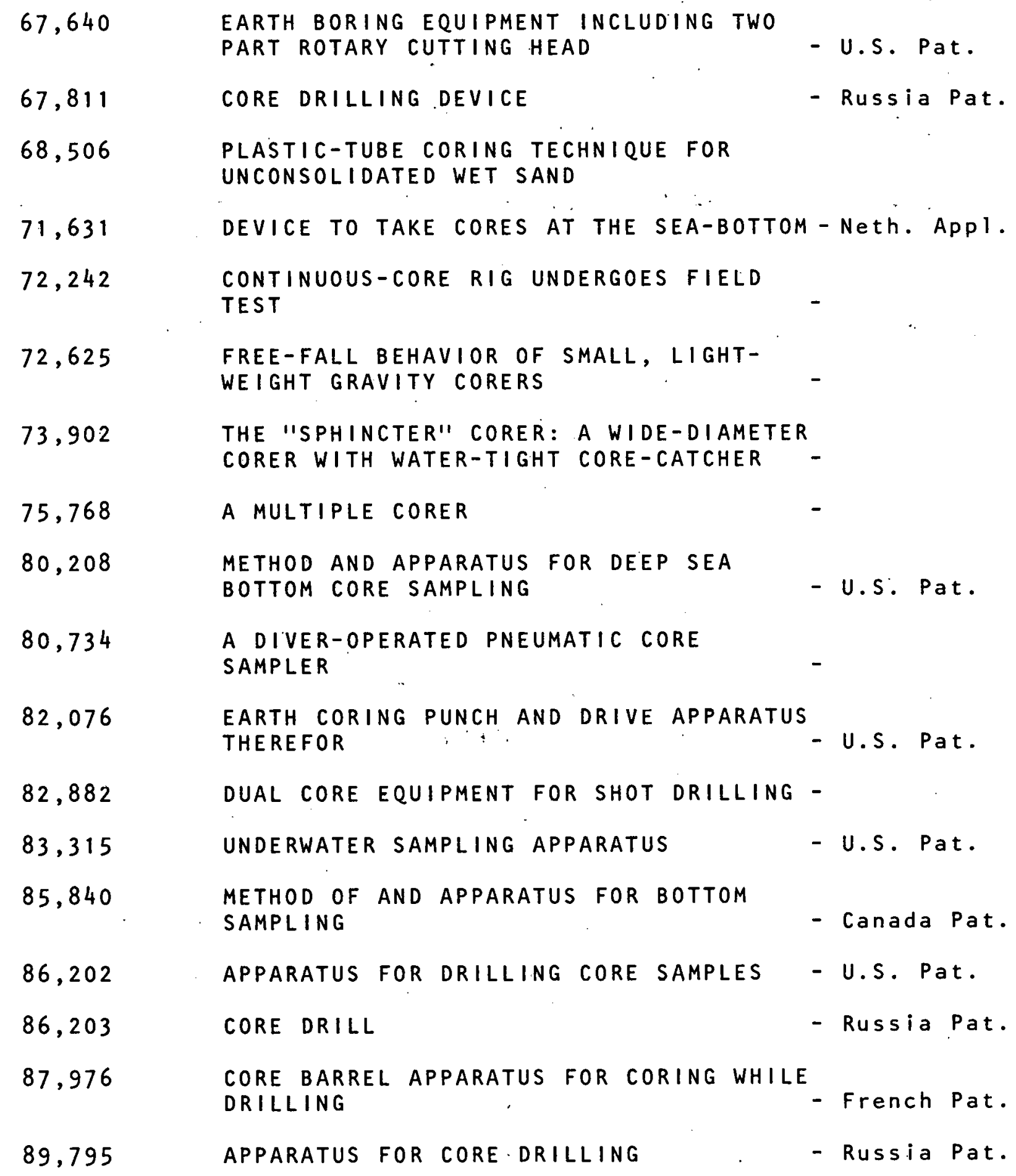




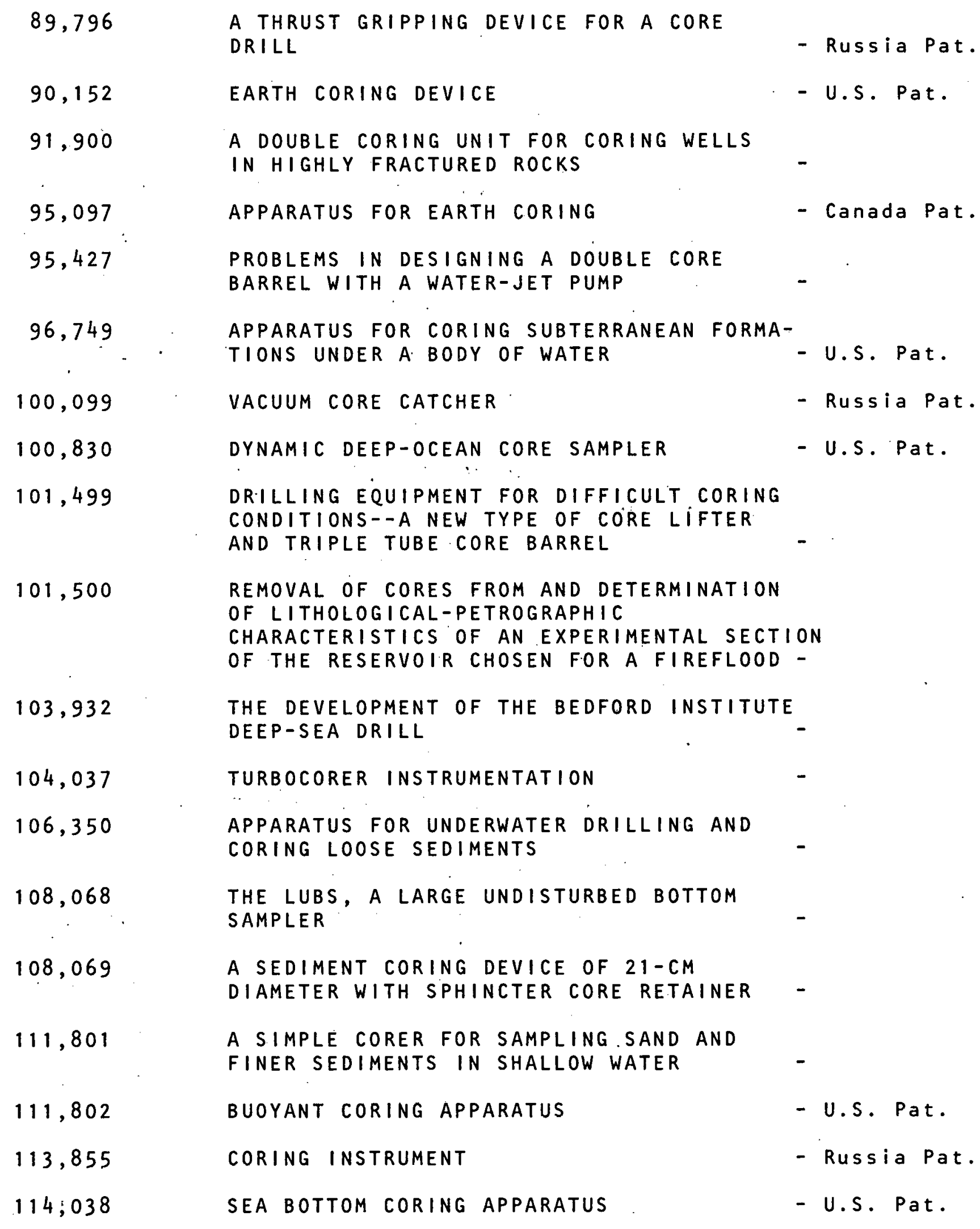



114,458
DESCRIPTION OF A DUAL CORER FOR
OBTAINING PAIRED PISTION OR GRAVITY
CORES
117,520
A NEW "SPHINCTER"CORER WITH A RECOILLESS PISTON
118,133
A DEVICE FOR RELEASING A PISTON CORER AND DEACTIVATING THE PISTON
118,728
RHEOLOGICAL STUDIES OF KAOLIN-CONTAINING DISPERSIONS, PART 1
118,730
IMPROVEMENTS IN BOREHOLE SURVEY MEANS AND CORE SAMPLE ORIENTATING MEANS
119,576
INSTALLATION TO TAKE BOTTOM SAMPLES
- Neth. Appl.
121,608
DRILL PIPE FOR CORE DRILLING APPARATUS -
123,288
THE "MONO" CORER; A WIDE DIAMETER, GENERAL PURPOSE, GRAVITY CORING TOOL
124,372
A HYDRAUL IC CORER FOR USE IN WATER SATURATED SEDIMENT
128,011
THE NPS ROCKET CORER; A FIRST GENERATION ROCKET POWERED CORING TOOL
128,390
AS SELF-DEACTIVATING PISTON FOR A PISTON CORER
128,791
UNDERWATER ELECTRIC TOOL BUILT TO CORE SEA FLOOR
129,653
A HYDRODYNAMICALLY ACTUATED DEEP SEA HARD ROCK CORER
130,830
IFP CUTS SUBSEA CORING COSTS WITH NEW ELECTRODRILL
131,388
AN AUTOMATIC-RELEASE PISTON FOR USE IN piston coring
132,135
ELECTRICALLY CONTROLLED AND POWERED SUBMARINE ROTARY CORER SYSTEM
- U.S. Pat.
133,070
EXPERIMENTAL USE OF EJECTING CORING TOOLS FOR INCREASING RECOVERY OF CORES
135,770
NEW DEVELOPMENT IN SEA-BOTTOM SAMPLING 
PETROLEUM

ABSTRACTS NO.

TITLE

\begin{tabular}{|c|c|c|}
\hline 136,073 & $\begin{array}{l}\text { A NEW LARGE DIAMETER PISTON CORER AND } \\
\text { CORE-LINER CUTTER }\end{array}$ & - \\
\hline 136,485 & PISTON CORING APPARATUS WITHOUT RECOIL & - French Pat. \\
\hline 137,657 & $\begin{array}{l}\text { VIBRATING CORER COLLECTS HARD SAND } \\
\text { SAMPLES }\end{array}$ & - \\
\hline 140,376 & CORE DRILLING APPARATUS & - Germany Pat. \\
\hline 143,731 & DESIGN OF AN AUTOMATIC MARINE CORER & - \\
\hline 145,083 & DESIGN OF AN AUTOOMATIC MARINE CORER & - \\
\hline 149,995 & PRINCIPAL TRENDS IN CORE. DRILLING & - \\
\hline 151,159 & $\begin{array}{l}\text { INFLUENCE OF LUBRICANTS AND POLYMER } \\
\text { COATINGS ON PENETRATION OF } \\
\text { OCEANOGRAPHIC CORING TOOLS }\end{array}$ & - \\
\hline 151,161 & $\begin{array}{l}\text { METHODS AND APPARATUS FOR DIRECTIONAL } \\
\text { DRILLING }\end{array}$ & - U.S. Pat. \\
\hline 152,656 & $\begin{array}{l}\text { THE SACLANTCEN SPHINCTER CORER } \\
\text { ASSEMBLY, PART } 1 \text { A WIDE-DIAMETER } \\
\text { CORER WITH WATERPROOF CORE-CATCHER, } \\
\text { PART 2. AN ELECTRICAL TRIGGERING } \\
\text { SYSTEM. }\end{array}$ & - \\
\hline 154,505 & $\begin{array}{l}\text { A SIMPLE CORER AND A METHOD FOR } \\
\text { SAMPLING THE MUD-WATER INTERFACE }\end{array}$ & - \\
\hline 154,997 & $\begin{array}{l}\text { HYDRAULIC CORE DRILL FOR DRILLING } \\
\text { OPERATIONS }\end{array}$ & - French Pat. \\
\hline 156,740 & SOFT FORMATION CORE BARREL & - U.S. Pat. \\
\hline 156,741 & $\begin{array}{l}\text { APPARATUS FOR OBTAINING CORE SAMPLES } \\
\text { IN UNCONSOLIDATED SOIL }\end{array}$ & - Germany Pat. \\
\hline 157,025 & $\begin{array}{l}\text { AIDS TO UTILIZATION OF A SHALLOW } \\
\text { PENETRATION SEAFLOOR SITTING DRILL }\end{array}$ & - \\
\hline 158,204 & $\begin{array}{l}\text { APPARATUS FOR DRILLING A SMALL BOREHOLE } \\
\text { DOWNWARDLY FROM THE BOTTOM OF A LARGE } \\
\text { BOREHOLE }\end{array}$ & - U.S. Pat. \\
\hline 158,437 & PERCUSSION CORING APPARATUS & - French Pat. \\
\hline, 354 & $\begin{array}{l}\text { A METHOD OF AND APPARATUS FOR OBTAINING } \\
\text { UNDERWATER CORES }\end{array}$ & - Gr. Brit. Pa \\
\hline
\end{tabular}


PETROLEUM

ABSTRACTS NO.

TITILE

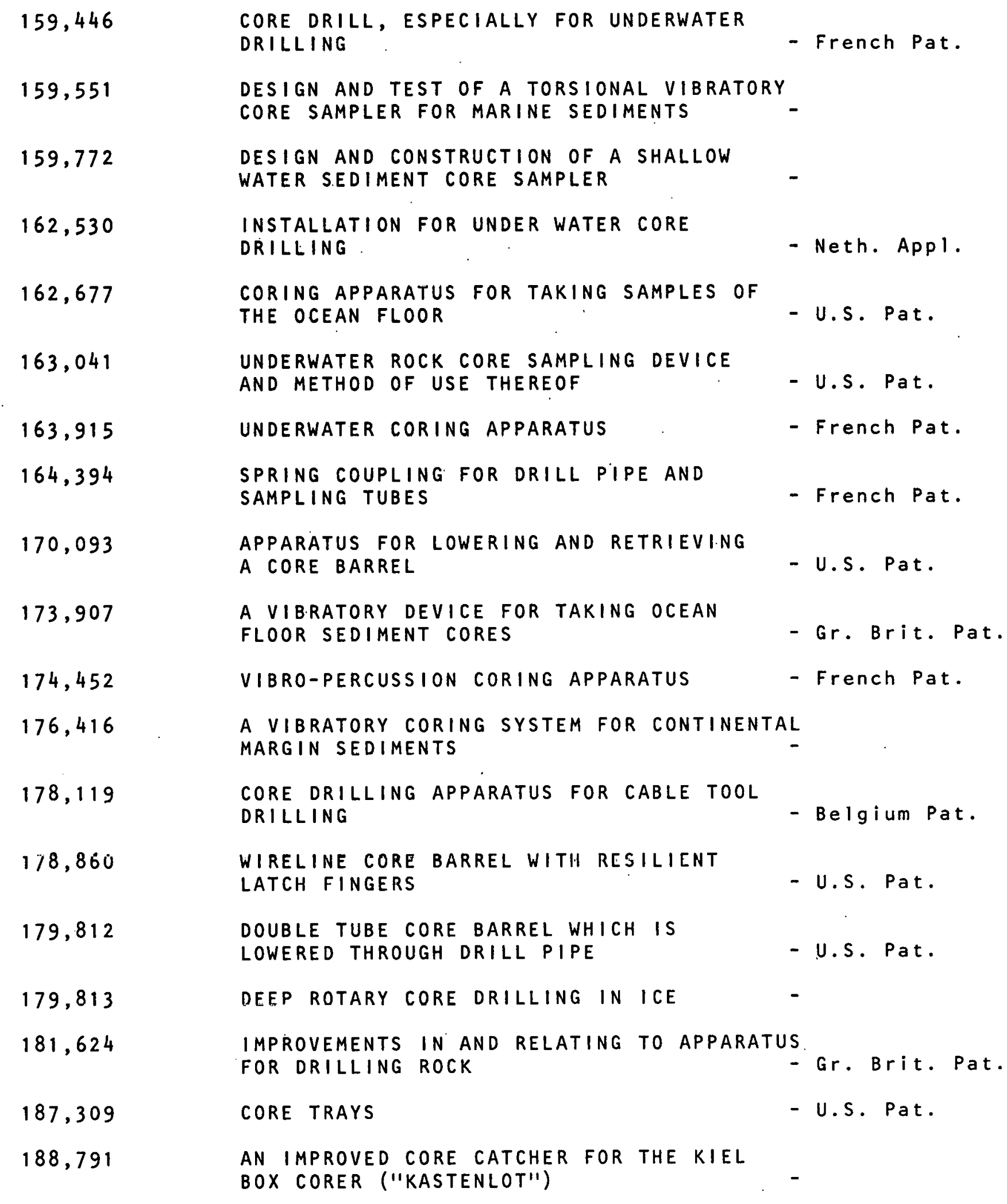


PETROLEUM

ABSTRACTS NO.

TITLE

\begin{tabular}{|c|c|c|}
\hline 191,265 & CORE DRILLING APPARATUS & - U.S. Pat. \\
\hline 193,555 & APPARATUS FOR BOTTOMHOLE CORING & - U.S. Pat. \\
\hline 194,270 & THE CBI POGO STICK CORER & - \\
\hline 195,649 & CORE SAMPLING DEVICE AND METHOD & - \\
\hline 197,038 & $\begin{array}{l}\text { AN INESPENSIVE HAND-OPERATED SEDIMENT } \\
\text { CORER }\end{array}$ & - \\
\hline 198,557 & $\begin{array}{l}\text { CONCEPTUAL DESIGN OF A CORING } \\
\text { SUBTERRENE GEOPROSPECTOR }\end{array}$ & - \\
\hline 198,777 & $\begin{array}{l}\text { DOWNHOLE ELECTRICAL CORE DRILLING } \\
\text { SYSTEM }\end{array}$ & - U.S. Pat. \\
\hline 199,308 & CORING APPARATUS & - Belgium Pat. \\
\hline 199,647 & $\begin{array}{l}\text { DRILLING ASSEMBLY AND PROCESS FOR } \\
\text { LIFTING IT TO THE SURFACE }\end{array}$ & - French Pat. \\
\hline 199,648 & $\begin{array}{l}\text { INSTALLATION TO TAKE SAMPLES IN LOOSE } \\
\text { GROUND }\end{array}$ & - Neth. Appl. \\
\hline 202,045 & $\begin{array}{l}\text { DRILL INSTALLATION WITH REMOVABLE CORE } \\
\text { BARREL AND CENTRAL PART }\end{array}$ & - Neth. Appl. \\
\hline 206,677 & $\begin{array}{l}\text { TECHNICAL AND ECONOMIC ADVANTAGES OF } \\
\text { THE HYDRAULIC ANNULAR VIBRO-HAMMER FOR } \\
\text { UNDERWATER SAMPLING AND GEOTECHNICAL IN- } \\
\text { SITU INVESTIGATIONS }\end{array}$ & - \\
\hline 210,075 & CORE DRILLING APPARATUS & - Canada Pat. \\
\hline 211,907 & $\begin{array}{l}\text { REMOTELY OPERATED SEAFLOOR CORING AND } \\
\text { DRILLING METHOD AND SYSTEM }\end{array}$ & - U.S. Pat. \\
\hline 212,682 & CORE DRILL FOR SOIL LAYERS & -. French Pat. \\
\hline 214,772 & $\begin{array}{l}\text { UNDERWATER DRILLING APPARATUS, } \\
\text { ESPECIALLY CORE DRILL }\end{array}$ & - German Pat. \\
\hline 214,773 & CUTTER DEVICE FOR EARTH CORING & - Gr. Brit. Pat. \\
\hline
\end{tabular}


EARTH BORING EOUIPMENT INCLUDING TWO PART ROTARY CUTTINC: HEAD - U. S. 3,241,624, c.3/22/66, f. 1/24/63 (Appl. No. 253,626):

C. L. Rasoieur, asr.; (Central Mine Equipment Co)

This earth-boring equipment includes a 2 -part rotary cutting head. The c'stting head includes an outside part that is hollow, an inside part latched in place. and the necessary tools for removing and replacing the inside cutting head part while the cutting head is connected to the end of a hollow drill string such as a string of hollow auger sections detachably connected end-to-end and to the cutting head. The equipment can be used to depths of 200-300 ft. The equipment accomodates the passage of a sampling tool by removing one of the parts to provide for passage of the sample-taking tool. The closure plug can be unlatched and removed by a simple fishing operation performed through the hollow drill string. $(6$ claims

$\stackrel{\dot{\omega}}{\sigma}$

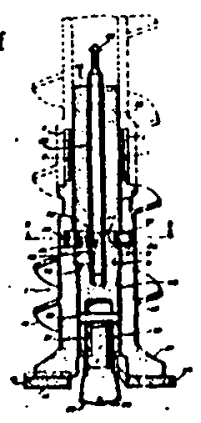

CORING EQUIPMENT

67,8112

CORE DRILLING DEVICE - U.S.S.R. 178, 323, f.5/31/63; V.1. Maksimov, A. A. Volokitenkov, M. M. Rozin and V. M. Shvetsov; IZOBRET. PROM: OBRA7. TOVARNYE ZNAKI v. 43, No. 3, pp 7-8, 1966 (In Russian)

A core drilling device consists of a tubular housing, a column of drill pipe, a drilling tip, an impeller pump, and a slurry-collecting pipe. In order to assure reliable operation of the punp during drilling, both in monolithic and in fractured rocks, the pump propeller is fixed in the drill string with its ring or band rigidly secured to the toul's housing. The apparatus is provided at the top with a bracing device, made in the form of one or more pairs of spring-activated levers.

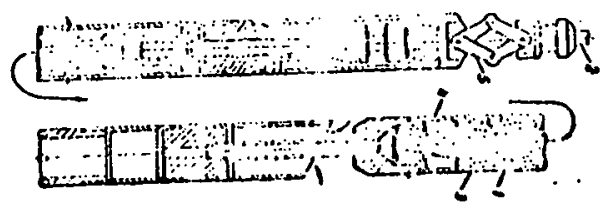

\section{CORING METHODS}

$68,506 \longleftarrow$

PLASTIC-TUBE CORING TECHNIQUE FOR UNCONSOLIDATED WET SAND D. E. Shier (Shell Oil Co) and R. प. Oaks, Jr. (Esso Production Res Co); J. SEDIMENT. PETROL. v. 36, No. 1, pP 241-244, March 1966

Cores of unconsolidated wet sand can be obtained by: (1) hammering plastic tubing into sand with a board; (2) filling the remainder of the tube with water and corking the tube to create a vacuum; and (3) pulling the tube, releasing the vacuum, and extruding the core. Depositional structures, concentrations of opaque minerals, differences in oxidation, orientation and preservation of shells, and stratigraphic contacts are strikingly well preserved in the resulting cores.

\section{CORING EQUIPMENT}

$71,631 \sim$

DEVICE TO TAKE CORES AT THE SEA-BOTTOM - Neth. Appl. 6, 515, 742, f.12/3/65 (pr. Fr. 12/4/64, Appl. 997, 552); (Inst Francaia du Petrole) (In Dutch).

A device to obtain cores on the sea-bottom can be lowered from a surface installation. It consists of a support frame with a large base surface, a lowering-hoisting cable, a coring bit including a coring motor connected to it, and flexible tubing wound on a storage drum. The oystem of the core motor and the instrumentation forms one rigid part of the coring device with the flexible tubing attached to its end. A motorized pump feeds the coring instrument with water under pressure, the discharge side being connected to the flexible tubing. The motorized pump is connected to the ourface installation with electrical feeder leads. The coring instrument has electrical instrumentation to regulate the winding and unwinding of the flexible tubing on the drum. This instrumentation is remotely controlled from the surface installation. (6 claims) 
CONTINUOUS-CORE RIG UNDERGOES FIELD TEST - PETROL. INTERAM. v. 24, No. 7, pp 44-46, 48, July 1966

A new system of core drilling now being tested holds promise of increasing the efficiency and economy of exploration in shallow-to-medium depth formations. The new method cores continuously from the top of the hole to total depth. Core recovery and quality are amazingly high, and cost is only slightly higher than conventionsl drilling. Contral feature of the system is a 2 -tube drill string in which the freshly cut cores circulate to the surface with the return mud stream. Among the advantages claimed for the continu. ous core method are the following: (1)accurate determination of depth to key horizons; (2) measurement of dip, both for magnitude and direction;

(3) detection of facies changes; and (4) accurate location of faults, pinchouts, sand lenses, porosity traps, overiaps, reefing, and minerals other than petroleum. Because the cores are pumped to the surface, recovery is virtually complete. Even cores of soft formation which cannot support their own weight in a conventional core tube are readily recovered by the new system. Because the core is exposed to the drilling fluid for a very short time compared to conventional coring, it arrives at the surface with less I damage from mud flushing.

$\omega$

$\stackrel{1}{\mathrm{~T}}$
THE "SPHINGTER" CORER. A WIDE-DIAMETER CORER WITH WATERTIGHT CORE-CATCHER - A. Kermabon, P. Blevier, V. Cortis (Saclant ASW Res Ctr Italy) and H. Delauze (Natl Sci Rea Ctr Marseillea); MAR. GEOL. v. 4, No. 2, pp 149-162, April 1966 (Recd. Oct. 1966)

A long. wide-diameter corer with a watertight core-catcher il doncribed. The main new features of this corer are: (1) a "Sphincter-type", nylon corecatcher, which seals the cores within a watertight container during retrieval; and (a) a split piston, which prevents suction of the core when the corer is retrieved from the sediments. This paper also describes an electrical release system which preventa accidental triggering due to sudden shocks, thereby making it safer than other systems when working in beavy seas. The design of this corer is close to those thooretically ideal proportions generally accepted as providing minimum sample disturbance. The equipment has worked successfully, and little or no disturbance has been observed in the cores taken with it. (10 refe.)
CORING EQUIPMENT

$72,625^{2}$

FREE-FALL BEHAYLOR OE SMALL, LIGHT-WEIGHT GRAVITY CORJRS R. E. Burns (Washington Univ Seattle); MAR. GEOL. v. 4, No. 1, pp 1-9, Feb. 1966 (Recd. Aụg. 1966)

The increasing use of sma!l, light-weight gravity corers equipped with freefall devices, has raised the question of applicability of the optimum free-fall distance criteria originally established for large, heavy corers. Measirement have been made of the free-fall velocities of soveral devices representative of the class of small corers. These data indicate an optimum free-fall st:ting of 2-3 m, with general caution indicated on the minimum setting and specific caution indicated on the maximum for corers not fitted with stabilizing fins.
CORING EOUIPMENT

A MU I.TIPLE CORER - G. A. Fowler and L. D. Kulm (Oregon State Univ) LIMNOL. \& OCEANOGR. v. 11, No. 4, pp 630-633, Oct. 1966

The multiple corer operates on the principle of the gravity corer and contains the saine basic components: a weight, core barrel, plastic liner, cutting head, and one-way valve. The main core body is composed of 5 disk-shaped lead weighto; 3 of them weigh approximately $110 \mathrm{~kg}$ each, and the other 2 weigh $55 \mathrm{~kg}$ each. Each weight was molded with 5 holes to accommodate the core barrels. The weights are held together with pieces of pipe with cuuplings ocrewed to each end. Steel plates are used at the top and bottom of the stack of weights to prevent the couplings from denting the soft lead. A corer is suspended by a chain and bale arrangement attached to the upper plate. The maximum size of the present model was determined by a desire to have the corer heavy enough to achieve adequate penetration and to be used by itgelf in deep water with a fairly large diametor cable. It can also be used as a trip weight for large-sized piaton corers. 
METIOD AND APPARATUS FOR DEEP SEA BOTTOM CORE SAMPLING U.S. 3,301,336, c. 1/31/67, f. 3/24/64 (Appl. 354,400); W. W. Mount

This is a method and apparatus for deep sea bottom core sampling. The apparatus consista of a core tube with a weight at the end of a cable, suspended in part from the top of the core tube and in part from the shp, and attached for movement along the core tube. During operation, cable means raise the weight upward along the tube so that a force is produced urging the tube downward when it is positioned at force is produced urging the tube downward when it is positioned at
the bcttom of the sea. Near the lower end of the core tube but above the cutter sleeve, are located one or more holes to admit water. The holes are below the spring fingers of the core catcher 80 that water coursing down the annular space and entering the inside of the core tube at high pressures cannot directly jet against the sediment around which the core tube is falling, while its purpose is to provide a lubricant between the outside of the core sediment and the inside of the cc.re tube. (20 claims)

A DIV:IR-OPERATED PNEUMATIC CORE SAMPLER - B. WalkeT (Frestiwater Biol ABsoc); LIMNOL OCEANOGR. v. 12, No. 1, pP $144-146$, Jan. 1967

A pneumatic sampler that can be handled by a diver has been degigned. The anchor chamber is made of a steel cylinder closed at the upper end by a steel plate. Compressed alr is carried in a cylinder of 750 liters capacity at $126 \mathrm{~kg} / \mathrm{cm}^{2}$ and mounted on the outer tube close to the operating valves. The cylinder holds enough air to take approximately 3 cores when using the 2. 4-m corer or 2 using the 4. $3-\mathrm{m}$ corer in a water depth 0 to $9 \mathrm{~m}$. From 9 to $2.5 \mathrm{~m}, 2$ cores can be taken with the 2.4-m or one with the 4. 3-m corer. The cylinder clamp on the outer tube accomodates larger cylinders if necesuary, and a charging connection allows a spare cylinder to be used if the operating cylind $r$ is emptied during the coring operation. The approximate weights of the corers, including the air cyllnder, are 25 and $34 \mathrm{~kg}$. A buoyancy pack enables the diver to manouver the unit into any attitude when moving into position to take coro.
EARTH CORING PUNCH ANU DRIVE APPARATUS THEREFOR U.S. 3,308,897, c. 3/14/67, 1.4/6/64 (pr. Can. 11/6/63, Appl. 888, 474); N. D. Becker, asr.; (Becker Drlg (Alberta) Ltd)

This is an earth coring punch for excavating holes for highway guard rails in earth or fill which contains coarse gravel or boulders. The apparatus is transportable and the punch has any desired cross section and length. The punch is suspended by its upper ond from a high-energy percussion engine. The engine and punch are located on an adjustable framework on the vehicle and can be adjusted in position laterally and vertically. The punch is also independently pivoted about a horizontal axis adjacent to its upper end. Its lower end is fitted with an integral shoe with integral teeth aligned with the axis of the punch and spaced about the periphery of the shoe. A series of rock-breaker chisel-like teoth extend inward as well as below the cutting edge and project into the opening of the shoe to shatter or otherwise displace rocks in order that the fragmente will move up through the shoe. (5 claims)

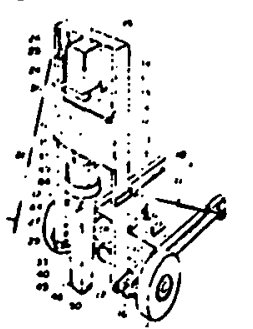

CORING EQUIPMENT

DUAL CORE EQUIPMENT FOR SHOT DRILLING - A A Grebeniuk, G. G. Moiseev and V. I. Khaustov; RAZVED OKHRANA NEDR No. 1, pp 27-32, Jan. 1967 (In Russian)

The construction and operation are described of the dual DKC- 2 core drill, designed for shot drilling to a depth of about $500 \mathrm{~m}$. Previous models of this type core drill had several disadvantages, the chlef ones being that much of the core was lost in drilling fractured, shaly, and weakly consolidated siunds. The DKC-2 drill recovers $60-80 \%$ core, continuously feeds shot to hole bottom while isolating shot from core, and breake core and stores it in core barrel. The shot is transported through the core drill by the circulating drilling fluid. Under typical operating conditions the core drill rotates at $153 \mathrm{rpm}$, witl a load of $650 \mathrm{~kg}$, and drilling fluid circulation rate of $40-50 \mathrm{liters} / \mathrm{min}$. Cast Iron shot, 2-3 mm in diameter are circulated at rate of 75-100 \& per 5 min. A schematic diagram of the core drill and typical performance data are given. 
UNDER WATER SAMPLING APPARATUS - U.S. 3, 313,357, c.4/11/67, f. $11 / 23 / 64$ (Appl. 413, 106); A. A. Venghlattis, asr.; (Dresser Industries Inc)

An apparatus for obtaining earth eamples from submerged lands such as o:sean, lake, and river beds 18 described. The apparatus includes an explooively operated coring device which can be lowered into the water by a cable and is actuated by contact with the ocean or lake bed. The gun includes an explosively dischargeable coring barrel, and is lowered through the water in a muzzle-down position. When the muzale of the coring barrel contacts the bed, the core barrel is pushed back into the apparatus to actuate the explosive charge. Actuation of the charge drives the core barrel out of the gun and into the ocean bed. The core barrol remaine connected to the gun by flexible cables. and thus when the gun io lifted to the surface the cables will carry the coro barrel with it. $(17$ claims $)$

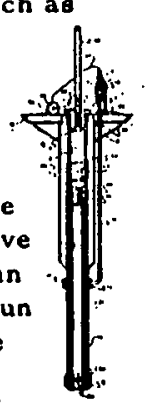

$\underset{\tilde{O}}{\dot{\omega}}$

\section{CORING EQUIPMENT}

$85.840 \sim$

METHOD OF AND APPARATUS FOR BOTTOM SAMPLING - Can. 763, 300, c. 7/18/67, 1. 9/25/64 (pr. Jap. 9/27/65. Appl. 50,816); N. Nasu, H. Yamazaki, H. Shinozaki and T. Yonekura, asro.; (Asahi Kasei Kogyo KK) and (Tsurumi Seiki Kosak Co Ltd); CAN. PAT. OFFICE REC. v. 95, No. 29. pp 6195-6196, 7/18/67

This bottom sampler is operated by lowering it to the submarine floor and locating it at the desired position. The rockets which are mounted on the ampler are then ignited to push the core barrel downward. The oample is recovered by igniting ro that exert an upward force. The number of rockets to be used can be varied in order to meet the requirement for a specific area. For instance, more rockets would be needed in areas where the bottom samples are harder to penetrate. (2 claims)

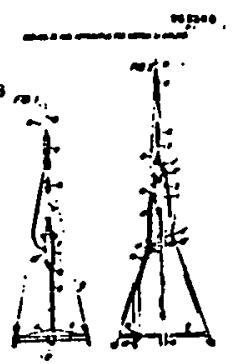

APPARATUS FOR DRILLING CORE SAMPLES - U.S. 3, 329,220, c.7/4i67, f.7/10/64 (Appl. 381,820); R.K. Dyer, asr.; (Sinclair Research Inc)

\section{An apparatus is provided for core drilling which consiste of an elongated tubular housing and packing means disposed around the housing for sealing the well bore into which the apparatus can be inserted. The lower portion of the housing contains a core barrel. The barrel is connected to, and in fluid communication with, a hollow ahaft above it. Hydraulic motors are used for reciprocating and rotating the ohaft and core barrel. In addition, a mud pump circulates drilling fluid down through the haft baxrel and up around the outside the shaft. (14 clalms)}

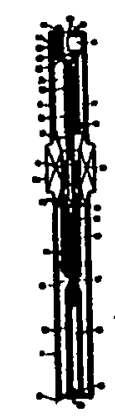

\section{CORING}

86.203

CORE DRILL - U.S.S.R. 185,807, f.7/2/65; V.I. Kot, N.F. Krivun, P.T. Sheshenya et al.; IZOBRET., PROM. OBRAZ.. TOVARNYE ZNAKI v.43, No.18, p 15, 9/12/66 (In Rusgian)

A hydraulic cylinder is used to. force a core drill through rock as it rotates. A hydraulic cylinder is pressurized to a desired level and the core drill is rotated. As the core penetrates the rock, the pressure is depleted. When this occurs, drilling is ceased and the cylinder is repressurized.

This process is repeated until the desired length of core has been drilled.

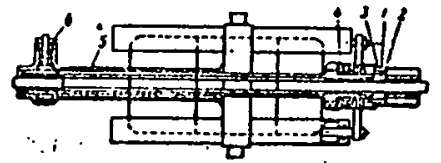


CORE BARREL APPARATUS FOR CORING VHILE DRILLING -

F. 1.489,560, c.6/12/67, 6.8/16/66 (pr. U.S. B/27/65, Appl. 483, 102): L. A. Lindelof, asr.; (Longyear (EJ) Col; Abstr., BULL. OFFIC.

PROPRIETE IND. (FR.) v.8, No.29, P 10094, 7/21/67 (In French)

An apparatus for coring while drilling includes a core barrel with one end tbreaded, this end being connected to an extraction cap in which a core catcher is mounted. The core catcher consists of a ring transverso to the core barrel and which has internal grooves near the base, axially aligned with the core barrel axis. The ring is removable and is limited in axial displacement to a point near the core barrel, thus allowing cutting off the core by forcing it through the core cattcher and into the core barrol.

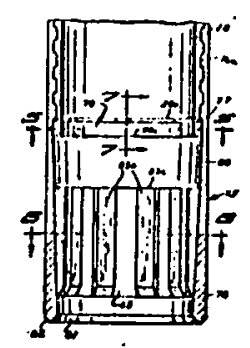

APPAEATUS FOR CORE DRILLING - U. S. S. R. 198,269, f. 4/26/66; V. I Slilov and L. I. Shilov; Abstr. IZOBRET. PROM. OBRAZ. TOVAF:NYE ZNAK1 v. 44, No. 14, p 6, 6/28/67 (In RuBsian)

This core drilling device is similar to U. S.S. R. Patent No. 137,855. The improvement consists in the core barrel having a greater reliability in the retention of cores from loose, unconsolidated rock. The lower part of the elastic core barrel is closed by means of elastic valves.
A THRUST GRIPPING DEVICE FOR A CORE DRILL - U.S. S. R. 199, 052, f. $12 / 29 / 65$; S. N. Blinov, I. G. Komissarov, F. Z. Krasnoyakii et al. Abstr., IZOBRET. FROM. OBRAZ., TOVARNYE ZNAKI v. 44, No. 15, p 6. $7 / 13 / 67$ (In Russian)

A thrust gripping device for a core drill includes the gripping section, rods, coil spring, reversible slip device, and a drilling platform. Essentially, the device provides a means of controlling the loss of the cutting instrument as related to its connection with the drilling column socket. The device has its ends in the form of hinged attachments, resembling yokes, on the drilling platform, with every yoke joined at one end of the cutter with the section clamps and the braces of the converter, and with the other end interacting with the pipe cap through a spring coil. In one aspect, the working surface of the section clamps is equipped with a frictional lining.

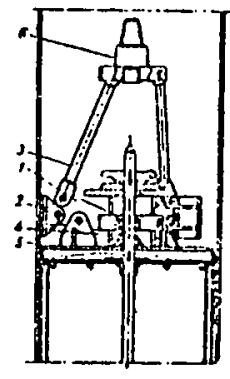

\section{CORING EQUIPMENT}

90. 15:

EARTH CORING DEVICE - U.S. 3, 344,869, c. 10/3/67, f. 9/3/65 (APp). $484,805) ;$ W. B. Tijmann and A. Cody

An explosively driven coring device is especially usoful in taking soil corea for soil analysis, or for other purposes. The device has a threefold recoil system in which 3 separate and accumulative recoil mechaniums are able to absorb the recoil to the operator. A sealing asembly holde the expanding gas resulting from the explosive charge captive in a chamber at the head of the core sampling projectile in which the projectile forms one portion of the sealed chamber. The opposite portion is formed of a novel piston arrangement which functions to expand against a chamber wall under pressure and which further yieldo to absorb a substantial portion of the impact of the explosive charge $: 0$ that the seal and the recoil absorption are accomplished in a single apparatus. The explosive gases are prohibited from entry into the recoil and sealing apparabus, thus proventing the mechanism from being contaminated by the chargo gases. (13 claims)

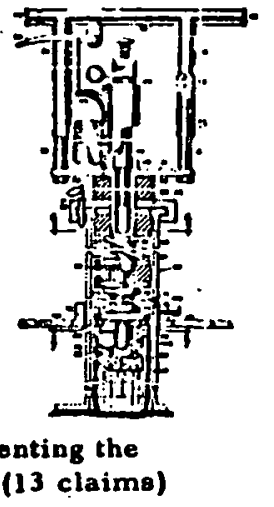




\section{CORING EQUIPMENT}

91,900

A DOUBLE CORING UNIT FOR CORING WELLS IN HIGHLY FRACTURED ROCKS - S.S. Sulakahin; RAZVED. OKHRANA NEDR No. 8, PP 51-52, Aug. 1967 (In Eussian)

Considerable difficulty is experienced in coring hard, highly fractured rocks. The main problem is trapping of cores in the core barrel. In this article a echematic draving of a core drill, deaigned to drill and hole fractured cores, is described and prosented. The corotholding and storage chamber is sealed by opring-actueted and hydraullcally actuated mechanioms.

$\stackrel{\omega}{\omega}$

CORING EQUIPMENT

95,097

APPARATUS FCR EARTH CORING-- Can. 779, 148, c. 2/27/68, f. 2/19/66 (pr. Can. 4/5/65, Appl. 927,325); S.G.Atkins and S.B. Baillie; Abstr., CAN. PAT. OFFICE REC. v. 96, No. 9, p 1973, 2/27/68

A coring assembly consist 8 , in combination, of a longitudinally extending body portion with a plurality of earth-plug segmenting fins secured around the body portion. These fins extend zadially outward from the body portion and diagonally outward from one end of it toward the other end. A cutting ring is secured to the outer end of the fins, concentrically with the body portion. The ring is sharpened on its leading edge The trailing edge and the portion of the ring adjacent tc the trailing edge curves inward toward the body portion and forme an obtuse angle with the remainder of the ring. (5 claims)

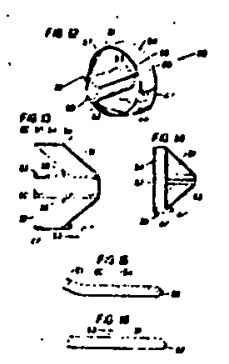

PROBLEMS IN DESIGNING A DOUBLE CORE BARREL WITH A WATER-JET PUMP.- G. I. Neudachin, A. V. Kolomoets, Yu. A. Polozov and B. Z. Sultanov, IZV. VYSSH. UCHEB. ZAVEDENH, NEFT GAZ No. 10, pP 27-30, 1967 (In Rusiian)

Operating efficiency of a double-barrel core drill was increased by installation of a water-jet pump in the core barrel. The water jet pump increased core recovery to $80-90 \%$. Penetration rate of core drill with the pump was 15 . $20 \%$ higher than without the pump. A schematic diagram of the core barrel with the jet-pump is shown. Essentially, the water-jet pump is an arrangement of nozzles, tubes, and valves which circulate water or other drilling fluid upward through the core barrel, thereby aiding the recovery of core. Driving force for the water-jet pump comes from the mud pump. The relationship between dimensions of pump components. drilling fluid circulation rate, and operating efficiency of the core barrel are shown analytically.

\section{CORING EQUIPMENT}

APPARATUS FOR CORING SURTERRANEAN FORMATIONS UNDER A BODY OF WATERe-U.S. 3,373,827, c. 3/19/68, f. 6/14/66 (Appl. 557,531): J. N. Biron, D. B. Junes and D. L.Sims, asre.; (US Natl Sci Found)

This apparatus, for lowering on a flexible line, is used to core formations below a body of wascr. The core barrel of the apparatus is kept substantially vertically oriented while being lowered through the water and while cutting the core, even though the flexible line supporting the apparatus does not extend vertically to the surface of the water. A float is attached to the flexible line adjacent to the apparatus. By controlling its buoyant force, the float tends to nullify the effect on the attitude of the core barrel of the wire line extending upward from the apparatus at an angle. The buoyant force is less than the weight of the apparatus in the water so that the apparatus will sink. However, the float exerts a buoyant force sufficient to keep the short section of line between the

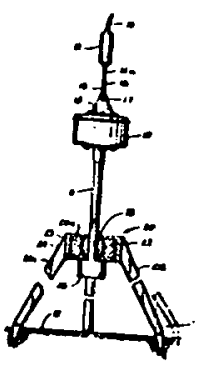
float and the coring assembly taut. (1 claim) 
YACUUM CORE CATCHER--U.S.S_R_209, 356, f. 12/26/66; G. I. Potapov; Abst $r$. IZOBRET. PROM. OBRAZ. TOYARNYE ZNAKI v. 45, No. 5

p 9. 1968 (In Russian)

A vacuum core catcher consiste of a housing with a core catching cup with a lid through which passes a shaft with the valve the reon, and having packing seeals. In orde $r$ to increase the tightness of the connection, the

thaft is made in the form of acrew upon which

io mounted the cover, the latter having threade.

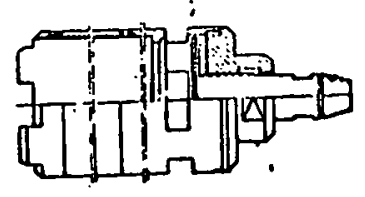

w

\section{CORING EQUIPMENT}

$100,830 \longleftarrow$

DYNAMIC DEEP-OCEAN CORE SAMPLER -- U. S. 3,392, 794, c. 7/16/68, f. 3/28/66 (Appl. 538,912); M. R. Kurillo, Jr. and L. R. Russel

The description discloses a deep-ocean core sampler which is self-supporting on the ocean bottom and will obtain vertical samplea therefrom even though the ocean bottom may be inclined or has an irregular surface. The core oampler may include a ampling tube, a barrel which receives the oampling tube into the ocean bottom, and gimbals mounting the barrel and driving means to a support means which is adapted to rest on the ocean bottom. The barrel and driving means are free from restraint except for the gimbal connection to the oupport meane. (8 claims)

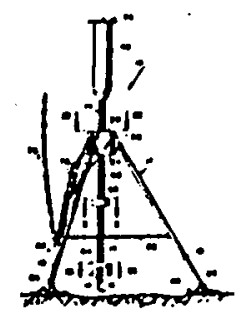

DRILLING EQUIPMENT FOR DIFFICULT CORNG CONDITIONS-A NEW TYPE OF CORE LIFTER AND TRIPLE TUBE CORE BARREL-

J. B. Robinson et al. : PROC. AUSTRALAS INST. MIN. MET. No. 224, pp 37-46, Dec. 1967; Abstr., No, L 52, IND, DIAMOND REV. v. 28, No. 333, p 378, Aug. 1968

Although considerable improvements in diamond drilling equipment have been made since the early 1950 's, deficiencies in existing equipment led to the development of a new type core lifter and opecial 20 ft triple tube core barrel designed to operate in bad coring conditions. It ig claimed that although developed essentially for coal drilling, the new equipment could bo adapted to other fields of diamond drilling with the coat advantage of increased lifo of the core lifter.

\section{CORE BARREL}

REMOVAL OF CORES FROM AND DETERMINATION OF LTHOLOGICAL PETROGRAPHIC CHARACTERISTICS OF AN EXPERUMENTAL SECTION OF THE RESERYOIR CHOSEN EOA A FIREFLOOD- B. D. Panov and V.T.Malyohok; NEFT. KHOZ. No. 4, pp 57-61, April 1968 (In Ruseian)

Productive zonee in injection and productng welle of Pavlova Gora field were completely cored, co that detailed information could be obtained concerning characteristics of the reservoix, chosen to be firellooded. The constructicin of a core barrel, designed to remove large-diameter cores from unconsolidated sands and shales, is doscribed. The cores gave information on textural characteristics of the reservoir, granular make-up, igrain form of rock-forming minerals and petrographic composition of brecciated and cementing parte of the rocks. The reservolr wae found to be heterogeneouls. Sandetone is separated by ohale stringers. The reservoir consiste of sanile and shales with various degrees of oll saturation. Granular analysis indicates that the middle part of the reservoir has the best properties. Recervoir properties are given by thbular data. 

J. Brooke and R. L. G. Gilbert (Bedford Inst, Nova Scotia); DEEP-SEA FES. v. 15, No. 4, pp 433-490, Aug. 1968

A new concept for arilling ohort cores of reck from the floor of the deep ocean is described. The power for operating the drill is obtained from wates: which moves from the no:mal ambient hydrostatic pressure into a low pressure void. A general description is given of the complate drill aseembly and its method of operation. The results of 3 series of experiments at sea, and of a number of tests on land are given, from which the pbilities and limitations of the $\mathrm{Jrill}$ in its present form may be inferred. The pla ne for future work are described and long-range objectives are outlined.

TURBOCORER INSTRUMENTATION-_B =oum \& Root, Inc. Staff; PB- 178, 836 Approx. 90 Pp, 7/5/67. (Recd. Oct. 1968)

The overall length of the turbocorer instrument depending upon the size of the core-barrel in use, ranges from 38 to $68 \mathrm{ft}$. In use, the instrument package with core-barrel assembly is lowered by the logging cable through the drill pipe and inside the turbocorer proper. When the package reaches its proper position, it is automatically. locked into operation position by a mechanical latch. At this time, drilling can commence. To retrieve the core specimen, drilling is otopped; the logging-cable tension at the instrument-package head must be increased to $1,0: 00$ lb in order to digengage the latch from the latch body. The specific parameters measured are as follows: (1) cort-bit speed; (2) the amount of core in the core-barrel; (3) pressure drop across the turbine and bit; (4) maximum. allowable thrust-bearing weax; (5) inclination of the turbocorer; (6) cable tension at the instrument package head; (7) instrument package latck position; and (8) instrument package input voltage. 
APPARATUS FOR UNDERWATER DRILLING AND CORING LOOSE SEDIMENTS-OS. Afr. 68/2,887, c. 10/18/68, f. 5/6/68 (pr. Fr. 5/8/67);

J. Delacour, A. Castela and P. Moulin, asrs.; (Ingt Francais du Petrole)

Abstr.. PATENTJOERNAAL (S. AFR.) v. 1, No. 11, p 165, Nov. 1968

An apparatus operable from a surface installation for driving into the underwater floor consists of a number of elements which are connected end to end and used for offohore drilling and coring operations. It consiste osentially of a base member seated on bottom which is provided with a central well through which the pipe otring

passes. Rigid guide members extend in a

tion parallel to the axis of the ceatrsi woll.

Substantially parallel guide cables connect the

surface installation to the tops of the guide columns.

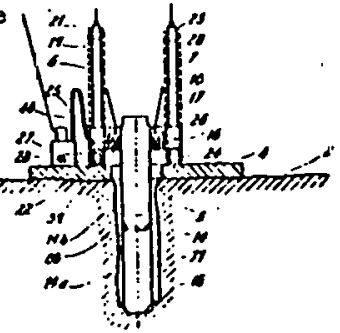

A drilling head with a submersible motor is elldable

along the guide columns. A moans is provided in the base to hold the pipe

elements. Cables for power, for soisting, and for lowezing are provided.

$\omega$

(5 claims)

CORING ROUIPMENT

$10 \mathrm{~B}, 116 \mathrm{HL}$

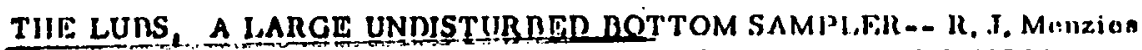
(Florida State Univ) and G.T. Rowe (Duke Univ): LIMNOL. OCEANOGle. v. 13, No. 4, pp 708-714, Oct. 1968

A new benthic collecting device, the LUBS (large undisturbed benthos sampler), which oatisfies many of the criteria for a successful soft-bottom quantitative sampler is described. The besign is simple, inexpensive, and such that samples may he canned on retrieval. Stratified sediments can be collected in large diameters, so the device also should be useful to geologists. The LUBS recovers stratified sediments intact, impossible with the clam-shell grab. The volume of sediment captured by LUES is known as soon as the sample arrives on deck and there is no need to dump the sample into a tray or can to measure its volume. A.second advantage of LUBS is the capture of epifauna and of the in situ water overlying the sediment. A third advantage is that the sample is collected in its own container and may be preserved in toto for subsequent study of animalssediment relationships, tracks, tubes, and so on. (12 refs.)
A SEDIMENT CORING DEVICE OF 21-CM DIAMETER WITH SPHINCTER CORE RETAINER-- J. C. Burke (Woods Holo Oceanogr Inst); LIMNOL OCEAIJOGR. v. 13, No. 4, pp 714-718, Oct. 1968

A 2 l-cm-ID gravity corer of a now design was developed to provide large crose section core amples for analysio of fallout radionuclides in sediments of Crater Lake, Ore. The study of vertical profiles of the concentration of fallout radionuclides (which havo been avallable for sedimentation only oince the early $1950^{\prime}$ s in most places) also demands efficiont sampling of the topmost layers of eediment and their recovery in aitu. Some ovidonce from atudicu of more conventionally collected cores indicates that these uppor layers are cominonly loot, either by washout at the top of the core tube or by being "wept away from the point of impact by the shock wave of rapidly falling corore. Another requirement is officiont retontion of a variety of sediment types, ranging from very oft muds to coarse, shaxp aands; loss of water through the usual core-rotalning dovicos commonly flushos out such samplos. The new coring device, combining large diameter with positive, watertight closing of both bottom and top of the core tube at the time of pullout, meets all these requir ements.

A SIMPLE CORER FOR SAMPLING SAND AND FINER SEDIMENTS IN SIIALLOW WATER -- P.S. MaITIAnd: LIMNOL. OCEANOGR. v. 14, No. 1 , PP 151-156, Jan. 1969

The main types of substrate found in aquatic environments can be divided into gilte and finer sediments, sands, gravele, and consoer oubatrates. Each of theoc substrates preoste it own difficulties for quantitative oampling, upon which are superimponed the varintions in tochnique nocoesary witl difforont depthe of wator. The eampler descrlbed is eatiofactory for ands and finor sedimente and for short-atalked macrophytes growing in such sedimente. In practice, it ie useful in depthe lese than $5 \mathrm{~m}$. 


\section{CORING EOUIPMENT}

111,802 レ

BUOYANT CORING APPARATUS-- U.S. 3,434,551, c. $3 / 25 / 69$, f. $6 / 26 / 67$ APPl. 649,438); A. M. Rogfolder, ar.; (US Navy)

A buoyant rig for oupporting coring operations of an underwater coring barrel is described. The buoyant rig includes a float and a bottom. weighted otand which are interconnected by at least one guide wire. Tho coro barrol olldably extende through the woighted stand and is positionod parallol to the guido wiro and is olidable thorealong by a guide menno. When tho core barrel is powered, the barrel will bo guided along the guide wire as It penetratee the ocean bottom. A gimbal connection between the coro barrel and the atand for uneven ocean bottoms and the guide wire may be separated from the stand after a sample is obtained so that the float will raleo the coro barrel and the romaining sigging apparatue to the ocean aurface. (10 claima)

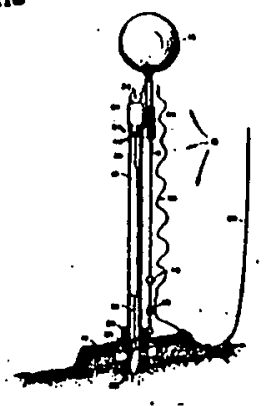

. -

$\omega_{\omega}^{\prime}$

\section{CORING BIT}

$$
113,855 \leftarrow
$$

CORING INSTRUMENT - - U.S.S.R. 232,880, f. 12/27/65; M. M. Rozln N. M. Tsekhmistrenko and A.A. Volokitenkov; Abstr. , OTKRYTIYA, $\frac{\text { IZOBRET., PROM. OBRAZIY, TOVARNYE ZNAKI }}{1969 \text { (In Rusuian) }}$ v. 46, No. 2, p 9.

A coring instrument is deaigned to inclyde a drilling head and a sub. The sub is equipped with spring-loaded plungers and lateral channels that communicate with the annulus of the core barrel during plunger displacement. (Abstract only - original not avallable)
SEA BOTTOM CORING APPARATUS=- U.S, 3,442,339, c. 5/6/69, f. 2/17/67 (Appl. 616,893); T. N. Williamson, asr.; (Hughes Tool Co)

A marine bottom coring apparatus for drilling into and obtaining core samples from subsea formations is described. It is particularly useful for obtaining core samples from hard rock formations. The apparatus includes a frame having buoyancy, which has sufficient capacity to float the apparatus in the unballast condition. Ballasting means are also connected to the frame and having ballast capacity sufficient to over come a buoyancy of the buoyancy means. Release meang are provided for releasing the ballast at a predetermined time. The frame has the core drilling means attached to it and is supported on the sea bottom, whereby the apparatus may be sunk to the sea bottom by the ballast. a core sample drilled from the subsea formation, and the apparatus floated to upon release of the ballast. (11 claims)

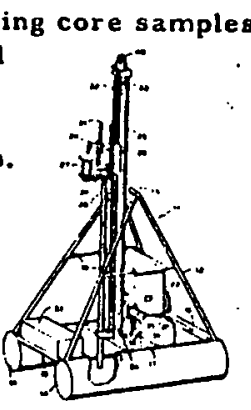

CORING LOUIPMENT

\section{$114,458 \sim$}

DESCRIPTION OF A DUAL CORER FOR OBTAINING PAIRED PISTON OR GRAVITY CORES.- A. Blackman and R.S. Anderion (US Naval Oceanogr Office): MAR, TECINOL, SOC, J. v. 3, No. 2, pp 73-74, March 1969

A simple method of obtaining paired cores spaced $3 \mathrm{~m}$ apart with known relative azimuth is described. A dual corer, fabricated from standard materials and available equipment, has been designed to take 2 long cores simultaneously. The advantage of working with paired cores is that it provides a means of studying sejiment variability over a relatively short predeter mined distance. An estimate of the direction of sedimentary processes is obtained by using a compass, which gives the relative orlentation of the cores. The dual corer was used successfully in the field and 8 paired gravity cores were obtained in 8 lowerings in water depths of $4,000 \mathrm{~m}$. 
A NEW "SPHNYCTER". CORER WITH ARECOULLESS PISTON-- A. Kermabon (Cie Maritime Expertioes) and U. Curtis; MAR. GEOL. v. 7, No. 2, pp 147-159. April 1969

The Sphincter corer to an improvement over most of the existing piston corers. It includes a Sphincter-type nylon core catcher, which seals the cores within a watertight container during retrioval, asd a oplit piston, which prevents ouction of the core wher the corer te retrieved from the sediments. A simple oystem for monttoring the platon relatively to a fixed platform lylng on the 80 a floor to described. The devtce involve only cables and thin pulleys and can be adapted to any existing Sphincter corer. The equipment has worked ouccesefully and little or no dleturbance has beon observed in the cores.

A DEVICE FOR RELEASING $A$ PISTON CORER AND DEACTIVATING THE

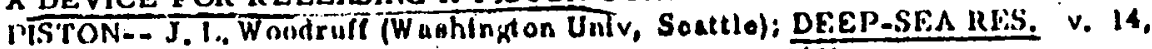
No. 6, pp 809-810, I Pl. , Dec. 1967 (Recd. Sept. 1969)

A device to described for roleasing a ploton corer, holding the platon cable during ireo fall and penetration, and deactlvating tho pioton by dropplrig the piston cable. Combined in the instrument are cocking and tribgering device. a sety catch, and a closed-system timing cylinder with a needle vale that controlu circulation of oil and thereby regulates the time the piston cable is held. The device eliminates the complexity, unroliabllity, and much of the time involved in the use of previous deactivator.
RHEOLOGICAL STUDIES OF KAOLIN-CONTAINING DISPERSIONS, PT - 1 Z. Cruros, J. Bozzay and B.Zsoldos; PERIOD. POLYTECH. CHEM. ENG. v. 12, No. 4, pp 381-394, 1969 (In Corman)i EAST EUROPE. SCI. ABSTR. CHEM. No. 114, p $80,9 / 2 / 69$

The rheological properties of hydrolyzed starch and kaolin-dispersions, and dispersions containing both hydrolyzed starch and kaolin were investigated. Aqueous kaolin suspensions were pseudoplastic at low concentrations, plastic at higher concentrations. At higher concentrations, thixotroptc effects became evident. Addition of disparsant reduces viscosity up to a certain concentration; thereafter. further additions of dispereant have no effect. The rheological properties of the disperslons change upon addition of dispersant. Increasing concentrations of hydrolyzed starch increase the viscosity of the dispersion. There is an inverse linear relation between apparent

viscosity and absolute temperature. (Abstract only - original not available)

IMPROVEMENTS IN BOREHOLE SURVEY MEANS AND CORE SAMPLE ORIENTATING MEANS - S. Afr. 69/0,260, c. 6/26/69, f. 1/14/69 (pr. Austral. 1/19/68); J. B. Robinson, asr. ; (Jolnt Coal Board); Abotr. . PATENTJOERNAAL (S. AFR.) v. 2, No. 8, p 189, Aug. 1969

A borehole survey means consists of a hollow cylinder adapted at its upper A borehole survey meantially the escape of fluid from the end to prevent substantially the lower end upper end. It has holes through its wall se that air may be trapped in the upper to admit drilling fluid so that air may be trapped the uppe end of the cylinder. A gel tube is provided to hold a gellable liquid. A receptacle is provided to hold a second liquid, that when first liquid initiates gelling of it. A pasage when mixed with the and receptacle. A valve normally closes the connects the gel tube and receptacle. A valve nor pressure on passage but is designed, on sudden reduction of the pressure the trapped air, to open and to allow the recond llquid to flo
into the gel tube and mix with the first liquid. ( 9 claims) (Abotract only - original not avallable)

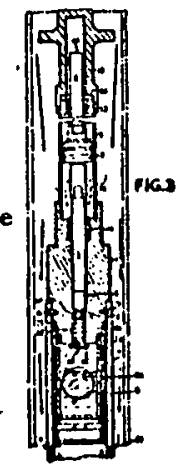


INSTALLATION TO TAKE BOTTOM SALCLLES-- Neth. Appl. 6, 717,831, f. 12729/67; B. P. Heigeman, asr.; (Werf Conrad \& St Hijsch NV) (In Dutch)

A drilling installation to take bottom samplea consiots of a hollow pipo which can be driven into the bottom by means oi vibrations. A vacuum pump

installed in the hollow pipe is activated by the vibration movement of the pipo. Thiore is always an 2 nderpressure between the upper part of the core and the vacuum pump. The resistance of the core moving into the pipe barrel is thus decreased and the pipe can be driven deeper into the bottom, thus increasing the percentage of recovered core. (4 claims)

$\stackrel{\omega}{\omega}$ CORING EQUIPME.NT

$\underset{v}{\omega}$

DRILL PIPE FOR CORE DRILLING APPARATUS-- Gor, 1, 298, 469.

c. 7/3/69, 1. 272/E6 \{Appl. 93,916), N. D; Bockor and F. W. Bocker, aer 8.

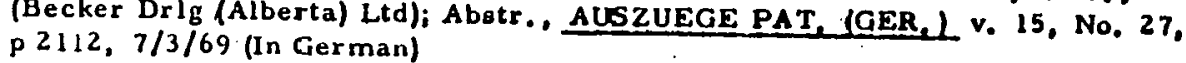

This drill pipe for impact core drilling with reverse circulation consiste of double-walled pipe stands and suitable cellare equipped with an annular space, sD that a continuous flow path for the descending mud is frovided between the walle of tho pipe string. The lower end of the coupling is connected only to the outer pipe and contains an axially displaceable inner tube with radial holes; the upper end of the coupling is also connected to the outer tube only and has an inner cyllndrical surface sealing against the inner pipe. The holos for the mud are drilled only in the upper par: of the coupling and communicate with a sealed annular s sace through radial and axial groaves. (Abstract only-original not availablel

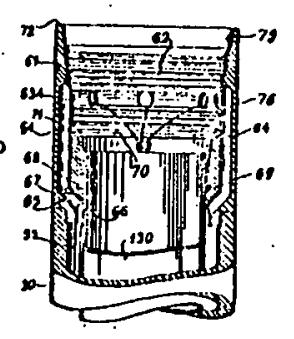


THE "MONO" CORER; A WIDE DIAMETER, GENERAL PUR POSE, GRAVITY CORING TOOL-- R. P. Onorati; U.S. Naval Postgraduate Sch. MS Thesis, 56 pp, Dec. 1968; AD-694, 912; Abatr., U.S, GOV, RES, DEVELOP, REP v. 69, No. 23, p 135, 12/10/69

A gravity corer in its simplest form consista of a tube with a check-valve at the upper end which la.driven into the sediment by encircling weights in order to obtain a sample. At many oceanographic institutions where a variety of research is undertaken relative to the ocoan bottom, an efficient and rellable general purpose coring device is required. Such a device should enable the biologist, geologist, sedimentologlst or engineer to obtain a sample which meet his particular requirement, , A imple gravity corer fits many of these needs. The gravity corers in use at the present time have not oignificantly changed from the earlier corers. Even the most reliable of gravity corers are not without some drawbacks. An attempt is made to solve some of these problums and produce a rellable, easy to handle, general purpose, gravity coring tool useful for all phases of ocoanographic research. (Abatract only original not available)

$\underset{\omega}{\omega}$

\section{CORING EQUIPMENT}

$124,372 \sim$

A HYDRAU LIC CORER FOR USELIN WATER SA TURATED SEDIMENT-J. A. Gifford (Miami Univ, Florida); J. SEDIMENT. PETROLOGY v. 39. No. 4. pp 1619-1621, Dec. 1969

A suction corer utilizing an expendable plastic core liner was developed to A suction corer utilizing an expendable plastic core the device is lightwelght, simple to operatc, and contains a minimum number of moving parts. With it, continuous cores up to $10 \mathrm{ft}$ in length and retaining sediment inter atitial water continuous cores up to cores averaging $10 \mathrm{ft}$ in length were taken in 4 field daye. Actual coring time averaged 30 min per core; tranoporting the equipment Actual coring time averaged 30 min per core; tranoporting tho equipment occupied the remaining time. Most of the cores taken with this device are composed of moder ately coarse sand, but the corer successfully penetrated peat, compact silt strata, and shell debris. The problem of vacuuming in ment not directly in the patls of the corer did not prove serious. Careful measurements of barrel penetration v8. actual core length indicated a maximum of 5 to $8 \%$ elongation, a figure which may be oubatantially minimized by applying sufficient force to the corer before opening the vacuum tanks.
THE NPS ROCKET CORER: A FIRST GENERATION ROCKET POWERED CORING TOOL-- G. E. Pierce and R.J.Smith (Naval Postgraduate Sch):

Rept. No. NPS-58SJ70011A, 36 pp, 1/14/70; AD-700, 707; Abstr., U.S. GOV. RES. DEVELOP. REP. v. 70, No. 7, $\mathrm{p} \mathrm{82,4/10/70}$

A rocket motor-powered corer has been designed and built. Limited tests of the rocket corer, conducted in a sand-silt-clay bottom at a depth of $100 \mathrm{ft}$ of Pitas Point in Ventura County, showed promising results. It has been demonstrated that available rocket motors can be used to drive coring devices in relatively shallow water. Further teste are warranted to determine the maximum depth that rocket-powered instruments may be used. It presently appears posolble that rocket motors may be used as a ganeral source of powcr for varted underwator applications. (Abstract only - original not available)

\section{CORING EOUIPMENT}

128,390

\section{ASSELF-DEACTIVATING PISTON FOR A PISTON CORER -. J. L. Woodruff} (Hawaii Univ); OCEAN ENG. V. 1. No. 6. pp 597-599, Feb. 1970

Described is a piston containing an internal valve that is closed during penetration and open during extraction of the corer. It requires no cocking or other preparatory steps before usie, and provente liner collapse, core diatortion, and consequent erroneous interpretation of the core materiale as sometimell occurs when a conventional pleton to used. 
UNDERWATER ELECTRIC TOOL BUILT TO CORE SEA FLOOR -- WOF: LD OIL v. 170, No. 6, pp 98-99. May 1970

An electric-powered underwater coring tool has been developed for sampling up to $130 \mathrm{ft}$ of consolidated, ocean-bottcm formations in a much as $1,000 \mathrm{ft}$ of water. This assembly sits vertically on the sea floor and can retrieve core below the ocean floor. Surface components are a power input of a $150 \mathrm{kVA}$, remote-control electric cable handled by an electrically powered winch and a testing and control panel. This device was developed by the Inotitut Francale du Petrole. The afocification of the electric core drill are given. Drilling and coring cycles are minimized due to the power available for bit rotation and water circulation. Total operations time varies mostly with time required to lower, lift, and handle the assembly aboard ship.

$\omega$

\section{CORING EQUIPMENT}

A HYDRODYNAMICALLY ACTUATED EIEEP SEA HARD ROCK CORER H. Frohlich and J. F. McNary (Miami Univ, Florida); MAR. TECHNOL. SOC, J. v. 3. No. 3, pp 53-60, May 1969 (Recd. May 1970)

The prourese of sereral important geological studies is strongly handicapped by the lack of an efficlent deep-sea hard-rock coring tool. A new, hydrodynamically actuated rock samplor has rielted promising results. Comparable in weight and in speed and ease of handing to regular gravity corers, the new instrument is capable of producing impazt forces of several million newtons.
IFP CUITS SUBSEA CORING COSTS WITH NEW ELECTRODRILL-. f. Morrisoni OILGASINT. v. 10, No. 4, PP 78, 81-82, April 1970

To reduce the high cost of sea-bed surveys to a minimum, Institut Francais du Petrole (IFP) has developed a system which allows prior selection of coring sitis. This in turn is backed by a new subsea coring device designed to recover samples of consolidated formation down to $330 \mathrm{ft}$. Surface support for the IFP aystem is a dynamically positioned omall tonnage vesiel equipped with a sonlc seismic device for recording sea-bottom profiles. These show the subsea formations down to several hundred feet. Since the proflles highlight the characteristics of the area ocanned, coring site locatione can be plannerl economically. Cores taken are $6-1 / 2$ ft long and $3-1 / 2 \mathrm{ln}$. diam. A complcte geological proflle of the first $330 \mathrm{ft}$ of oubsea formation can be formulated by drilling holes to that depth and then taking successive $6-1 / 2-\mathrm{ft}$ long cores. While the subsea corer can bo operaled from any vessel equipped with gear able to lift the $22,500-1 b$ welght of the unit, the veseel must be provided with the means to hold itsolf almoat vertical over the holo.

AN AUTOMATIC-RELEASE PISTON FOR USE IN PISTON CORING-B. Winterhalter (Finland Geological Survey); MAR. GEOL. v. 8, No. 5, pp 371-375, May 1970

An automatic-release piaton has been developed to replace the conventional fixed plston/wire combination used in Kullenberg-type corers. At the end of penetration of the corer into the sediment, thls piston broaks into 2 parts. The actual piston is jammed in place by spring-actuated barbs that are pressed Into the P. V.C. core liner. The released upper portion to which the piston wire ls attached, is free to move up against the piston stop at the top of the barrel before the corer is pulled out and brought to the surface. In the case of incomplete penetration, core disturbances due to suction caused by the movement of a conventional piston during pull ont are thus eliminated. 
ELECTRICALLY CONTROLLED AND POWERED SUBMARINE ROTARY CORER SYSTEM-- U.S, 3,516,503, C. 6/23/7), f. 12/23/68 (Appl. 785, 918) E. F. Mayer, W. Brannon, E.S.Schaller, Jr. and F. C. Pickard, asrs. (US Dept Interior)

A core-sample drilling apparatus is described which is made operable when A corement in the spparatus supports a self-contained pump and drill-drive mechaniom governed by inter related remote and internal control devices. Included is an internal control device for automatically connecting the drill drive to a cariage retracting mechanis $m$ at the end of the drilling stroke. (5 claims)

$\stackrel{\dot{\prime}}{\dot{\leftrightarrow}}$

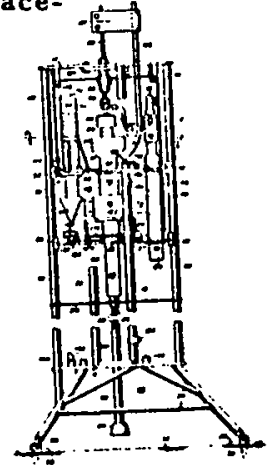

CORING EOUIPMENT

EXPERIMENTAL USE OF EJECTING CORING TOOLS FOR INCREASING RECO VERY OF CORES- - B.L. Bykov, G. L. Lebodinskil, E. L.Katenelson and SAUCH, -TEKH. SB. SER. BURENIE. No. 2, pP $12-15$, 1970 (In Rusian)

ecovery from friable and fractured limestones is about $20 \%$ with ordinary colopment and use core drills. Core recovery was greatly increased by developmention and 2 of epecialy designed ejector coring deta are presented. The essential such core drills are described, and coring is removed feature of this coring unit is a hydraulic system with which core A schematic from will bottom, and placed in a core storing com diagram and specifications of the unit are shown.
NEW DEVELOPMENT IN SEA-BOT TOM SAMPLING-- OCEAN IND, v. 5 , No. 10, P 32, Oct. 1970

Conrad-Stork and the Dutch Geological Survey Department have developed Geodoff II, the latest of their units designed for remote-control drilling of the upper $50 \mathrm{~m}$ of the sea floor and for recover ing undisturbed samples. The new drilling method to a combination of 2 different penotration methods; 1.8. pressure penetration and ordinary rotary drilling. The new unit has the advantage over other methods for obtaining undiaturbed amples of being able to penetrale hard formations effictently. The Geodoff. Il can operate at any wator depth on the continental shelf completely independent of the ship. No asuiatance from okin divers is required. The main body with its 3 lego emplacod on the s.sa bottum, contatng tho rutary drilling duvicu and a rotaling oupply disk on which the complete drill otring is placed in 12 lengths of about $4 \mathrm{~m}$ each. The electric motor driving the hydraulic pumpe, the computer, etc. are housed in the drume on the main body. An umbilical cord from the surface vessel supplies electric power, electric signals, and drilling.mud. The filled core barrels are stored by mechanical arms after every pipe length of drilling progres3. The tubes are placed on the supply disk in special clamps. By omitting the core barrela and connecting the rotary drilling device with the. ohip by means of a hose, a continuous flow of amples can be obtained by the

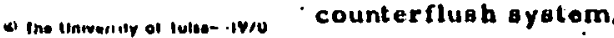

pinted in use 3

\section{CORING EQUIPMENT}

136,073

A NEW LARGE-DIAMETER PISTON CORER AND CORE-LINER CUTTER-A. Langford, J. C. McDougall and N. Robertson; NEW ZEAL. J. MAR. FRESHW ATER RES. v. 3, No. 4, pp 595-601, 1969; DEEP-SEA RES. OCEANOGR. ABSTR. v. 17 , No. 4, p A433, Aug. 1970

A newly developed piston sediment corer utilizing a neat-fitting piaton operating within a $2-7 / 8-i n$. -diam plastic liner has successfully cored heayy gravel, coarse shell, and 8 andy sediments. A quick fit and release junction for pipe lengths and cutter has been devised. (Abstract only - original not available) 
PISTON CORING APPARA TUSWITHOUT RECOIL-- Fr. 1,597,431, c. 6/29/7 F. 8/7/68 (Appl. 22, 360); A. Kermabon; Abotr., BULL, OFFIC, PRdPRIETE IND. (FR.) v. 11, No. 32, p 14772, 8/7/7) (In Fronch)

A coring apparatus has eot of sheaves attached to the upper end of the core tube, and a second, symmetrical set of sheaves attached to the exterior of the penetrating nose. A plat:orm acrose which the core tube can freely move in the vertica: dizection is attached in 2 symmetrical pointe to ateol cable pasaing over the obeaves and onding inside tho coring apparatue orer the wheave atteched. to the sealed plston. (Abstract only - origian not available)

VIBRATING CORER COLLECTS HARD SAND SAMPLES -. L. Purrett; UIR/RES. NEWSLETTER V. 5, No. 1. P 7, Spring 1970

A coring device that vibrates its way into lake and ocean sodiments may enable oceanographers to obtain core samples from types of sediments that are impenetrable to present tools. The corer is designed eapecially for obtaining cores from hard sand. When agitated in the presence of water, 8 and

forms a fluid. The device takes advantage of this so-called thixotropic effect. A onall turbine vibrates the core tube abole its vertical axis. As it enters the sand. this vibration creates a thin layer of liqaid around the outer surface of the tube, which enables it to slip easily. The same process takes place along the tube's inner walls, resulting in minimu:n disturbance of the sample. 
CORE DRILLING APPARATUS- - Ger, 1,963,239, c. 12/17/70, f. 12/17/69 (App) 1,963, 239): W.Schulz, W. Mager and H.Gaus, aurs.; (Salzgitter Maschinen AG); Abstr., AUSZUEGE PAT. (GER.) v. 16, No. 51, p 2555, $12 / 17 / 70$ (In German)

Thi s coie-drilling apparatus conaists of a drill pipe and an inner tool, which recoive the core and which can be either brought into rigid connection with the drill pipe or pulled out by means of a cable. The rigid connection between the inner tool and drill pipe is achieved by a tongue and groove arrangement. (Abstract only - original not availeble)

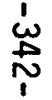

\section{CORING EQUIPMENT}

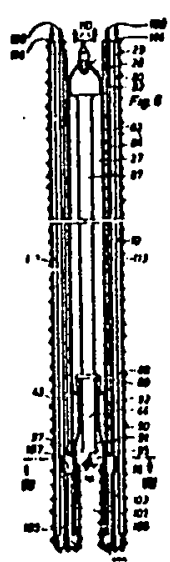

DESIGN OF AN AUTOMATIC MARINE CORER -- E. I. Bailey and G. L. Davis (Texas A\&M Univ); Rept. No. TAMU-SG-71-202, 93 pp, Nov. 1970:

PB-195, 984; Abstr., U.S. GOV. RES. DEVELOP. REP. v. 71, No. 3, p 121 , $2 / 10 / 71$

A self-contained automatic seafloor setting corer which will: (1) extract up to $50 \mathrm{ft}$ of continuous undisturbed core. (2) operated in depths up to $1,000 \mathrm{ft}$ of water, (3) coro in hard as woll as oft material, and (4) be as compact as possible to facilitato shipboard handling was designed. The Seacore 50 is doscribed. (Abatract only - original not avallable)
DESIGN OF AN AUTOMATIC MARINE CORER -- E. I, Bailey and H. O. Hender Bon (Texas A\&M Univ) and G. L. Davia (Cameron Iron Works Inc); 3RD ANNU. OFFSHORE TECHNOL. CONF. (Houston. 4/19-21/71/) PREPRINT No. OTC-1365, pp I-397-1-416, 1971 (v. I)

A program was intiated at Texas A\&M University under the Sea Grant Program to design a self-contained automatic sea-floor setting corer which will (1) extract up to $50 \mathrm{n}$ of continuous undiaturbed core. (2) operate in depths up to $1,000 \mathrm{ft}$ of water, (3) core in hard as well as soft material, and (4) be as compact as possible to facilitate shipboard handling. The Seacore 50 will extract a 3-in. diameter core 49.5 ft long in 11 sections. The unit is octagonal in cross sectiona measuring $6 \mathrm{ft}$ side to $\theta$ ide and is $12 \mathrm{ft}$ in height. When the unit reaches the oea floor, 4 logs fold down and level the unit on slopes of up to $15^{\circ}$. The unit welghs $10,000 \mathrm{lb} \mathrm{dry,8,000} \mathrm{lb}$ in water, and is lowered to the sea noor by a ingle power-tension cable. An automatic control oystem is contained in tho unit with ohipaide manual control available at any time.

\section{CORING EQUIPMENT}

PRINCIPAL TRENDS IN CORE DRILLING-- I. and S.F.Alekseeva; NEFT.KHOZ. No. 5, pp 27-30, May 1971 (In Rusian)

The principal trend in developing core drilling is to design and introduce equipment which would allow obtaining cores of bigger diameter and maximum possible ratio between diameters of the coro and the drilling head. It is suggested that for rotary core drilling, there should be 3 types of core devices apecially designed for groups or rocks characterized similar coring problems. For dense and monolithic rocks, core barrels which rotate during drilling can be used. In fissured and alternating with respect to hardness rocks, the core a semtly must have a nonrotating core carrel suspended on bearings, smaller outer diameter of the assembly body, a syotem of core breakers to completely cover the core entrance, and meane to flush the core barrel before setting it on the hole bottom. Assemblies for collecting cores from loose, easily drillable rocks must have elastic core containers. For turbo-core drilling. assemblies with bigger diameter core containers can be used. However, the uee of rotary core drilling is preferable, In most cases. The optimum ratio of core diameter and diameter of drilling head is 0.37 to 0.42 for ponretrievable and 0.21 to 0.28 for retrievablo core barrels. Recommendations for designing core bits are given. 


\section{CORING EQUIPMENT}

151,159

INF LUENCE OF LUBRICANTS AND POLLYMER COATINGS ON PENETRATION OF OCEANOGRA PHIC CONING TOOLS-R.A. Erchul; AD-845, 189, 59 pp, Dec. 1968; Abstr.. GOV. REP. ANNOUNCE. v. 71, No. 13, 7/10/71

The friction developed on the inner and outer faces of oceanographic coring tubes tends to decrease penetration and grose rocovered length and to increas sample disturbance. An effort was made to decrease this friction through use of lubricants and polymer coatings and to thereby increase the penetration of smooth steel surfaces into fine-grained sediments. Tests were conducted in the laboratory using steel plates and an Atwood test apparatus, and at sea using gravity corers. In the laboratory tests, the lubricants STP, CRC, zinc grease, and lithium grease increased ponctration 46, 25, 24, and $20 \%$ respectivaly. Tests at sea showed that use of STP lubricant increased corer penetration 18 and $35 \%$ and grose recovery length of cores $16 \%$. Statiatical analysis indicated that the above increases were highly significant.

(Abstract only - original article not available from T.U.)

\section{'́ DIRECTIONAL DRILLING}

$\stackrel{\omega}{\omega}$

METHODS AND APPARATUS FOR DIRECTIONAL DRILLING- -

151,161

U.S. $3,593,810,7.120171,10113 / 69$

(Schlumberger Technol Curp)

A tool carrying a drill bit is dependently coupled from a drill string and lowered into a borehole which is to be excavated in a deslred direction. First and sccond sets of wall-engaging members are operatively arranged around the tool in such a manner that as the welght of the rotating tool is ouccessively supported by each of the firet members, commensurate outwardly directed forces will be successively imposed on each of the second members for urging the drill bit in a desired lateral direction. Various controls adapted for operation from the surface of the earth are disclosed for selectively interconuecting the flrot and econd wall-engaging members so as to oither maintain the course of the drill bit along a vertical axis or eloe to direct the drill bit in a selected azimuthal direction and inclination. (37 refs.)

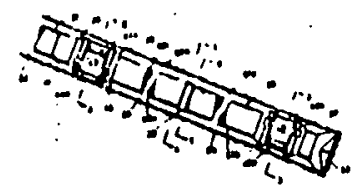

THE SACLANTCEN SPHINCTER CORER ASSEMBLY. PT. I. A WIDEDIAMET ER COIR ER WITH WAT ERPIOOF CORE-CATCHER. PT. 2. AN ELECTRICAL TRICGERING SYSTEM-- A. Kermabon, P. Blavler and U. Cortia; Rept. No. SACLANTCEN-TR-34, 29 pp, 3/1/65; AD-808, 766; Abstr. , GOV. REP. ANNOUNCE. v. 71, No. 16, pp 100-101, 8/25/71

A long, wide-diameter corer with a waterproof corecatcher is deacribed. Its design is closer to theoretically ideal proportions than most oceanographic corers, and the cores it provides appear to be unmodified samples of the sediments. A sphincter-type, nylon-sleeve core-catcher seals the cores within a waterprool container during retrieval. An electric triggering bystem for this and other heavy corers, is described. The use of a mercury switch instead of counterweights prevents accidental triggering by sudden shocks, thereby making it much safer than other oysteme when working in beavy seas. (Abstract only original articlo not avallable from $T, U$.)

COR E BARR EL

154,505

A SIMPLE COR ER AND A METHOD FOR SAMPLING THE MUD-W ATER INT ERF ACE.- A. L. W. Kemp; H. A.Savile, C. B. Gray and A. Mudrochova; LIMNOL. OCEANOGR. v. 16, No. 4, pp 689-694, July 1971

A triple corer has been designed, based on a modification of the Benthos corer. Satisfactory cores have been taken in clay muds, sllty clay mudo, ollta, and glacio..lacustrine clays at depths up to $250 \mathrm{~m}$. The sediment is exruded layer by layer on a aimple screw thread ploton device. Renults ohow that extrusion of each tube separately is reproducible and that it is possible to subsample the cores at close intervals. Bottom water for analyois also is collected by the 


\section{DRLLHE}

CORING EQUIPMENT

HYDRAULIC CORE DRILL FOR DRILLING OPERATIONS-- Fr. 2;066,895, c. $8 / 13 / 71$, f. 10/28/69 (Appl. 36,849); (Craeliuo Diabor): Abstr. B BULL OFFIC. PROPRIETE IND. (FR.) v. 12, No. 37, Pt. 2 (No. 32), P 20032 , 9/17/71 (In F rench)

This coru drill consiate essentially of a rotating extorior tubo and an interior tube which is not driven in rotation. The

internal lube receives the core and can be

reised to the ourface. The control elemente

are hydraulically actuated and conolat of a head

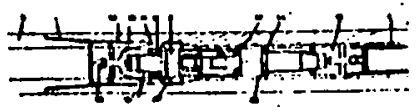

a thrust sleove with corresponding surfaces, oubjected to the action of the drilling mad. This core drill is particularly applicable to coring operatione in petroluum exploration. (Abotract only - original article not available from in petrol
T. U.)

$\stackrel{\omega}{\stackrel{\omega}{D} .}$ 
SOFT FCRMATION CORE BARREL-- U.S. $3,621,924$, c. $11 / 23 / 71$,

f. 3/24/i0 (Appl. 22,251); M.P. Lebourg

$\Lambda$ core bárrel device lor producing and retrieving subterrancan corcs, particularly from soft or unconsolidated formations, utilizes a fluid-pressure collapsible sleeve above the corer to receive and hold the core material and permit its retrieval in its original subterranean condition. Pressure respansive valves mainta in huid pressure behind the collapsible sleeve to retain it in the collapsed position until the core is received in the sleeve and aloo permit fluid behind the sleove to exliaust as the core enters the aleeve while the sleeve continues to offer lateral pressure oupport for the core and also remains collapsed above the core. When the coring device is withdrawn, a small amount of core material falls from the lower portion of the core barrel and the lower portion of the sleeve collapses to retain the remainder of $\omega$ the core within the core barrel. $(27$ claims $)$

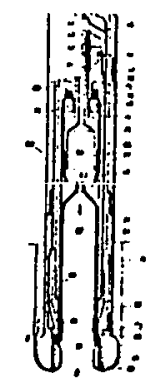

\section{CORING EQUIPMENT}

APPARATUS FOR OBTAINING CORE SAMPLES IN UNCONSOLIDATED SOILGer. 2, 104,442, c. 12/16/71, f. 1/30/71 (Appl. 2, 104,442); $M$. Reichling and H. Dombrowski, asro. ; (Woma App Maasberg Co GmbH); Abstr. , AUSZUEGE PAT. (GER.) v. 17, No. 51, p 3554, 12/16/71 (In German)

An apparatus for obtaining core samples in unconsolidated soil consists ba $\theta i c h l l y$ of 2 concentric tubes, with the drilling mud flowirg downward in the annular space, a drilling bit attached to the lower end and equipped with means for reversing the direction of how of the mud, and suitable means fur removing the soil sample from the inner tube which acts as a core barrel. An annular space above the drilling bit is provided for radial distribution of the high pressure drilling fluid to jets. The jets facilitate the penetiation of the core barrel into the bottom of the hole being drilled; the core barrel and the drilling bit are unde the influence of a percussion device. (Abstract only original article not available from $T$. U.)

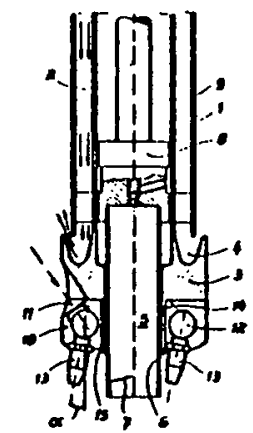

AIDS TO UTILIZATION OF A SHA LLOW PENETRATION SEAFLOOR SITTING DRILL- R. D.O'Brien and E.J. Duley (Marine Minerals Technol Center); Rept. No. NOAA-TM-ERL-MMTC-1, 16 pp, Sept. 1971; COM-71-01011; Abstr., GOV. REP. ANNOUNCE. v. 71, No. 24, pp 69-70, 12/25/71

Drilling and sampling in the marine environment present a number of problem. unique to the ocean-oriented investigators. This otudy lo concerned with ono of these problems. The initial penetration of a marine sediment to a depth of $10 \mathrm{ft}$ deep is the most difficult in which to obtain reliable, relatively undisturbed samples, rapidly. Suspending a drilling tool over the side of a ship and under water, where visibility often is zero, raises problems relating to assuring that the penetration into the marine sediments is perpendicular to the sea fluor. One way to solve this problem is presented in the description of a break-away tripod, which provides support for the initial penetration, and then collapses to allow further penetration. The drilling/sampling tool described can be suspended over the side of a small ship by a cable, with an air hose from the ship as an umbilical connection for operation. (Abstract only - original article not available from T.U.)

\section{CORING EQUIPMENT}

$158,204 \sim$

APPARATUS FOR DRILLING A SMALL BCREHOLE DOWNWARDLY FROM THE BOTTOMOF A LARGE BOREHOLE-- U.S. 3,635.295, c. 1/18/72, f. 12/2/69 (Appl. 881, 394); J. H. Cobbs, asr.; (Fenix \& Scisson Inc)

An apparatus is provided for drilling a small diameter borehole extension to large diameter borehole. Generally, the apparatus consiats of a hollow splined drill shaft which terminates on the lower end with a bit. Coaxially connected to the upper end of the drill shaft is a drive drum having driving lugs on the outer periphery which engage flutes on the inner wall of a tubular large borehole drilling or coring tool affixed to the lower end of a rotatable drill string in a large borehole. Rotation of the large borehole drilling tool cause s rotation of the omall borehole drilling tool. Extending upwardly from the drive drum is a hollow neck having an annular sealing means which forms in cooperation with the neck and the inner wall of the large borehole drill string a fluid chamber such that fluid pumped into the interior of the large borehole drilling tool creates a downwardly ecting hydraulic thrust force to cause the rotating emall borehole drilling tool to penetrate the earth. (7 claims)

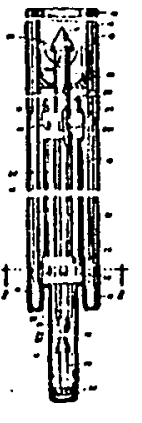


PERCUSSION CORING APPARATUS-- Fr. 2, 081, 149, c. 12/3/70, f. 3/10770 (APpI. 8,542); J. Lautaud, agr.; (ERA P); Ab8tr., BULL. OFFIC PROPRIETE IND (FR $)$ 13, No. 1, Pt. 2 (No, 48), Pp 296-297, 1/7/72 (In French)

This addition to $F r .183,118$, is sued $12 / 31 / 68$, covers improvements in underwater coring apparatus of the porcussion type,

consisting of a housing which cau bc attaclicd and

detached from an extcrior pipc. An interior core tube reccives the core and is equipped with means for cutting and holding the core. At the upper end, directional guidance fins and conduits for circulating water a ro provided. The improvement consists in providing valves in the conduits, the closing of which is actuated by the coring apparatus arriving at the end of its course. This

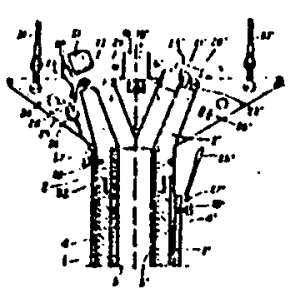
preve of the sea. (Abstract only - original article not available from $T . U$. )

$\underset{1}{\omega}$

\section{CORE BARREL}

$159,354 \longleftarrow$

A METHOD OF AND APPARATUS FOR OBTAINING UNDERWATER CORESCr. Brit. 1, 268,629; c. 3/29/72, f. 7/25/68 (Appl. 35, 432); J. L. Abrahams. asr.; (Rock Fall Co Ltd)

A mothod of and a pparatua for obtalning undorwater cores are described. 'The method consiste of embedding one end of a heavy hollow cylindrical outer casing in a bed of material from which the core is to be taken, so that the outer casing otands oubstantially rigidly in an upright position. A relatively lighter coring casing is inserted down the outer casing, embedding one end of the casing in the bed of material. A drill string is then inserted down the coring casing to obtain the core from the bed of materlal. The outer casing. coring casing; and coring rods are sequentlally connectible by connecting means to the chuck of standard-eize drlling equipment. Preforably, the connecting means is provided with a central actlon water fuabing and is compressed. (8 claims)
CORE DRILL ESPECIA LLY FOR UNDERWATER DRILLING--

Fr. 2,085,365, c. 12/24/71, 1. 4/17/70 (Appl. 13, 380); (COCEAN); Abstr. , BULL. OFFIC. PROPRIETE IND. (FR.) v. 13, No. 4, Pt. 2 (No. 51 ), P2541, 1/28/72 (In French)

This core drill is of the type containing a vertically vibrating core tube and a concentric coring bit which cute the core in the formation.

The vibrating core tube is dioplaced axlally with respect to the coring blt during the coring operation. The 2 movemonts--vibration and dieplacement of the coro tube, and rotation and advancement of the coring bit--are controlled -oparatoly and Independently, imultanoously or not. This apparatue pormite drilling of large dlamoter cores in mixed formations. (Abutract only - origlanl article not avalleblo from T.U.)

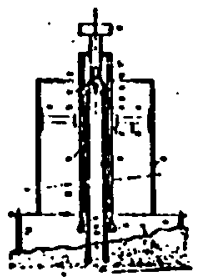

CORING EOUIPMENT

DLSIIIN AND IIEST OF A TORSIONAL VIBRATORY CORE SAMPLER FOR MARINE SEDIMENTS- - R.j. Hierker and R:M.Shah-(Wiaconoin Univ); INT. UNESCO ET AI. E.NG. PROPFRTIES OF SEA FIOOR SOILS GEOPIYYS.

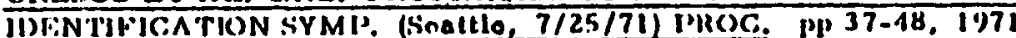

Studios of marino sediments for geologlcal, blological or engineering purposes is an area of increasing importance a more inveatigationo are directed toward curveys of submerged bottoms of oceane, lakes, and rivers. This paper summiarizes a project initiated in Jan. 1969, to design, develop, and test prototype coring equipment for marine environments. The torsional oystem of vibration offers several opecific advantage 8 with respect to penetration of a marine sediment probe: (1) chear atroseos, for Inducing thixotropic transformation in the oediment, are obtained without involving the prelond mas in the vibratory system, by swivel mounting; (2) a sawing action is provided at the leading edge of the probn; and (3) a square tube in torsion generates an envelope by oil compression, both outeide and within the tube. The square tube has further advantages in facilitating construction of a core retainer and in allowing transverse sampling for daughter cores through porte in the oldewall. 


\section{CORING EOUIPMENT}

159.772

DESIGN AND CONSTRUCTION OF A SFALLOW WATER SEDIMENT CORE SAMPLER-T.C. DañieTand G. Chesters (Wisconsin Univ); ENVIRO v. 1, No. 3, PP 225-228, 1971; Abstr. No. W72-01738, SELEC. WATER RESOURCES ABSTR. v. 5, No. 4, p 53, 2/15/72

A shallow-water core ampler wa conetructed from plumbing materials and extruded P.lexiglas tubing. Construction of the sampler is simple and the total cost of materiale lo approx. \$35. The asmpler is capable of taking cores at wate $x$ depths up to $6 \mathrm{~m}$ and by modification greater depths. The total weight of the sampler is $12 \mathrm{~kg}$; It is easy to operate and can be used for sediments ranging from and to highly orgaric slayey material. Core aamples varying in length and crose-sectional aroa can be obtained by changing the dimensions of the Plexigles tubo. (Abstract only - original article not a vailable from T.U.

$\stackrel{i}{*}$

\section{CORING 'EDUIPIENT}

162,530

INSTTALLATION FOR UNDER WATER CORE DRILLING--

Neth. Appl. 7, i11,812, 1. 8/27/71 (pr. Fr. 9/24/70, Appl. 34,727);

(Inst Francalo du Petrole) (In Dutch)

The invention relates to underwater core drilling as described in Neth. Appl. $6,515,742$, but has the following opecifics. The foot section of the installation consists of a rigid frame having 2 feet. This Irame torma a first pland. One foot is hinged to one of the tops of the frame and can move through a plane mainly perpendicular to the first plane. This movable foot is removed from the plane in a first position, thereby forming a 3 -legged construction which can rest atably on the bottom. The movable leg has a second position closer to the frame to reduce It 8 olze, thereby making the transportion of the foot section easier. (4 claims)
CORING APPARATUS FOR TAKING SAMPLES OF THE OCEAN FLOOR-U.S. 3,666, 028, c. 5/30/72, 1. 9/25/70 (Appl. 75, 519); M. L. Greene, as r. (US Navy)

An appart

An apparatus for ext recting a core from the ocean floor Includes a core tube that is held In a cocked position, and can bo driven into the ocean floor by a oet of olatic bands whon the reatralning cord is cut. An ext racting collar, also hold in a cocked pooltion and powered by elactic bando is uoed to ext ract the coro tube, with ite core, from the ocean floor when collar's restralning cord ie cut. The invention relates to the use of a coring oyotem oultable for use by a manned deep submeroible so that bottom samples may be taken at locatione aelected by the crew of the manned submeraltile without endangering the crew. Some or the prlor coring eycteme used one et of rockete mounted on the coring tube to drivo the coring tube Into the bottom and thon a second eot of rocket a to withdraw the tube. (3 claime)

CORING EQUIPMENT

$163,041 \longleftarrow$

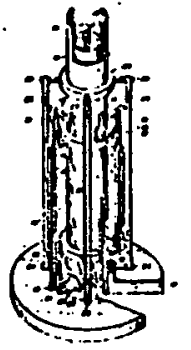

OF USE THEREOF-C U $3,664,438$, c 5/23/72, 8/26/70 (A ppl. 66, 935); C. L. Winget, G. W. Gibson and W.S. Shultz, asrs.; (US Navy)

A rotary diamond rock core drill capable of obtaining a $3 / 4$ in. diam core 4 in. long at any depth down to 6,000 $\mathrm{n}$ is provided. The drill is adapted to be used with manned deep submerslbles and is operated by the submersible's power supply. The drive motor is encased in an oil-filled pressure-compensated chamber. A water pump in the drill maintains a steady low pressure flow of wate $r$ against the sample during drilling operations, washing away rock chips and mud. The water flow may be reversed after the core has been cut, holding the specimen within the core tube as the $d$ rill is extracted from the rock outcrop. The sample is then ejected by again reversing the drive motor and pump, forcing the water flow down through the.core tube, and expelling the specimen. (10 claims)

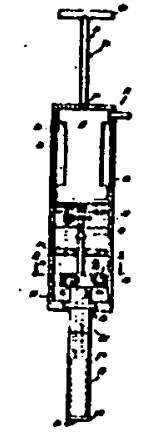


UNDERWATER CORING APPARATUS-- Fr, 2, 102, 709, c. $4 / 7 / 72$, , $8 / 17 / 70$ (Appl. 30, 229); P. Grotet and Y.Castel, asro.; (Inat Francals du Petrolo); Abstr., BULL. OFFIC. PROPRUETE IND, (FR.) v. 13, No, 19, Pt. 3 (No. 14), P 12414, 5/12/72 (In Erench)

This addition to Fr, 1,463,801 issued $12 / 4 / 64$ presents an improvement in an underwater coring apparatus. The means for controlling the

winding on, or the unwinding trom, the storage drum of the nexible conduit include a reversible hydraulic

apparatus. This apparatus is used in coring under water.

(Abstract only - original article not available from T.U.)

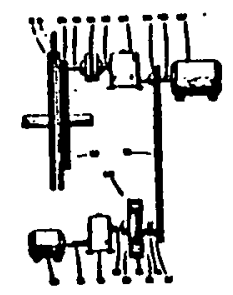

㠥.

\section{CORING EOUIPMENT}

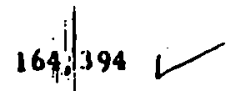

SPRING COUPLING FOR DRILL PIPE AND SAMPLING TUBES--

Fr. 2, 105,013, c, 4/28/72, P. 9/16/70 (Appl. 33, 503); (Acker Drill Co Inc); Abstr., BULL, OFFIC, PROPRIETE IND, (FR) v. 13, No. 22, Pt. 2 (No. 17), P $13921,6 / 2 / 72$ (In F rench)

The sample tube is fed water trom the atring of drill pipe. The water flow is regulated by a spring-loaded piston which acts as a flow regulator and reduces or even completely Interrupts the flow of water when a soft formation is encountered. This apparatus to eapectally usetul in prospecting for soft coal and for copper minerale. (Abstract only original article not available (rom T.U.)

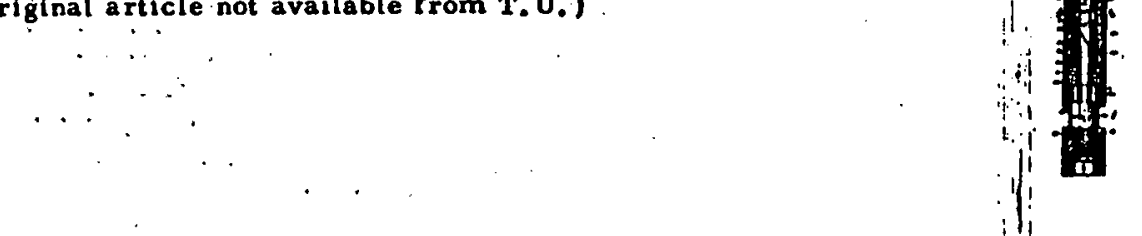


CORE BARREL

C PPARATUS FOR LOWERING AND RETRIEVING A CORE BARREL $=$ U.S. 3, 701, 756, c. $1275 / 72$, 6. 7/19/71

(Appl. 163,640); T.O. Wolda, esr.; (Boyloe Induatriee Ltd) $A$ lowering and rotrieving eyatem lo

doecribed that may bo usod when coro drilling. - lther up or down, including drtlling at any inclination. A flexdblo coel element is mounted iround the poriphery of the lowering and retrieving device and looped ovor a pin on a movable actintor oloment. The fexiblo eal olemont forme a fuid eeal with a hollow drill otring -llowing the low oring and retrieving dovico to be pumpod through the drill atring. An elongated - pear bead on a retractable core barrel contacta and moves the movable actuator element thoroby changing the position of the flexdblo eeal oloment and a fuld chamel around the lowering and rotrleving dovice lo openod. (11 claims)

CORE BARREL 173,907

A VIBRATORY DEVICE FOR TAKING OCEAN FLOOR SEDIMENT CORES-Gr. Brit. 1. TIZ, 20, c. 4/4/73

W. 6. 8/4/70 (A ppl. 37, 654); Z. P. Edigariev, E. L. Kudinov $\Psi$ and V. E. Sukhov, anro.: (USSR Agency)

The present lavention rolates to devices for taking sediment cores from tho ocean foor. It conoista io a vibratory dovice, comprising a otriog of plpe, a vibrator diupoed on the string of pipe for ainking the. pipo into the ccoan floox, arrangeriont for providlag for poriodical engegement and diengagement of the vibrator with tho eagegemont and alocogagament of tho vibrator witho tho etriag of pipe, a holot providing for portodical displacemont of the vibrator, which ls origlaally dieposed on the lower poxtion of the striag of pipe, up the etring an the latter io boing ounk into tho ocesn noor, and operativoly coupled with tho engaging arrangement. A piston is frooly displacoablo in the etriog of pipe and fixed relative to the dloplacoablo in tho otrlag of plpo and thed retain the ocea noor edimente la the pipo. The coro of eediment is noor eedimente lo the pipo. The core of eediment is and atmospheric pressures. A eyotom lo provided for otibulzing tho device coneleting of a load platform. flat, and guide cablos. (6 clalme) APPARATUS-- Ex. 2, 133, 132 , C. $11 / 24 / 72$, f. 4/8/71 (A ppl. 12, 554); Sondageo Injoct Forages SA); Abatr., BULL. OFFIC. PROPRIETE IND. (FR.) v. 13, No. 52, Pt. 3(No, 47) $30154,12129 / 72$ (In French)

The core tube is a soociated with a bottomholetype pneumatic hammer. This apparatue is used mainly in clvil engineering work. (No more information) (Abstract only - original article not avallable from T.U.)

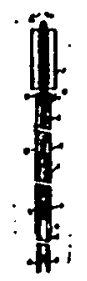

CORING EQUIPMENT $176,416 \nu$

\section{A VIBRATORY CORING SYSTEM EOR CONTINENTAL}

MA RGIN SEDIMENTS-- R. L. MCMaster and C. E.

MícClennen (Rhodo Island Univ); J. SEDIME.VT. PETROLOGY v. 43, No. 2, pp 550-552, June 1973

A vibratory coring aystem has been developed opecifically to sample eands on continental margins for more detailed data concerning aedimeata ry processes. It conaigts of 3 vibration mechaniama with attached $2 \mathrm{~m}$ coring tubes, a battery powered energy aource, and a locking compase for orientation. Coring unite, $2 \mathrm{~m}$ apart, are located at the apices of a triangular platform. Field test ir dicate that the syoters te operational at al! depths on the continental oholf.

\section{CABLE TOOL DRTLLINO}

178.119

CORE DRI LLING A PPARATUS FOR CABLE TOOL

DRILLING=-BeIg.732,032. T. 4724/69; (Dlamant Boart

No. 4. P $1594,3 / 16 / 73$ (In Eronch)

Thio core drill coneiate of a eat of oxterior

tubos, a.drilling bit, and moans of retrieval by

carrie. tho drilling bit and is equippod with means for breaking off tho core, a det of inner core tubes, and means for locking and unlocking the apparatus. The moen for retrioval cansiot of oloeves sliding within each other. The d:illing hesd and the means of rotrieval can alide within the sxterior set of

tubes under the action of a prosenrized fluid or of a cable. (Abstract only - original articlo not avallablo from T.U.

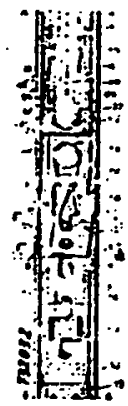


CORE BARREL

178,860

WIRELINE CORE BARREL WITH RESILIENT LATCH

FINGERS:-U. S. 3, 739.865, c. 6/19/73, f. 6/7/71 (Appl. 150.485); T. O. Wolda, asr.; (Boyles Industries Ltd)

This wireline core barrel syotem may be used - 1 when drilling up or down, including drilling at whious inclinations. Latch fingers that are flexible and resilient are rigidly connected to the core ble and resilient are rigidly connected to the core barrel body. The latch fingers are moved into and retracted from a latch seat by a movable actuato that bends the latch finger $\theta$ in a first actuator posi- : tion and allows them to spring back into shape in a second actuator position. The core barrel system provides a predetermined pressure signal indicating latching and blocks fluid now until the core barrel is properly latched. (17 claims)

\section{CORE BARREL}

179,812

DOUB LE T UBE CORE BABBEL WHCH IS LOWERED THROUGH DRILL PIPE-- U.S. 3, 741,323, c. 6/26/73.

c. 3/19/71 (Appl. 126, 029); D. Conelantinoscu. S. Cruceanu, E. Spataru and N. Mereanu, arro.; (Inst Proiec Cerc Util $\omega$ Petr)

G A double tube core barrel, which is to be

lowered through a drill pipe. has a locking by its sturdy and gimple congtruction. The 1 : 1 locking system has 2 free, unlinked oscillating $\vdots:$ : locking plates, the cloging of the plates for releasing the locking aystom being accom plished by means of a sliding sleeve of special construction. This oystem eliminates overy kind of failure of the locking system due to cems provided with links. The cors bar of classical sysThe barrel of the is:ention a novel system for breaking the core. uch core breaking system is provided with 2 core $r$ etainers. The supplementary core retainer is mounted on the outside tube; this allows the avoidance of traction overloadisg of the inner tube by reason of the taking over of these stresses by the outside tube. The system of the invention can te applied to core barrels with large sizes. When coring in 5 st rocks, the stipplementary core rotainer can be omitted. (1 cla im)
CORIVG

179.813

DEEP ROTARY CORE. DRILLING IN ICE -- G. R. LAIge;

COLD REG. RES. \& ENG. LAB. TECH. REP. No. 94,

46 pp, Feb. 1973; Abstr. No. W73-09079. SELEC. WATER RESOURCES ABSTR. v. 6, No. 14, pP $5-6,-7 / 15 / 73$

A method of drilling holes and obtaining core to depths of $1.500 \mathrm{ft}$ in high polar elaciers was required for taternational Gecphyaical Year (JGY) glaciological investiga tions. Futary drilling equipment was modified and sent to Greenland and the Antarctic. Principal modificationa included the use of chilled compressed air as a circulating fluid and specially designed coring bits. During initial trials in NW. Greenland in 1956 nearly continuous core was obtained to $970 \mathrm{ft}$, but the core was tadly cracked at depth. A second season in Greenland produced much more continwous core to $1,000 \mathrm{ft}$, and single coring runs at the $1,100-$. 1.200- and 1,300-ft levels produced usable core. Core cracking at depth persisted although it was less severe. During the Antarctic field season of 1957-1958 oimilar equipment was used to take continuous core to $1,000 \mathrm{ft}$ at Byrd Station for the IGY glaciological program. The use of a special constant rate of feed device for coring and improved techniques based on experience gained in Green land resulted in further improvements in core condition and rate of recovery. (Abstract only - original article oot avallable from $T$. U.)

\section{JARINE EXPLORATION EQUIPMENT} 181,624 IMPROVEMENTS IN AND RELATING TO APPARATUS FOR DRILLING ROCK--Gr. Brit. 1, 334,651. c. $10 / 2+/ 73$. t. 11/25/69 (Appl. 57, 554); D. Flinn and E. Harrieon An apparatus is describod for drilling rock under water as on the floor. Such a relatively omall and transportable rock drilling or sampliag apparatus 1: intondod principally for eeci:ing omall rock. emples. When the drilling tool has cut a eample core, the latter may be umapped off cleanly from the parent rock by operation of the wedge mernber and continued rotation of the tool untll the drilling operation has been interrupted. It is preferred that the tool drivias means is an electric motor whlch may. conveniently, be carried by the support, and may bo onergized trom storage batrories. (11 clnime) 


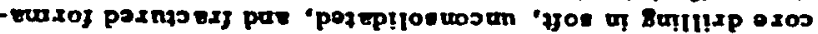

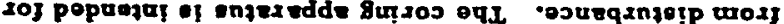

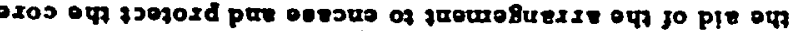

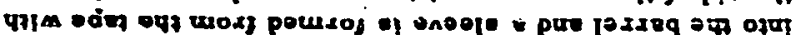

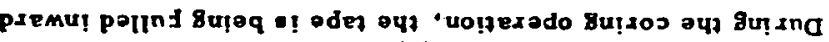

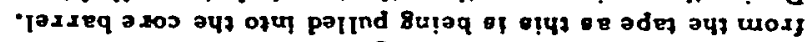

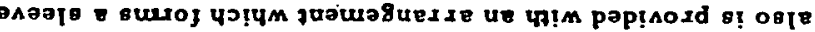

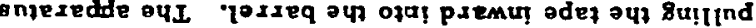

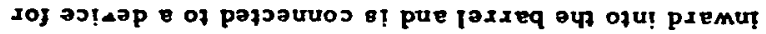

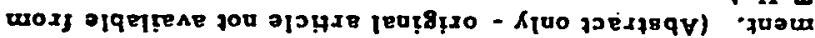

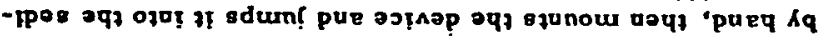

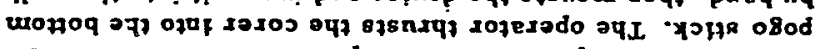
D,PITY e roye pausoned of $10 x 03$ oq. -doop un $\varepsilon$ moqe of dn sxojex ol ejuacurpos poutexs-oug jo gexos paqshjstpun

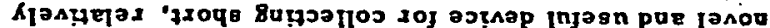

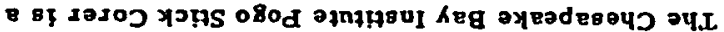

$$
02 / 1 / 2.06 \text { d } 61 \cdot 0 \mathrm{~K}
$$

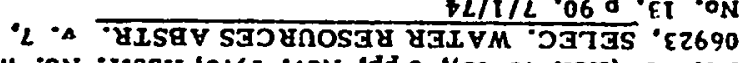

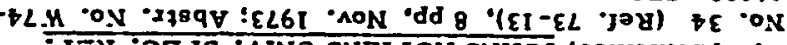

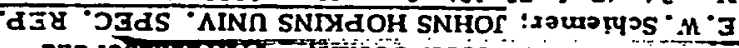
$0<2 \div 61$

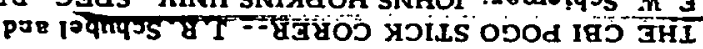
IN3MdInO3 anIXOY

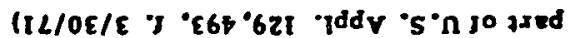

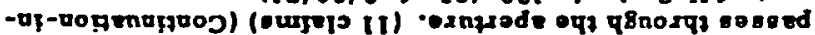

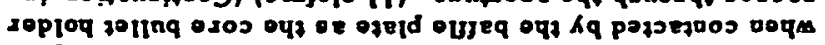

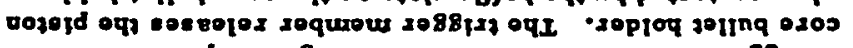

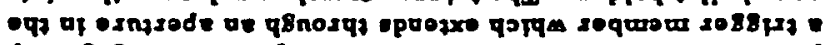

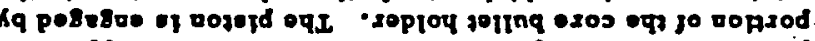

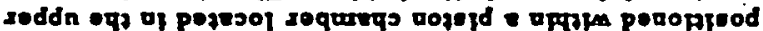

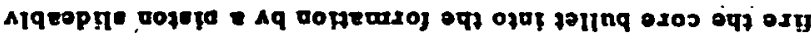

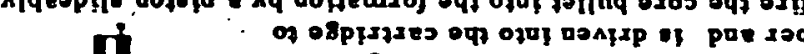

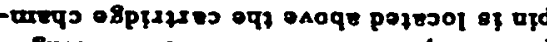

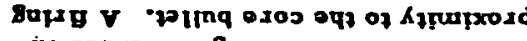

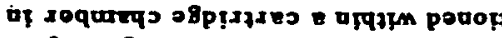

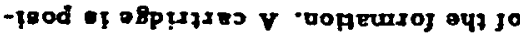
ojdues pollupan de 073011 nq $0 x 03$ ay jo

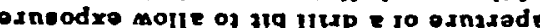
De y

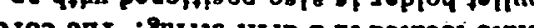

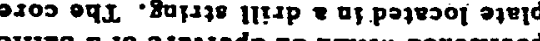

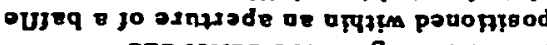
pae jolinq osos \& Bupky xOpIOY

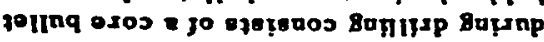
$\rightarrow 1$

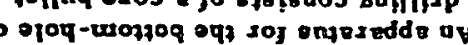

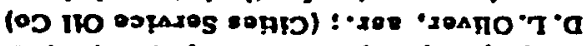

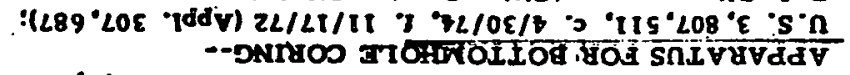
S5S ${ }^{\circ} \varepsilon 6 \mathrm{I}$

138 y8 3803 3MIT 3810

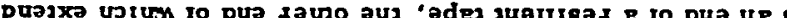
jasseq asos 2:qejejosuou e jo sotrejxa out uo pajumow Te ja u!

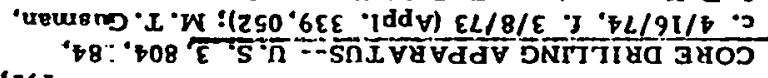
$592 * 16$

-juow!pos oy jo jno pelind

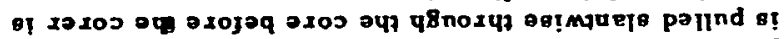

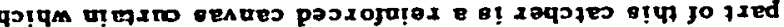

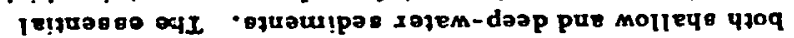
1

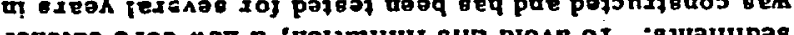

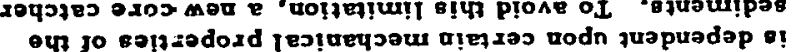

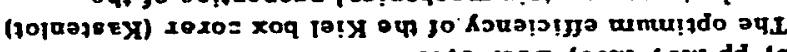
EL6I 200 ' $59 N-69 \mathrm{~N}$ dd 's 'ON

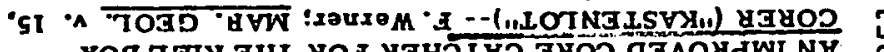

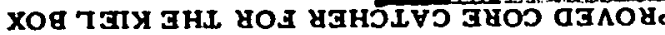
$16 L^{\prime} 881$

138478 3803/

$10 L / 12 / 9^{\circ}, 02 L^{\circ} 20$

.1ddy . 2.070 .358 -

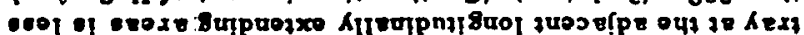
०น

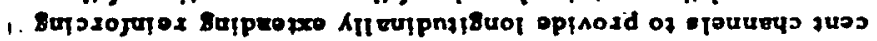

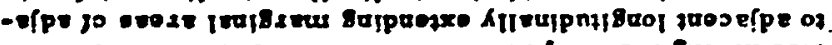

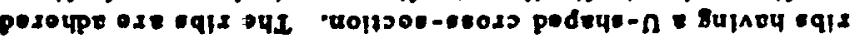

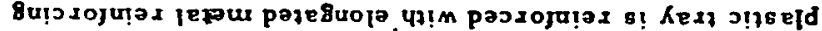

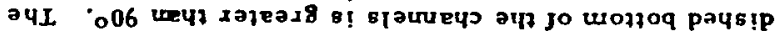

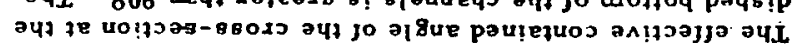

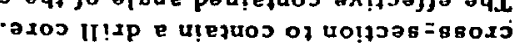
u! pays!p axe yग!ym diysuo!je!ax

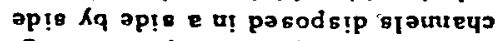
Su!puejxa $K$ II Eu!pn!! Suol jo raqunu e 8UTARY ad, aYt jo Kex\} axOJ II!.PP

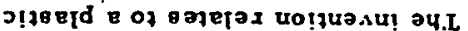

(prT

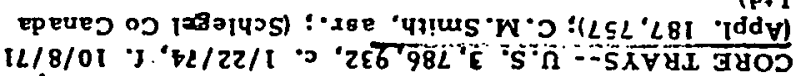

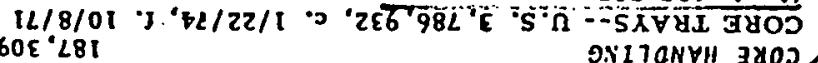


TARY CORE BARREL

195.649

COHE SAMPLING DEY:CE AND METHOD..- S. Afr.

73/3,751, c. 3/10/74, !. 6/4/73 (pr. Austral. 6/9/72,

Appl. 9, 290): P.R. Dobson, asr.; (Gray (G) \& Co Pty Lid);

Abstr., PATENTJOER:A.L (S. AFR.) v. 7, No. 4, p 218 , April 1974

A method for ob:aining a core sample consists of: (1) drilling to s specifiet (1) drilling to sacing sample taking depth; (2) :
passing a core tube casing containing an opes

core sample tube into tie rraterial below the depth to receive a core sample, such that it.e core sample tube is maintained in fixed reiation to the casing, and the casing and sample tube extend into the ma-erial from within a hollow auger or the taking dupth. taking depth. Thereb, actualing closure meang to seal the sample tube adjacent i:s inne-most end: and (4) withdrawin the sample tube, contaiting the sample. (H claims) (Ab stract only - original pe:e:? not available from T.U.

\section{CORING EQUIPMENT}

197,038

\section{AN INESPENSIVE HAND-OPERATED SEDIMENT CORER--}

R. G.Sutton (Rochester Univ); J. SEDIMENT. PETROLOGY v. 44, No. 3, pp 928-930. Sept. 1974

ploton corer has been developed that permite eamp ling of shallow-water and dry beach oands. It is aimple, light weight, eanlly operated and inexpenolve. The pioton light wean celloce of cellulose aponge that pormita head consule the core partial vaculm to bell as allowing water to soak the sedi tube penetration aces wiction and facilitates extrusion. menty that reduces friction and facilitates extrusion.

\section{CORING EQUIPMENT} 197,039

THE CBI POGO STICK CORER -- J.R. Schubel and

-E. W.Schiemer (Johis Hopkins Univ)i J. SEDIMENT.

(1)

The CBI Pogo stick Corer is a novel and us eful devico for collecting hort, relatively undisturbed cores of finegrained sediments in water up to about $3 \mathrm{~m}$ deep. The crained is patterned after a child's pogo otick. The operator thrusts the corer into the sediment by hand, then mounts the device and forces it into the sediment with a jumping motion.

TUL DESIGN OF A CORING SUBTERE NNE

GEOPROSPECTOR-- J. W. Neudecker; Los Alamos Scientific Lab. Rep. No. LA-5517-MS, 14 pp, Feb. 1974; Abstr. No. 26788 , NUCL. SCI. ABSTR. v. 29, No. 11, p 2591 . $6 / 15 / 74$

A rock-melting Subterreno avstem is desçribed that can obtain a continuous core along the projected route of a tunnel. System epecifications, individual component functiozs. proliminary design concepts, and design alternatives are included; and subcomponents that can be as sembled from conmerclally available hardware are indicated. The device requires $150 \mathrm{kw}$ of electric power to melt an accurate $300-\mathrm{mm}$ (1-ft)-diam glass-lined hole and remores a $200-\mathrm{mm}$ (8-in.)-diam glass-cased core at an advance rate of 0.4 $\mathrm{mm} / \mathrm{sec}(5 \mathrm{ft} / \mathrm{hr})$. The accurate hole diameter and stablo bole lining allow the use of a packer-thruster located at the beated hole-melting and hole-forming penetrator as sembly. An orientation eensor and a guldance unit can also be located in this assembly. A hollow, flexible otem trailiag behind the assembly contains the electric-power, coolant, and instrumentation lines, and provides a passage for debrio removal. Core sections are removed through the nexible stem intermittently with wire-lina core-retrleval hardware. (Abstract only - original article not available from T.U.)

CORING EQUIPMENT

198,777 ERE DRILLING SYSTEM-U.S. 3, 837,412, c. 9/24/74, f. 12/6/72 (Appl. 312,629) W. B. Driver

A downhole electric core drilling system is described that is lowered into a well hole by an electric cable to drill a core ample or to drill a well hole. The system conaiat of a core bit, core barrel, and a reduction transmission powered by an electric motor. This assembly is attached to the downhole end of a drill collar, which he electric cable, which is used to raise and lower the system in a well hole and provide electric power to the system. The core

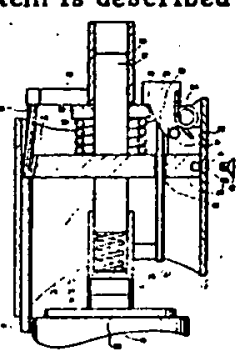
barrel containg a mechanism, which when activated by a drilled core, cuts the drilled core from the formation from which it was drilled, and holds the drilled core in the core barrel whll = the syotem is holsted to the top of a well holc. (7 clalme) 
(1) 9/8/71

(Appl. 772, 340); (Liamant Boart SA); Abstr., REC. BREV. INVENT. (BELG.) V. 1974, No. 22, p $333,8 / 1 \frac{1}{2 / 7}$ (In French)

This invention describes a coring apparatus with arf extractor spring having a longitudinal slot and equipped with teeth on its internal surface. Grooves on the internal surface defined by row $\theta$ of teeth are arrazged symmetrically with respect to the axial plane through the center of the longitudinal slot. This arrangement Imparts a rigidity to the extractor spring which is proportional to the flexing moment, between the rows of teeth and on each side of the plane of symmetry. (Abstract only - original patent not available from T.U.

. 10/16/73 (pr. Japan 10/16/72, Appl. 1(12, 734).

(Sumitomo Metal Mining Co); Abstr.. BULL. OFFIC. PROPRIETE IND. (FR.) v. i5, No. 24, Pt. 2 (No. 19) p9382, 6/14/74 (In French)

This drilling apparatus intended for great depthe conoivts of a drill pipe and a cutting element which can be inserted into the pipe, including a locking mechanism. This locking mechanism is attached to a pulllng device which is engaged in the pulling mechanism of the lifting apparatus, $\theta 0$ that when the pulling device is activated, an interior pipe and an exterior pipe which are part of the locking mechamism move with respect to each other and thus unlock the drill pipe and the cutting element. This is accompliahed faster and sasier than by the conventional techrique. This apparatus is used in particular for obtaining geclogic samples. (Al so related to Japan 11/20/72 (Appl. 132,752), Japan 7/28/73 (Appl. 84,594), Japan 8/8/73 (Appl. 88,520), Japan 8/10/73 (Appl. 93,640) and Japan 8/21/73 (Appl. 97.233)) (Abotract only - original patent not avallable from $T$. J.)
INSTALLATION TQ TAKE SAMPLES IN LOOSE GROUND--

Neth. Appl. 7, 402, 346, f. 2/20/74 (pr. Fr. 2/20/73,

Appl. 6, 000); (Inst Francais du Petrole) (In Dutch)

The invention relates to an installation to take sam-

ples in loose ground. It contains a rigid, tube-shaped body In which a sample carrier tube can be moved under the Infuence of remote-control means. The sample tube can move from a first position in which the tube is oecured in the body to a second position wherein the tube extende from the body aind penetrates into the loose ground. The body is connected to a source of drilling fluid and to driving means cor rotation. The body has a drilling crown having a bore through which the aample tube can move into the second position. There are means to close off the end of the am ple tube. (18 claime)

¿RISG EQUIPMENT
DRILL INSTALLATIOIN WITH REMOVABLE CORE

BARREL ANND CENTRA L PART - - Noth. Appl. 7, 405, 173 6. 4/17/74 (pr. Fr. 4/17/73, Appl. 13, 967); (Cio Francaloo Petroles) (In Dutch)

The invention relatea to a core drilling apparatuo

with an interchangeable core barrel and central part. The core barrel and removable part of the tool each contain a carrying pipe in which the mechanioms are installed. The pipe is kept vartical by a seat on a recelver tube which rotates with the tool. The carrying pipe is isolated at its upper part from the drilling fluid by an element containing a closeoff, which is installed against the fastening pipe, rotating with the tool. The core barrel and removable central part contaln pasages to circulate the drilling fluid at a pressure which is lower than the pressure of the drilling fluid above the closeoff element. (10 claims) 
CORING EQUIPUENT

206.677

TECHNICAL AND ECONOMIC ADV ANTAGES OF THE FYDRAULIC ANNULAR VIBRO-HAMMER EOR UNDERWATER SAMPLING AND GEOTECHNICAL IN-SITU DVVESTIGATIONS-- L. Menard; 11TH INT. ACOBOR EXPINIT, OF THE OSEANS COLIOQ: (BordeaLX; Fr. 10/1-4/74) TRANS. Y. 2, $17 \mathrm{pp}, 1974$ (Bx 117) (In Frooch) The Vibro-Hammor is a hydraulic underwater cortas \$ool with 4 double action unbalanced welght with an Incorporatod hammer. Ito rotary action extende sampling posaltilltlea from sedimente to rocke. It can work in $200 \mathrm{~m}$ of water and recover up to $100 \mathrm{~m}$ of samples. It can be worked from a supply veesel. The maximum welght if about ope ton. It is ueod for anchorlng of oll platform pllige, proapecting lor ore doponlts, esmple-taking for geological purponos, etc.

CORING

210,075

DRILLING APPARATUS.-- Can. 971,550,

C.22/75, 2/15/73 (ADPL, 163, 829); M. T. Gueman,

L. P. Konstantinov, B. D. Malkin, G. M. Nikitin et al. , asrs.; (USSR Agency); Abatr.. CAN. PAT. OFFICE REC.

v. 103, No. 29, p 29-54, 7/22/75

The present invention provides a coring apparatus for core drilling consisting of a splined telescopic joint to adapted to be connected to a drill string. A housing is attached to the oplined telescopic joint at it 8 upper end and connected to a core bit at it lower end. A core barrel is arranged inside the housing and suspended from the housing by means of bearing. A sleeve, insuring producing and by manal of core in undiotrubed condition is formed of a retrieval of core in unditrubed conditon to tormed of tape made of resilient material. One end of the tape is mounted on the exterior of the corebarrel. The other end extend $s$ inward into the barrel, and the longhudinal edges of tape are adapted to be joined one with another 80 as to form the sleeve which encaseg the core as it is produced and enters the core barrel. Means for pulling the tape inward into the core are provided. A clamping device is connected to the end of the tape providing A cord into the core barrel and to the means for pull. Ing the tape inward into the core barrel. Means for joining the longitudinal edgea of the tape and forming the eleeve from the tape are provided. (3 clalmo) (Abetract only - original patent not avallablo from T.U.
CORING EQUIPMENT

211,907

REMOTELY OPERATED SEAFLOOR CORING AND DRIL IING METHOD AND SYSTEM -. U.S, 3,891,037.

C. 6/24/75, f. 12/26/72 (Appl. 318,114); D. E. Well and K. C. Marley

A method and apparatus are described for emplacing a structure such as a

casing, piling or core

barrel into the floor of

a body of water. The

structure is mounted

on a towable and sub

mersible vessel which

includes a number of

ballast tanks. Means

are provided to selec -

ively vary the ballast

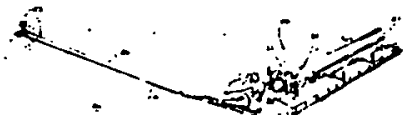<smiles></smiles>

$\because-\frac{\pi}{10}$

$\therefore \rightarrow \frac{10}{20}$

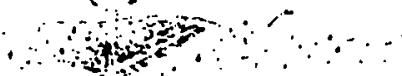

manner to cause the vessel to have selectively controllable negative or positive buoyancy for descent or ascent. A support device on the vessel moves the structure between horizontal orientation for towing and descent and an upright position for drilling. The vessel descends with a positive metacenter to maintain the established orientation until it reaches the sea floor, after which it is anchored and leveled for the drilling operation. (3 claims)

CORING

212,682

CORE DRILL FOR SOIL LAYERS-- Fr. 2, 240, 346,

c. 3/7/75, f. 8/8/73 (Appl. 29, 050); (Armadillo Holdinge Ltd); Abatr. BULL. OFFIC. PROPRIETE IND. (FR.) v. 16, No. 15, Pt. 2 (No. 10), p 1617, 1/11/75 (In French)

This core drill with back-and-forth movement consiste of a central obaft and a circular ehield surrounding the shaft. maintained concentric with the shaft by 4 cutting blades. The shield decreases in diameter from fnre to afi to wh to ellightly compreso the core belag drilled. The back odgon of the cutting blado aro equipped with alterastely bent tee which holp in puehing out the core when it ie axtracted from the coro drill. (Abetract only - orlatnal patent not avallable from T.U.)

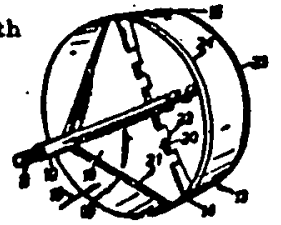


CORE DRIIL--Ger. 2,121,007, c. : $/ 19 / 75$, f. 4/29/71

(Appl. 2, 121, 007); R. Stock, A. Tiemon and H. Bertele,

asrs. ; (Dornier Syotem GmbH); Abstr.. AUSZUEGE

AUSLEGESCHRIFTEN (GER:) v. 21, No. 25, p 1813,

6/19/75 (In German)

This underwater core drilling apparatus consiste of

a supporting frame carrying the drive and at least one drill string with a bit. The frame also carries a magazine containing at least 2 drill strings with their own bits, in an axially parallel arrangement. (Abstract Dnly - original patent not avallable from T.U.)

CORING EQUIPHENT

214,773

CUTTER DEVICE FOR EARTH CORING--

Gr. Brit. 1, 412, 542, c. $11 / 5 / 75$, t. $7 / 27 / 73$

(Appl. 36,000); S. G. Atkins and S. B. Ballie, asze.

(Armadillo Holding s Lid)

A cutter device is described, for use in push-pull earth coring, consisting of a shaft for attaching the device to a push-pull driving means. A shell surrounds the shaft, and knife means extend between the ohaft and the shell to and knife means extend between the spaced from the shaft. maintain the shell concentrically spaced from the shaft
The shell is in the form of a truncated cone, with the

narrower end adjacent to one end of the shaft and the wider end adjacent to the other end of the ohalt. The knife means is odge-gharpened on the edge adjacent to the wider diameter end. (6 claims) 